
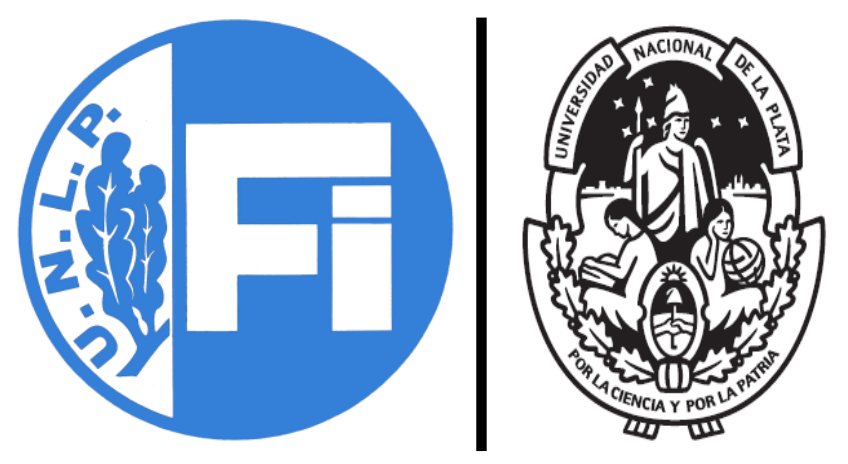

UNIVERSIDAD NACIONAL DE LA PLATA

\title{
MATERIALES COMPUESTOS BIODEGRADABLES CON USOS AGRONÓMICOS A PARTIR DE RAÍCES TUBEROSAS
}

Tesis doctoral presentada por

Ing. Florencia Versino

ante la Facultad de Ingeniería de la Universidad Nacional de La Plata para acceder al grado académico de

Doctor en Ingeniería

Directora: Dra. María Alejandra García Jurado de Tesis: Dra. Marina de Escalada Pla Dra. Ana María Rojas Dra. Adriana Mauri 


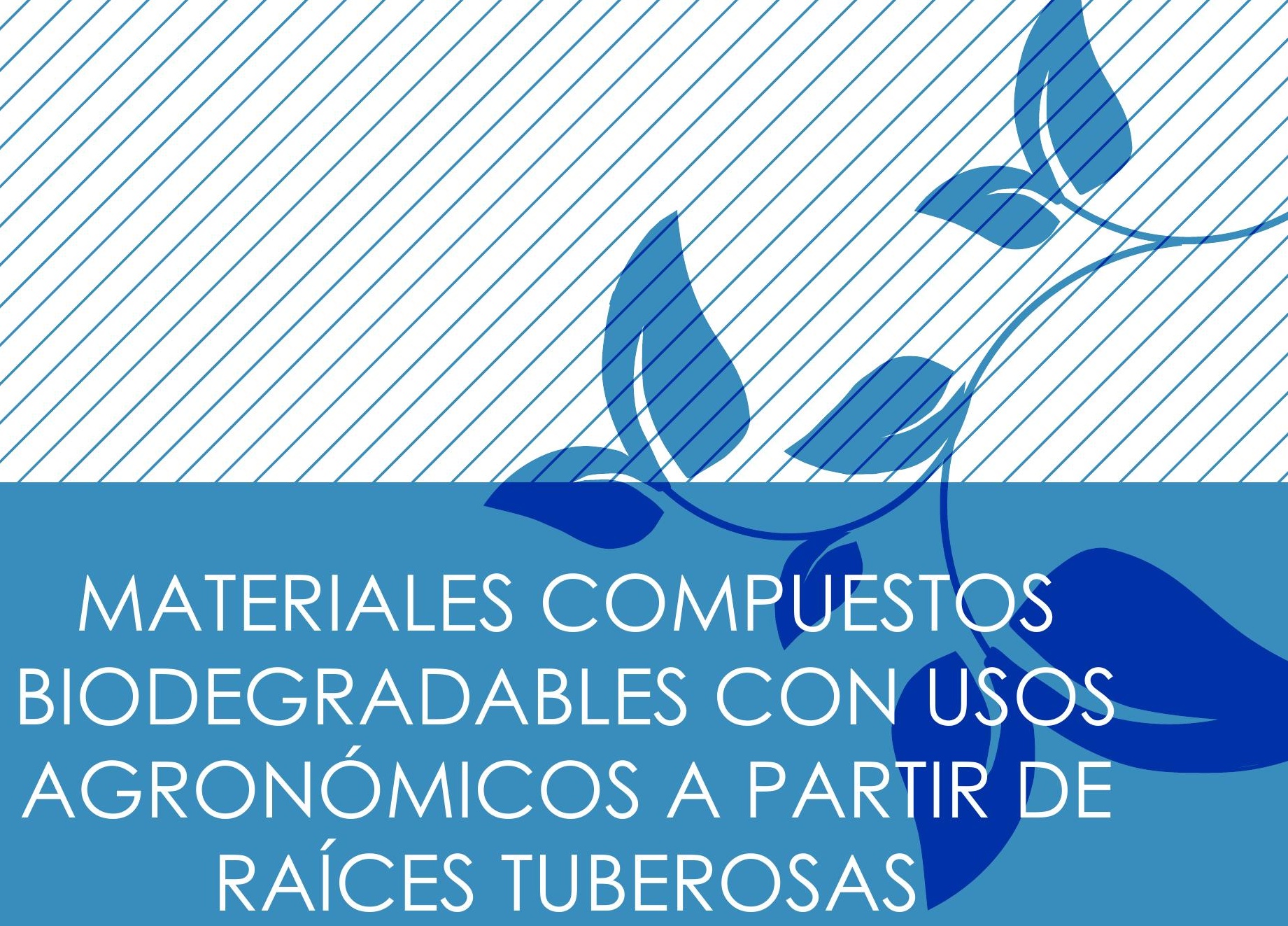


"In nature nothing exists alone."

- Rachel Carson, Silent Spring 


\section{AGRADECIMIENTOS}

"Cien veces al día me recuerdo que mi vida interna y externa depende del trabajo de otros hombres, vivos y muertos, y que he de esforzarme para dar en la misma medida que he recibido y que sigo recibiendo."

-Albert Einstein (1875-1955)

Son muchas las personas que han contribuido a hacer posible el desarrollo y concreción del presente trabajo. Quisiera nombrar a cada uno pero como sé que no podré hacerlo en este breve espacio les agradezco a todos sinceramente con el corazón.

No obstante quisiera agradecer esencialmente:

A mi directora y guía en este trabajo de tesis, Alejandra García, por haber depositado su confianza en mí. Agradezco la incondicionalidad, generosidad y humildad que la caracterizan, por las cuales sin dejar de instruirme, como excelente docente que es, me ha permitido trabajar, intercambiar ideas y debatir con ella como un par dando lugar al diálogo; el cual considero resulta sumamente enriquecedor tanto para el trabajo en cuestión como en lo personal. Aprecio mucho además sus críticas, sugerencias y aportes al trabajo realizado y su colaboración tanto en el papel como en el laboratorio, y agradezco haber podido compartir con ella estos 5 años de trabajo y estudio.

Al Consejo Nacional de Investigaciones Científicas y Técnicas (CONICET) y a la Agencia Nacional de Promoción Científica y Tecnológica que han financiado las becas con las cuales he podido dedicar mi tiempo a mis estudios de Doctorado.

A los directivos del Centro de Investigación en Desarrollo y Criotecnología de Alimentos (CIDCA) por abrir sus puertas para que pueda desarrollar este trabajo los últimos 5 años.

A la Escuela de Posgrado y Educación Continua (EPEC), en especial a Grisel y Ana por su predisposición y buena voluntad para contestar todas mis inquietudes respecto a cuestiones administrativas que suelen ser bastante tediosas. 
A Javier Lecot y Daniel Russo por las numerosas muestras ensayadas y por instruirme en las técnicas de DMA y DSC.

A la Bibl. Diana Velasco por su predisposición y eficiencia en el apoyo bibliográfico, el cual es un pilar básico de las tareas de investigación.

A Alicia Mudridge por la asistencia en el lavado, pelado, rayado, corte y peso de las raíces de mandioca y ahipa, que a veces no parecía tener fin.

Quiero agradecer muy en especial a Marina Urriza, por su paciencia y dedicación, y su colaboración en las tareas de laboratorio a pesar de los horarios y días poco convencionales. Por el sin número de muestras ensayadas y replicadas.

A mis compañeros del CIDCA, en los cuales he encontrado nuevos amigos, por su calidez y compañerismo.

A ambas Cecilias por introducirme en este grupo de trabajo, dándome una mano en el laboratorio cuando no sabía aún ni dónde estaba parada.

A Sandra y Majito por las risas compartidas, las ganas contagiosas de trabajar y su generosidad.

A Yuliana, Andrea, Eliana, Florencia, Alejandro y Javier por los días compartidos en el laboratorio trabajando en equipo y haciendo malabares para entrar todos en nuestro pequeño nicho.

A Matías, Nelson, Esteban, Sandro y Martín por darme una mano en cuestiones específicas de su conocimiento cuando lo necesite, tolerando mis insistentes y recurrentes preguntas e innumerables muestras.

A Silvana, Flavia, Vanesa y Carolina por hacerme un lugar en su invernadero y compartir conmigo parte de su tiempo, ideas y consejos.

A los integrantes del grupo de vegetales: Magali, Lucía, Carolina, Luis, Laura, María José, Joaquín, Facundo y Natalia, por tener siempre la puerta del laboratorio abierta y estar dispuestos a dar una mano cuando hace falta. 
A Olivia por su calidez y paciencia al recibirme en Bahía Blanca. Gracias por hacer de mi primera estadía de trabajo en otro centro de investigación un lindo recuerdo.

A Sonia Viña por contestar las mil y un preguntas de fisiología vegetal que me han surgido, sin perder nunca la sonrisa.

A mis compañeras de cátedra Marita, Ivana y Lucía, por su compresión y apoyo todos estos años a poder destinar más tiempo y esfuerzo en desarrollar mi tesis doctoral. Muy en especial a Osvaldo por todo lo anterior, su asesoramiento en las cuestiones académicas y por sus consejos en general.

A mis compañeros y amigos de box Nora, Pablo, Jessica, Eliana y Melisa por hacer que todos los días más llevaderos con charlas, risas y consejos compartidos café y mate mediante.

A las chicas de los boxes vecinos: Natalia, Adriana, Estela, Laura, Aline, Sandra, Marina y Miriam por las charlas y experiencias compartidas, y sus consejos tanto laborales como personales.

A todos los integrantes del grupo de los viernes por alegrar y endulzar las mañanas.

A mis padres porque siempre se esforzaron para darnos todas las posibilidades que pudieron para nuestra realización personal y profesional. Especialmente a mi mamá por su apoyo incondicional que supera toda distancia física.

A mis hermanas, Carolina y Luciana, por hacerme un lugar en su hogar siempre que lo necesito y aguantar la vorágine de esta última etapa. En particular quiero darle las gracias a Luciana por su aporte creativo para el diseño de este trabajo de tesis.

A mi familia y amigos, que son la extensión de la familia, porque su cariño y compañía hacen el camino más ameno y disfrutable.

Y por último, quiero agradecer a Leandro, mi compañero de vida, por no dejarme nunca bajar los brazos, por ser mi contención y mi consejero. 


\section{ÍNDICE}

RESUMEN

INTRODUCCIÓN

1. CONSIDERACIONES GENERALES $\mathbf{5}$

1.1. Películas biodegradables Y SUS aplicaciones 8

1.1.1. MATERIALES DE RELLENO: FIBRAS NATURALES 10

1.2. ALMIDONES: FUENTES Y USOS 13

1.2.1. ALMIDÓN DE MANDIOCA 18

1.3 MATERIALES COMPUESTOS 21

1.3.1. Materiales de Relleno: fibras naturales 22

2. OBJETIVOS GENERALES 24

3. BIBLIOGRAFÍA 24

CAPÍTULO I_PELÍCULAS DE ALMIDÓN DE MANDIOCA REFORZADAS CON BAGAZO DE MANDIOCA: EFECTO DEL PLASTIFICANTE Y DEL CONTENIDO DE RELLENO

1. INTRODUCCIÓN 31

2. OBJETIVOS 32

3. METODOLOGÍA Y TÉCNICAS EMPLEADAS 33

3.1. OBTENCIÓN DE ALMIDÓN Y CARACTERIZACIÓN 33

3.2. CARACTERIZACIÓN DE MATERIALES DE RELLENO 33

3.2.1. DISTRIBUCIÓN DE TAMAÑO DE PARTÍCULA

3.2.2. COMPOSICIÓN QUÍMICA 35

3.2.2.1. CONTENIDO DE HUMEDAD

3.2.2.2. Cenizas tOtales

3.2.2.3. FRACCIÓN LIPÍDICA 36

3.2.2.4. PROTEÍNA BRUta 37

3.2.2.5. FibRA DIETARIA TOTAL (FDT) 38

3.2.2.6. CONTENIDO DE LIGNINA 39

3.2.2.7. CONTENIDO DE CARBOHIDRATOS TOTALES 40

3.2.3. CAPACIDAD DE RETENCIÓN DE SOLVENTES (CRS) 40

3.2.4. MICROSCOPÍA ELECTRÓNICA DE BARRIDO (SEM) 41 
3.3. PLASTIFICANTE 41

3.4. PREPARACIÓN DE PELÍCULAS Y MATERIALES COMPUESTOS 41

3.4.1. SUSPENSIONES FILMOGÉNICAS 41

3.4.1.1. CARACTERIZACIÓN REOLÓGICA DE LAS SUSPENSIONES FILMOGÉNICAS DE ALMIDÓN 42

3.4.2. PREPARACIÓN DE Películas POR CASTING 44

3.5. CARACTERIZACIÓN DE PELÍCULAS BIODEGRADABLES Y MATERIALES COMPUESTOS 45

3.5.1. ESPESOR $\quad 45$

3.5.2. HUMEDAD 45

3.5.3. MicRosCopía ELECTRÓNICA DE BARRIDO (SEM) 45

3.5.4. PeRmeabilidad al VAPOR de Agua y Al OXÍGeno 45

3.5.5. PROPIEDADES ÓPTICAS 46

3.5.6. PROPIEDADES MECÁNICAS 48

3.6. ANÁLISIS ESTADÍSTICO 50

4. RESULTADOS Y DISCUSIÓN

4.1. ALMIDÓN Y BAGAZO: OBTENCIÓN Y CARACTERIZACIÓN 50

4.2. CARACTERIZACIÓN DE LA SUSPENSIÓN FILMOGÉNICA 56

4.3. PROPIEDAdES FISICOQUíMICAS DE LA PELÍCULA DE ALMIDÓN DE MANDIOCA 60

5. CONCLUSIONES $\mathbf{7 2}$

6. BIBLIOGRAFÍA

\section{CAPÍTULO II_PELÍCULAS DE ALMIDÓN DE MANDIOCA REFORZADAS CON} BAGAZO DE MANDIOCA: EFECTO DEL TAMAÑO DEL RELLENO

1. INTRODUCCIÓN $\quad 79$

2. OBJETIVOS 81

3. METODOLOGÍA Y TÉCNICAS EMPLEADAS $\quad 81$

3.1. MATERIALES 81

3.2. Preparación de Películas 82

3.3. CARACTERIZACIÓN DE PELÍCULAS 82

3.3.1. MICROSCOPÍA ELECTRÓNICA DE BARRIDO (SEM) 82

3.3.2. ESPECTROFOTOMETRÍA INFRARROJA POR TRANSFORMADA DE FOURIER CON REFLECTANCIA TOTAL ATENUADA (FTIR-ATR) $\quad 82$

3.3.3. CAPACIDAD DE BARRERA UV Y OPACIDAD 83

3.3.4. PeRmeabilidad al VAPOR de Agua 83

3.3.5. PROPIEDADES MECÁNICAS 83

3.3.6. TERMOSELLADO

3.3.7. BIODEGRADACIÓN EN SUELO 85 
3.4. ANÁLISIS ESTADÍSTICO 86

4. RESULTADOSY DISCUSIÓN

4.1. CARACTERIZACIÓN DE LAS FRACCIONES DE BAGAZO DE MANDIOCA 86

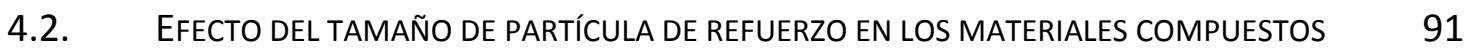

5. CONCLUSIONES 105

6. BIBLIOGRAFÍA 106

\section{CAPÍTULO III_PELÍCULAS DE ALMIDÓN TERMOPLÁSTICO REFORZADAS CON RESIDUOS DEL PROCESAMIENTO DE LA MANDIOCA}

$\begin{array}{lll}\text { 1. INTRODUCCIÓN } & 108\end{array}$

$\begin{array}{ll}\text { 2. OBJETIVOS } & 110\end{array}$

3. METODOLOGÍA Y TÉCNICAS EMPLEADAS 111

3.1. MATERIALES UTILIZADOS: OBTENCIÓN Y CARACTERIZACIÓN 111

3.2. PREPARACIÓN DE PELÍCULAS Y MATERIALES COMPUESTOS 111

3.2.1. PREPARACIÓN DE MEZCLAS 111

3.2.2. PREPARACIÓN DE PELÍCULAS POR TERMOCOMPRESIÓN 112

3.4. CARACTERIZACIÓN DE PELÍCULAS BIODEGRADABLES Y MATERIALES COMPUESTOS 112

3.4.1. ESPESOR 112

3.4.2. HUMEDAD 112

3.4.3. MICROSCOPÍA ELECTRÓNICA DE BARRIDO (SEM) 112

3.4.4. ESPECTROSCOPÍA DE INFRARROJO CON TRANSFORMADA DE FOURIER (FTIR) 112

3.4.5. ANÁLISIS TERMO-MECÁNICO: DMA Y MDSC 113

3.4.6. Permeabilidad Al VAPOR DE AgUa 114

$\begin{array}{lll}\text { 3.4.7. PROPIEDADES ÓPTICAS } & 114\end{array}$

$\begin{array}{lll}\text { 3.4.8. PROPIEDADES MECÁNICAS } & 114\end{array}$

3.5. ANÁLISIS ESTADÍSTICO 115

4. RESULTADOS Y DISCUSIÓN

4.1. CARACTERIZACIÓN DE LOS SUBPRODUCTOS DE LA MANDIOCA 115

4.2. PROCESAMIENTO DEL ALMIDÓN TERMOPLÁSTICO 119

4.3. CARACTERIZACIÓN MICROESTRUCTURAL DE LOS COMPUESTOS DE TPS 125

4.4. PROPIEDADES TÉRMICAS 129

4.5. PROPIEDADES ÓPTICAS 131

4.6. PROPIEDADES MECÁNICAS Y DE BARRERA 134

5. CONCLUSIONES 139

6. BIBLIOGRAFÍA 140 


\section{CAPÍTULO IV_PELÍCULAS DE ALMIDÓN DE MANDIOCA REFORZADAS CON BAGAZO: FUNCIONALIZACIÓN}

1. INTRODUCCIÓN 145

$\begin{array}{ll}\text { 2. OBJETIVOS } & 147\end{array}$

3. METODOLOGÍA Y TÉCNICAS EMPLEADAS 148

3.1. MATERIALES 148

3.2. PREPARACIÓN DE PELÍCULAS Y MATERIALES COMPUESTOS 148

3.3. CARACTERIZACIÓN DE LOS MATERIALES OBTENIDOS 149

3.3.1. HUMECTABILIDAD Y CONTENIDO DE HUMEDAD 149

3.3.1.1.CONTENIDO DE HUMEDAD Y AW 149

3.3.1.2.ABSORCIÓN DE AGUA 149

3.3.1.3.HIDROFILICIDAD 150

3.3.2.PROPIEDADES ÓPTICAS Y DE BARRERA AL VAPOR DE AGUA 150

3.3.3.MICROESTRUCTURA DE LA PELÍCULA Y PROPIEDADES MECÁNICAS 150

3.3.3.1.ESPECTROSCOPIA DE INFRARROJO POR TRANSFORMADA DE FOURIER (FTIR) 150

3.3.3.2. CALORIMETRÍA DIFERENCIAL DE BARRIDO MODULADA (MDSC) 151

3.3.3.3. ENSAYOS MECÁNICOS 151

3.3.3.4. MICROSCOPÍA ELECTRÓNICA DE BARRIDO (SEM) 151

3.3.3.5. BIODEGRADACIÓN EN SUELO 151

3.3.3.6. LIBERACIÓN CONTROLADA DE UREA 152

3.4. ANÁLISIS ESTADÍSTICO 153

4. RESULTADOS Y DISCUSIÓN

4.1. EFECTO DEL TIPO PLASTIFICANTE SOBRE PELÍ́CULAS DE ALMIDÓN DE MANDIOCA 153

4.2. MATERIALES COMPUESTOS DE ALMIDÓN Y BAGAZO DE MANDIOCA FUNCIONALIZADOS CON UREA: EFECTO DEL CONTENIDO DE PLASTIFICANTE 164

5. CONCLUSIONES 173

6. BIBLIOGRAFÍA 175

\section{CAPÍTULO V_APLICACIONES AGRONÓMICAS DE LOS MATERIALES ESTUDIADOS}

1. INTRODUCCIÓN 178

2. OBJETIVOS 180

3. METODOLOGÍA Y TÉCNICAS EMPLEADAS $\mathbf{1 8 0}$

3.1. MATERIALES UTILIZADOS 180

3.2. PREPARACIÓN DE PELÍCULAS Y MATERIALES COMPUESTOS PARA COBERTURA 181

3.2.1. AlMACENAMIENTO BAJO CONDICIONES AMBIENTALES CONTROLADAS 181 
$\begin{array}{ll}\text { 3.2.1.1. DifRACCIÓN DE RAYOS X (DRX) } & 181\end{array}$

3.2.1.2. ANÁLISIS TERMO-MECÁNICO DINÁMICO: DMA 183

3.2.1.3. PROPIEDADES ÓPTICAS Y MECÁNICAS 183

$\begin{array}{ll}\text { 3.2.1.4. SOLUBILIDAD } & 183\end{array}$

3.2.2. ALMACENAMIENTO BAJO CONDICIONES AMBIENTALES REALES

$\begin{array}{ll}\text { 3.2.2.1. HUMEDAD } & 184\end{array}$

3.2.2.2. ESPECTROSCOPÍA DE INFRARROJO CON TRANSFORMADA DE FOURIER (FTIR) 184

3.2.2.3. DIFRACCIÓN DE RAYOS X (DRX) 184

3.2.2.4. PROPIEDADES ÓPTICAS 184

3.2.2.5. PROPIEDADES MECÁNICAS 185

3.3. PREPARACIÓN DE PELÍCULAS Y MATERIALES COMPUESTOS FUNCIONALIZADOS 185

3.3.1. ALMACENAMIENTO EN CONDICIONES CONTROLADAS 185

3.3.2. EFECTO DEL MATERIAL SOBRE EL CRECIMIENTO DE PLANTINES 185

3.3.2.1. ELECCIÓN DEL TIPO DE SEMILLA Y SUSTRATO 185

3.3.2.2. CAPACIDAD DE CAMPO DEL SUSTRATO Y CANTIDAD DE AGUA DE RIEGO 186

3.2.2.3. MACETAS BIODEGRADABLES PARA SPEEDLING 188

3.3.2.4. MATERIAL DE LIBERACIÓN CONTROLADA IN SITU PARA CRECIMIENTO DE PLANTINES 189

3.3.2.5. PARÁMETROS DE CRECIMIENTO DE LA PLANTA 192

3.2.1.1. CONTENIDO DE CLOROFILA Y CAROTENOIDES TOTALES 193

3.2.1.2. CONTENIDO DE NITRÓGENO 195

3.3. ANÁLISIS ESTADÍSTICO 196

4. RESULTADOS Y DISCUSIÓN 196

4.1. MATERIAL DE COBERTURA 196

4.1.1. AlMACENAMIENTO EN CONDICIONES CONTROLADAS 196

4.1.2. COMPORTAMIENTO BAJO CONDICIONES AMBIENTALES REALES 204

4.2. MATERIAL PARA LA LIBERACIÓN CONTROLADA DE FERTILIZANTE 210

3.3.1. AlMACENAMIENTO EN CONDICIONES CONTROLADAS 210

3.3.2. EFECTO DEL MATERIAL SOBRE El CRECIMIENTO DE PLANTINES DE TOMATE 214

5. CONCLUSIONES 232

5.1. MATERIAL DE COBERTURA 232

5.2. MATERIAL PARA LA LIBERACIÓN CONTROLADA DE UN FERTILIZANTE 233

6. BIBLIOGRAFÍA 233

$\begin{array}{lr}\text { CONCLUSIONES } & 237\end{array}$ 


\section{RESUMEN}

En el presente trabajo de Tesis se desarrollaron y estudiaron materiales biodegradables y eco-compatibles a base de almidón de mandioca reforzadas con las fibras naturales provenientes del bagazo y la cáscara de la raíz, evaluando sus propiedades mecánicas, ópticas y de barrera. Considerando distintos plastificantes y aditivos para otorgar propiedades específicas a la matriz, así como técnicas de procesamiento. Por último se evaluó la potencialidad de los materiales obtenidos en aplicaciones agronómicas específicas como: cobertura de suelo y sistemas de liberación gradual de fertilizantes en la producción de plantines. Para ello fue preciso evaluar la estabilidad de los materiales frente a distintas condiciones de almacenamiento, así como su biodegradación en suelo y las distintas formas de utilización del material.

A tal fin se procesaron raíces tuberosas de mandioca para la extracción de almidón y caracterizaron los subproductos: el residuo fibroso remanente (bagazo), además de la piel o cáscara. Estos subproductos se diferenciaron por su composición química, siendo mayor el contenido de proteína y fibra en la cáscara. El bagazo presentó una distribución heterogénea del tamaño de partículas, con una fracción importante (56 \%) de partículas pequeñas $(<53 \mu \mathrm{m})$, constituidas principalmente por el almidón residual.

Mediante la técnica de casting fue posible obtener películas a base de almidón de mandioca reforzadas con distintas concentraciones de relleno $(0,75 ; 1,5$ y $3 \% \mathrm{p} / \mathrm{p})$ y glicerol como plastificante $(0-35 \% p / p$ respecto al contenido de almidón). Se caracterizó el comportamiento reológico de las suspensiones filmogénicas el que resultó pseudoplástico- tixotrópico. En todos los casos las micrografías SEM evidenciaron que la carga estaba estructuralmente incorporada en la matriz polimérica, indicando la compatibilidad química de los constituyentes. La compatibilidad entre los distintos constituyentes de la matriz se estudió a través de FTIR-ATR. Las películas obtenidas se caracterizaron evaluando principalmente sus propiedades ópticas, mecánicas y de barrera. Las concentraciones seleccionadas de 
plastificante y agente de refuerzo ( $25 \mathrm{~g}$ de glicerol/ $100 \mathrm{~g}$ de almidón y 1,5 \% de bagazo de mandioca) resultaron del compromiso entre las propiedades mecánicas y de barrera del material. El agregado de bagazo no sólo mejoró la resistencia mecánica de las películas, evidenciando el refuerzo de la matriz, sino que contribuyó a la capacidad de barrera UV-visible de las mismas.

El bagazo obtenido se tamizó, separándolo en diferentes fracciones de tamaño de partícula: F: $<500 \mu \mathrm{m}$; G: 500 - $250 \mu \mathrm{m} ; \mathrm{M}: 250-53 \mu \mathrm{m} ;$ Y P: $<53 \mu \mathrm{m}$. Se estudió la morfología de las diferentes fracciones al SEM y la caracterización se completó por FTIR-ATR. El tamaño de partícula de relleno afectó las propiedades de los materiales compuestos. Las partículas de mayor tamaño $(G)$ aumentan la capacidad de barrera UV-visible de la matriz, las de tamaño medio (M) mejoran el comportamiento mecánico propiedades mecánicas, y las partículas pequeñas $(P)$ reducen la WVP. La incorporación del bagazo conteniendo todas las fracciones $(F)$ presentó, como era de esperar, un comportamiento intermedio debido a la combinación de los efectos individuales de G, M y $\mathrm{P}$ en la matriz. Las películas reforzadas presentaron además capacidad de termosellado, el modo de falla (cerca del cierre) se atribuyó en todos los casos a la resistencia del sello. A través de estudios de biodegradación en suelo se demostró que en un plazo menor a 50 días las películas de almidón presentan un alto grado de degradación, siendo la cinética de biodegradación más lenta para las matrices reforzadas. La naturaleza biodegradable de las películas desarrolladas y su capacidad de termosellado son atributos importantes para el desarrollo de envases para aplicaciones específicas.

Considerando la mayor opacidad, resistencia mecánica y menor velocidad de biodegradación en suelo se seleccionaron las películas biodegradables a base de almidón de mandioca reforzadas con 1,5 \% de bagazo de la raíz y se evaluó su estabilidad bajo condiciones ambientales controladas simulando fotoperíodos regulares de luz UV-visible. Luego de 60 días de almacenamiento se observó que ambos 
materiales presentaron signos de envejecimiento aunque el efecto fue menor para aquellos reforzados con fibras. Además, dado que estos materiales podrían ser adecuados para cobertura de suelo de cultivos de ciclo corto, se estudió la estabilidad de las películas bajo condiciones ambientales reales, siendo este un avance que distingue al presente trabajo de Tesis. Con este fin se registraron las condiciones meteorológicas y se evaluaron los cambios estructurales de los materiales. Las películas empleadas lograron mantener la humedad del suelo durante el período estudiado, aunque las reforzadas con fibra habían sufrido una degradación mayor que aquellas sin relleno. Asimismo, la transmisividad PAR de las películas reforzadas no se modificó, lo cual resulta de particular interés para aplicaciones agronómicas.

Por otra parte, fue posible obtener materiales compuestos a base de TPS por moldeo y termo-compresión reforzados con subproductos del procesamiento de mandioca: bagazo y cáscara, la que contenía mayores cantidades de fibra y proteína que el bagazo. Bajo las condiciones de procesamiento ensayadas las interacciones entre almidón y relleno se vieron favorecidas, disminuyendo la energía necesaria para la plastificación. Se demostró la compatibilidad entre la matriz y los diferentes rellenos por análisis de FTIR y TGA. Ambos subproductos refuerzan las matrices de TPS, a pesar de la baja concentración utilizada, siendo el bagazo un relleno más eficiente debido a su alto contenido en almidón residual y menor proporción de partículas de mayor tamaño. Además, la adición de las cargas mejoró las propiedades de barrera UV-visible del material, especialmente aquellos que contienen cáscara.

El agregado de urea a la formulación permite no sólo generar una matriz polimérica activa sino también plastificarla. Comparativamente, tanto la urea como el glicerol y la mezcla de ambos son plastificantes compatibles con la matriz. La mayor eficiencia de la urea como plastificante se demostró por la disminución de la $\operatorname{Tg}$ y la mejora del comportamiento mecánico. La estructura y propiedades de las películas de almidón de mandioca reforzadas dependen fuertemente del contenido de urea incorporado, 
siendo 37,5 g de urea/ 100g de almidón la máxima concentración admitida por la matriz. Los resultados obtenidos de liberación controlada de urea en suelo se correlacionan con los de biodegradación y de capacidad de absorción de agua ya que estos procesos ocurren en forma simultánea.

Fue posible obtener macetas biodegradables a partir de las películas reforzadas desarrolladas, sin embargo su aplicación para macetas de speedling no resultó viable debido a la fitotoxicidad que provoca la descomposición de la urea. Se propusieron diferentes estrategias de uso de las películas aditivadas como sistemas de liberación controlada de fertilizante, los que promovieron el desarrollo de platines de tomate. Se realizó un exhaustivo estudio de los parámetros de crecimiento vegetativo de los plantines con el fin de evaluar la efectividad de los sistemas de liberación propuestos. En relación al empleo de sistemas soportados, la utilización de barras o bastones fue la opción más eficiente.

El presente trabajo de Tesis se propuso un uso integral de la raíz tuberosa de mandioca, ya que se desarrollaron películas a base del almidón que se reforzaron con el bagazo y/o la cáscara de la raíz, valorizando estos subproductos agroindustriales. Teniendo en cuenta sus propiedades, se propusieron distintas aplicaciones agronómicas específicas para estos materiales. La inclusión de urea en la matriz permitió el desarrollo de sistemas de liberación controlada del fertilizante los que demostraron su eficiencia en cultivos de ciclo corto. 


\section{CONSIDERACIONES GENERALES}

Los materiales poliméricos abarcan un amplio abanico de compuestos tanto naturales (proteínas, almidones, etc.) como sintéticos (polietilenos, poliuretanos, resinas epoxy, etc.) cuya versatilidad y fácil procesamiento los ha vuelto adecuados para un gran número de aplicaciones industriales, desde la alimenticia hasta la textil, incluyendo la petroquímica y la automotriz. Desde 1980, la producción de plásticos de origen petroquímico aumentó a una tasa anual media de alrededor del $5 \%$, equivalente a un volumen de producción mundial de 288 millones de toneladas en 2012, que representa el $5 \%$ del suministro total mundial de energías primarias [1]. Sin embargo, a raíz de la creciente necesidad de mitigar las emisiones de gases de efecto invernadero, reducir la acumulación de residuos sólidos y disminuir el consumo de recursos no renovables, el interés en el desarrollo de materiales biodegradables y/o de fuentes renovables (denominados en inglés bio-based) ha crecido fuertemente en las últimas décadas. No obstante, debe tenerse en cuenta que el reemplazo de plásticos convencionales por sustitutos biodegradables constituye una solución parcial para atenuar el daño medioambiental susodicho, siendo necesario elevar el nivel de concientización social de manera de que se tienda hacia una actitud más responsable en el consumo y gestión de recursos, incentivando además la reutilización y reciclado.

En particular, varios materiales poliméricos biodegradables (independientemente de su origen) se han investigado en vistas de reemplazar a sus contrapartes de origen petroquímico no biodegradables -de aquí en más denominados plásticos convencionales- en numerosas aplicaciones, tales como: materiales de embalaje y envases (bolsas de basura, envoltorios y recubrimientos, espuma de relleno, envases de alimentos, papel laminado); textiles descartables sin tejido (indumentaria descartable de uso hospitalario, vendajes y apósitos, material de limpieza descartable) y productos de higiene personal (pañales, hisopos, toallas higiénicas); insumos médicos

y farmacéuticos (hilos de sutura, cápsulas para medicamentos de liberación 
controlada); bienes de consumo (vajilla de comida rápida, bandejas, envases, cajas de huevos, mangos de afeitadoras descartables, juguetes); materiales de uso agrícolas (macetas de replantación, plásticos de cobertura, silobolsas); entre otros [2-17].

Por su lado, los materiales poliméricos derivados de fuentes renovables han tenido un fuerte crecimiento en el mercado mundial. Según un informe de la empresa en estudios de mercado Allied Market Research titulado "World Bioplastics Market Opportunities and Forecast, 2014-2020", en 2014 el mercado mundial de bioplásticos se estableció en 4869,2 kilo toneladas y se estima una tasa de crecimiento anual del 17,5\% durante 2015-2020 [18]. Dicho crecimiento se debe a las diversas potenciales aplicaciones antes expuestas, sumado a políticas gubernamentales favorables tendientes a aumentar la producción y consumo de productos sustentables y amigables con el medio ambiente. Sin embargo, los costos de producción resultan aún altos en comparación con los plásticos convencionales, lo cual ha obstaculizado hasta cierto punto el crecimiento del mercado.

Dentro de la familia de los materiales poliméricos denominados bioplásticos se incluyen polímeros de distinto origen y características. En la Figura 1 se presenta una breve clasificación de los materiales plásticos, diferenciando el subgrupo de los bioplásticos. En general, los bioplásticos son aquellos materiales poliméricos derivados de fuentes naturales y, a excepción de los denominados polímeros verdes, son también biodegradables o compostables. Los polímeros verdes (en inglés denominados green) provienen de fuentes renovables pero no son biodegradables, un ejemplo muy conocido es el polietileno verde: I'm green ${ }^{\mathrm{TM}}$ de la empresa Braskem (Brasil) [19]. El resto de los bioplásticos son biodegradables pero difieren en su forma de obtención. El ácido poliláctico (PLA), por un lado, producido a escala industrial por empresas como NatureWorks (EEUU), FKuR (Alemania) y Corbion (Holanda), se obtiene por reacción de polimerización del ácido láctico derivado de fuentes naturales como la caña de azúcar. Por otro lado, los biopolímeros obtenidos a partir de microorganismos como 


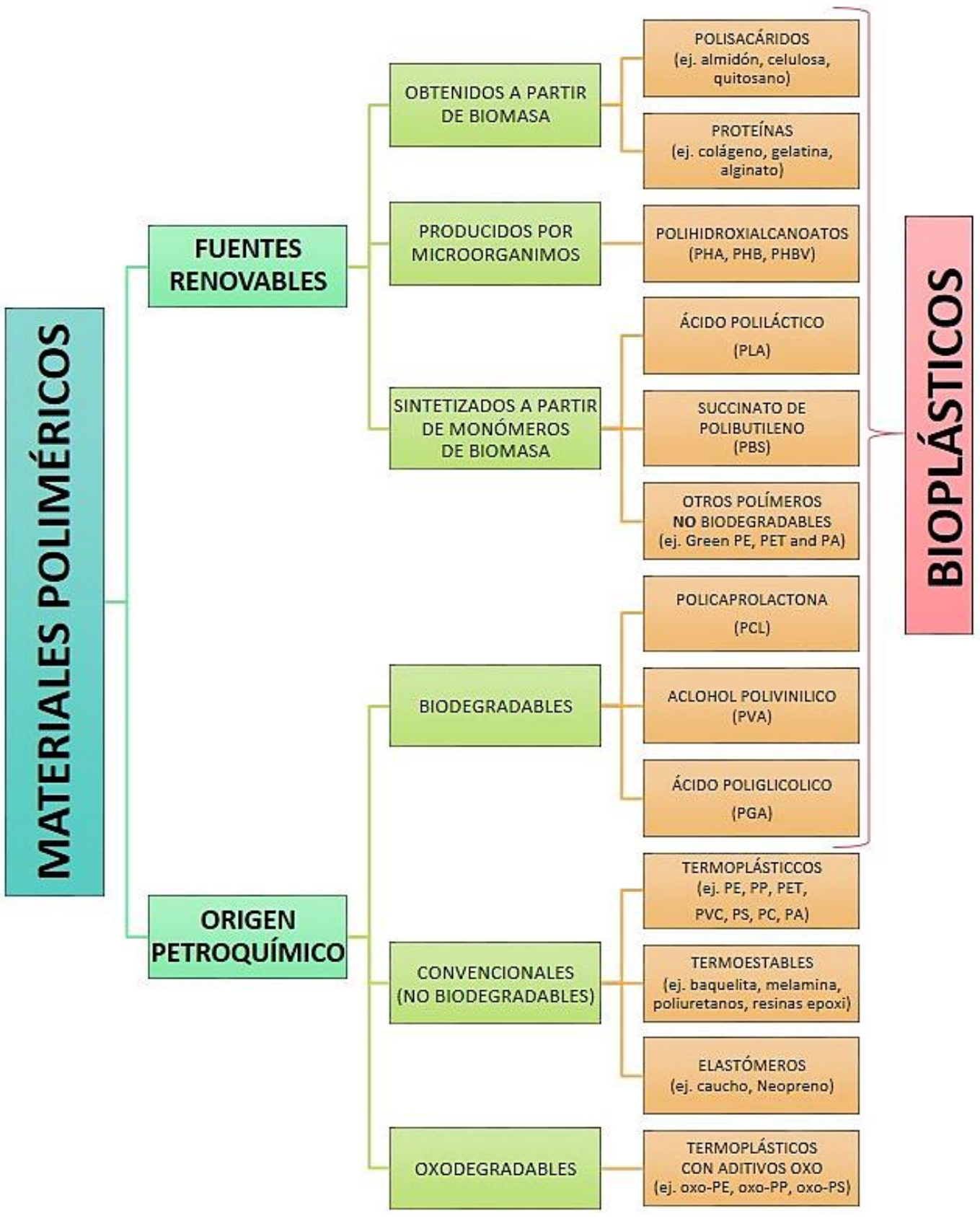

Figura 1. Clasificación de los materiales poliméricos

el polihidroxialcanoato (PHA) o el polihidroxibutirato (PHB) -producidos por empresas como Metabolix (Reino Unido) y GreenBio (China) entre otras - se obtienen por fermentación bacteriana de azúcares. Y por último, biopolímeros que derivan 
directamente de fuentes naturales tanto vegetales como animales como el almidón, la celulosa, la gelatina, el quitosano, entre otros. Hasta el momento no se encuentran en el mercado materiales poliméricos puros de este tipo, aunque se comercializan diversas mezclas con polímeros sintéticos como Mater-Bi ${ }^{\circledR}$ de Novamont (Italia), CardiaBioplastics $^{\circledR}$ (Australia) e InnoviaFilms (Reino Unido) [18]. Algunos autores también se refieren a estos materiales como agro-polímeros.

Existen asimismo plásticos biodegradables que se producen a partir de combustibles fósiles, como la policaprolactona (PCL) o el alcohol polivinílico (PVA), que también se denominan bioplásticos.

En cuanto a los materiales oxobiodegradables, si bien los mismos sufren una degradación y desestructuración acelerada debido a la incorporación de aditivos prodegradantes que los sensibilizan a los efectos de la radiación solar y la temperatura, sería más adecuado denominarlos oxodegradables ya que no hay consenso en cuanto a que sean biodegradables [20]. A este respecto, las normas establecen que para poder ser considerado biodegradable el material debe ser capaz de descomponerse a dióxido de carbono, metano, agua, compuestos inorgánicos (no tóxicos) o biomasa, principalmente por acción enzimática de microorganismos en un tiempo acotado (generalmente menor a 6 meses). Además, la biodegradabilidad del material debe poder cuantificarse mediante normas internacionales y estándares específicos, tales como: ASTM D6400, ASTM D5988 y ASTM D5338; EN 13432; ISO 17556 e ISO 14855. En Argentina desde 2009 existe una normativa específica para la evaluación de plásticos biodegradables y oxodegradables, las normas IRAM 29420 (2009) e IRAM 29421 (2011).

\subsection{Películas biodegradables y sus aplicaciones}

Como se mencionó previamente, la obtención de envases biodegradables ha recibido considerable atención en los últimos años, su uso se orienta hacia la protección del 
medio ambiente y se destinan principalmente a la comercialización de productos orgánicos, cuya reglamentación es muy exigente.

Pocas son las aplicaciones reportadas de los materiales biodegradables en el área agronómica, en relación a los desarrollos en el área de alimentos y farmacéutica. Se ha informado el uso de materiales compuestos biodegradables como macetas [21] y cobertura del suelo o mulching $[22,23]$. Esta última es una práctica agronómica ampliamente utilizada, que permite controlar el crecimiento de malezas, impide el contacto del fruto con el suelo, reduce la erosión, mantiene la humedad y mejora la productividad de los cultivos [22]. Generalmente se utilizan materiales sintéticos como el polietileno de baja densidad que no se degradan, por lo que se requiere su posterior recolección y/o reciclado [24]. La utilización de materiales eco-compatibles con este fin permitiría reducir los problemas de contaminación asociados a esta práctica con la consecuente ventaja económica. Moreno y Moreno [23] utilizaron materiales biodegradables para mulching comerciales en el cultivo de tomate siendo su desempeño equivalente al de los sintéticos. Bilck y col. [22] desarrollaron películas biodegradables por extrusión a partir de mezclas de almidón de mandioca y polibutilenadipato-tereftalato (PBT) las que fueron utilizadas exitosamente como cobertores en el cultivo de frutillas. Además, el estudio de las propiedades de barrera a la radiación solar $[25,26]$ y el efecto del agregado de aditivos específicos, absorbedores de la radiación UV, resultan relevantes en los materiales con fines agronómicos, ya que condicionan su estabilidad y sus propiedades de barrera [27]. Asimismo, Briassoulis [3] señaló la importancia del estudio de la resistencia mecánica de estos materiales en relación a sus potenciales aplicaciones. Una estrategia viable en este sentido es la incorporación de rellenos, que se discutirá más adelante en la sección 1.3.

Los materiales biodegradables encuentran a su vez un creciente campo de aplicación en lo que respecta a la liberación controlada de compuestos activos. Las 
investigaciones relacionadas a la funcionalización ${ }^{1}$ de materiales compuestos mediante el agregado de compuestos activos es una opción en creciente aumento, sobre todo en el área farmacéutica y biomédica. Estos materiales inteligentes permiten la dosificación del componente activo, y en algunas aplicaciones deben poder biodegradarse completamente $\mathrm{o}$, en el caso de aplicaciones biomédicas, ser absorbidas con lo cual deben ser biodegradables y biocompatibles. La aplicación de estos compuestos con fines agronómicos que incluyan fungicidas y fertilizantes (micro y macro-nutrientes) han sido poco desarrolladas hasta el momento, encontrándose sólo información referida al encapsulado de urea [28] o a su inclusión en matrices mixtas [29]. Asimismo, los estudios referidos a la liberación controlada se han desarrollado en su mayoría en simulantes líquidos y muy pocos en condiciones reales de aplicación $[30,31]$.

\subsubsection{Películas a base de almidón}

El almidón es la materia prima agrícola más comúnmente utilizada para la formulación de películas biodegradables y comestibles. Debido a su gran disponibilidad, buen desempeño y bajo costo, es considerado el polímero natural con mayores posibilidades de ser usado a escala industrial; siendo las películas desarrolladas a partir de éste ampliamente estudiadas [30, 32-35]. Sin embargo, la estructura del almidón presenta numerosos desafíos para sus potenciales aplicaciones en la industria de los bioplásticos [36]. El origen botánico y los factores ambientales a lo largo del crecimiento de las plantas, dan como resultado propiedades y estructuras moleculares distintas, así como diversas formas, tamaños y composición de los gránulos de almidón [37].

\footnotetext{
${ }^{1}$ Cabe aclarar que en el presente trabajo de Tesis el término "funcionalización" no se utiliza para referirse a la inclusión de grupos funcionales al sistema matriz. En este caso el término hace referencia a la inclusión de un compuesto o aditivo que otorga al sistema una característica o propiedad específica que le permite cumplir una función distinta a la usual para el sistema base que no incluye este compuesto o aditivo. Por ello, de aquí en más se emplea este término y todos sus derivados en este sentido.
} 
En comparación con los materiales sintéticos, el almidón tiene dos desventajas principales. En primer lugar, los tres grupos hidroxilo por unidad D-glucosa -monómero de las macromoléculas constituyentes, amilosa y amilopectina-imparten un alto grado de hidrofilicidad al almidón. Por lo tanto, como el agua es un plastificante efectivo para este polisacárido, los cambios de humedad pueden tener un impacto significativo sobre las propiedades fisicoquímicas y mecánicas de los materiales a base de almidón. En segundo lugar, el almidón nativo no es termoplástico, ya que la pirólisis se produce antes de que se alcance el punto de fusión de las regiones cristalinas del almidón. Por consiguiente, el almidón no se puede procesar por fusión a través de equipos de plástico convencionales sin adición de plastificantes [38].

Con el fin de mejorar la resistencia al agua del almidón o impartir propiedades funcionales específicas o compatibilizarlo con otros polímeros para producir materiales compuestos con características equilibradas, este biopolímero puede modificarse química o físicamente [39]. Varios autores han informado el uso de almidones modificados en la formulación de películas, principalmente sustituidos y pregelatinizados [30, 40-42] a fines de reducir la sensibilidad a la humedad de los materiales desarrollados. Otra alternativa viable en este sentido es el entrecruzamiento de la matriz siendo los agentes entrecruzantes más ampliamente utilizados oxicloruro de fósforo y epiclorhidrina [10, 43]. Sin embargo, estos agentes químicos son relativamente tóxicos, caros y en algunos casos no inducen mejoras importantes en las propiedades deseadas. Por el contrario, los ácidos policarboxílicos resultan económicos, seguros y han sido ampliamente utilizados para mejorar el desempeño de proteínas y derivados de celulosa en el área textil [43].

También se ha estudiado ampliamente la compatibilidad del almidón con otros polímeros biodegradables, tales como PCL o PLA entre otros, así como el procesado de compuestos con micro y nano-rellenos [44-46]. Al variar los componentes de la mezcla y las condiciones de procesamiento, la morfología y, por tanto, las propiedades 
funcionales y estructurales pueden ser cuidadosamente reguladas para mejorar la eficiencia de los materiales biodegradables [6].

Las películas de almidón se pueden obtener mediante dos procesos: uno "húmedo" que consiste básicamente en la gelatinización del almidón (ver sección 1.2), denominado casting; y otro "seco" basado en las propiedades termoplásticas de este biopolímero a bajas concentraciones de agua y/u otros plastificantes. El método de casting se utiliza principalmente a escala de laboratorio con baja eficiencia energética, puesto que se insume mucha energía en la gelatinización de suspensiones acuosas de almidón y su posterior deshidratación controlada [33, 47-49]. Dado que no es un proceso continuo, esta técnica presenta varias limitaciones, incluyendo: tamaño y cantidad restringida de las películas producidas, largos tiempos de producción y grandes volúmenes de eliminación de disolventes (ya que la relación entre la materia seca y el disolvente es baja). Empero, esta tecnología es clave para el estudio de recubrimientos en diferentes superficies, tales como revestimientos de papel, medicamentos, semillas y productos alimenticios.

La siguiente escala en la producción de películas a base de almidón, es mediante el proceso semi-continuo de tape-casting: en el cual también debe gelatinizarse el almidón en suspensión acuosa, pero el secado se realiza sobre cintas transportadoras calefaccionadas, facilitando su procesamiento y reduciendo el tiempo de secado $[50,51]$.

Consecuentemente, es preciso estudiar los potenciales materiales a base de almidón con el fin de que se adapten a las tecnologías existentes para obtener materiales poliméricos convencionales, de manera de poder ampliar su producción y mejorar su competitividad [52]. En este respecto, los métodos industriales continuos más utilizados son: la extrusión seguida de moldeo por soplado, inyección o termocompresión, que son altamente productivos y energéticamente eficientes $[38,48,52-55]$. 


\subsection{Almidones: fuentes y usos}

El almidón es un polisacárido de reserva energética de los vegetales y se localiza principalmente en granos, raíces, tubérculos, frutas y semillas. En los tejidos vegetales se presenta en entidades discretas, semicristalinas, las cuales reciben el nombre de gránulos. El tamaño, forma y estructura de los gránulos difieren substancialmente con la fuente botánica. Su forma varía de esférica o de discos para los gránulos de almidón de trigo, poliédricos en arroz y maíz, con forma de ostras irregulares en papa, o alargados y filamentosos en almidones de maíz de alto contenido de amilosa, entre otros $[56,57]$.

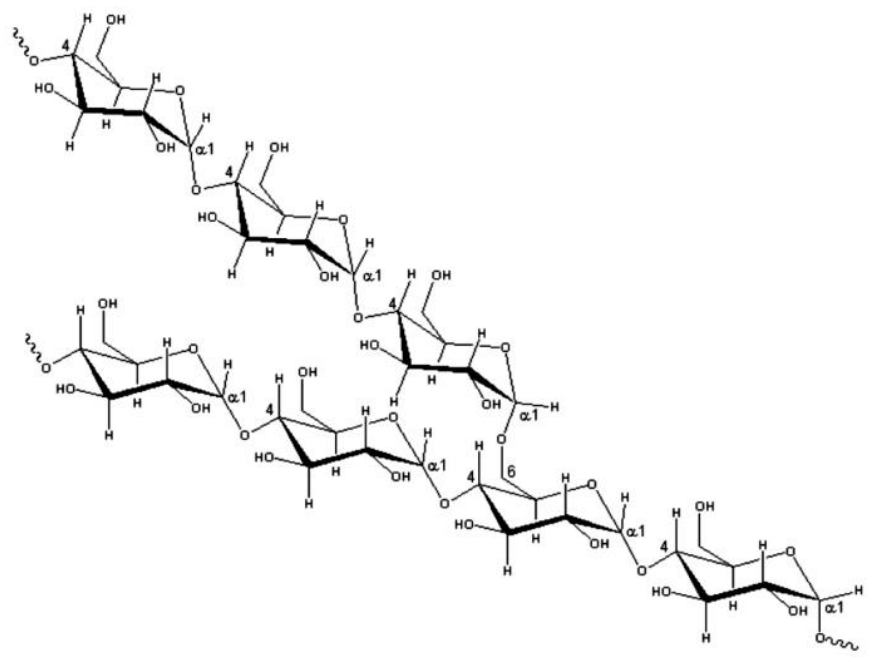

Figura 2. Estructura química de la amilopectina

La mayoría de los gránulos de almidón naturales, independientemente de la fuente o tejido de la planta, contienen dos tipos principales de polisacáridos: amilosa y amilopectina. No obstante, los gránulos también contienen trazas de otros constituyentes como lípidos polares, nitrógeno y fósforo (en forma de fosfolípidos) que, en muchas ocasiones, juegan un rol importante en las propiedades funcionales del almidón [58]. La relación amilosa/amilopectina y su organización física dentro de la estructura granular, le confieren a los almidones propiedades fisicoquímicas y funcionales características [59]. 
Tanto la amilosa como la amilopectina son polímeros de $\alpha$-D-glucosa conectados por enlaces $\alpha-(1 \rightarrow 4)$ en cadenas más cortas o más largas. La amilopectina (Figura 2$)$, el componente principal de la mayoría de los almidones, está formada por cadenas cortas de $\alpha$-D-glucosa concatenadas fundamentalmente por enlaces $\alpha$ - $(1 \rightarrow 4)$ y altamente ramificadas, con un $4-5 \%$ de enlaces $\alpha-(1 \rightarrow 6)$. Se encuentra en una proporción de $70-80 \%$ y en ciertos casos alcanza niveles de hasta $98-99 \%$, dependiendo de la fuente botánica del almidón [60]; y tanto su estructura como su proporción en el almidón contribuyen notablemente a las propiedades funcionales del mismo [61]. El peso molecular es del orden de $1 \times 10^{8} \mathrm{Da}$, con aproximadamente 600.000 restos de glucosa y se encuentra ramificada al azar, razones por las cuales posee una alta viscosidad intrínseca. Por calentamiento en agua, proporciona soluciones claras y de alta viscosidad, que son además filamentosas y cohesivas. Sus soluciones no tienen casi tendencia a la retrogradación, y tampoco presentan envejecimiento ni formación de gel aunque la concentración de las mismas sea muy elevada.

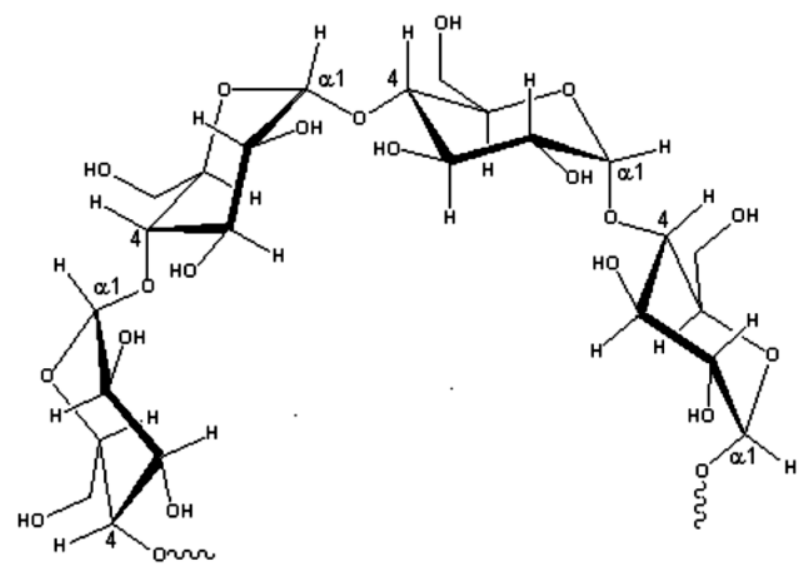

Figura 3. Estructura química de la amilosa

Por otro lado, la amilosa (Figura 3) consiste en cadenas largas de restos de $\alpha$-D-glucopiranosilo unidos por enlaces $\alpha-(1 \rightarrow 4)$, haciendo que la molécula sea lineal o ligeramente ramificada [58, 62]. El contenido de amilosa de la mayoría de los almidones es entre un 20 y un $30 \%$. El tamaño molecular varía entre $1 \times 10^{5}$ y $1 \times 10^{6} \mathrm{Da}$ 
y puede contener entre 500 y 6000 unidades de glucosa. La naturaleza lineal y de gran longitud le confieren a la amilosa algunas propiedades únicas, como por ejemplo su capacidad para formar complejos con yodo, alcoholes o ácidos orgánicos y su tendencia a asociarse consigo misma, precipitando de la solución. Cuando se enfría, la amilosa presenta una fuerte tendencia a la retrogradación, donde cristaliza formando geles de almidón, aumentando así la viscosidad de la solución.

Si bien la organización exacta de estos componentes dentro del el gránulo todavía no está totalmente aclarada. Se conoce que el gránulo presenta regiones cristalinas en una masa predominantemente amorfa. La región cristalina está formada por cadenas de racimos de la amilopectina organizadas en forma de doble hélices, mientras que la región amorfa consiste en puntos de ramificación de la amilopectina y fracciones de amilosa $[60,63]$. Sin embargo, algunos autores han indicado que la amilosa también puede formar parte de la estructura cristalina del gránulo modificando el empaquetado de las cadenas de amilopectina $[64,65]$.

Debido a la anisotropía de los gránulos de almidón, en solución acuosa estos presentan doble refringencia o birrefringencia que, cuando se ve observa microscópicamente bajo luz polarizada, se evidencia como una "Cruz de Malta" (Figura 4.b). Este fenómeno se debe a la presencia alternante de regiones cristalinas y amorfas, y se caracteriza por la orientación radial de las macromoléculas $[66,67]$.

El centro o hilum, encontrado en el centro de la cruz, es considerado el punto original de crecimiento del gránulo, el cual se presenta en forma de anillos concéntricos (Figura 4.a). La existencia de estos anillos de crecimiento sugiere que el almidón recién sintetizado se deposite en la superficie, haciendo con que los gránulos aumenten su tamaño. Uno modelo para ese desarrollo sugiere que la primera capa de crecimiento esté en el hilum, que contiene una gran proporción de terminales reductores de las moléculas de almidón y es normalmente menos organizado que el resto del gránulo; mientras que los terminales-no reductores de amilosa y amilopectina irradian a la 
superficie, permitiendo la adición de más residuos de glucosa para aumentar las cadenas de amilopectina [64].
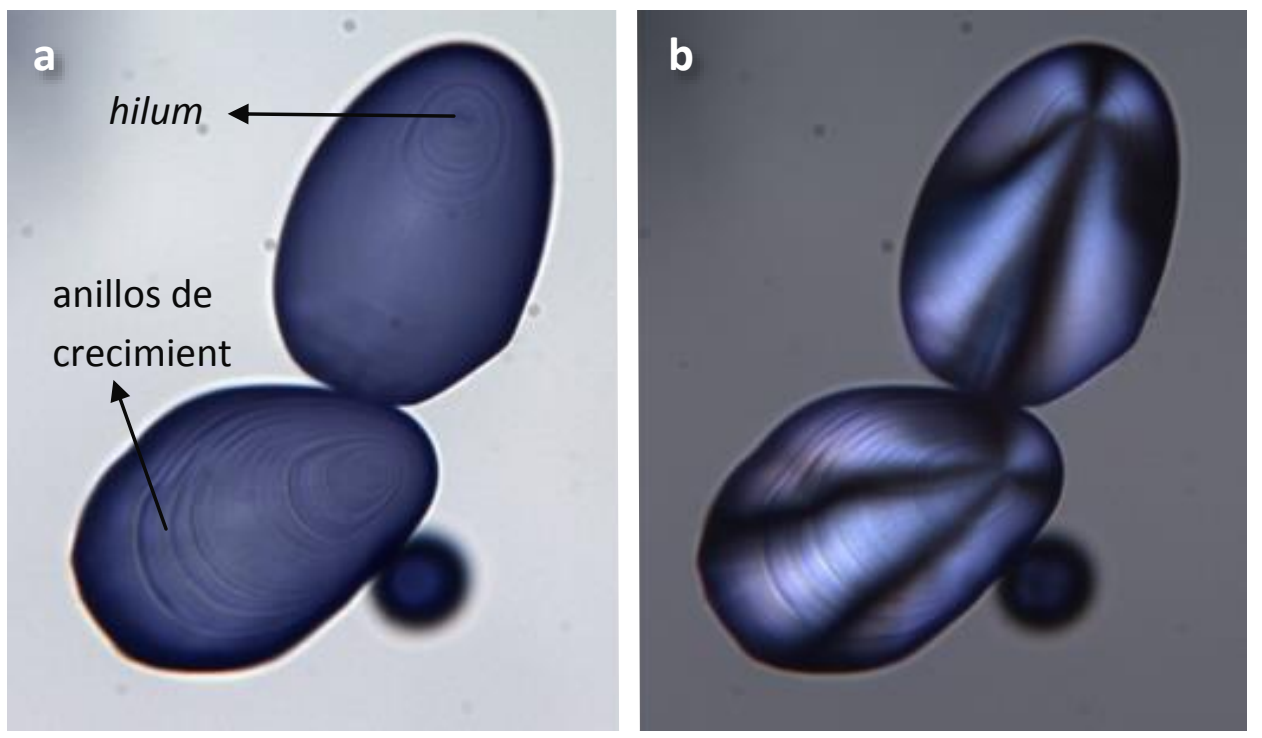

Figura 4. Ejemplo de gránulos de almidón de papa mostrando: a) su tinción con $I_{2}$ donde se pueden observar el hilum y los anillos de crecimiento, y b) las cruces de Malta observadas bajo luz polarizada.

Adaptado de http://archaeobotany.dept.shef.ac.uk/wiki/index.php/Image:PotatolKI.jpg.

Aunque los gránulos de almidón son insolubles en agua fría, cuando se calientan en un medio acuoso se hinchan, en lo que constituye la primera etapa del proceso de gelatinización. Inicialmente el hinchamiento es reversible, sin embargo cuando se alcanza una cierta temperatura el hinchamiento llega a ser irreversible afectando la estructura del gránulo. Este proceso es conocido como gelatinización y ocurre en un intervalo de temperatura, ya que los gránulos presentan diferente resistencia debido a su tamaño, composición y grado de cristalinidad. La gelatinización es un proceso endotérmico durante el cual ocurre la lixiviación de la amilosa y se observa la pérdida de birrefringencia del gránulo de almidón antes mencionada. El rango de temperaturas a la que ocurre la gelatinización depende de la fuente botánica de la que proviene el almidón, del contenido de humedad de la muestra y de ciertas condiciones 
experimentales tales como $\mathrm{pH}$, presencia de sólidos, etc. [68]. Al final de este fenómeno se genera una pasta en la que coexisten cadenas de amilosa de bajo peso molecular altamente hidratadas que rodean a los restos de los gránulos, también hidratados (Figura 5).

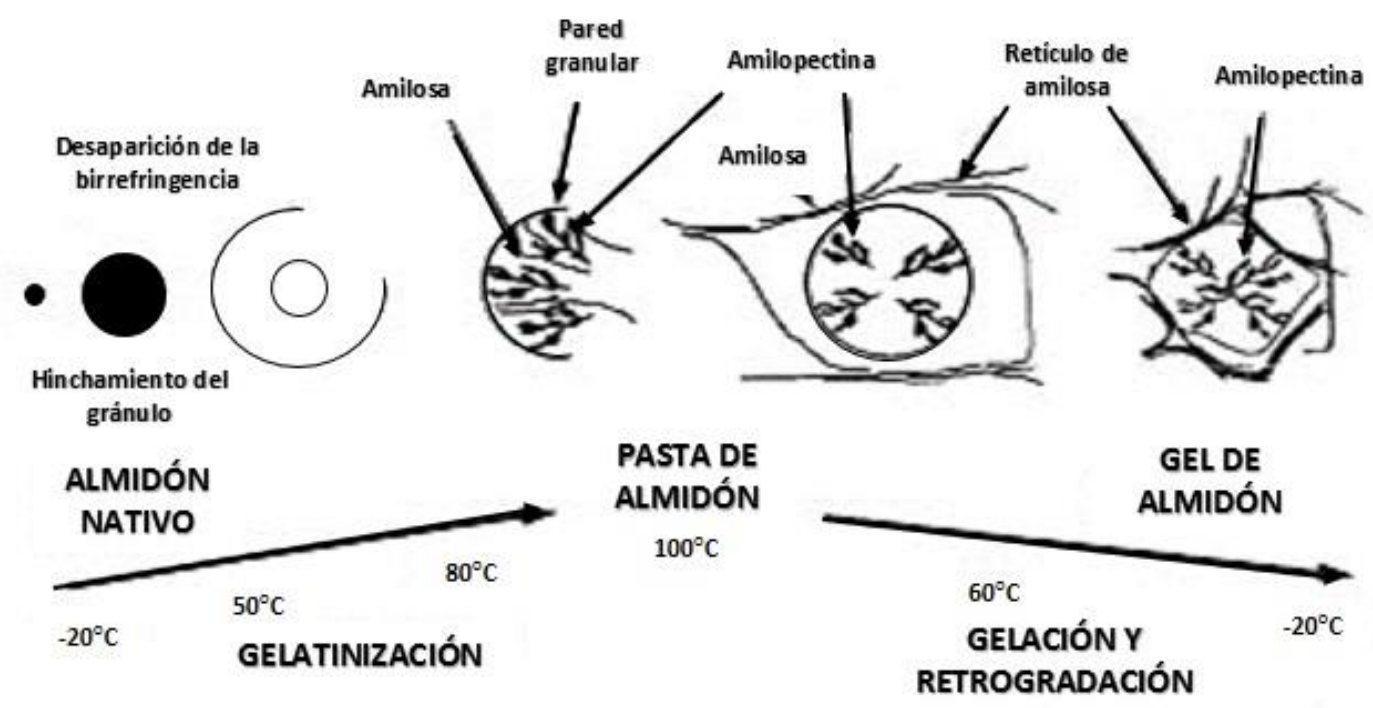

Figura 5. Efecto del procesamiento hidrotérmico sobre las características del almidón: hinchamiento, gelatinización, gelación y retrogradación. Adaptado de Eliasson [67].

Los almidones comerciales se obtienen de los granos de cereales, particularmente de maíz (Zea mays), trigo (Triticum spp.), arroz (Oryza sativa) y de algunas raíces y tubérculos, especialmente de papa (Solanum tuberosum), batata (Ipomoea batatas) y mandioca (Manihot esculenta).

Aunque la principal fuente de almidón para uso humano son los cereales, las raíces y tubérculos también son cultivos importantes. De la producción mundial anual de almidón aproximadamente el $58 \%$ corresponde a los cereales y el $40 \%$ a raíces y tubérculos [69]. El cultivo de tubérculos se encuentra ampliamente distribuido, de los 
cuales cinco especies proporcionan casi un $99 \%$ de la producción mundial: papa (46\%), mandioca (28\%), batata (18\%) y ñame (Dioscorea spp., $6 \%$ ).

En comparación con los procesos de extracción de almidón a partir de cereales por molienda húmeda, la extracción de almidón de tubérculos es muy sencilla. Las operaciones de extracción de granos implican etapas sucesivas de maceración y separación puesto que sus aceites, germen y proteínas son subproductos comercializables. En cambio, los subproductos de la extracción de almidón a partir de raíces tuberosas no son valorizados, y por consiguiente el proceso consta de las siguientes etapas: lavado, pelado, rallado, filtración, decantación y secado.

Es sabido que el almidón es uno de los principales carbohidratos en la alimentación humana y ofrece un amplio rango de propiedades tecnológicas [70].

\subsubsection{Almidón de mandioca}

La mandioca es un arbusto perenne euforbiáceo, autóctono y extensamente cultivado en Sudamérica y el Pacífico por su raíz tuberosa rica en almidón de alto valor alimentario (Figura 6). Junto al maíz, el tomate, la papa, los frijoles y el girasol, la mandioca es uno de los legados de la América precolombina a la agricultura mundial. Originaria del nordeste del Brasil, los portugueses la esparcieron ampliamente a mediados del siglo XVI en otras zonas tropicales y subtropicales de África, Asia y el Caribe.

La mandioca es la séptima fuente mayoritaria de alimentos básicos del mundo, siendo uno de los más importantes recursos para la alimentación en extensas áreas de los trópicos. Además de su utilización como alimento de primera necesidad, se comercializa en el mercado internacional en forma de alimento deshidratado en trozos (tipo snack), pellets, harina o almidón [71]. En particular, este tubérculo es una importante fuente de almidón en algunos países como Brasil [72], Tailandia, Malasia, Indonesia y algunas regiones de África [73]. Asimismo, es un cultivo apreciado por su 
adaptabilidad a diversos ecosistemas, alta tolerancia a sequías y suelos degradados, gran flexibilidad para la siembra y la cosecha, y gran productividad; ventajas que le confieren una alta competitividad $[71,74]$.

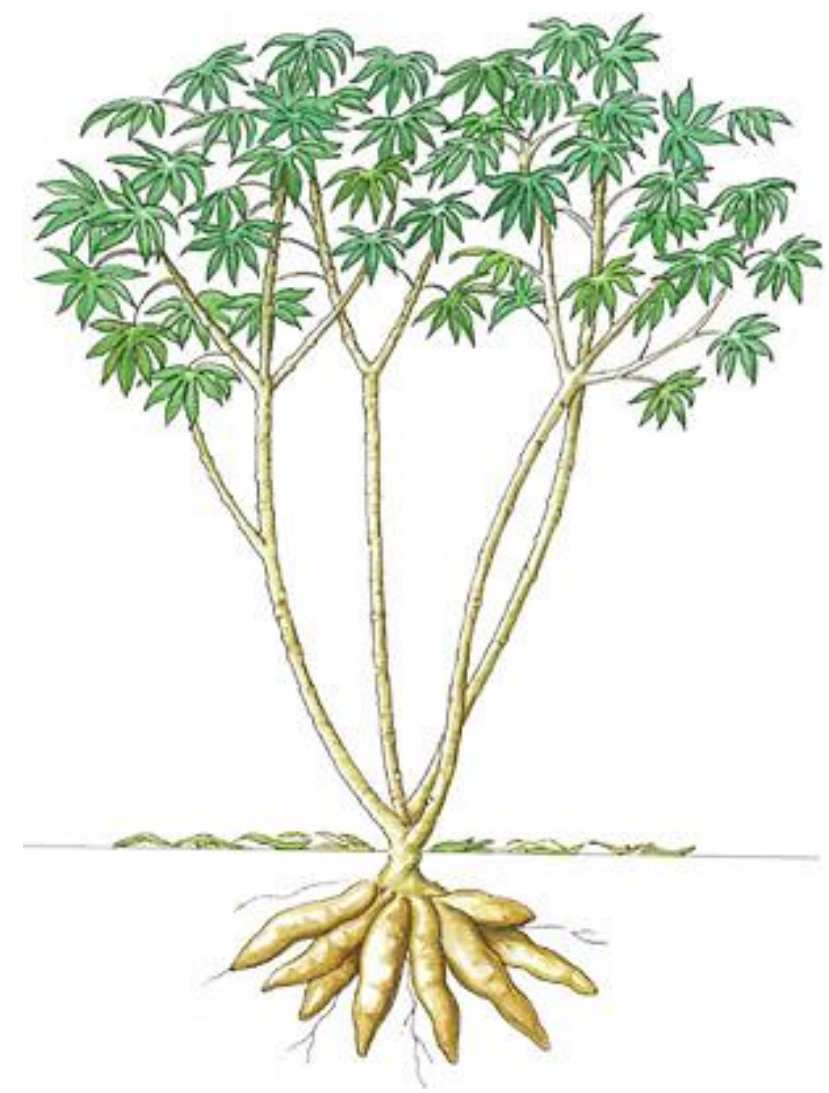

Figura 6. Planta de Mandioca (Manihot Esculenta).

Adaptado de http://www.fao.org/ag/save-and-Grow/cassava/es/index.html.

Como fuente de almidón, la mandioca es muy competitiva: la raíz contiene más almidón, por peso en seco, que casi cualquier otro cultivo alimentario, y su almidón, como se explicó anteriormente, es fácil de obtener con tecnologías sencillas. Los precios de exportación, que hoy rondan los 225 dólares estadounidenses por tonelada en el caso del almidón de mandioca superfino de Tailandia, son más bajos que los del almidón de la papa, el maíz y el trigo, que se produce en la Unión Europea y en los Estados Unidos. Asimismo, en comparación con los almidones obtenidos de casi todas las demás plantas, sus pastas son más claras y presentan mayor viscosidad, es muy 
estable en alimentos ácidos, y a su vez tiene propiedades óptimas para su uso en productos no alimentarios, como los farmacéuticos y los termoplásticos naturales.

Según la FAO, se calcula que anualmente se extraen unas 60 millones de toneladas de almidón a partir de diversos cultivos, para uso en una asombrosa variedad de productos: como agentes estabilizadores en sopas y alimentos congelados, revestimiento para pastillas y papel, adhesivo para estampillas y madera laminada, para el acabado de textiles, como materia prima para elaborar etanol e incluso como agente de cohesión en el concreto; de los cuales un 10 \% proviene de la producción de raíces de la mandioca. Puesto que hoy en día se producen unos 200 millones de toneladas de raíces de mandioca al año, la FAO considera que muchos países en desarrollo podrían fortalecer su economía rural, e incrementar los ingresos de los productores de mandioca, mediante la conversión de esa materia prima de relativo bajo costo en almidones de elevado valor para los mercados interno e internacional [74]. Si bien ha crecido la demanda mundial de almidón de mandioca en los últimos 25 años, sólo Tailandia ha pasado de la producción del alimento básico a la de productos y materias primas para la industria.

En América Latina y el Caribe está creciendo la producción comercial de almidón de mandioca, con una fuerte tendencia a la producción de almidones modificados, que obtienen precios más elevados. Sin embargo, la extracción de almidón representa sólo una parte muy pequeña del total de la producción: de toda la producción regional de raíces de mandioca, entre el $60 \%$ y el $70 \%$ (que equivale a unos 40 millones de toneladas al año) se destina a la elaboración de alimentos tradicionales, y la región aporta apenas un $4 \%$ al suministro mundial de almidón de mandioca, produciendo un volumen mucho mayor de almidón de maíz.

En Argentina, en la provincia de Misiones el cultivo de mandioca (Manihot esculenta Crantz) es intensivo, donde se asientan industrias almidoneras que procesan de 13.000 a 15.000 toneladas anuales de almidón [75]. El procesamiento de las raíces tuberosas 
genera grandes cantidades de residuos cuya disposición final constituye un problema ambiental, por lo que la transformación de dichos desechos en subproductos con mayor valor agregado puede contribuir a disminuir este inconveniente.

Como se mencionó anteriormente es posible considerar que tanto el cultivo como el consumo de esta especie se favorecerían si hubiera un mayor número de opciones de transformación de las mismas. Dichas raíces constituyen la materia prima para la obtención de biopolímeros tales como almidón y fibra. Su aplicación podría llevarse a cabo tanto a nivel alimentario como en otras áreas industriales.

\subsection{Materiales compuestos}

Los materiales compuestos de matriz polimérica se han presentado como una alternativa económica y ecológica a los materiales convencionales como metales, cerámicos, así como los mismos materiales poliméricos sintéticos puros. De este modo, la incorporación de componentes orgánicos e inorgánicos como refuerzos en matrices poliméricas ha dado lugar a una nueva variedad de materiales con propiedades fisicoquímicas, ópticas, eléctricas, magnéticas, térmicas o mecánicas específicas. Además, la posibilidad de reemplazar las matrices poliméricas convencionales por otras de fuentes renovables ha despertado interés, aunque aún se requiere una extensa investigación de las características y propiedades de estos materiales para su uso como por ejemplo en la construcción en seco de viviendas o la fabricación autopartes.

Como ya se describió, hoy en día, el interés en el desarrollo de materiales de almidón se basa en su biodegradabilidad y carácter sustentable. Desafortunadamente, comparados con los sintéticos, los materiales biodegradables a base de almidón presentan ciertas limitaciones debido a la hidrofilicidad de este polisacárido [76, 77]. Esto, representa una limitación para ciertas aplicaciones, puesto que puede derivar en pobres propiedades mecánicas y capacidad de barrera al vapor de agua, en comparación con los polímeros sintéticos [76]. Con el fin de superar estos 
inconvenientes, se ha estudiado la incorporación de diferentes cargas, tanto naturales como minerales, a matrices de almidón termoplástico (TPS) con el objetivo de mejorar el rendimiento mecánico, las propiedades de barrera y la estabilidad en condiciones ambientales de alta humedad relativa $[78,79]$.

Los rellenos comprenden un grupo extremadamente diverso de materiales, tales como minerales, metales, partículas cerámicas, fibras naturales, o incluso otros polímeros. Las propiedades de los compuestos obtenidos dependen no sólo de la composición química del relleno y la matriz, sino también del tamaño y la forma de los componentes de relleno utilizados en su formulación. Así, el grado de dispersión y alineación, la relación de aspecto y el tamaño de las cargas son factores importantes que afectan las propiedades finales del material compuesto. En este contexto, el uso de rellenos podría revolucionar la industria del plástico con aplicaciones prometedoras en electrónica, envasado de alimentos, y tecnología médica, entre otros [80-82].

\subsubsection{Materiales de relleno: fibras naturales}

Una opción ecológica y económicamente favorable para mejorar las propiedades finales de estos materiales es el empleo de fibras lignocelulósicas como refuerzo [83]. En comparación con las fibras sintéticas, las de origen natural presentan ciertas ventajas: alta disponibilidad, bajo costo, baja densidad, buena resistencia, inocuidad, biodegradabilidad y carácter renovable [84]. La actual tendencia a procurar utilizar rellenos renovables, se debe a que generalmente éstos se componen de productos o subproductos agroindustriales de fuentes sostenibles de bajo costo [85-90]. En este respecto, se han llevado a cabo diversas investigaciones sobre la utilización de cargas naturales en compuestos biodegradables y no biodegradables. Un aumento en el contenido de fibra promueve materiales más rígidos y, en algunos casos por ejemplo, con mayor resistencia al impacto $[85,90]$.

A pesar de su potencial como agentes de refuerzo, la incompatibilidad de las fibras naturales con matrices de polímeros hidrófobas, su tendencia a formar agregados 
durante el procesamiento, su pobre resistencia a la humedad, menor durabilidad, estabilidad térmica y estructural limitada, así como las dificultades para adaptar su incorporación en los procesos de fabricación convencionales, constituyen desafíos significativos para su implementación industrial [91-93]. En este sentido, los pretratamientos químicos, físicos y biológicos de las fibras pueden reducir su susceptibilidad a la humedad, mejorando la interacción relleno matriz y la estabilidad térmica de los materiales compuestos [91, 94-96].

Shalwan y Yousif [83] y Azwa y col. [91] han revisado la utilización de fibras como agentes de refuerzo en matrices biodegradables. Así, se han incorporado fibras de celulosa aisladas de pulpa de madera [97], yute [98] y salvado de trigo [99] a matrices de hidrocoloides lográndose en todos los casos aumentar la resistencia mecánica y la estabilidad térmica de los materiales compuestos obtenidos. La utilización de subproductos agroindustriales como refuerzos es una opción poco estudiada; Chiellini y col. [100] propusieron incorporar bagazo de caña de azúcar como fibra vegetal a películas de gelatina, pero se requiere profundizar los estudios en este sentido.

Finalmente, es importante también señalar que el procesamiento de hortalizas y otros productos vegetales acarrea un problema para la industria alimentaria, derivado de la disposición de residuos. La transformación de subproductos o desechos en materiales con mayor valor agregado puede contribuir a disminuir este inconveniente [101]. Asimismo, el uso de fibras a partir de nuevas fuentes vegetales es un área de interés para diversas agroindustrias. Con todo lo expuesto, la utilización de subproductos industriales como refuerzos y/o soportes es una opción interesante aún en estudio $[99,102]$. 


\section{OBJETIVOS GENERALES}

En el presente trabajo de Tesis se desarrollaron y estudiaron materiales biodegradables y eco-compatibles a base de almidón de mandioca reforzadas con las fibras naturales provenientes del bagazo y la cáscara de la raíz, evaluando sus propiedades mecánicas, ópticas y de barrera. Se consideraron distintos plastificantes y aditivos para funcionalizar la matriz, así como dos técnicas de procesamiento.

Por último se evaluó la potencialidad de los materiales obtenidos en aplicaciones agronómicas específicas como: cobertura de suelo y sistemas de liberación controlada de fertilizantes en la producción de plantines. Para ello fue preciso evaluar la estabilidad de los materiales frente a distintas condiciones de almacenamiento, así como su biodegradación en suelo y las distintas formas de utilización del material.

\section{BIBLIOGRAFÍA}

[1] I. Tsiropoulos, A.P.C. Faaij, L. Lundquist, U. Schenker, J.F. Briois, M.K. Patel, Life cycle impact assessment of bio-based plastics from sugarcane ethanol, Journal of Cleaner Production 90 (2015) 114-127.

[2] S. Guilbert, P. Feuilloley, H. Bewa, V. Bellon-Maurel, Biodegradable polymers in agricultural applications, en: Biodegradable Polymers for Industrial Applications, 2005, pp. 494-516.

[3] D. Briassoulis, Mechanical behaviour of biodegradable agricultural films under real field conditions, Polymer Degradation and Stability 91 (2006) 1256-1272.

[4] K. Madhavan Nampoothiri, N.R. Nair, R.P. John, An overview of the recent developments in polylactide (PLA) research, Bioresour Technol 101 (2010) 8493-8501.

[5] M. Fernandez-Perez, F.J. Garrido-Herrera, E. Gonzalez-Pradas, Alginate and lignin-based formulations to control pesticides leaching in a calcareous soil, J Hazard Mater 190 (2011) 794801.

[6] T. Galicia-García, F. Martínez-Bustos, O. Jiménez-Arevalo, A.B. Martínez, R. Ibarra-Gómez, M. Gaytán-Martínez, M. Mendoza-Duarte, Thermal and microstructural characterization of biodegradable films prepared by extrusion-calendering process, Carbohydrate Polymers 83 (2011) 354-361.

[7] R. Jayakumar, M. Prabaharan, P.T. Sudheesh Kumar, S.V. Nair, H. Tamura, Biomaterials based on chitin and chitosan in wound dressing applications, Biotechnol Adv 29 (2011) 322337. 
[8] O. Cadar, M. Paul, C. Roman, M. Miclean, C. Majdik, Biodegradation behaviour of poly(lactic acid) and (lactic acid-ethylene glycol-malonic or succinic acid) copolymers under controlled composting conditions in a laboratory test system, Polymer Degradation and Stability 97 (2012) 354-357.

[9] C. Chen, L. Liu, T. Huang, Q. Wang, Y. Fang, Bubble template fabrication of chitosan/poly(vinyl alcohol) sponges for wound dressing applications, Int J Biol Macromol 62 (2013) 188-193.

[10] M.M. Reddy, S. Vivekanandhan, M. Misra, S.K. Bhatia, A.K. Mohanty, Biobased plastics and bionanocomposites: Current status and future opportunities, Progress in Polymer Science 38 (2013) 1653-1689.

[11] C. Li, J. Moore-Kucera, J. Lee, A. Corbin, M. Brodhagen, C. Miles, D. Inglis, Effects of biodegradable mulch on soil quality, Applied Soil Ecology 79 (2014) 59-69.

[12] S. Sharma, A. Dua, A. Malik, Polyaspartic acid based superabsorbent polymers, European Polymer Journal 59 (2014) 363-376.

[13] M. Niaounakis, Medical, Dental and Pharmaceutical Applications, en: Biopolymers: Applications and Trends, Elsevier Inc., Oxford, UK, 2015, pp. 291-405.

[14] M.A. El-Samahy, S.A.A. Mohamed, M.H. Abdel Rehim, M.E. Mohram, Synthesis of hybrid paper sheets with enhanced air barrier and antimicrobial properties for food packaging, Carbohydrate Polymers 168 (2017) 212-219.

[15] G. Sanchez-Olivares, A. Sanchez-Solis, F. Calderas, J. Alongi, Keratin fibres derived from tannery industry wastes for flame retarded PLA composites, Polymer Degradation and Stability 140 (2017) 42-54.

[16] Y. Song, Y. Li, W. Song, K. Yee, K.Y. Lee, V.L. Tagarielli, Measurements of the mechanical response of unidirectional 3D-printed PLA, Materials \& Design 123 (2017) 154-164.

[17] H. Ventura, J. Claramunt, M.A. Rodríguez-Pérez, M. Ardanuy, Effects of hydrothermal aging on the water uptake and tensile properties of PHB/flax fabric biocomposites, Polymer Degradation and Stability 142 (2017) 129-138.

[18] S. Shukla, World Bioplastics Market - Opportunities and Forecast, 2014 - 2020, Allied Analytics LLP (2015).

[19] http://www.braskem.com/site.aspx/Im-greenTM-Polyethylene.

[20] I. Kyrikou, D. Briassoulis, Biodegradation of Agricultural Plastic Films: A Critical Review, Journal of Polymers and the Environment 15 (2007) 125-150.

[21] H. Horinouchi, N. Katsuyama, Y. Taguchi, M. Hyakumachi, Control of Fusarium crown and root rot of tomato in a soil system by combination of a plant growth-promoting fungus, Fusarium equiseti, and biodegradable pots, Crop Protection 27 (2008) 859-864.

[22] A.P. Bilck, M.V.E. Grossmann, F. Yamashita, Biodegradable mulch films for strawberry production, Polymer Testing 29 (2010) 471-476.

[23] M.M. Moreno, A. Moreno, Effect of different biodegradable and polyethylene mulches on soil properties and production in a tomato crop, Scientia Horticulturae 116 (2008) 256-263. 
[24] M.O. Rutiaga, L.J. Galan, L.H. Morales, S.H. Gordon, S.H. Imam, W.J. Orts, G.M. Glenn, K.A. Niño, Mechanical Property and Biodegradability of Cast Films Prepared from Blends of Oppositely Charged Biopolymers, Journal of Polymers and the Environment 13 (2005) 185-191.

[25] A. Immirzi, G. Santagata, G. Vox, E. Schettini, Preparation, characterization and fieldtesting of a biodegradable sodium alginate based spray mulch, Biosystems Engineering 102 (2009) 461-472.

[26] G. Vox, E. Schettini, Evaluation of the radiometric properties of starch-based biodegradable films for crop protection, Polymer Testing 26 (2007) 639-651.

[27] E. Schettini, G. Vox, B. De Lucia, Effects of the radiometric properties of innovative biodegradable mulching materials on snapdragon cultivation., Scientia Horticulturae 112 (2007) 456-461.

[28] L. Chen, Z. Xie, X. Zhuang, X. Chen, X. Jing, Controlled release of urea encapsulated by starch-g-poly(I-lactide), Carbohydrate Polymers 72 (2008) 342-348.

[29] S.A. Riyajan, Y. Sasithornsonti, P. Phinyocheep, Green natural rubber-g-modified starch for controlling urea release, Carbohydrate Polymers 89 (2012) 251-258.

[30] O.V. López, N.E. Zaritzky, M.V.E. Grossmann, M.A. García, Acetylated and native corn starch blend films produced by blown extrusion, Journal of Food Engineering 116 (2013) 286297.

[31] S. Rivero, L. Giannuzzi, M.A. García, A. Pinotti, Controlled delivery of propionic acid from chitosan films for pastry dough conservation, Journal of Food Engineering 116 (2013) 524-531.

[32] M.A. García, M.N. Martino, N.E. Zaritzky, Microstructural Characterization of Plasticized Starch-Based Films, Starch - Stärke 52 (2000) 118-124.

[33] M.A. García, A. Pinotti, M.N. Martino, N.E. Zaritzky, Chapter 6 - Characterization of Starch and Composite Edible Films and Coatings, en: M.E. Embuscado, K.C. Huber (Eds.) Edible Films and Coating for Food Applications, Publisher Springer Science, New York, NY, USA, 2009, pp. 169-210.

[34] T. Janjarasskul, J.M. Krochta, Edible packaging materials, Annual Review of Food Science and Technology 1 (2010) 415-448.

[35] S. Mali, M.V.E. Grossmann, L.B. Karam, L.P. Ramos, Relationships among the composition and physicochemical properties of starches with the characteristics of their films, Journal of Agricultural and Food Chemistry 52 (2004) 7720-7725.

[36] G.M. Glenn, W. Orts, S. Imam, B.-S. Chiou, D.F. Wood, en: P.J. Halley, L. Avérous (Eds.) Starch Polymers: From Genetic Engineering to Green Applications, Elsevier B.V., San Diego, USA, 2014, pp. 421-452.

[37] L. Copeland, J. Blazek, H. Salman, M.C. Tang, Form and functionality of starch, Food Hydrocolloids 23 (2009) 1527-1534.

[38] A. Mohammadi Nafchi, M. Moradpour, M. Saeidi, A.K. Alias, Thermoplastic starches: Properties, challenges, and prospects, Starch-Stärke 65 (2013) 61-72.

[39] A.K. Shrestha, P.J. Halley, Chapter 5 - Starch Modification to Develop Novel StarchBiopolymer Blends: State of Art and Perspectives, en: Starch Polymers, Elsevier, Amsterdam, 2014, pp. 105-143. 
[40] G. Bonacucina, P. Di Martino, M. Piombetti, A. Colombo, F. Roversi, G.F. Palmieri, Effect of plasticizers on properties of pregelatinised starch acetate (Amprac 01) free films, Int J Pharm 313 (2006) 72-77.

[41] C. Fringant, M. Rinaudo, M.F. Foray, M. Bardet, Preparation of mixed esters of starch or use of an external plasticizer: two different ways to change the properties of starch acetate films, Carbohydrate Polymers 35 (1998) 97-106.

[42] M. Tarvainen, S. Peltonen, H. Mikkonen, M. Elovaara, M. Tuunainen, P. Paronen, J. Ketolainen, R. Sutinen, Aqueous starch acetate dispersion as a novel coating material for controlled release products, J Control Release 96 (2004) 179-191.

[43] B. Kaur, F. Ariffin, R. Bhat, A.A. Karim, Progress in starch modification in the last decade, Food Hydrocolloids 26 (2012) 398-404.

[44] A.S. Abreu, M. Oliveira, A. de Sa, R.M. Rodrigues, M.A. Cerqueira, A.A. Vicente, A.V. Machado, Antimicrobial nanostructured starch based films for packaging, Carbohydrate Polymers 129 (2015) 127-134.

[45] J. Andersons, J. Modniks, R. Joffe, B. Madsen, K. Nättinen, Apparent interfacial shear strength of short-flax-fiber/starch acetate composites, International Journal of Adhesion and Adhesives 64 (2016) 78-85.

[46] K. Wilpiszewska, A.K. Antosik, T. Spychaj, Novel hydrophilic carboxymethyl starch/montmorillonite nanocomposite films, Carbohydrate Polymers 128 (2015) 82-89.

[47] M.A. Cerqueira, B.W.S. Souza, J.A. Teixeira, A.A. Vicente, Effect of glycerol and corn oil on physicochemical properties of polysaccharide films - A comparative study, Food Hydrocolloids 27 (2012) 175-184.

[48] S.K. Flores, D. Costa, F. Yamashita, L.N. Gerschenson, M.V. Grossmann, Mixture design for evaluation of potassium sorbate and xanthan gum effect on properties of tapioca starch films obtained by extrusion, Materials Science and Engineering C 30 (2010) 196-202.

[49] O.V. López, C.J. Lecot, N.E. Zaritzky, M.A. García, Biodegradable packages development from starch based heat sealable films, Journal of Food Engineering 105 (2011) 254-263.

[50] J.O. de Moraes, A.S. Scheibe, A. Sereno, J.B. Laurindo, Scale-up of the production of cassava starch based films using tape-casting, Journal of Food Engineering 119 (2013) 800-808.

[51] C.M. Ortiz, J.O. de Moraes, A.R. Vicente, J.B. Laurindo, A.N. Mauri, Scale-up of the production of soy (Glycine max L.) protein films using tape casting: Formulation of film-forming suspension and drying conditions, Food Hydrocolloids 66 (2017) 110-117.

[52] M. Thunwall, A. Boldizar, M. Rigdhal, Compression Molding and Tensile Properties of Thermoplastic Potato Starch Materials, Biomacromolecules 7 (2006) 981-986.

[53] F.M. Pelissari, F. Yamashita, M.A. Garcia, M.N. Martino, N.E. Zaritzky, M.V.E. Grossmann, Constrained mixture design applied to the development of cassava starch-chitosan blown films, Journal of Food Engineering 108 (2012) 262-267.

[54] H.A. Pushpadass, D.B. Marx, M.A. Hanna, Effects of Extrusion Temperature and Plasticizers on the Physical and Functional Properties of Starch Films, Starch - Stärke 60 (2008) 527-538.

[55] M. Thunwall, V. Kuthanova, A. Boldizar, M. Rigdahl, Film blowing of thermoplastic starch, Carbohydrate Polymers 71 (2008) 583-590. 
[56] D. French, Organization of Starch Granules, en: R.L. Whistler, J.N. BeMiller, E.F. Paschall (Eds.) Starch: Chemistry and Technology, Academic Press Inc., Orlando, Florida, 1984, pp. 184248.

[57] N.L. García, L. Famá, A. Dufresne, M. Aranguren, S. Goyanes, A comparison between the physico-chemical properties of tuber and cereal starches, Food Research International 42 (2009) 976-982.

[58] H.-D. Belitz, W. Grosch, P. Schieberle, Food Chemistry, 4 ed., Springer-Verlag Berlin Heidelberg, Berlin, Germany 2009.

[59] M. Hernández-Medina, J.G. Torruco-Uco, L. Chel-Guerrero, D. Betancur-Ancona, Caracterización fisicoquímica de almidones de tubérculos cultivados en Yucatán, México, Ciência e Tecnologia de Alimentos 28 (2008) 718-726.

[60] H.F. Zobel, Starch Crystal Transformations and Their Industrial Importance, Starch - Stärke 40 (1988) 1-7.

[61] L.A. Bello-Pérez, P. Osorio-Díaz, E. Agama-Acevedo, J. Solorza-Feria, J.F. Toro-Vázquez, O. Paredes-López, Chemical and physicochemical properties of dried wet masa and dry masa flour, Journal of the Science of Food and Agriculture 83 (2003) 408-412.

[62] D.J. Thomas, W.A. Atwell, Starches, Eagan Press, 1999.

[63] R.D. Hancock, B.J. Tarbet, The Other Double Helix-The Fascinating Chemistry of Starch, Journal of Chemical Education 77 (2000) 988-992.

[64] C. Casagrande Denardin, L. Picolli da Silva, Estrutura dos grânulos de amido e sua relação com propriedades físico-químicas, Ciência Rural 39 (2009) 945-954.

[65] D. Kuakpetoon, Y.J. Wang, Internal structure and physicochemical properties of corn starches as revealed by chemical surface gelatinization, Carbohydrate research 342 (2007) 2253-2263.

[66] F.R. Katz, S.L. Furcsik, F.L. Tenbarge, R.J. Hauber, R.B. Friedman, Behavior of starches derived from varieties of maize containing different genetic mutations: effects of starch genotype on granular morphology, Carbohydrate Polymers 21 (1993) 133-136.

[67] A.-C. Eliasson, Starch in food - Structure, function, and application, Woodhead Publishing Limited, Cambridge, UK, 2004.

[68] D.P. Huang, L.W. Rooney, Starches for Snack Foods, en: Snack Foods Processing, CRC Press, 2001.

[69] M.L.M. Broeren, L. Kuling, E. Worrell, L. Shen, Environmental impact assessment of six starch plastics focusing on wastewater-derived starch and additives, Resources, Conservation and Recycling 127 (2017) 246-255.

[70] U. Lehmann, F. Robin, Slowly digestible starch - its structure and health implications: a review, Trends in Food Science \& Technology 18 (2007) 346-355.

[71] T. Abera, S. Admasu, G. Desse, Effect of Processing on Physicochemical Composition of Cassava: Cyanide and other Antinutrients in Cassava, VDM Verlag Dr. Müller, Saarbrücken, Germany, 2010.

[72] M. Leonel, S.B. Sarmento, M.P. Cereda, F.L. Cãmara, Extração e caracterização de amido de jacatupé (Pachyrhizus ahipa), Ciência e Tecnología de Alimentos 23 (2003) 362-365. 
[73] United Nations Conference on Trade and Development, INFOCOMM Commodity Profile: CASSAVA, (2012).

[74] International Fund for Agricultural Development Food and Agriculture Organization of the United Nations, Global cassava market study: Business opportunities for the use of cassava, FAO and IFAD (2004).

[75] Instituto Nacional de Tecnología Agropuecuria (INTA), en, Ediciones INTA, Misiones, Argentina, 2012, pp. 72.

[76] L. Averous, N. Boquillon, Biocomposites based on plasticized starch: thermal and mechanical behaviours, Carbohydrate Polymers 56 (2004) 111-122.

[77] T. Phattaraporn, S. Waranyou, W. Thawien, Effect of palm pressed fiber ( PPF ) surface treatment on the properties of rice starch films, International Food Research Journal 18 (2011) 287-301.

[78] C.M.O. Müller, J.B. Laurindo, F. Yamashita, Effect of cellulose fibers addition on the mechanical properties and water vapor barrier of starch-based films, Food Hydrocolloids 23 (2009) 1328-1333.

[79] V. Tunjano, F. Salcedo, I. Jiménez, J. Medina, O. Alvarez, E. Prieto, en: Suplemento de la Revista Latinoamericana de Metalurgia y Materiales, Universidad Simón Bolívar, Venezuela, 2009, pp. 29-36.

[80] B. Sarkar, P. Alexandridis, Block copolymer-nanoparticle composites: Structure, functional properties, and processing, Progress in Polymer Science 40 (2015) 33-62.

[81] E. Thostenson, C. Li, T. Chou, Nanocomposites in context, Composites Science and Technology 65 (2005) 491-516.

[82] S. Ummartyotin, C. Pechyen, Microcrystalline-cellulose and polypropylene based composite: A simple, selective and effective material for microwavable packaging, Carbohydrate Polymers 142 (2016) 133-140.

[83] A. Shalwan, B.F. Yousif, In State of Art: Mechanical and tribological behaviour of polymeric comopistes based on natural fibres, Materials \& Design 48 (2013) 14-24.

[84] T. Kunanopparat, P. Menut, M.H. Morel, S. Guilbert, Reinforcement of plasticized wheat gluten with natural fibers: From mechanical improvement to deplasticizing effect, Composites Part A: Applied Science and Manufacturing 39 (2008) 777-785.

[85] F.M. Al-Oqla, S.M. Sapuan, Natural fiber reinforced polymer composites in industrial applications: feasibility of date palm fibers for sustainable automotive industry, Journal of Cleaner Production 66 (2014) 347-354.

[86] A. Ashori, A. Nourbakhsh, Reinforced polypropylene composites: effects of chemical compositions and particle size, Bioresource Technology 101 (2010) 2515-2519.

[87] O.V. López, L.A. Castillo, M.A. García, M.A. Villar, S.E. Barbosa, Food packaging bags based on thermoplastic corn starch reinforced with talc nanoparticles, Food Hydrocolloids 43 (2015) $18-24$.

[88] M. Phiriyawirut, P. Maniaw, Cellulose Microfibril from Banana Peels as a Nanoreinforcing Fillers for Zein Films, Open Journal of Polymer Chemistry 2 (2012) 56-62. 
[89] S.M. Sapuan, K.F. Tamrin, Y. Nukman, Y.A. El-Shekeil, M.S.A. Hussin, S.N.A. Aziz, 1.8 Natural Fiber-Reinforced Composites: Types, Development, Manufacturing Process, and Measurement, (2017) 203-230.

[90] P. Sinha, S. Mathur, P. Sharma, V. Kumar, Potential of pine needles for PLA-based composites, Polymer Composites (2016).

[91] Z.N. Azwa, B.F. Yousif, A.C. Manalo, W. Karunasena, A review on the degradability of polymeric composites based on natural fibres, Materials \& Design 47 (2013) 424-442.

[92] D.B. Dittenber, H.V.S. GangaRao, Critical review of recent publications on use of natural composites in infrastructure, Composites Part A: Applied Science and Manufacturing 43 (2012) 1419-1429.

[93] A.K. Mohanty, M. Misra, L.T. Drzal, Sustainable Bio-Composites from Renewable Resources: Opportunities and Challenges in the Green Materials World, Journal of Polymers and the Environment 10 (2002) 19-26.

[94] M. George, M. Chae, D.C. Bressler, Composite materials with bast fibres: Structural, technical, and environmental properties, Progress in Materials Science 83 (2016) 1-23.

[95] S. Kalia, B.S. Kaith, I. Kaur, Pretreatments of natural fibers and their application as reinforcing material in polymer composites-A review, Polymer Engineering \& Science 49 (2009) 1253-1272.

[96] K.G. Satyanarayana, G.G.C. Arizaga, F. Wypych, Biodegradable composites based on lignocellulosic fibers-An overview, Progress in Polymer Science 34 (2009) 982-1021.

[97] A.A.S. Curvelo, A.J.F. De Carvalho, J.A.M. Agnelli, Thermoplastic starch-cellulosic fibers composites : preliminary results, Carbohydrate Polymers 45 (2001) 183-188.

[98] O.A. Khondker, U.S. Ishiaku, A. Nakai, H. Hamada, A novel processing technique for thermoplastic manufacturing of unidirectional composites reinforced with jute yarns, Composites Part A: Applied Science and Manufacturing 37 (2006) 2274-2284.

[99] L. Famá, L. Gerschenson, S. Goyanes, Starch-vegetable fibre composites to protect food products, Carbohydrate Polymers 75 (2009) 230-235.

[100] E. Chiellini, P. Cinellia, A. Cortia, E.R. Kenawy, Composite films based on waste gelatin: thermal-mechanical properties and biodegradation testing, Polymer Degradation and Stability 73 (2001) 549-555.

[101] M.F. de Escalada Pla, N.M. Ponce, C.A. Stortz, L.N. Gerschenson, A.M. Rojas, Composition and functional properties of enriched fiber products obtained from pumpkin (Cucurbita moschata Duchesne ex Poiret), LWT - Food Science and Technology 40 (2007) 1176-1185.

[102] L. Ludueña, A. Vázquez, V. Alvarez, Effect of lignocellulosic filler type and content on the behavior of polycaprolactone based eco-composites for packaging applications, Carbohydrate Polymers 87 (2012) 411-421. 


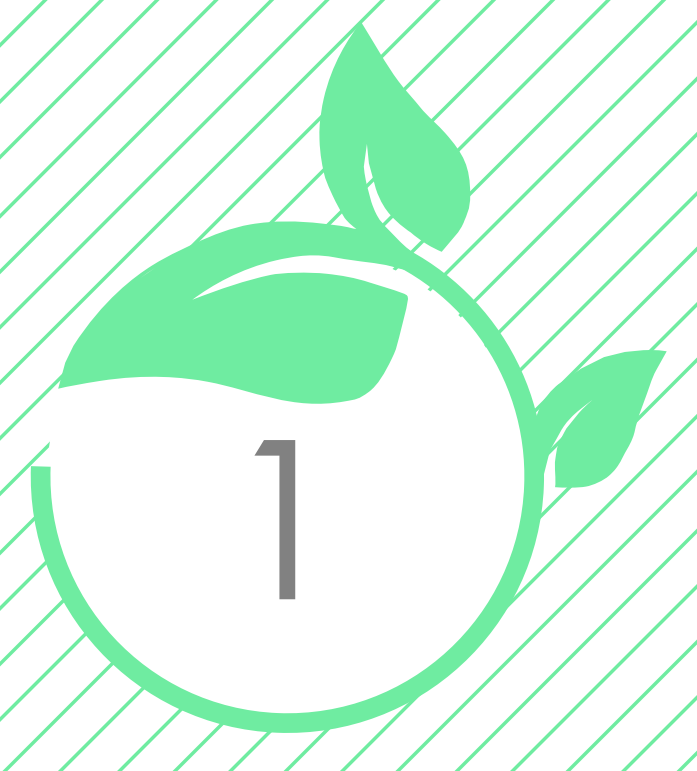

Películas de almidón de mandioca
reforzadas con bagazo de mandioca:

EFECTO DEL PLASTIFICANTE Y

DEL CONTENIDO DE RELLENO 


\section{INTRODUCCIÓN}

El interés en el desarrollo de películas biodegradables a partir de fuentes renovables está creciendo debido a la progresiva concientización ambiental. Entre los polímeros naturales, el almidón ha sido considerado como uno de los materiales más prometedores debido a la atractiva combinación de amplia disponibilidad, bajo precio y alto rendimiento $[1,2]$. La mandioca (Manihot esculenta), en particular, es una importante fuente de almidón en algunos países como Brasil - el mayor productor mundial [3]- así como en Tailandia, Malasia, Indonesia y algunas regiones de África [4]. Además, se ha estudiado ampliamente el uso de almidón de mandioca para la formulación de películas [5-7]. En trabajos anteriores se desarrolló y optimizó un procedimiento para la extracción de almidón a partir de raíces tuberosas como ahipa (Pachyrhizus ahipa) y mandioca $[2,8]$.

En general, las propiedades de las películas biodegradables obtenidas dependen de la naturaleza del almidón, el proceso de producción y, el tipo y contenido de aditivos. Por ejemplo, se agregan plastificantes para mejorar la flexibilidad del material o refuerzos estructurales que confieren mayor resistencia mecánica. La utilización de fibras lignocelulósicas como refuerzo en matrices poliméricas en comparación con las cargas inorgánicas viene siendo objeto de muchas investigaciones, ya que éstas presentan numerosas ventajas, tales como su naturaleza renovable, biodegradabilidad, bajo consumo de energía, amplia variedad en todo el mundo, bajo costo y densidad, así como su alta resistencia y módulo específicos [9-11]. Además, presentan una alta atenuación acústica y un procesamiento relativamente fácil debido a su flexibilidad y naturaleza no abrasiva que permiten altos niveles de carga [12, 13]. A pesar de estas propiedades deseables, los rellenos lignocelulósicos se usan sólo en forma limitada en las prácticas industriales, debido principalmente a las dificultades asociadas con la interacción superficial en el caso de los polímeros sintéticos $[11,13]$. 
Las fibras naturales pueden obtenerse de residuos agroindustriales o agrícolas, aportando valor añadido a las materias primas de las que derivan. Se han discutido y revisado materiales compuestos de almidón con diferentes fibras de celulosa, entre los que se incluyen fibras de madera y kenaf [14], fibras cortas de pulpa de madera [15], cascarilla celulósica de pehuen [16], fibra de pulpa de aspen [17] y fibras de palmito y lino [18]. Asimismo, se han añadido cargas lignocelulósicas a otros materiales biodegradables y sintéticos. Behera y col. [19] informaron la inclusión de fibras de yute en una matriz de proteína de soja y Ludueña y col. [20] han reforzado las películas de policaprolactona $(\mathrm{PCL})$ con fibras de algodón para mejorar las propiedades del material.

Hasta donde sabemos, pocos son los reportes de películas reforzadas con el residuo remanente de la extracción de almidón (bagazo), con un estudio exhaustivo de las características del relleno y sus efectos sobre las propiedades finales de los materiales. Por lo tanto, la composición química de los residuos y la morfología deben estudiarse en relación con su capacidad de refuerzo, así como las propiedades de los materiales obtenidos que contienen este relleno natural. Se trata de una aplicación innovadora e interesante para revalorizar y agregar valor a estos residuos industriales, con la consecuente disminución de los volúmenes de desechos.

\section{OBJETIVOS}

- $\quad$ Obtención de películas biodegradables de almidón de mandioca plastificadas con glicerol y reforzado con bagazo de mandioca por el método de casting.

- Evaluar el efecto del contenido de plastificante sobre las matrices poliméricas con y sin relleno.

- Evaluar el efecto del contenido de agentes de refuerzo sobre las propiedades de las películas de almidón plastificadas. 


\section{METODOLOGÍA Y TÉCNICAS EMPLEADAS}

\subsection{Obtención de almidón y caracterización}

Para los ensayos realizados se empleó: almidón de mandioca extraído por el método optimizado previamente por López y col. [8], a partir de raíces tuberosas cultivadas en la Estación Experimental Agropecuaria perteneciente al INTA Montecarlo

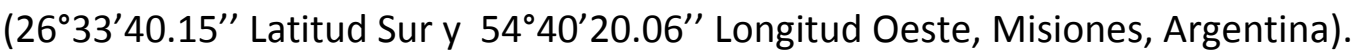

El método de extracción a partir de las raíces frescas se esquematiza en el diagrama de bloques de la Figura I.1. El mismo consiste en la recepción y el lavado de las raíces para eliminar restos de tierra. Proseguido por una etapa de desinfección con el fin de reducir la carga microbiana de las raíces, la cual consiste en un segundo lavado con solución de hipoclorito de sodio ( $250 \mathrm{ppm}$ de $\mathrm{Cl}_{2}$ ) durante 10 minutos. Luego las raíces se pelan y se procesan con un rallador de disco rotatorio especialmente diseñado para este fin. La pasta rallada se coloca en agua en una relación de 2 L por kg de raíz, y se almacena a $4{ }^{\circ} \mathrm{C}$ durante $24 \mathrm{hs}$. Luego, la mezcla se filtra a través de una muselina y se obtiene el almidón en suspensión acuosa, denominado "lechada de almidón”. La suspensión se decanta a $4{ }^{\circ} \mathrm{C}$ y se recupera el material insoluble sedimentado constituido principalmente por almidón, el que luego se seca a $40{ }^{\circ} \mathrm{C}$. Finalmente, el material seco es sometido a molienda y almacenado en recipientes herméticos para su conservación.

\subsection{Caracterización de materiales de relleno}

A partir del proceso de extracción descripto en la sección anterior se obtuvieron dos subproductos de la raíz de mandioca: la cáscara y el bagazo o residuo remanente (Figura I.1). Los mismos fueron secados en estufa a $50{ }^{\circ} \mathrm{C}$ para estabilizarlos (detener procesos de degradación enzimática naturales), procesados y tamizados con tamices de malla normalizada (ALEIN International, Argentina) como se describe a continuación. 


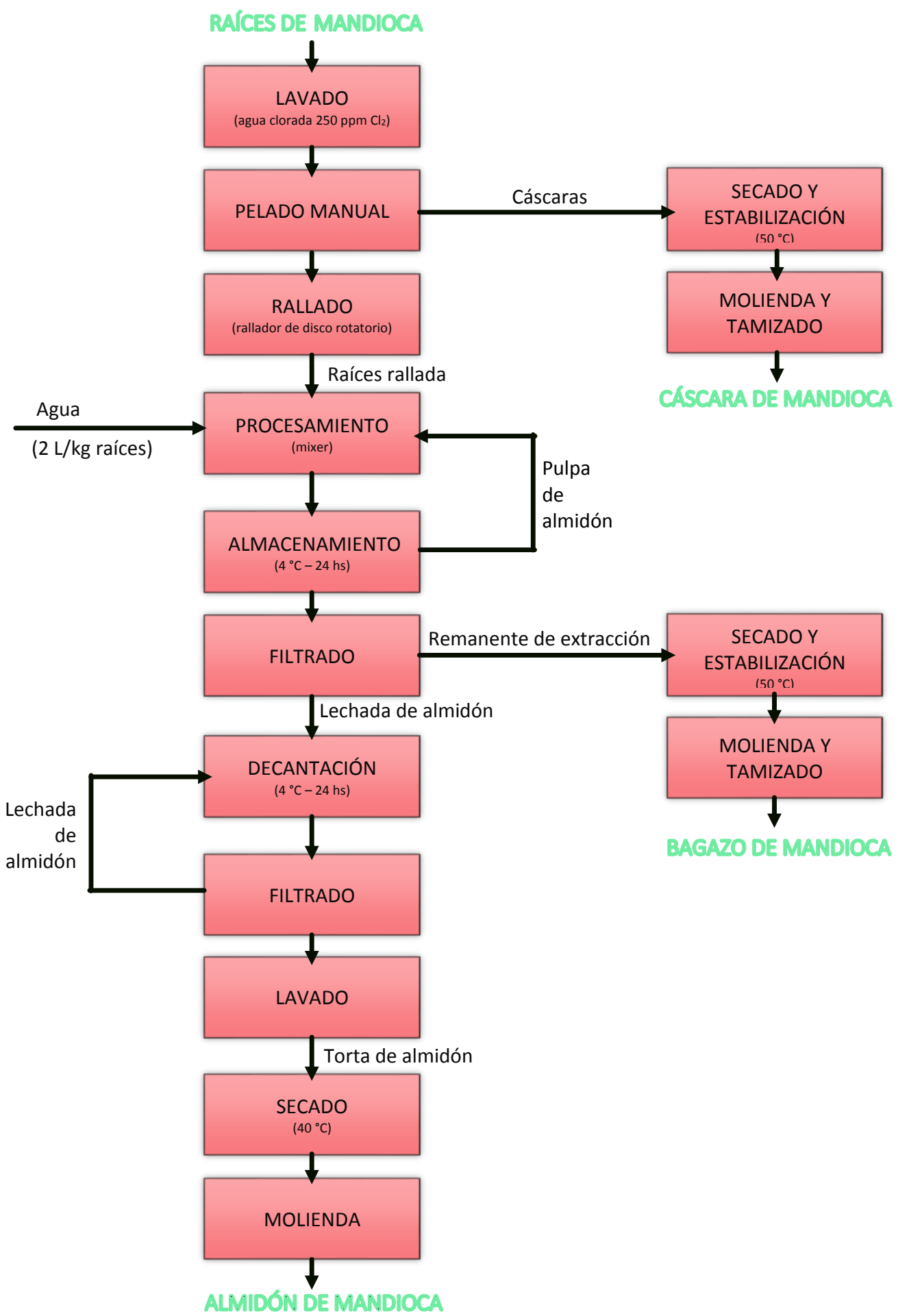

Figura I.1. Diagrama de bloques del proceso de extracción de almidón de raíces de mandioca y sus subproductos: cáscara y bagazo. 


\subsubsection{Distribución de tamaño de partícula}

La distribución de tamaño de partícula de relleno se estudió utilizando una torre tamizadora de laboratorio (ALEIN International, Argentina) con el siguiente conjunto de tamices de mallas estándar ASTM: 500, 425, 355, 300, 250, 212, 180, 150, 106, 75 y $53 \mu \mathrm{m}$ colocados sobre una plataforma vibratoria [21]. Al menos dos muestras de 100

$\mathrm{g}$ de residuo (pesados en balanza analítica con una precisión de $\pm 0,0001 \mathrm{~g}$ ) se tamizaron durante $10 \mathrm{~min}$. Luego las fracciones retenidas en cada malla fueron separadas y pesadas.

\subsubsection{Composición química}

\subsubsection{Contenido de humedad}

El contenido de agua residual se cuantificó gravimétricamente colocando muestras de residuos en una estufa (GMX 9203A PEET LAB, USA) a $105{ }^{\circ} \mathrm{C}$ hasta alcanzar peso constante. Los resultados se expresaron como porcentaje (\%) del peso inicial en base seca. Todas las medidas se realizaron al menos por duplicado.

\subsubsection{Cenizas totales}

La cuantificación total de cenizas se realizó según el método estandarizado AOAC 923.03 [22]. El mismo se basa en la destrucción por calcinación de la materia orgánica de la muestra y determinación gravimétrica del residuo. Se pesaron en cápsulas de porcelana $2 \mathrm{~g}( \pm 0,0001 \mathrm{~g})$ de muestra homogenizada. Al menos dos replicados de la muestra se incineraron en una mufla (Indef 331, Argentina) a $550 \pm 25^{\circ} \mathrm{C}$ durante aproximadamente $5 \mathrm{hs}$, hasta obtener cenizas blancas o levemente grisáceas. El contenido de cenizas totales en base seca se calculó a partir de la masa de cenizas restantes ( $\left.m_{\text {cenizas }}\right)$ respecto a la masa inicial ( $\left.m_{\text {inicial }}\right)$ de muestra corregida por el contenido de humedad $(\mathrm{H})$, como sigue:

$$
\text { Cenizas totales }(\%)=\frac{\left(m_{\text {cenizas }}-m_{\text {cápsula }}\right)}{\left(m_{\text {inicial }}-m_{\text {cápsula }}\right) *\left(1-{ }^{H} / 100\right)} * 100
$$




\subsubsection{Fracción lipídica}

Los lípidos son solubles en disolventes orgánicos, pero escasamente solubles o insolubles en agua, por lo que la determinación de la fracción lipídica de las muestras consiste en una extracción por solvente selectiva. La extracción de las muestras de bagazo se realizó con hexano en un aparato Soxhlet, según el método normalizado AOAC 920.39 [23]. Al menos dos replicados de $12 \mathrm{~g}$ de muestra cada uno se pesaron en balanza con una precisión de $0,1 \mathrm{mg}$ y se colocaron en un aparato Soxhlet con hexano (CAS\# 110-54-3, Anedra, Argentina). El procedimiento de extracción de Soxhlet es un proceso semicontinuo que permite la acumulación del disolvente en la cámara de extracción durante aproximadamente 20 - $30 \mathrm{~min}$. A lo largo del proceso de extracción el hexano se lleva a ebullición $\left(\sim 69^{\circ} \mathrm{C}\right)$, se condensa a una velocidad de 2 a 3 gotas por minuto mojando la muestra y luego se sifona nuevamente dentro del balón de ebullición (Figura I.2). El mismo se lleva a cabo durante al menos 8 horas. Una vez recuperado y evaporado el solvente se pesa el residuo obtenido (lípidos totales) en el balón previamente pesado.

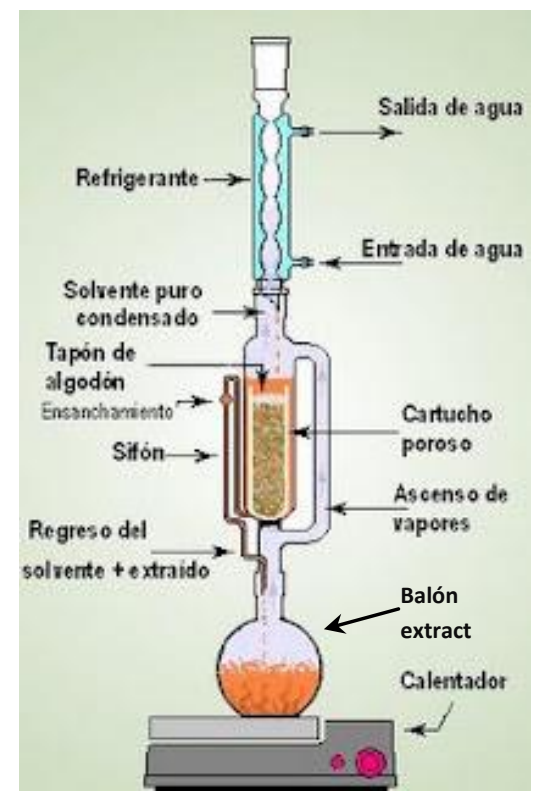

Figura I.2. Esquema del aparato de extracción Soxhlet.

Adaptado de http://slideplayer.es/slide/3822570/. 
Los resultados se expresaron como porcentaje (\%) en base seca:

$$
\text { Lípidos totales }(\%)=\frac{\left(m_{\text {balón+lípidos }}-m_{\text {balón extractor })}\right.}{\left(m_{\text {muestra }}\right) *(1-H / 100)} * 100
$$

\subsubsection{Proteína bruta}

El contenido de proteína cruda de las muestras de bagazo de mandioca se analizaron sobre $1 \mathrm{~g}$ de muestra por el método de Kjeldahl [24]. Este método cuantifica el nitrógeno total, proveniente principalmente de las proteínas y otras fuentes de nitrógeno no proteico (ácidos nucleicos, por ejemplo), y mediante un factor de conversión se estima la cantidad de las mismas presentes en la muestra. El método consiste en tres pasos: digestión, destilación y titulación.

La digestión se realiza en un digestor Büchi K-435 (Suiza), con 25 mL de ácido sulfúrico concentrado (CAS\# 7664-93-9, Anedra, Argentina) en presencia de un catalizador, hasta disolución y oxidación completa de la muestra (solución translúcida). El nitrógeno contenido en la muestra se convierte en sulfato de amonio según la siguiente reacción:

$$
\text { Proteínas }(-\mathrm{N})+\mathrm{H}_{2} \mathrm{SO}_{4} \stackrel{\text { Catalizador }}{\longrightarrow}\left(\mathrm{NH}_{4}\right)_{2} \mathrm{SO}_{4}+\mathrm{CO}_{2}+\mathrm{H}_{2} \mathrm{O}
$$

Para la destilación se utilizó una unidad de destilación Büchi K-350 (Suiza). A la muestra previamente enfriada se le añade un exceso de solución de hidróxido de sodio ( $32 \% \mathrm{p} / \mathrm{v}$ ) para neutralizar el $\mathrm{H}_{2} \mathrm{SO}_{4}$ y alcalinizar el medio, lo cual torna la muestra a un color pardo oscuro. De esta manera se obtiene amonio por destilación, el cual es colectado en un Erlenmeyer con $50 \mathrm{~mL}$ de solución $4 \% \mathrm{p} / \mathrm{v}$ de ácido bórico (CAS\# 10043-35-3, Cicarelli, Argentina) y 5 gotas del indicador Mortimer (cuya composición es $20 \mathrm{mg}$ rojo metilo $+100 \mathrm{mg}$ de verde de bromocresol $+100 \mathrm{~mL}$ etanol) que presenta un viraje a pH cercano a 5,0 (que es el pH del ácido bórico al 4-5\%). El indicador es rojo a dicho $\mathrm{pH}$ y se vuelve azul cuando se le agrega $\mathrm{NH}_{3}$ destilado, que alcaliniza el medio. La destilación se lleva a cabo hasta que la solución de $\mathrm{H}_{3} \mathrm{BO}_{3}$ vira al verde-azulado $(250 \mathrm{~mL})$. 


$$
\left(\mathrm{NH}_{4}\right)_{2} \mathrm{SO}_{4}+2 \mathrm{NaOH} \stackrel{\mathrm{NaOH}}{\longrightarrow} 2 \mathrm{NH}_{3}(\text { gas })+\mathrm{Na}_{2} \mathrm{SO}_{4}+2 \mathrm{H}_{2} \mathrm{O}
$$

Finalmente el destilado recogido se tituló con una solución de $\mathrm{H}_{2} \mathrm{SO}_{4}$ valorada $(0,1 \mathrm{~N}$ normalizado con $\mathrm{NaOH}$ ) hasta que el color del mismo vire nuevamente al rojo claro. Un ensayo en blanco se realizó para descartar el nitrógeno que podrían aportar los reactivos.

Con los datos obtenidos se calculó el contenido de proteínas, expresado en porcentaje $(\% p / p)$, a partir de la siguiente ecuación:

$$
\text { Proteína cruda }(\%)=\frac{\left(V_{\text {titulación }}-V_{\text {blanco }}\right) * N_{H_{2} \mathrm{SO}_{4}} * P_{e q_{N}} * f}{\left(m_{\text {muestra }}\right) *\left(1-{ }^{H} / 100\right)} * 100
$$

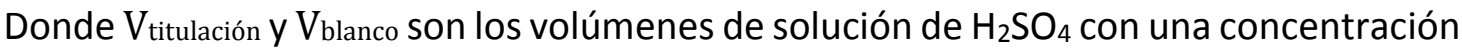
normal ( $\mathrm{N}_{\mathrm{H} 2 \mathrm{SO}}$ ); $\mathrm{P}_{\text {eqN }}$ es el peso equivalente del nitrógeno; $\mathrm{m}_{\text {muestra }}$ el peso de muestra empelado y $\mathrm{H}$ su contenido de humedad porcentual; y f el factor de conversión de $\mathrm{N}$ a proteína, que depende de la muestra que se analiza. En los alimentos en general, como consecuencia de la estructura a base de aminoácidos individuales, el contenido en nitrógeno de las proteínas varía sólo entre límites muy estrechos (15 a 18 \%, en promedio $16 \%)$. Es decir que en $100 \mathrm{~g}$ de proteína promedio hay $16 \mathrm{~g}$ de nitrógeno $(\mathrm{N})$, entonces $1 \mathrm{~g}$ de nitrógeno corresponderá a 6,25 g de proteína.

\subsubsection{Fibra dietaria total (FDT)}

El contenido de FDT se determinó por duplicado en muestras secas del residuo de mandioca mediante el kit enzimático K-TDFR 05/12 Megazyme® (Irlanda) siguiendo el método AOAC 985.29 [25]. Las muestras se trataron a $100{ }^{\circ} \mathrm{C}$ con $\alpha$-amilasa (3000 Ceralpha Unidades $/ \mathrm{mL}$ ) para gelatinizar, hidrolizar y depolimerizar el almidón presente; luego se incubaron a $60{ }^{\circ} \mathrm{C}$ con enzima proteasa (E-BSPRT, 350 Tirosina Unidades $/ \mathrm{mL}$ ) para solubilizar y depolimerizar proteínas, y amiloglucosidasa (E-AMGDF, 200 p-NP- $\beta$ maltósido Unidades $/ \mathrm{mL}$ ) para hidrolizar fragmentos de almidón a glucosa. Posteriormente fueron tratadas con etanol $96 \% \mathrm{p} / \mathrm{p}$ para precipitar 
la fibra soluble y eliminar la proteína depolimerizada y la glucosa (proveniente del almidón). Cada residuo se filtró, se lavó con etanol 78 \%, etanol $95 \%$ y acetona, y se secó en crisoles filtrantes de vidrio previamente pesados. Un duplicado se utilizó para analizar proteínas por el método de Kjeldahl y el otro se calcinó a $550^{\circ} \mathrm{C}$ en mufla para determinar el contenido de cenizas (procedimientos previamente explicados). El contenido de FDT resulta de la diferencia entre el peso del residuo filtrado (mresiduo) y seco $\left(m_{s e c o}\right)$ y la suma del peso de proteínas (mproteínas) y cenizas (mcenizas), como sigue:

$$
\operatorname{FDT}(\%)=\frac{\left(m_{\text {residuo }}-m_{\text {proteínas }}-m_{\text {cenizas }}\right)}{m_{\text {muestra seca }}} * 100
$$

Los resultados se expresaron como porcentaje (\%) sobre base seca.

\subsubsection{Contenido de lignina}

El contenido de lignina Klason se determinó siguiendo el método estandarizado TAPPI T222om-11 (2011), que se basa en el aislamiento de lignina luego de la hidrólisis de polisacáridos por tratamiento con ácido sulfúrico concentrado (CAS\# 7664-93-9, Anedra, Argentina). Muestras del residuo fibroso $(2,0 \pm 0,1 \mathrm{~g})$ se maceraron con $\mathrm{H}_{2} \mathrm{SO}_{4}$ al $72 \%(40 \mathrm{~mL})$, durante 2 horas a temperatura ambiente $\left(20 \pm 1{ }^{\circ} \mathrm{C}\right)$. La disolución acuosa se diluyó más tarde hasta una concentración de $3 \%$ de $\mathrm{H}_{2} \mathrm{SO}_{4}$ y el sistema se mantuvo después bajo condiciones de destilación con reflujo total durante 4 horas. El contenido de lignina insoluble en ácido se calculó gravimétricamente considerando el sólido seco (a $105^{\circ} \mathrm{C}$ hasta peso constante) obtenido por filtración.

Por otro lado, la concentración de lignina soluble Klason $\left(C_{\text {Klason }}\right)$ se determinó midiendo la absorbancia a $280\left(\mathrm{~A}_{280}\right)$ y $215\left(\mathrm{~A}_{215}\right) \mathrm{nm}$ de la solución de filtrado en un espectrofotómetro U-1900 (HITACHI, Japón), según la Eq. (5) basada en la ley de Lambert Beer [26]:

$$
C_{\text {Klason }}(g / L)=\left(4,53 * A_{215}-A_{280}\right) / 300
$$


Los resultados se expresaron como porcentaje (\%) en base seca de al menos dos replicados de cada muestra.

\subsubsection{Contenido de carbohidratos totales}

El contenido de carbohidratos totales se calculó por diferencia, después de la cuantificación de los otros componentes del análisis centesimal (humedad, cenizas, proteínas, lípidos totales y lignina). Este valor se corresponde con el contenido de azúcares solubles, almidón y carbohidratos estructurales (principalmente celulosas, hemicelulosas y pectinas) tomados conjuntamente. Los resultados se expresaron como porcentaje (\%).

\subsubsection{Capacidad de retención de solventes (CRS)}

La capacidad de retención del residuo se analizaron siguiendo el método AACC 56-11.02 [27]. Este método, ampliamente utilizado en la caracterización de harinas y derivados, permite predecir la contribución funcional de los distintos polímeros presentes en el residuo y su capacidad de interacción con otros componentes. Los disolventes utilizados fueron agua desionizada, soluciones de sacarosa (50\%p/p), carbonato de sodio (5\%p/p) y ácido láctico (5\%p/p). La CRS se expresó como porcentaje (\%).

Se considera que la capacidad de retención del carbonato de sodio (CRCS) está relacionada con el contenido de almidón dañado, ya que una solución de carbonato de sodio al $5 \% \mathrm{p} / \mathrm{p}$ eleva el $\mathrm{pH}$ por encima de 11 , donde los grupos hidroxilo del almidón comienzan a ionizarse y por lo tanto se carga negativamente [28-30]. En general, la capacidad de retención del ácido láctico (CRAL) se asocia con la formación de la red de glutenina y la fuerza del gluten de una harina, debido a que un $\mathrm{pH}$ inferior a 7 favorece el entramado de la red por los polímeros de gluten relativos a los polisacáridos $[28,29]$. Dini y col. [28] observaron una correlación lineal $\left(r^{2}>0,84\right)$ entre el contenido de FDT y la capacidad de retención de agua (CRA). Por último, la capacidad de retención de 
sacarosa (CRSA), está asociada al contenido de pentosanos soluble en agua, que se cuantifica como fibra soluble.

\subsubsection{Microscopía electrónica de barrido (SEM)}

Se estudió la microestructura y morfología del residuo fibroso seco, molido y tamizado por SEM con un microscopio FEI QUANTA 200 (Japón). Las muestras se montaron en tacos de bronce utilizando una cinta doble faz de grafito y se recubrieron con una capa de oro (40-50 nm), todas las muestras se analizaron utilizando un voltaje de aceleración de $10 \mathrm{kV}$, bajo condiciones de alto vacío.

\subsection{Plastificante}

Como plastificante se utilizó glicerol 99 \% (CAS\# 56-81-5, Andera, Argentina), que se ha demostrado es un plastificante eficiente y compatible con matrices de almidón [31-40]. El glicerol es un polialcohol que contiene tres grupos hidroxilo (Figura I.3) que pueden interactuar por puentes de hidrógeno con el almidón, lo cual reduce las interacciones entre moléculas de polímero aumentando el volumen libre del sistema y la flexibilidad de la matriz, lo cual se conoce como plastificación [39].

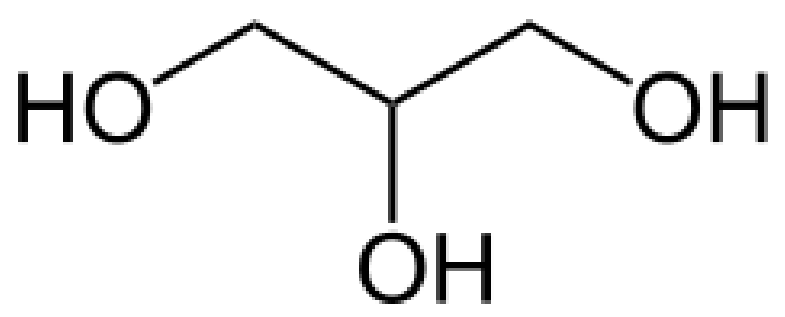

Figura I.3. Estructura química del glicerol.

\subsection{Preparación de películas y materiales compuestos}

\subsubsection{Suspensiones filmogénicas}

Suspensiones acuosas al $3 \% p / p$ de almidón de mandioca se gelatinizaron térmicamente a $90{ }^{\circ} \mathrm{C}$ en un baño de agua con regulador de temperatura TE-10D (Techne, Reino Unido) durante 20 min. La temperatura de gelatinización se determinó 
a partir de ensayos previos realizados por el grupo de investigación de manera de garantizar la gelatinización completa de la mezcla de almidón de mandioca. El almidón de mandioca tiene un rango de gelatinización más amplio que otros almidones, como el almidón de maíz o papa, el cual varía entre 54 y $85^{\circ} \mathrm{C}$ [2]. Como plastificante se utilizó glicerol, agregado en concentraciones variables de 0 a $35 \%$ respecto al contenido de almidón. En las formulaciones que incluían bagazo, previo a la gelatinización del almidón se incorporó la fibra molida y tamizada en concentraciones de 0 a $3 \% p / p$ de suspensión. Debido a su alta viscosidad, las suspensiones debieron ser desgasificadas bajo vacío para evitar la aparición de burbujas en las películas.

3.4.1.1. Caracterización reológica de las suspensiones filmogénicas de almidón

Las propiedades reológicas de las suspensiones filmogénicas se analizaron en un reómetro Rheo Stress 600 ThermoHaake (Haake, Alemania), con un sistema plato-plato PP35 con separación de $1 \mathrm{~mm}$ (Figura I.4) a temperatura controlada $\left(25^{\circ} \mathrm{C}\right)$.

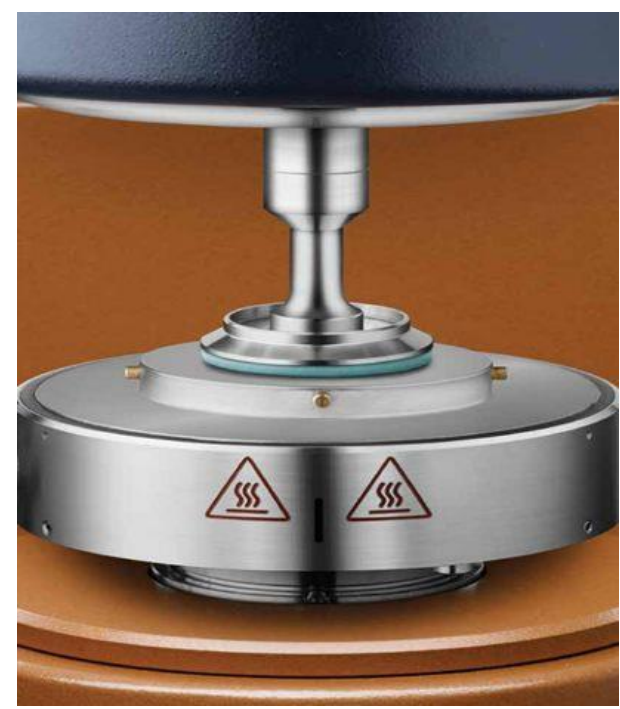

Figura I.4. Sistema plato-plato utilizado para ensayos de reológia.

Ensayos rotacionales se emplearon para determinar el comportamiento de flujo de las suspensiones de almidón. Las curvas obtenidas, de esfuerzo de corte o cizalla $(\tau)$ frente 
a la velocidad de deformación $(\dot{\gamma})$ se ajustaron matemáticamente al modelo de Ostwald de Waele según:

$$
\tau=k * \dot{\gamma}^{n}
$$

Donde k es el coeficiente de consistencia y $\mathrm{n}$ el índice de comportamiento de flujo [41].

También se determinó la viscosidad aparente de las suspensiones filmógenicas no newtonianas a $500 \mathrm{~s}^{-1}$, de modo de evaluar la dependencia temporal de estos sistemas. La histéresis de las curvas permite determinar si los geles presentan un comportamiento tixotrópico o reopéctico (anti-tixotrópico), es decir si muestran respectivamente una disminución o aumento de la viscosidad aparente con el tiempo a una velocidad de deformación constante $[42,43]$ (Figura I.5).

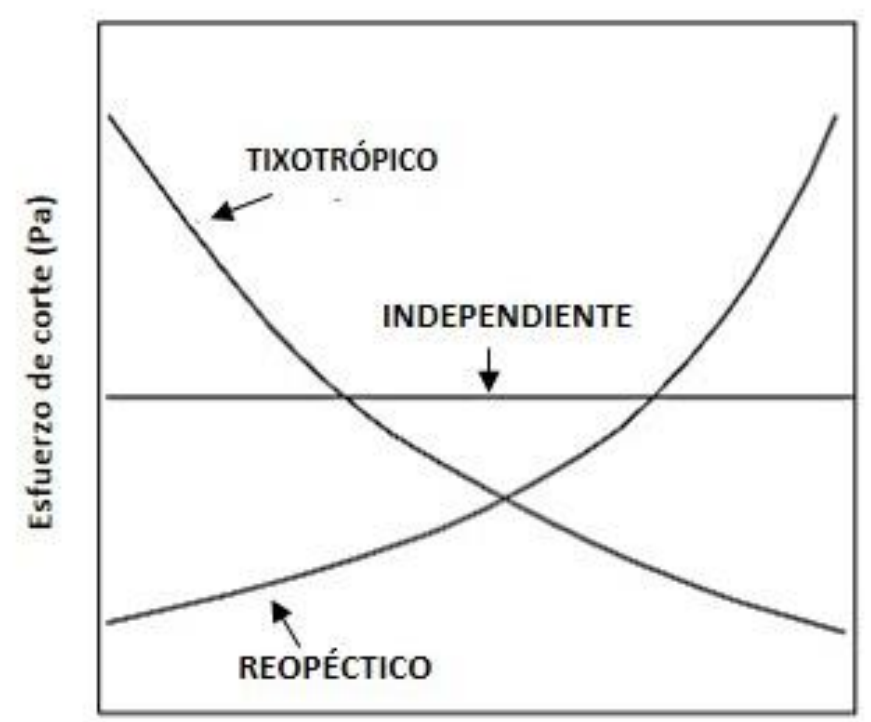

Tiempo a una velocidad de deformación constante (s)

Figura I.5. Esquema del comportamiento reológico de fluidos en el tiempo. Adaptado de Steffe [43]. 
Los índices de tixotropía o anti-tixotropía se calcularon como el área entre las curvas de flujo ascendente y descendente, tomando valores positivos para los sistemas tixotrópicos y negativos para los reopécticos.

Los geles de almidón presentan un comportamiento viscoélastico, es decir, exhiben simultáneamente un comportamiento similar a un líquido (viscoso) y a un sólido (elástico). El estudio de este comportamiento es de especial relevancia en el procesamiento de plásticos y alimentos tales como masas o geles que presentan un componente elástico importante, ya que afecta sustancialmente la fluidodinámica del sistema [43]. Las suspensiones de almidón fueron sometidas a ensayos reológicos dinámicos dentro del rango de viscoelasticidad lineal de las mismas, donde la muestra se deforma sin sufrir ruptura estructural. El rango de viscoelasticidad lineal se determinó en un ensayo de barrido de esfuerzo (0 - $30 \mathrm{~Pa}$ ) a una frecuencia constante (1 Hz). A continuación, se realizaron barridos de frecuencias $(0,01-100 \mathrm{~Hz})$ a esfuerzo constante. Los parámetros reológicos dinámicos registrados fueron el módulo de almacenamiento ( $G^{\prime}$ ) y el módulo de pérdida (G"). También se adquirió la tangente del ángulo de fase ( $\tan \delta=G^{\prime \prime} / G^{\prime}$ ) y el esfuerzo de corte complejo (G*). Estos parámetros se midieron en las suspensiones de almidón gelatinizado y después de 24 h y 48 h, para evaluar el efecto del tiempo de almacenamiento. Los espectros mecánicos se obtuvieron trazando G' y G" frente a la frecuencia de oscilación $(\omega)$.

\subsubsection{Preparación de películas por casting}

Las suspensiones filmogénicas estudiadas se moldearon en placas de acrílico y se secaron durante $4 \mathrm{hs}$ a $50^{\circ} \mathrm{C}$ y $24 \mathrm{hs}$ a $20^{\circ} \mathrm{C}$. Este proceso se denomina en inglés casting, y por simplicidad de aquí en más se utilizará esta terminología para referirse a los materiales obtenidos por moldeo y deshidratación.

Una vez secas las películas se removieron de los moldes y se almacenaron bajo condiciones controladas $\left(20^{\circ} \mathrm{C}\right.$ y $60 \%$ de humedad relativa, HR) para su posterior caracterización. 


\subsection{Caracterización de películas biodegradables y materiales compuestos}

\subsubsection{Espesor}

Para medir el espesor de las mismas se utilizó un medidor electrónico de espesores Check Line DCN-900 (EEUU). Se tomaron al menos 10 medidas a lo largo de la superficie del material. Los valores reportados corresponden a la media algorítmica de cada espécimen.

\subsubsection{Humedad}

Se determinó midiendo la pérdida de peso de las películas luego de ser secadas en una estufa a $105{ }^{\circ} \mathrm{C}$ hasta peso constante. Las muestras se analizaron al menos por duplicado y los resultados fueron expresados en porcentaje (\%).

\subsubsection{Microscopía electrónica de barrido (SEM)}

La homogeneidad y la apariencia de las películas se examinaron mediante observación visual y microscopía electrónica de barrido (SEM) con un microscopio electrónico FEI QUANTA 200 (Japón). Para las observaciones de la sección transversal, las películas se criofracturaron mediante inmersión en nitrógeno líquido. Las piezas de películas se montaron sobre tacos de bronce con cinta de grafito y se recubrieron con una capa de oro (40 - $50 \mathrm{~nm}$ ), permitiendo la visualización de la superficie y de la sección transversal. Todas las muestras se analizaron usando un voltaje de aceleración de $10 \mathrm{kV}$, bajo un modo de alto vacío.

\subsubsection{Permeabilidad al vapor de agua y al oxígeno}

La permeabilidad al vapor de agua (WVP) de las películas se midió usando el método ASTM E96 [44] con algunas modificaciones. Las muestras se colocaron en celdas de permeación de acrílico con una abertura circular de área conocida, las cuales contenían en su interior sílica gel (0\%HR). Luego, las celdas se pesaron en una balanza analítica y 
se ubicaron en una cámara a $20{ }^{\circ} \mathrm{C}$ equilibrada a $75 \% \mathrm{HR}$ con una solución saturada de cloruro de sodio $(\mathrm{NaCl})$.

La diferencia de presión parcial de vapor de agua existente a ambos lados de la película proporciona la fuerza impulsora para el flujo de vapor. A intervalos regulares las celdas se pesaron y se calcularon los cambios de peso de las mismas en función del tiempo, obteniéndose así una recta luego de alcanzado el estado estacionario. La permeabilidad al vapor de agua se calculó a partir de la siguiente ecuación:

$$
W V P(g / s m P a)=\frac{(\Delta w / \Delta t) * \delta}{A * \Delta P}
$$

Donde $(\Delta \mathrm{w} / \Delta \mathrm{t})$ es la pendiente de la recta calculada mediante regresión lineal, expresada en $\mathrm{g} / \mathrm{s} ; \delta$ es el espesor de la película, expresado en $\mathrm{m}$; A es el área expuesta $\left(\mathrm{m}^{2}\right)$ y $\Delta \mathrm{P}$ es la diferencia de presión parcial de vapor de agua a través de la película $\left(1753,55 \mathrm{~Pa}\right.$ a $\left.20^{\circ} \mathrm{C}\right)$.

La permeabilidad al oxígeno se determinó un equipo de permeabilidad OX-TRAN ${ }^{\circledR}$ Modelo 2/21 (Mocon Inc., EEUU). Las muestras de película se colocaron en una celda de prueba que se divide en dos cámaras separadas por la muestra ensayada. La cámara interior está llena de nitrógeno (medio gaseoso) y la cámara exterior con oxígeno (gas de prueba). Las moléculas de oxígeno difunden a través de la película a la cámara interior y se registra la permeabilidad al gas por un sensor en la cámara adyacente. Las mediciones se realizaron a $25{ }^{\circ} \mathrm{C}$ y $60 \% \mathrm{HR}$. Además se emplearon mascarillas de aluminio precortadas para dejar un área expuesta de película de $5 \mathrm{~cm}^{2}$. Los resultados se expresaron en $\mathrm{cc} / \mathrm{m}^{2}$ día.

\subsubsection{Propiedades ópticas}

Las medidas de color superficial de las películas se realizaron con un colorímetro Minolta (CR 400, Osaka, Japón), calibrado con un standard $(Y=93,80$, $x=0,3133, y=0,3193)$. Se registraron las coordenadas $L^{*}, a^{*}, b^{*}$ de la escala CIE. En este 
sistema el parámetro $a^{*}$, representa la variación rojo-verde, tomando valores positivos para el primero y negativos para el segundo; el parámetro b*, representa la variación amarillo-azul, siendo positivo para el primero y negativo para el segundo y el parámetro $L^{*}$ de luminosidad varía entre 0, para el negro mate y 100 para el blanco (Figura I.6).

Además se determinaron los parámetros chroma $\left(\mathrm{C}^{*}\right)$, hue $\left(\mathrm{h}^{\circ}\right)$ y la diferencia de color con el patrón blanco $(\Delta \mathrm{E})$, que se obtienen a partir de los parámetros de cromaticidad según:

$$
\begin{array}{r}
C^{*}=\sqrt{a^{* 2}+b^{*^{2}}} \\
h^{\circ}=\tan ^{-1}\left(\frac{b^{*}}{a^{*}}\right) \\
\Delta E=\sqrt{\left(\Delta a^{*}\right)^{2}+\left(\Delta b^{*}\right)^{2}+\left(\Delta L^{*}\right)^{2}}
\end{array}
$$

Los resultados informados corresponden al promedio de al menos diez determinaciones a lo largo de la superficie de la película.

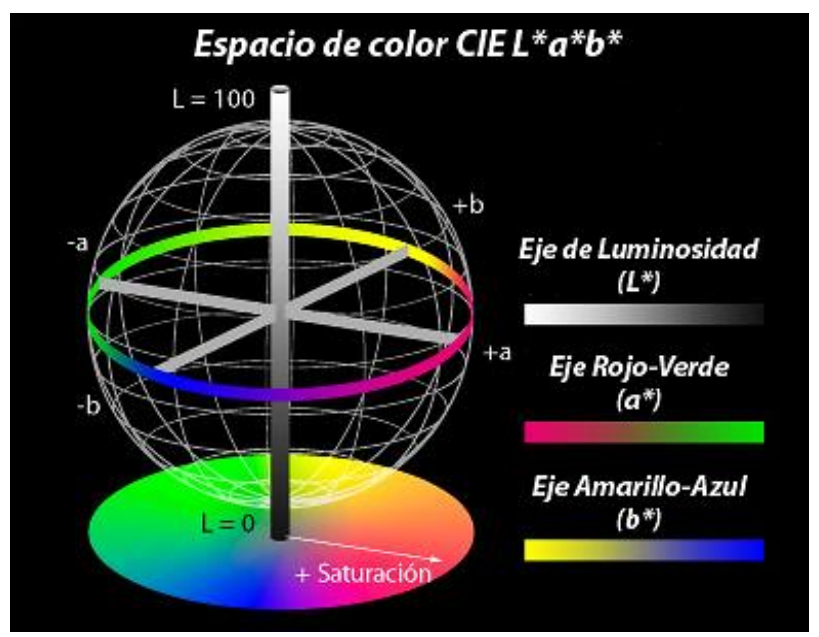

Figura I.6. Parámetros de color superficial: luminosidad ( $\left.L^{*}\right)$ y de cromaticidad a* (rojo-verde) y b* (amarillo-azul). 
Para evaluar la capacidad de la barrera a la luz (UV-visible) de las películas de almidón, se registró el espectro de absorbancia (200 - 700 nm) utilizando un espectrofotómetro U-1900 (HITACHI, Japón). Las películas se cortaron en rectángulos de $1 \mathrm{~cm} \times 3 \mathrm{~cm}$ y se colocaron en el interior de una celda espectrofotométrica de cuarzo. La opacidad se definió como el área bajo la curva entre 400 - 700 nm determinada por un procedimiento de integración de acuerdo con Castillo y col. [45] y el método estándar para determinación de transparencia y la trasmisión de luz para plásticos transparentes ASTM D1003-00 [46]. De forma similar se determinó la barrera a la radiación UV por integración del espectro entre 200 y $400 \mathrm{~nm}$. Los valores se determinaron al menos por duplicado y se expresaron en unidades de absorbancia por nanómetros (AUxnm).

\subsubsection{Propiedades mecánicas}

Se realizaron ensayos de tracción en un texturómetro TA.XT2i - Stable Micro Systems (Reino Unido) empleando mordazas de tensión A/TG. Se utilizaron probetas de películas de $7 \mathrm{~cm} \times 0,7 \mathrm{~cm}$ y se ensayaron al menos diez probetas por cada muestra. Mediante el software Texture Expert Exceed se registraron automáticamente las curvas de fuerza $(\mathrm{N})$ en función de la deformación $(\mathrm{mm})$ y a partir de las mismas se calculó el esfuerzo (MPa), la deformación porcentual a la ruptura (\%) y la tenacidad $\left(\mathrm{kJ} / \mathrm{m}^{3}\right)$, según la norma ASTM D882-00 [47] y como describen Sarantópoulos y col. [48]:

$$
\begin{gathered}
\sigma_{\text {máx }}(M P a)=F_{\text {máx }} / A_{\text {min }} * 1 \times 10^{-6} \\
\varepsilon_{\text {máx }}(\%)=D_{\text {máx }} / D M * 100 \\
E_{g}(\mathrm{~kJ} / \mathrm{m} 3)=\frac{\int F / D}{e * L * D M}
\end{gathered}
$$

Donde:

- $\quad \sigma_{\text {máx: }}$ resistencia máxima en la ruptura;

- Fmáx: representa la fuerza máxima registrada en la ruptura (N); 
- Amin: área mínima inicial de la sección transversal de la muestra $\left(\mathrm{m}^{2}\right)$, equivalente al espesor mínimo por el ancho de la probeta;

- $\quad \varepsilon$ máx.: elongación máxima en la ruptura;

- Dmáx: indica el estiramiento total de la probeta antes de la ruptura área medido como la distancia entre mordazas en ese punto $(\mathrm{mm})$;

- DM: distancia inicial entre mordazas ( $\mathrm{mm})$;

- Eg: tenacidad, energía necesaria para romper la probeta $\left(\mathrm{kJ} / \mathrm{m}^{3}\right)$;

- $\quad \int F / D$ : área bajo la curva de fuerza vs. deformación del ensayo de tracción;

- e: espesor medio de la probeta (m);

- L: largo inicial de la probeta $(\mathrm{m})$;

Además se realizaron ensayos de esfuerzo-deformación en un analizador dinámico mecánico DMA Q800 (TA Instruments, USA), usando una celda de tensión como la de la imagen (Figura I.7):

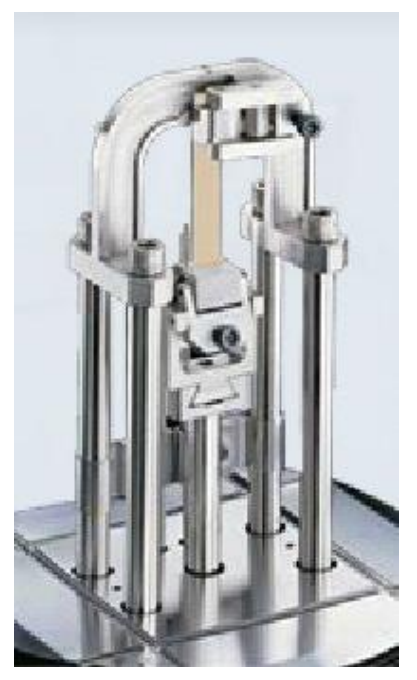

Figura I.7. Celda de tensión utilizada en los ensayos de DMA.

Se utilizaron probetas rectangulares de películas de $3 \mathrm{~cm} \times 6 \mathrm{~mm}$, cuyo espesor se determinó como se describió previamente. Se realizaron ensayos cuasi-estáticos uniaxiales, donde se aplica una fuerza de hasta $18 \mathrm{~N}$ a una velocidad de 0,3 N/min. Las 
curvas de esfuerzo vs. deformación obtenidas se modelaron matemáticamente para evaluar el módulo de elasticidad de las muestras, según la siguiente ecuación exponencial [33].

$$
\sigma_{T}=E c * \varepsilon_{T} * e^{\left(-\varepsilon_{T} * K\right)}
$$

Donde: $\varepsilon_{T}$ y $\sigma_{T}$ son la deformación verdadera y el esfuerzo verdadero, respectivamente, calculados como establecen Mancini y col. [49]; Ec es el módulo de elasticidad; y $K$ es una constante de ajuste. Los ensayos se realizaron al menos por triplicado.

\subsection{Análisis estadístico}

Para el análisis estadístico de resultados se utilizaron los softwares comerciales Systat ${ }^{\circledR}$ (Versión 10.0) e InfoStat [50]. Se efectuó el análisis de varianza (ANAVA) y la comparación de medias mediante la prueba de la diferencia mínima significativa (LSD) de Fisher, con un nivel de significación $p=0,05$.

\section{RESULTADOS Y DISCUSIÓN}

\subsection{Almidón y bagazo: obtención y caracterización}

El almidón empleado para la preparación de las películas había sido ampliamente caracterizado por el grupo de trabajo con anterioridad, considerando las características morfológicas, fisicoquímicas, funcionales, tecnológicas y nutricionales [51, 52]. En el presente trabajo de Tesis se trabajó con un almidón de mandioca cuyo contenido de amilosa era de 18,06 $\pm 0,90 \% p / p$ y una temperatura de gelatinización de $69,16 \pm 0,41^{\circ} \mathrm{C}[52]$.

La pulpa obtenida como residuo de extracción de almidón de raíz de mandioca como se describió en la sección 3.1 de este capítulo se secó en estufa de convección forzada a $50{ }^{\circ} \mathrm{C}$ para su estabilización y almacenamiento. Del proceso de extracción se obtiene 
un $36,13 \pm 1,07 \% p / p$ de bagazo de mandioca en base seca. A continuación, el bagazo molido se tamizó con una malla de $500 \mu \mathrm{m}$ (ASTM n³5), con el fin de tener un cota máxima de tamaño de partícula. El residuo fibroso presentó una distribución heterogénea de tamaño de partícula resultando el $56 \%$ de las partículas menores a $53 \mu \mathrm{m}$, lo cual se atribuye al almidón residual en el bagazo, evidenciado por SEM (Figura 1.8). Los gránulos de almidón identificados exhibieron formas redondas y poligonales, diferencias que se atribuyen a la típica distribución bimodal de tamaño de gránulos del almidón de mandioca descripto anteriormente por Doporto y col. [53].

En las micrografías pueden observarse los gránulos de almidón rodeados por las paredes celulares restantes del tejido parenquimatoso del tubérculo (parénquima de reserva), a lo que se suman las paredes celulares del tejido de conducción, principalmente el xilema, conformado por los vasos leñosos o tráqueas. Normalmente, existe una cierta proporción de fibras que se encuentran asociadas al tejido de conducción, que actúan como elementos de refuerzo. Si bien la composición varía según la especie vegetal y la función específica del tejido en la planta, en general la pared celular está principalmente compuesta por polisacáridos estructurales los cuales se generan a partir del carbono asimilado durante la fotosíntesis.

Las paredes celulares comúnmente se clasifican en dos tipos principales: primarias y secundarias. Las paredes primarias constituyen la matriz estructural y están presentes en células relativamente no especializadas. Las paredes secundarias son aquellas que se forman después de que la célula ha cesado el crecimiento, las cuales pueden ser altamente especializadas tanto en estructura y composición. Las células del xilema (mencionadas anteriormente) se caracterizan por presentar paredes secundarias muy engrosadas reforzadas con lignina [54].

En la intersección de las paredes celulares se ubica la lamela media, una sustancia viscosa con un alto contenido de pectina y proteínas, que en las fibras naturales también presenta altos contenido de lignina [55]. 

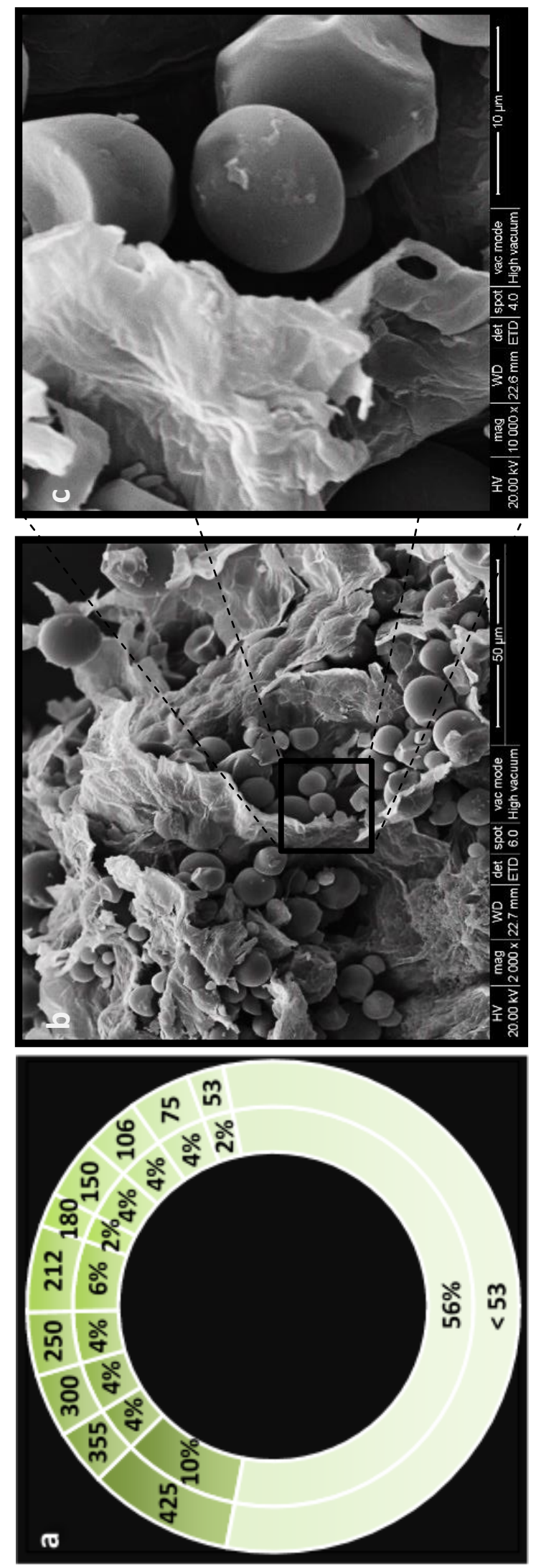

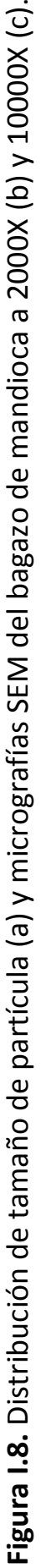


Como se muestra en el diagrama de la Figura I.9, en las paredes celulares primarias, las microfibras de celulosa están incrustadas en una matriz altamente hidratada con hemicelulosas en una matriz entrecruzada de pectinas que interactúan con proteínas estructurales. Esta estructura proporciona fuerza y flexibilidad.

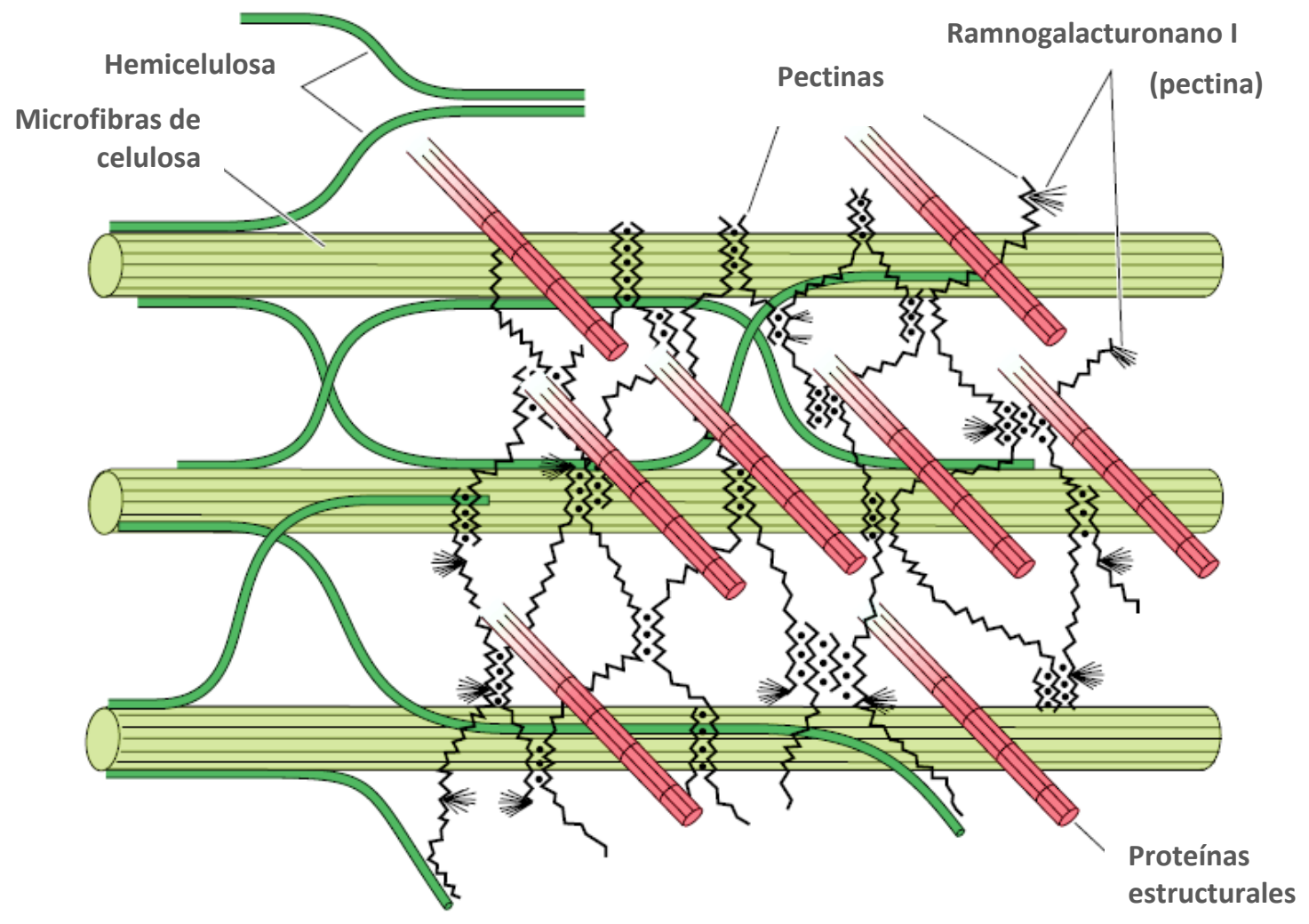

Figura I.9. Diagrama esquemático de los principales componentes estructurales de la pared celular primaria y su posible disposición.

Adaptado de Taiz y Zeiger [54].

Los principales componentes de la pared celular son:

- La celulosa que componen las microfibras está conformada por glucosas unidas por enlaces $\beta-(1,4)$ glucósido altamente alineados en forma de cinta ordenada, que le atribuye resistencia mecánica y al ataque enzimático. 
- Las hemicelulosas, este es el nombre tradicional que se le da a un conjunto de varios polisacáridos flexibles (xiloglucanos, xilanos, glucomananos y arabinoxilanos, entre otros), los cuales forman una red cohesiva con la celulosa.

- La lignina, un complejo polímero aromático que otorga una fuerza mecánica significativa a las paredes celulares y reduce su susceptibilidad a los ataques de patógenos.

- Las pectinas que forman una fase de gel hidratado en la que está incrustada la red de celulosa y hemicelulosa. Ellos actúan como relleno hidrofílico, para evitar la agregación y el colapso de la red de celulosa. También determinan la porosidad de la pared celular a macromoléculas.

En general, la pared primaria está compuesta de aproximadamente un $25 \%$ de celulosa, un $25 \%$ de hemicelulosas y un 35\% de pectinas, con tal vez 1 a $8 \%$ de proteína estructural, en peso seco [54]. Si bien se pueden encontrar grandes desviaciones de estos valores, los mismos se corresponden con aquellos obtenidos para el bagazo de mandioca aquí estudiado (Tabla I.1).

Además, cuando se encuentra en la planta viva la pared contiene entre un 75 a $80 \%$ agua, cuyo contenido resulta determinante de sus propiedad físicas [54]. No obstante, luego del secado del bagazo de la raíz el contenido de humedad se reduce sustancialmente dando lugar a un material más rígido y poco flexible.

El análisis de la composición química del residuo (Tabla I.1) también indicó un alto contenido de carbohidratos. De un total de $97,72 \%$ (en base seca) de carbohidratos más de un tercio corresponde a la fibra de la pared celular vegetal del tubérculo, por lo que puede considerarse que el resto corresponde principalmente al almidón presente en el residuo. La FDT está compuesta esencialmente por celulosa, hemicelulosa, pectina y lignina [56] y representa el 36,85 \% del bagazo, mientras que el contenido de lignina por el método de Klason representa aproximadamente un $5 \%$ del contenido de fibra. Además, el residuo contiene $11,82 \%$ de humedad, 


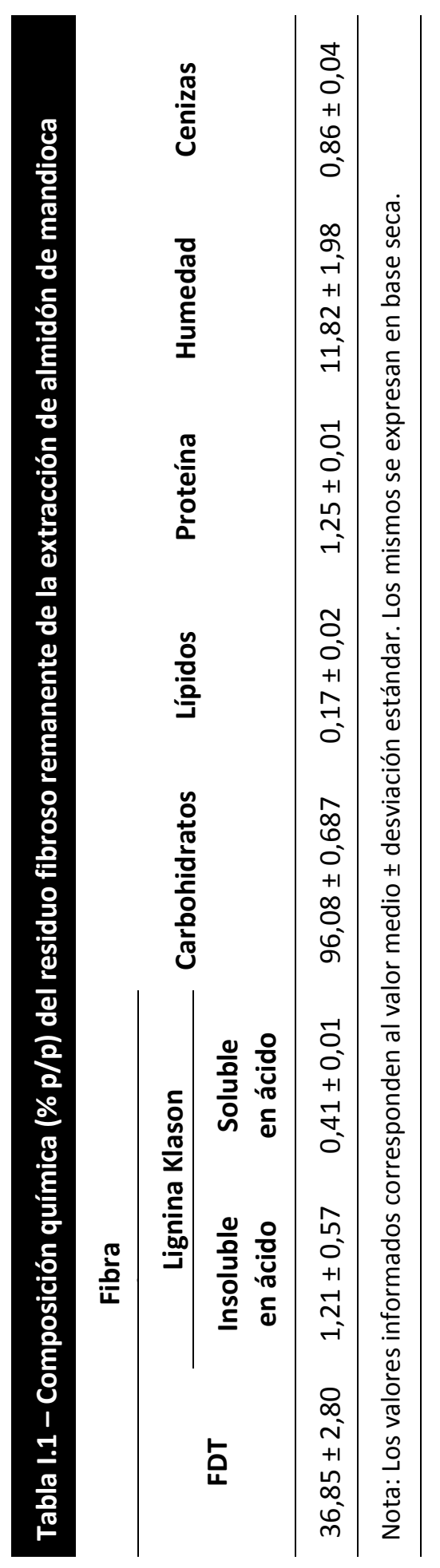


1,25 \% de proteínas, 0,86 \% de cenizas y 0,17 \% de lípidos (expresados en base seca del bagazo).

4.2. Caracterización de la suspensión filmogénica

El comportamiento reológico de las suspensiones de almidón filmogénicas es fundamental para determinar las condiciones de procesamiento necesarias para obtener películas a escala industrial. Asimismo, las propiedades reológicas están relacionadas con la presencia de defectos (burbujas y poros) en las matrices poliméricas [57]. En este sentido, los ensayos rotacionales permitieron analizar el comportamiento reológico de las suspensiones gelatinizadas de almidón cuando se presentan en condiciones cercanas a las de procesamiento industrial, tales como altos esfuerzos de corte.

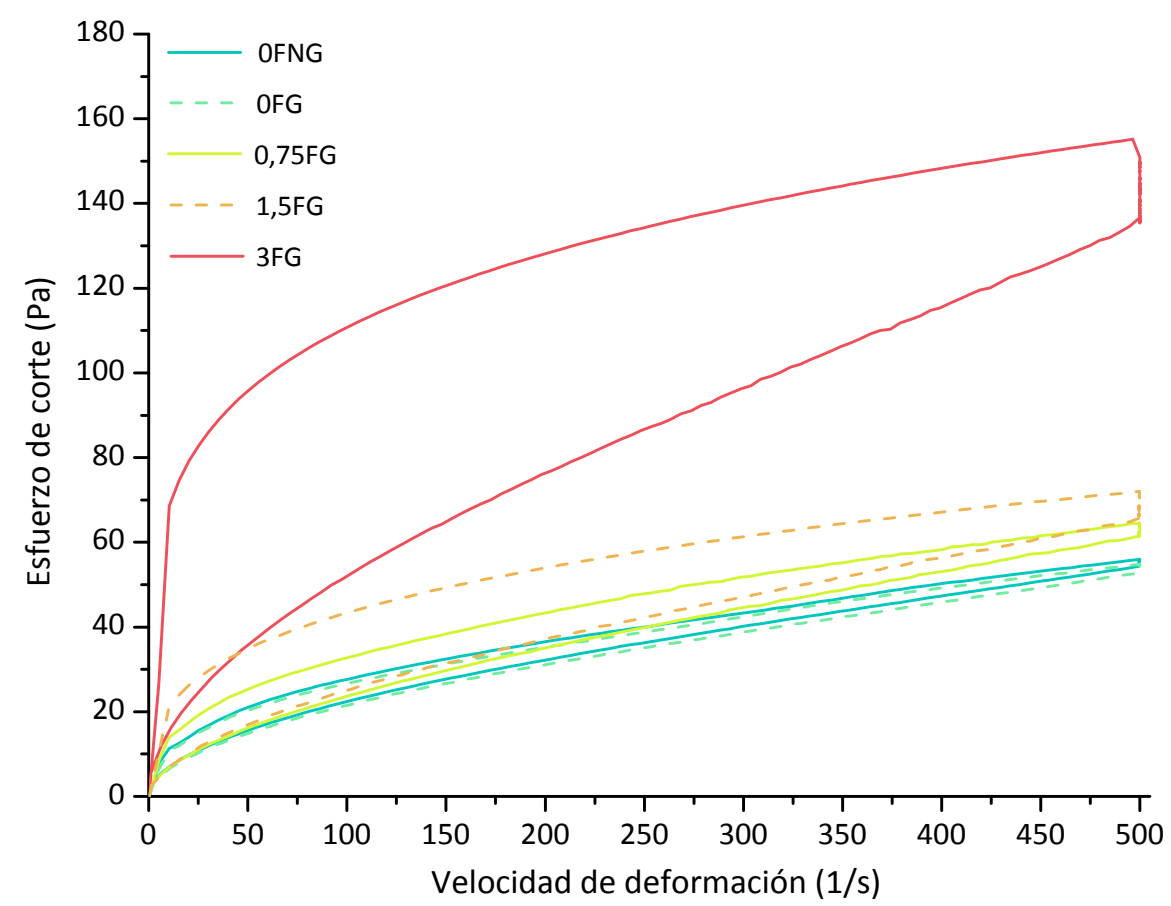

Figura I.10. Curvas de flujo de suspensiones filmogéncias de almidón de mandioca efecto del plastificante y el contenido de relleno. 
La Figura I.10 muestra curvas de flujo correspondientes a suspensiones de almidón gelatinizadas sin glicerol o fibra (OFNG), y las plastificadas con glicerol al $25 \%$ y diferentes concentraciones de fibra (OFG, $0,75 F G, 1,5 F G$ y $3 F G$ ). Todas las muestras presentaron un comportamiento pseudoplástico $(n<1)$, que se ajustaron satisfactoriamente al modelo de Ostwald de Waele, resultando el índice de consistencia mayor a mayor contenido de bagazo (Tabla I.2). Además, todas las suspensiones evidenciaron histéresis, revelando un comportamiento tixotrópico (Figura I.10).

Tabla I.2 - Parámetros reológicos de suspensiones filmogénicas a base de almidón de mandioca $(3 \% \mathrm{p} / \mathrm{p})$ y distintos contenidos de plastificante y carga

\begin{tabular}{ccccc} 
FORMULACIÓN & $\mathbf{K}$ & $\mathbf{N}$ & $\begin{array}{c}\text { Viscosidad aparente } \\
(\mathbf{m P a} . \mathbf{s})\end{array}$ & $\begin{array}{c}\text { Tixotropía } \\
\mathbf{( P a} / \mathbf{s})\end{array}$ \\
\hline OFNG & $3,79 \pm 0,15^{\mathrm{a}}$ & $0,43 \pm 0,002^{\mathrm{c}}$ & $112,07 \pm 2,61^{\mathrm{ab}}$ & $1977,5 \pm 96,9^{\mathrm{a}}$ \\
OFG & $3,29 \pm 0,10^{\mathrm{a}}$ & $0,45 \pm 0,00^{\mathrm{c}}$ & $105,68 \pm 2,46^{\mathrm{a}}$ & $1774,0 \pm 270,1^{\mathrm{a}}$ \\
0,75FG & $5,36 \pm 0,75^{\mathrm{a}}$ & $0,40 \pm 0,020^{\mathrm{c}}$ & $126,72 \pm 1,11^{\mathrm{bc}}$ & $3929,5 \pm 494,3^{\mathrm{ab}}$ \\
1,5FG & $12,57 \pm 3,42^{\mathrm{a}}$ & $0,29 \pm 0,040^{\mathrm{b}}$ & $137,56 \pm 3,95^{\mathrm{c}}$ & $7683,5 \pm 727,6^{\mathrm{b}}$ \\
3FG & $51,43 \pm 13,32^{\mathrm{b}}$ & $0,19 \pm 0,030^{\mathrm{a}}$ & $293,19 \pm 13,98^{\mathrm{d}}$ & $25515,0 \pm 4136,6^{\mathrm{c}}$ \\
\hline
\end{tabular}

Nota: Los valores informados corresponden al valor medio \pm desviación estándar. Letras diferentes en una misma columna indican diferencias significativas $(p<0,05)$.

La disminución de la viscosidad aparente de la muestra a una velocidad de cizallamiento fija en función del tiempo se atribuye a una desintegración de la estructura de gel de las red polimérica [43].

Los índices de tixotropía correspondientes se calcularon como el área entre las curvas de flujo, siendo 1977,5 y 1774,0 Pa/s para suspensiones de almidón sin relleno con y sin plastificante (OFG y OFNG), respectivamente; mientras que, para las suspensiones con concentración creciente de carga los índices resultaron más altos: 3929,5, 7683,5 y $25515,0 \mathrm{~Pa} / \mathrm{s}$ para $0,75 \%, 1,5 \%$ y $3 \%$ de contenido de relleno. El efecto del agregado de plastificante en el índice de tixotropía de las suspensiones filmogénicas no fue significativo $(p>0,05)$, mientras que las diferencias entre los índices de tixotropía resultaron significativas $(p<0,05)$ para muestras con contenido de relleno variable. 
Dichos resultados pueden atribuirse a defectos estructurales promovidos por las partículas de relleno que favorecen la ruptura de la red cuando se someten a alta velocidad de cizallamiento.

A partir de los ensayos rotacionales también se observó que con la inclusión de la carga en las suspensiones aumentó significativamente $(p<0,05)$ la viscosidad aparente (Tabla I.2).

Los ensayos oscilatorios, por otro lado, permitieron evaluar el comportamiento viscoelástico de suspensiones de almidón gelatinizado dentro del intervalo de viscoelasticidad lineal, donde las muestras no sufren daños estructurales. A partir de barridos de esfuerzo se determinó que el intervalo de viscoelasticidad lineal se extiende hasta 1,4 Pa o más para todas las pastas de almidón, por lo que para los barridos de frecuencia se seleccionó 1 Pa de esfuerzo cortante. Puesto que, como es sabido, la retrogradación de las pastas de almidón es un fenómeno dependiente del tiempo que podría afectar la estabilidad de las suspensiones filmogénicas, se estudió la variación de los parámetros viscoelásticos de las formulaciones con el tiempo. En la Figura I.11 se muestran los valores tanto del módulo de almacenamiento (G') como del módulo de pérdida ( $\left.G^{\prime \prime}\right)$ en función del tiempo de almacenamiento para todas las formulaciones ensayadas. Todas las muestras presentaron valores de $\mathrm{G}^{\prime}$ significativamente mayores $(p<0,05)$ que los de $G^{\prime \prime}$, los que permanecieron prácticamente constantes a lo largo de todo el rango de frecuencias analizado, comportándose como un gel débil. Ambos parámetros, G' y G', aumentaron con la adición de relleno fibroso a las suspensiones gelatinizadas de almidón de mandioca así como con el tiempo de almacenamiento. Sin embargo, aunque la firmeza de las pastas aumentó, no se observó segregación confirmando que las partículas de carga permanecieron suspendidas. Resultados críticos para el potencial escalado del proceso.

A pesar de que la incorporación del glicerol provocó una disminución tanto de G' como 
de G", la tendencia de las curvas resultó similar a las correspondientes a las películas no plastificadas. Un comportamiento similar ha sido reportado por diversos autores que trabajaron con suspensiones filmogénicas a base de almidón plastificadas con diferentes polioles y azúcares $[36,38,58]$.

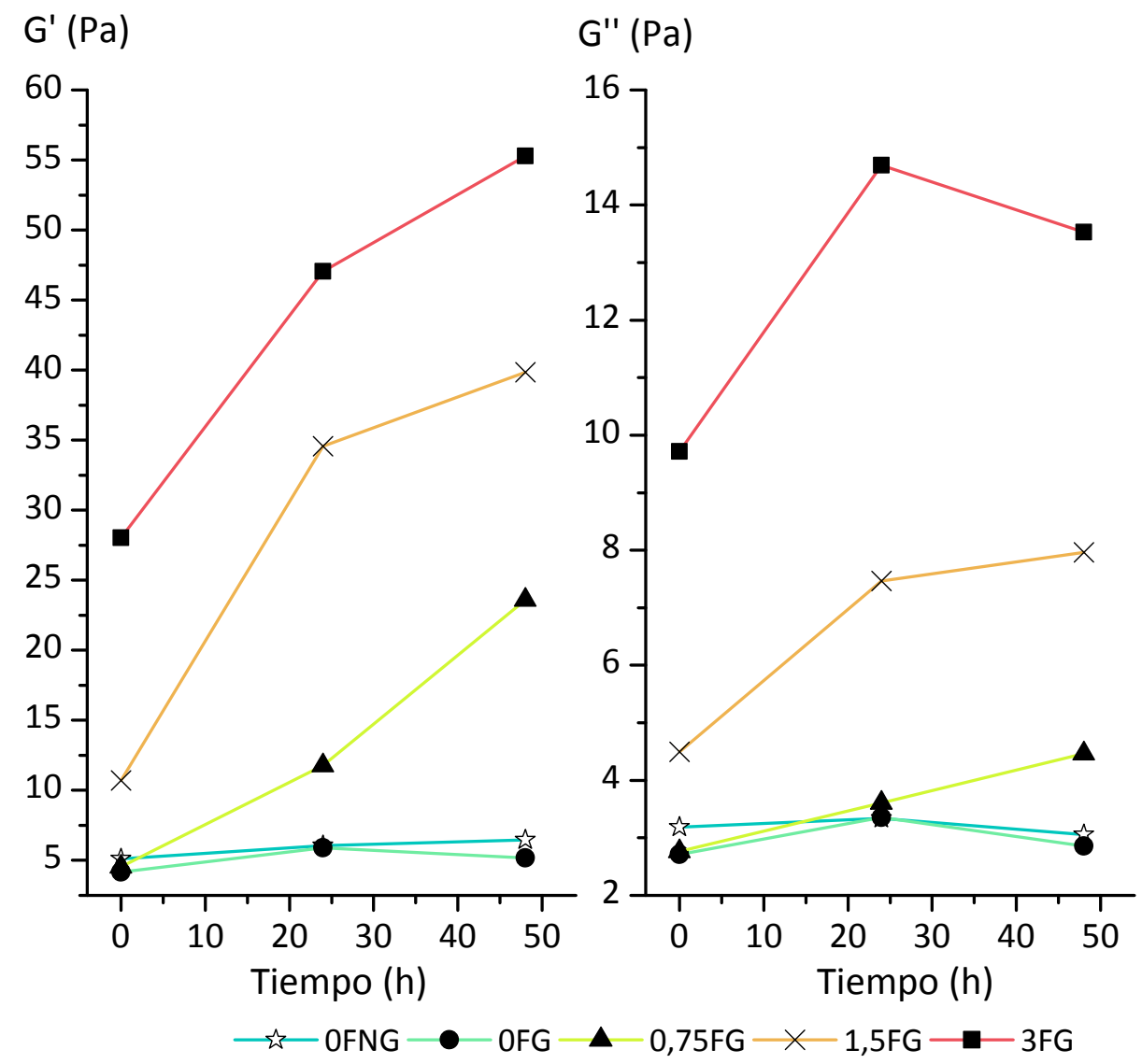

Figura I.11. Variación del módulo de almacenamiento ( $\left.G^{\prime}\right)$ y del módulo de pérdida (G") en función del tiempo para suspensiones filmogénicas de almidón de mandioca, efecto del plastificante y contenido de relleno.

Estos resultados se corresponden con las viscosidades aparentes observadas a una velocidad de deformación de $500 \mathrm{~s}^{-1}$. Para las muestras sin fibra, la adición de plastificante disminuyó la viscosidad aparente de 112 mPa.s a 105 mPa.s, mientras que la incorporación de $0,75,1,5$ y $3 \%$ p/p de carga aumentó este parámetro en 20,30 y $177 \%$, respectivamente. 
4.3. Propiedades fisicoquímicas de la película de almidón de mandioca Debido a su elevada viscosidad las suspensiones filmogéncias de almidón de mandioca al $3 \% \mathrm{p} / \mathrm{p}$ requerían una etapa adicional de desgasificación con vacío para eliminar las burbujas que podrían generar poros y defectos en la superficie de las películas durante el proceso de secado. Este procedimiento también fue aplicado por Perdomo y col. [59] trabajando en el desarrollo de matrices poliméricas de almidón de mandioca. Todas las suspensiones filmogénicas utilizadas fueron capaces de formar películas, las que se removieron fácilmente de las placas. Visualmente las que no incluían fibra presentaron mayor homogeneidad que las reforzadas, resultando más translúcidas. Las películas presentaron valores de espesor medio de alrededor de $67 \mu \mathrm{m}$, la adición de glicerol redujo el espesor de las películas a $48 \mu \mathrm{m}$. La comparación del grosor de película con los informados para películas basadas en hidrocoloides es difícil debido a que generalmente se omite la relación de moldeo usada. Por otra parte, la incorporación del bagazo derivó en películas significativamente más gruesas y rugosas, con un espesor medio aproximado a $140 \mu \mathrm{m}$ para películas con un contenido de fibra de 1,5 \%p/p. Este efecto, así como la alta desviación estándar asociada (Tabla I.3), se atribuyó a la presencia de partículas de carga de tamaño mayor al espesor medio, como se pudo observar por microscopía SEM (Figura I.12a).

La humedad de las películas fue significativamente $(p<0,05)$ afectada por la adición tanto de plastificante como de material de refuerzo. Como era de esperar, el contenido de humedad de las películas plastificadas era mayor que el de las no plastificadas, debido al carácter hidrofílico del glicerol. El efecto del plastificante sobre las películas de hidrocoloides ha sido ampliamente descripto en la literatura, y se atribuye a la promoción de interacciones químicas entre polímero y plastificante, que producen un aumento de la movilidad molecular y del volumen libre $[6,39]$. Mientras tanto, un aumento en el contenido de relleno dio como resultado un menor contenido de humedad de las películas reforzadas. 


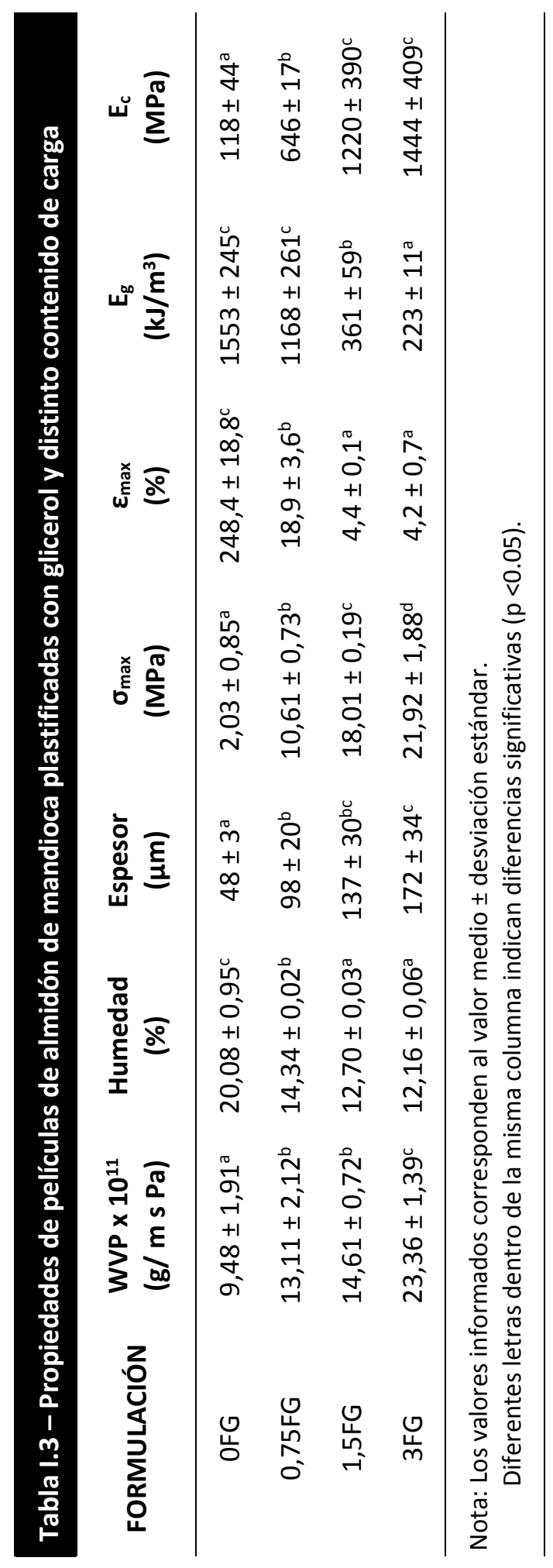


Se utilizó SEM para examinar la microestructura de los materiales en estudio y evaluar la adhesión interfacial del almidón de mandioca y el material de carga en los biocompuestos reforzados. La Figura 1.12 muestra las micrografías SEM obtenidas de las superficies criofracturadas de películas plastificadas a base de almidón de mandioca con y sin material de refuerzo. Las películas de almidón plastificadas mostraron superficies homogéneas y estructuras compactas (Figura I.12a). La adición de la carga condujo a la formación de películas con superficies más heterogéneas donde se pueden observar partículas de bagazo de gran tamaño cubiertas por la matriz de almidón (Figura I.12b y c). Esta discontinuidad también fue evidente en las mediciones de espesor, que presentaron mayor dispersión para muestras reforzadas (Tabla I.3). Además, como era de esperar, los espesores medios son mayores a mayor contenido de relleno, debido a modificaciones estructurales inducidas en la matriz (Figura I.12b, c, d y e).
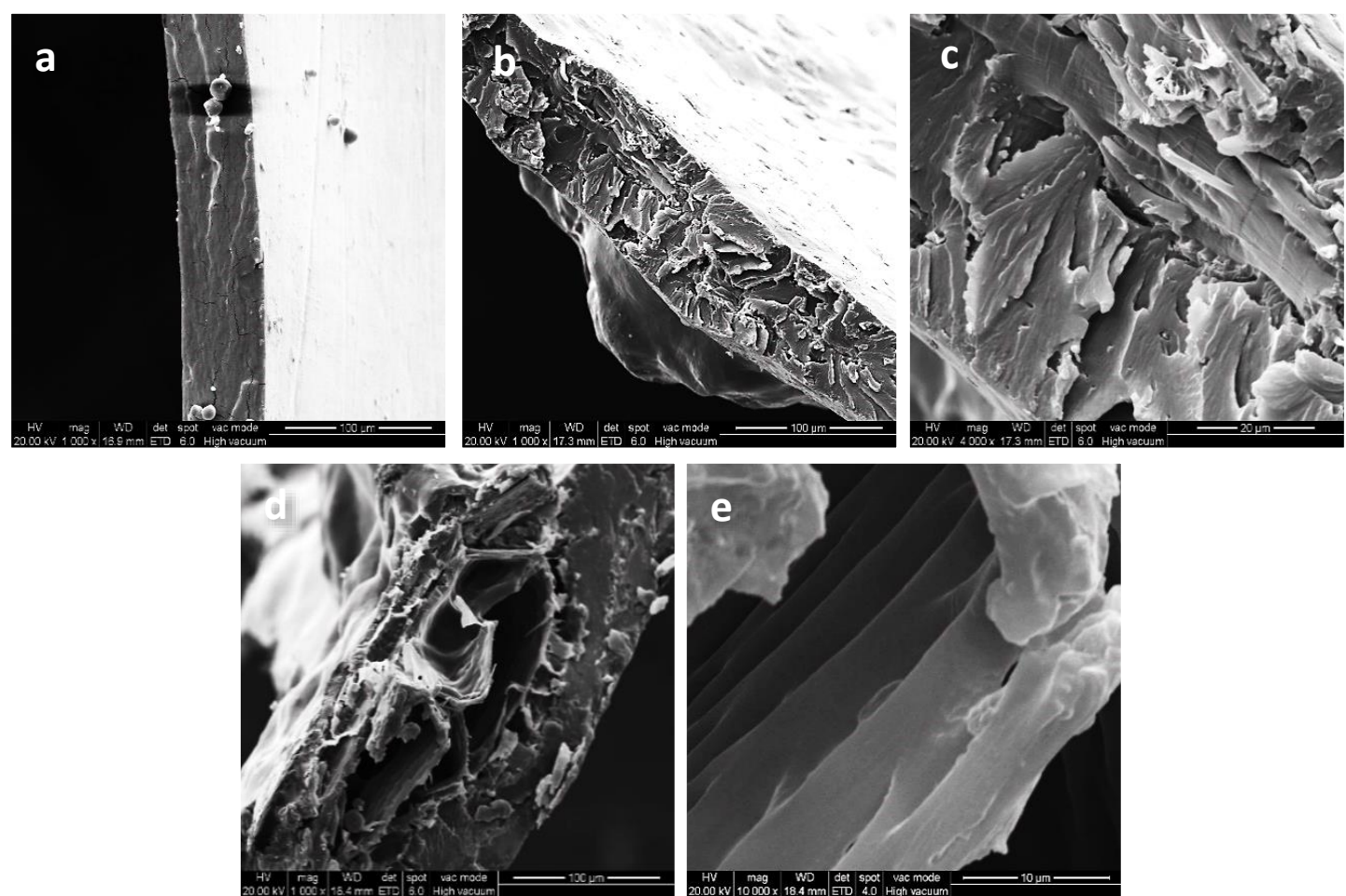

Figura I.12. Micrografía SEM de películas de almidón plastificadas con $25 \%$ de glicerol: a) sin fibra (1000X); b) con 1,5\% de fibra (1000X); c) detalle de muestra 1,5\%; d) con $3 \%$ de fibra (1000X); e) detalle de muestra 3 \% (10000X). 
No obstante, las partículas de bagazo se encontraban recubiertas por la matriz de almidón y no se observó desprendimiento durante la criofractura (pull-out en inglés), lo cual indica que el mismo se encontraba incorporado estructuralmente en la matriz polimérica debido a la gran compatibilidad entre ambos componentes. Una buena adhesión entre la carga y la matriz conduce a una interfaz resistente [14], reforzando por consiguiente la matriz y aumentando su resistencia mecánica. Observaciones similares han sido reportadas por otros autores sobre materiales compuestos a base de almidón $[18,39,60]$ y otras películas reforzadas biodegradables [19].

Cuando se utilizan contenidos de relleno más altos, la densidad de partículas aumenta promoviendo la interacción entre las partículas de relleno que podría inducir la formación de agregados. La presencia de estos agregados junto con partículas de gran tamaño de bagazo podría inducir defectos en la matriz que afecten la integridad de la estructura de la película debido a su alto volumen (Figura I.12d). Ludueña y col. [20] destacaron que los aglomerados no permiten la correcta interacción entre matriz y relleno, y por lo tanto se observa una adhesión interfacial de polímero-relleno más débil. En los materiales compuestos de almidón de mandioca y bagazo, a pesar de la alta compatibilidad de la carga y la matriz, cuando el contenido de relleno es alto se observa que las interacciones polímero-relleno están presentes solamente en la superficie de la partícula de bagazo (Figura I.12d).

Las Figuras I.12c y e corresponden a un detalle de las secciones transversales de las películas, en las que se identifican ciertos elementos anatómicos tales como restos celulares, presumiblemente de células parenquimatosas, y otros presentando terminaciones en forma de punta compatibles con restos de vasos leñosos o tráqueas.

El estudio de la capacidad de absorción de la luz UV-visible de las películas biodegradables es relevante para determinar sus posibles aplicaciones. La Figura I.13 muestra los espectros obtenidos y los valores de opacidad calculados para las películas plastificadas estudiadas. 


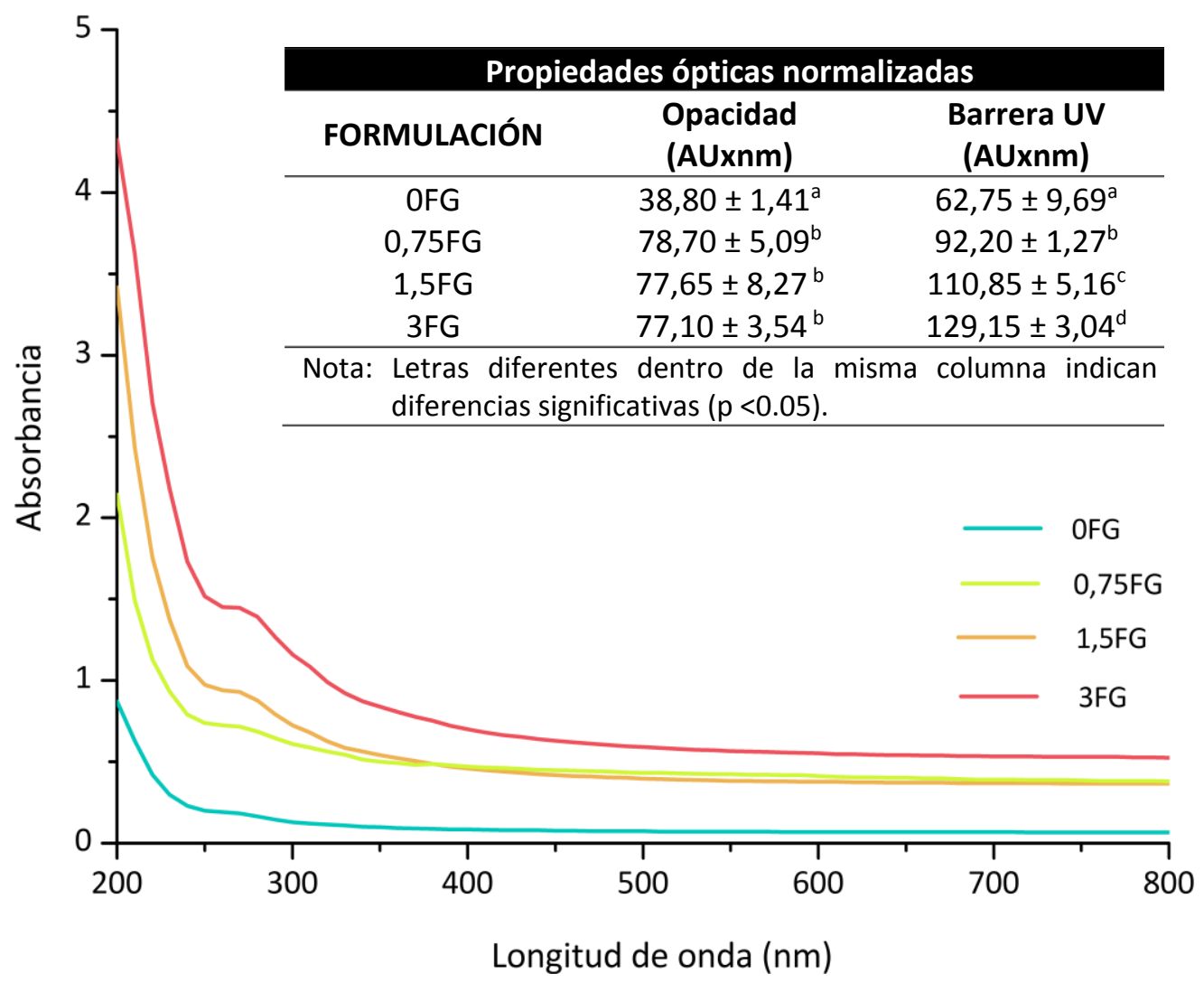

Figura I.13. Espectro de absorción de luz UV-Visible de películas de almidón de mandioca plastificadas con distinto contenido de bagazo. La tabla inserta muestra propiedades ópticas normalizadas de los materiales obtenidos.

Los espectros UV de películas reforzadas mostraron un pico característico a $250-300 \mathrm{~nm}$, que podría atribuirse principalmente a los componentes fenólicos de la lignina [61]. Con el fin de estimar la capacidad de barrera UV de las películas reforzadas, se calculó el área bajo la curva en dicha región (200-400 nm). Los resultados indicaron que este parámetro aumentó con el contenido de relleno, siendo los valores obtenidos: $155,77 \pm 14,49$ AUxnm para 0,75 \% de bagazo; 178,92 $\pm 34,28$ Auxnm para 1,5 \% de bagazo; y $220,89 \pm 9,16$ Auxnm para $3 \%$ de bagazo. La tendencia fue similar para los valores de opacidad obtenidos en la región visible (400-700 nm). Estas diferencias se atribuyen no solo a los componentes químicos del relleno, sino especialmente al aumento del espesor medio de las películas por la incorporación de la carga (como se 
ha mencionado previamente). Este efecto se evidencia al normalizar los valores obtenidos de opacidad y barrera UV a un espesor de película de $100 \mu \mathrm{m}$ como se muestra en la Tabla inserta en la Figura I.13. Si bien las diferencias siguen siendo significativas $(p<0,05)$ respecto al control $(0 F G)$ y en la región $U V$, los resultados obtenidos para películas con distintocontenido de fibra confirma el posible efecto de los compuestos fenólicos del relleno. Sin embargo, el efecto de la carga sobre la opacidad en la región visible no resulta significativo $(p>0,05)$ para un espesor normalizado.

Tabla I.4 - Parámetros de color de películas de almidón de mandioca reforzadas con distinto contenido de bagazo y plastificadas con glicerol

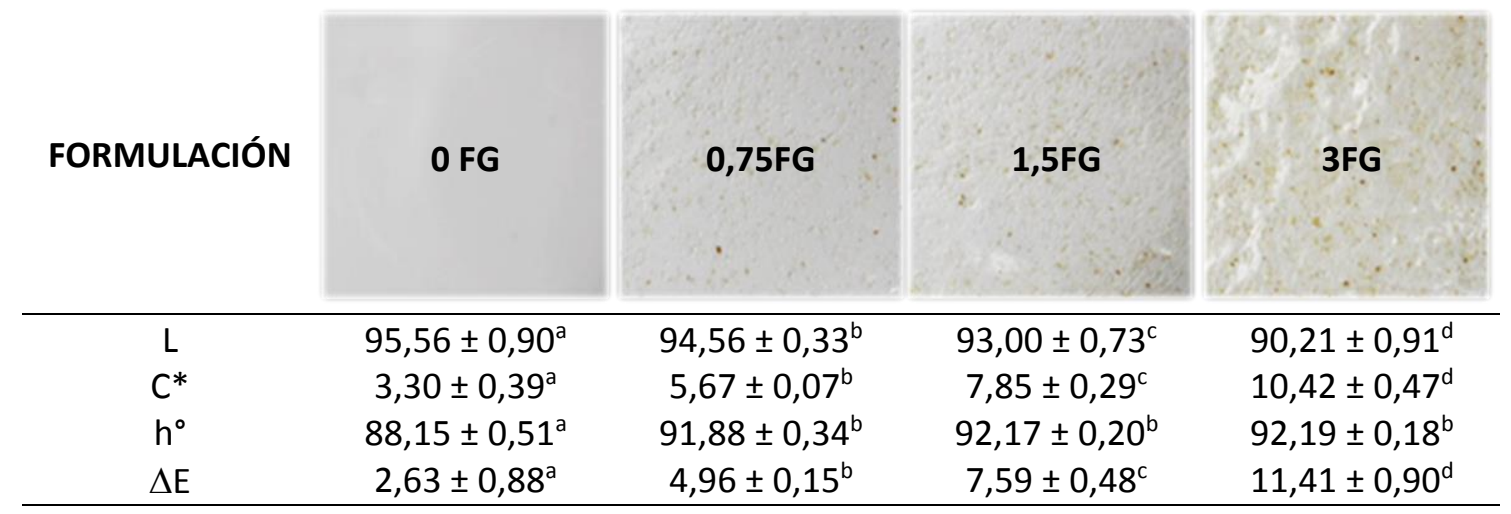

Nota: Letras diferentes en la misma fila indican diferencias significativas entre muestras $(p<0,05)$.

Visualmente las películas que no contenían relleno mostraron mayor homogeneidad de color que las reforzadas, resultando más translúcidas (Tabla I.4). El efecto de la adición de carga sobre las propiedades ópticas de las películas de almidón plastificadas se reflejó en los parámetros de color: la luminosidad (L) disminuyó con el contenido de carga, mientras que el parámetro chroma $\left(\mathrm{C}^{*}\right)$ relativo a la intensidad de color y la diferencia de color $(\Delta E)$ aumentaron. El cambio en el tono o hue $\left(h^{\circ}\right)$, sin embargo, permaneció constante independientemente de la concentración de fibra. Estos resultados concuerdan con las observaciones visuales y los resultados observados por espectroscopia UV-visible, puesto que una disminución de la luminosidad se 
correlaciona con el aumento de la opacidad al aumentar el contenido de material de relleno.

La permeabilidad al vapor de agua de las películas también fue significativamente afectada $(p<0,05)$ por la adición de glicerol y fibra. Se observó una reducción significativa $(p<0,05)$ en los valores de WVP con la adición de glicerol, dependiendo su concentración óptima del contenido de bagazo (Figura I.14). Como se explicó anteriormente la adición de glicerol interfiere con la asociación de las cadenas poliméricas disminuyendo la rigidez de la matriz, por lo que (en cantidades suficientes) da lugar a una estructura menos ordenada sin poros o grietas, disminuyendo la WVP [62]. Una tendencia similar fue informada por Galdeano y col. [34] para películas de almidón de avena plastificadas con glicerol ( 20 g/ 100 g de almidón).

En el caso de películas reforzadas, los valores de WVP inferiores correspondían al $25 \% \mathrm{p} / \mathrm{p}$ de glicerol respecto al contenido de almidón (Figura I.14a). No obstante, el efecto del plastificante sobre las propiedades de barrera al vapor de agua de las películas es menos significativo que el del contenido de relleno (Figura I.14b).

Se conoce que la transmisión de vapor de agua a través de un material resulta de un equilibrio entre tres mecanismos principales [20]: la cristalinidad del mismo, la tortuosidad del camino que debe recorrer el vapor dentro del espesor de la película, y la presencia de defectos superficiales o estructurales. Por lo tanto, aunque la presencia del material de refuerzo aumenta la tortuosidad del recorrido para las moléculas de agua, la presencia de partículas de bagazo relativamente grandes podrían promover la generación de huecos en la interfaz entre el polímero y el relleno, así como defectos superficiales que facilitan el transporte de las moléculas de agua a través de estas regiones. Según Garcia y col. [63] la WVP disminuye en películas más compactas con una estructura más homogénea. Por consiguiente, los resultados obtenidos de WVP concuerdan con las observaciones al SEM y podrían estar asociados a la estructura más heterogénea de las matrices reforzadas (Figura I.12b y d). 


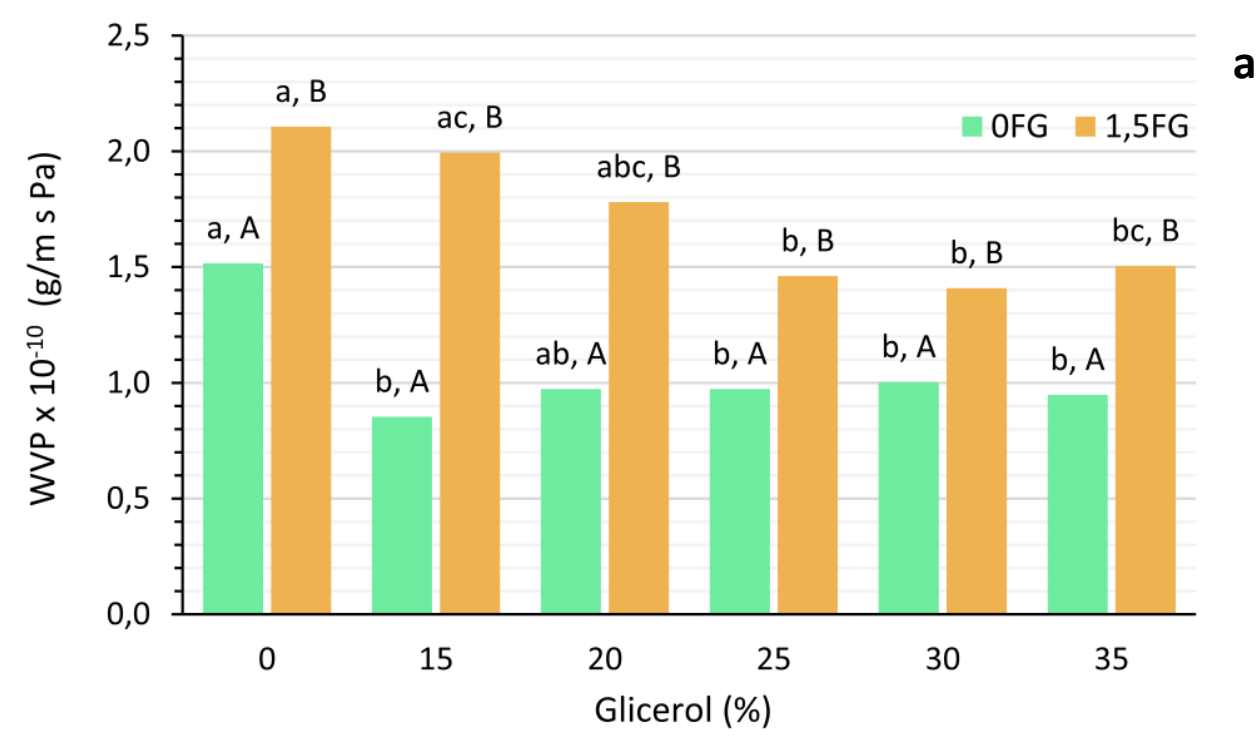

b

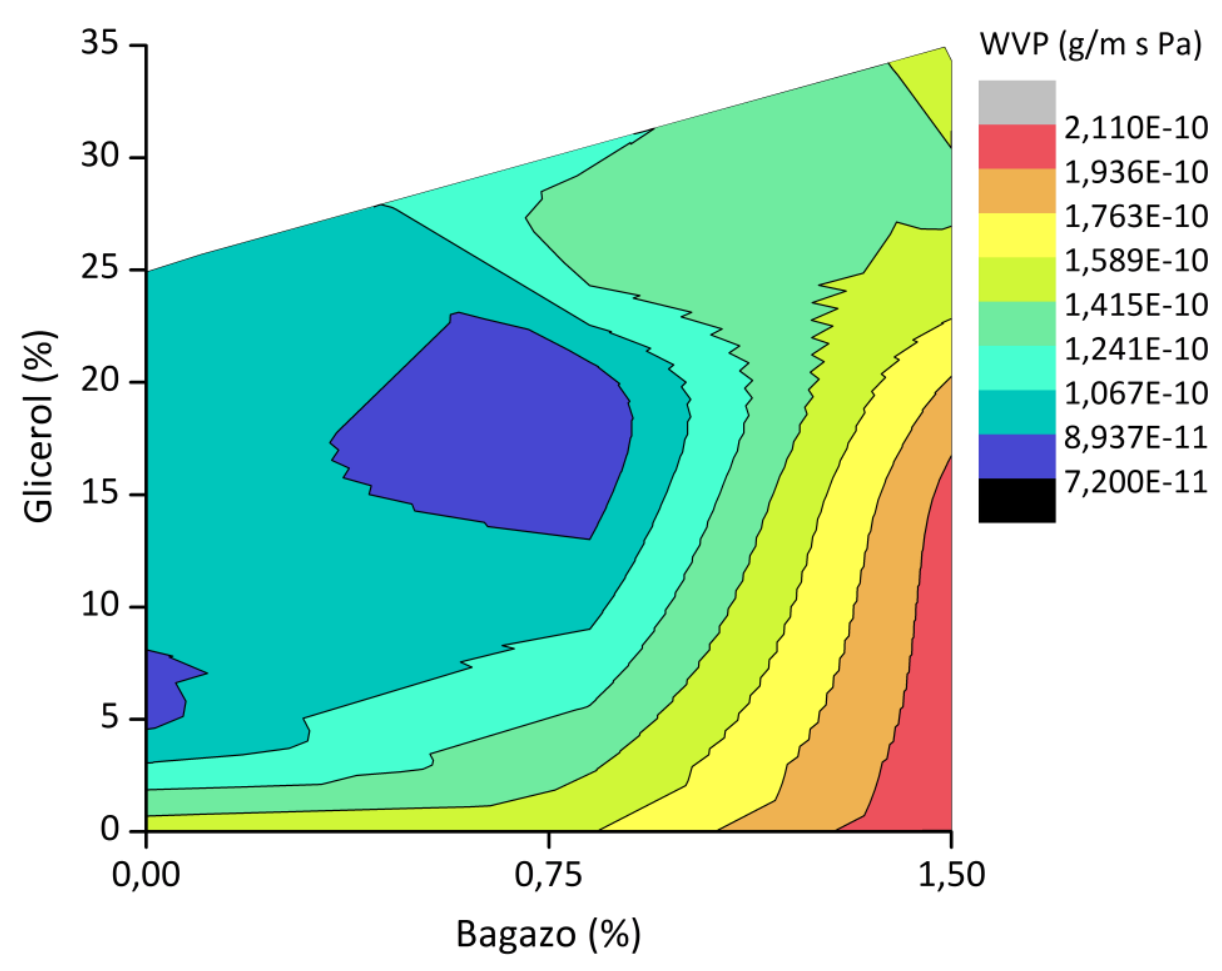

Figura I.14. Efecto del plastificante sobre la permeabilidad al vapor de agua de: a) gráfico de barras para WVP de películas a base de almidón de mandioca control y reforzadas con bagazo al 1,5\%p/p; b) gráfico de contornos para WVP de películas con distinta concentración de bagazo ( 0 a $1,5 \%$ p/p) y de glicerol ( 0 a $35 \% p / p$ respecto al almidón). 
Por el contrario, Ludueña y col. [20] indicaron que la presencia de fibras naturales disminuyó el grado de cristalinidad de la matriz de policaprolactona (PCL), aumentando así la permeabilidad del biomaterial a las moléculas de agua. Sin embargo, el efecto de los rellenos en las matrices biodegradables depende del tipo de relleno y la concentración, estructura del polímero y su compatibilidad, lo que ha dado lugar a discrepancias en las tendencias informadas. En el caso de las películas de almidón, un aumento de la cristalinidad es consecuencia de la retrogradación del almidón, lo cual deteriora la plasticidad del material y por tanto aumenta la probabilidad de que se generen grietas o fisuras en la matriz las que aumentarían drásticamente la permeabilidad. Aila-Suarez y col. [64] hicieron hincapié en que la adición de fibras de celulosa de algodón o chayote (una cucurbitácea muy fibrosa) a biocompuestos de almidón de papa aumenta las propiedades de barrera al agua. Asimismo, Müller y col. [15] trabajando con películas de almidón de mandioca reforzadas con fibras de pulpa de madera reportaron un efecto similar. Los valores de WVP para las películas de almidón de mandioca reforzadas con el residuo resultante de la extracción de almidón, correspondientes al presente trabajo de Tesis, se presentan en la Tabla I.3, mostrando un aumento en esta propiedad con el contenido de carga. Los valores obtenidos son similares a aquellos obtenidos por Müller y col. [15] teniendo en ambos casos contenidos equivalentes de almidón, glicerol y relleno.

Cabe destacar que los resultados obtenidos para la permeabilidad al oxígeno de las matrices reforzadas indican que el agregado de bagazo tampoco resulto positivo. El agregado de 1,5 \% de bagazo aumentó la permeabilidad al oxígeno de las películas de $12,79 \pm 1,5 \mathrm{cc} /\left(\mathrm{m}^{2}\right.$ día) a $238,95 \mathrm{cc} /\left(\mathrm{m}^{2}\right.$ día) para $0 \mathrm{FG}$ y $1,5 \mathrm{FG}$, respectivamente. El último valor de permeabilidad al oxígeno reportado, es mayor que los valores encontrados en la bibliografía para materiales sintéticos como polietileno de baja densidad (LPDE), aunque debe tenerse en cuenta que las condiciones de humedad relativa a la cual se han realizado los experimentos son diferentes [65]. 
En relación al comportamiento mecánico de las películas estudiadas, la adición de glicerol o de relleno promovieron comportamientos diametralmente opuestos entre los parámetros evaluados: resistencia y deformación máxima a la ruptura en ensayos de tensión (Figura I.15).

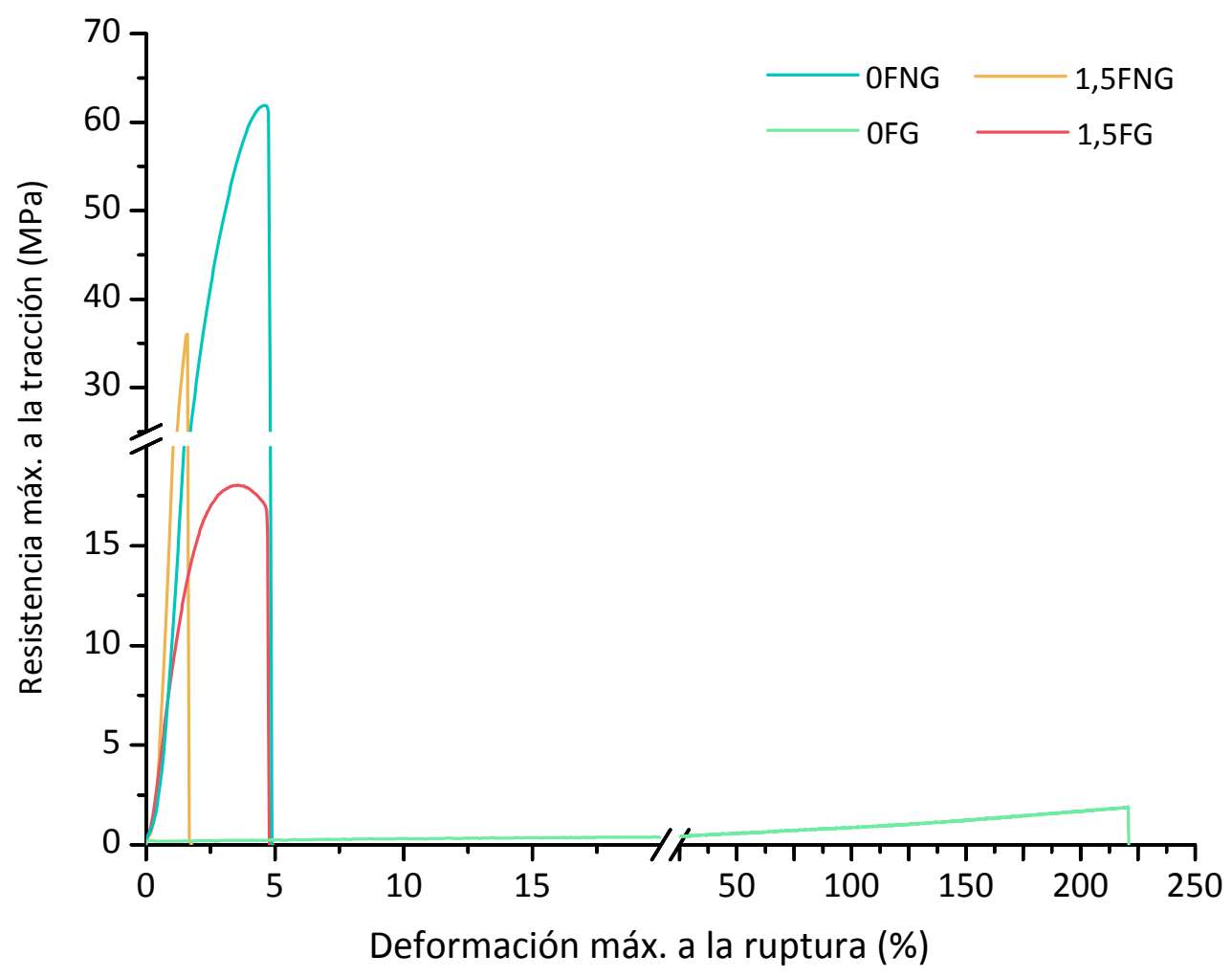

Figura I.15. Curvas de tensión-deformación de películas de almidón de mandioca: sin plastificante (OFNG), plastificadas con glicerol (OFG), con 1,5\% contenido de bagazo plastificadas $(1,5 \mathrm{FG})$ y no plastificadas $(1,5 \mathrm{FNG})$.

Independientemente del contenido de relleno con la adición de glicerol la resistencia de las películas disminuyó significativamente $(p<0,05)$, mientras que la deformación a la ruptura aumentó (Figura I.15). Por ejemplo, para las películas plastificadas con $25 \%$ de glicerol la deformación máxima aumentó un 4100 \% con respecto a las no plastificadas. Este comportamiento se explica debido a la reducción de la proximidad entre las cadenas de almidón en presencia del plastificante, lo cual, disminuye fuerzas 
de tracción, facilita el movimiento de las cadenas de almidón y por ende aumenta la elongación. Por el contrario, no se detectaron diferencias significativas $(p>0,05)$ en el estiramiento de películas reforzadas plastificadas dentro del rango de concentraciones de glicerol ensayadas. Teniendo en cuenta la composición química del residuo (Tabla I.1), el efecto amortiguado del plastificante en las películas reforzadas podría atribuirse a que el glicerol interactúa tanto con el almidón de la matriz como con los compuestos lignocelulósicos y los restos de almidón del residuo, permitiendo mayor interacción entre moléculas de almidón de la matriz para la misma concentración de plastificante [66].

Por otro lado, la adición del relleno aumentó la resistencia máxima a la tracción de la película confirmando el refuerzo del material (Figura I.16 y Tabla I.3). Este comportamiento ha sido ampliamente estudiado en compuestos poliméricos reforzados con fibras naturales, como describen generosamente en su trabajo Shalwan y Yousif [13].

Sin embargo, se observó que un contenido de bagazo del 3 \% condujo a la formación de materiales más frágiles, con mayor resistencia mecánica y módulo de elasticidad, pero menor elongación a la ruptura y tenacidad (Tabla I.3). Dichos resultados se correlacionan con las observaciones por microscopía SEM, donde se detectó la presencia de partículas de relleno más grandes (posiblemente también agregados de partículas de menor tamaño) que condujeron a una estructura más heterogénea (Figura I.12d). Kargarzadeh y col. [67] hicieron referencia a este fenómeno, indicando que el comportamiento mecánico depende de la interacción entre la matriz y la carga. Así al aumentar la concentración del relleno puede producirse aglomeración de las partículas, debido a la mayor interacción entre las partículas de refuerzo en detrimento de las interacciones con la matriz polimérica, lo que explicaría el comportamiento mecánico de las películas con 3 \% de bagazo. Cabe destacar que la resistencia máxima de las películas control no plastificadas fue mayor que las de materiales reforzados con 

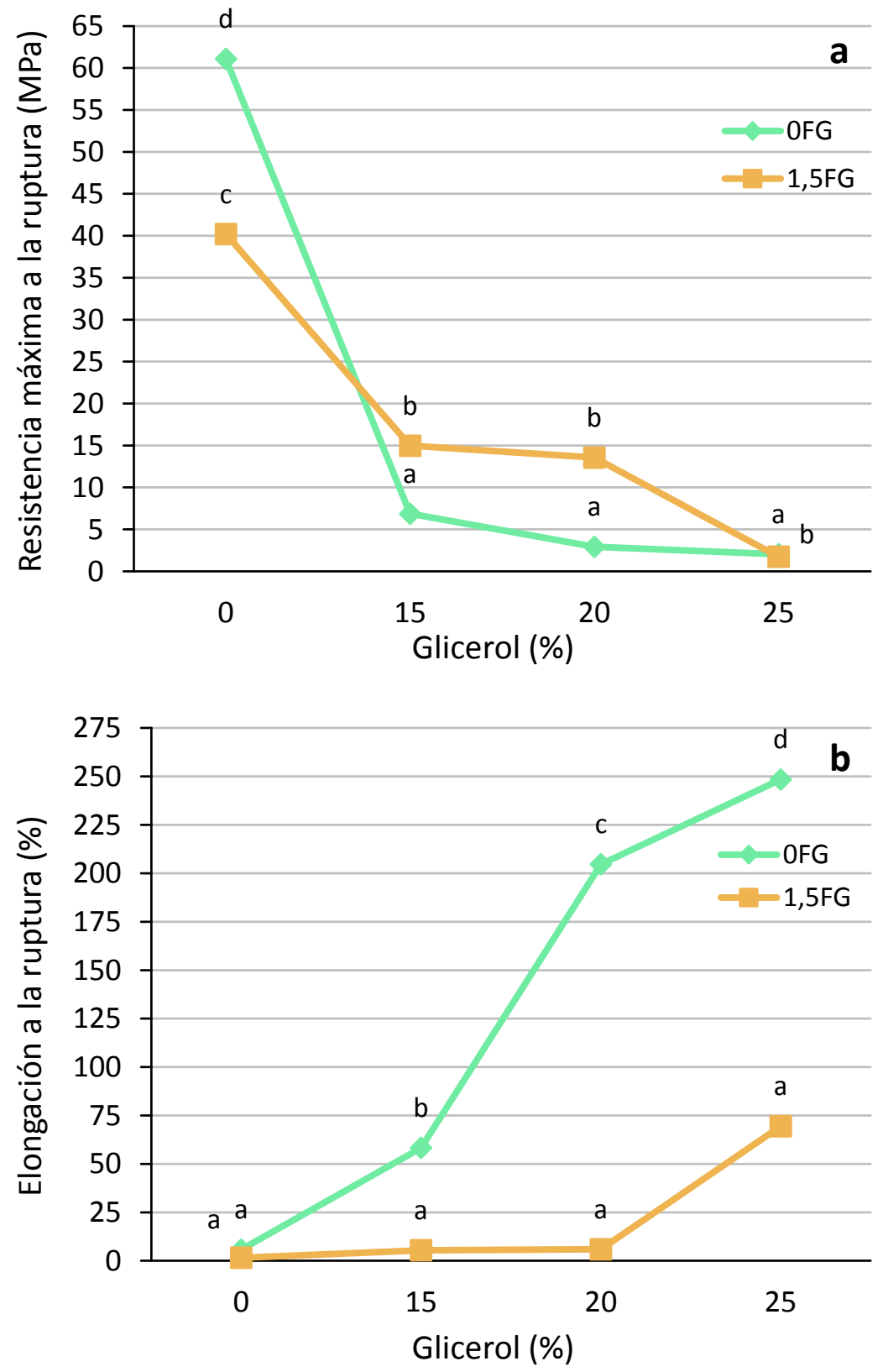

Figura I.16. Efecto del plastificante sobre: a) la resistencia máxima a la tracción y b) la elongación máxima en la ruptura, de películas a base de almidón de mandioca sin relleno y reforzadas con $1,5 \%$ de bagazo. ${ }^{1}$

\footnotetext{
${ }^{1}$ Las letras indican diferencias significativas $(p<0,05)$ entre muestras con el mismo contenido de relleno.
} 
bagazo debido a las fuertes interacciones entre las cadenas de almidón en la matriz (Figura I.16a), sin embargo es importante señalar que fue difícil obtener ejemplares que no se rompieran antes de realizar los ensayos de tracción.

La tenacidad, que representa la energía total absorbida por un material antes de la ruptura, comprende la relación sinérgica entre la resistencia a la tracción y la elongación. La tenacidad de las películas de almidón de mandioca fue de $1908 \pm 156 \mathrm{~kJ} / \mathrm{m}^{3}$, dentro del rango de los valores reportados por Chang y col. [32] para películas de almidón de mandioca producido en Tailandia. La adición de glicerol al $25 \%$ disminuyó ligeramente la tenacidad del material: $1553 \pm 245 \mathrm{~kJ} / \mathrm{m}^{3}$, aunque las diferencias no fueron significativas $(p>0,05)$. Por otro lado, la inclusión de $0,75 \%$ de relleno mantuvo la tenacidad de la película (Tabla I.3), mientras que las mayores concentraciones de carga disminuyeron significativamente $(p<0,05)$ este parámetro. Por tanto, la tenacidad sigue un comportamiento equivalente a la capacidad de deformación del material.

Los ensayos de DMA se correlacionaron bien con el análisis mecánico de tracción. Las curvas de tensión-deformación pudieron ser satisfactoriamente $\left(r^{2}>0,98\right)$ ajustadas al modelo propuesto por Chillo y col. [33]. Los valores obtenidos para el módulo elástico de las películas con diferentes contenidos de carga se presentan en la Tabla I.3, mostrando la misma tendencia que la resistencia máxima a la ruptura.

\section{CONCLUSIONES}

Se pueden obtener, por el método de moldeo y deshidratación, películas biodegradables homogéneas a partir de almidón de mandioca y el residuo fibroso remanente del proceso de extracción de almidón. El residuo presentó una distribución heterogénea del tamaño, con el $44 \%$ de las partículas más grandes que $53 \mu \mathrm{m}$. Las micrografías SEM evidenciaron que la carga estaba estructuralmente incorporada en la 
matriz de almidón, sin embargo con altos contenidos de carga se pudo observar una mayor contribución de partículas de fibra de relativo gran tamaño.

Las películas reforzadas exhibieron una capacidad de barrera UV, que aumenta con el contenido de relleno. Asimismo, la adición de bagazo aumentó la opacidad de la película mientras que el parámetro de luminosidad se vio disminuido. Los materiales obtenidos tenían buenas propiedades de barrera al vapor de agua y resistencia mecánica adecuada cuando se añadió como plastificante $25 \% \mathrm{p} / \mathrm{p}$ de glicerol. La adición de relleno reforzó la matriz polimérica aumentando su resistencia a la ruptura y el módulo elástico. La tenacidad sigue un comportamiento equivalente al de la elongación a la ruptura. La adición de glicerol al 25 \% disminuyó ligeramente la tenacidad del material, mientras que la inclusión del relleno redujo sustancialmente este parámetro.

Se podría concluir, que un compromiso de las propiedades mecánicas y de barrera se obtuvo para una concentración de $25 \%$ de glicerol y 1,5\% de bagazo de mandioca como agente de refuerzo. De este modo, la adición de agentes de refuerzo derivadas del remanente de extracción de almidón constituye una opción interesante para adaptar las propiedades de las películas compuestas resultantes y permite ampliar el rango de aplicación de materiales eco-compatibles basados en almidón. Haciendo un uso integral de la raíz tuberosa y valorizando un subproducto agroindustrial.

\section{BIBLIOGRAFÍA}

[1] H. Abdillahi, E. Chabrat, A. Rouilly, L. Rigal, Influence of citric acid on thermoplastic wheat flour/poly(lactic acid) blends. II. Barrier properties and water vapor sorption isotherms, Industrial Crops and Products 50 (2013) 104-111.

[2] O.V. López, M.A. García, Starch films from a novel (Pachyrhizus ahipa) and conventional sources: Development and characterization, Materials Science and Engineering C 32 (2012) 1931-1940.

[3] M. Leonel, S.B. Sarmento, M.P. Cereda, F.L. Cãmara, Extração e caracterização de amido de jacatupé (Pachyrhizus ahipa), Ciência e Tecnología de Alimentos 23 (2003) 362-365. 
[4] United Nations Conference on Trade and Development, INFOCOMM Commodity Profile: CASSAVA, (2012).

[5] L. Famá, S. Flores, L. Gerschenson, S. Goyanes, Physical characterization of cassava starch biofilms with special reference to dynamic mechanical properties at low temperatures, Carbohydrate Polymers 66 (2006) 8-15.

[6] S. Mali, L.S. Sakanaka, F. Yamashita, M.V.E. Grossmann, Water sorption and mechanical properties of cassava starch films and their relation to plasticizing effect, Carbohydrate Polymers 60 (2005) 283-289.

[7] J. Prakash Maran, V. Sivakumar, R. Sridhar, V. Prince Immanuel, Development of model for mechanical properties of tapioca starch based edible films, Industrial Crops and Products 42 (2013) 159-168.

[8] O.V. López, S.Z. Viña, A.N.A. Pachas, M.N. Sisterna, P.H. Rohatsch, A. Mugridge, H.E. Fassola, M.A. García, Composition and food properties of Pachyrhizus ahiparoots and starch, International Journal of Food Science \& Technology 45 (2010) 223-233.

[9] R. Bodirlau, C.-A. Teaca, I. Spiridon, Influence of natural fillers on the properties of starchbased biocomposite films, Composites Part B: Engineering 44 (2013) 575-583.

[10] W.N. Gilfillan, D.M.T. Nguyen, P.A. Sopade, W.O.S. Doherty, Preparation and characterisation of composites from starch and sugar cane fibre, Industrial Crops and Products 40 (2012) 45-54.

[11] K.G. Satyanarayana, G.G.C. Arizaga, F. Wypych, Biodegradable composites based on lignocellulosic fibers-An overview, Progress in Polymer Science 34 (2009) 982-1021.

[12] F.M. Al-Oqla, S.M. Sapuan, Natural fiber reinforced polymer composites in industrial applications: feasibility of date palm fibers for sustainable automotive industry, Journal of Cleaner Production 66 (2014) 347-354.

[13] A. Shalwan, B.F. Yousif, In State of Art: Mechanical and tribological behaviour of polymeric comopistes based on natural fibres, Materials \& Design 48 (2013) 14-24.

[14] S. Kuciel, A. Liber-Knec, Biocomposites on the base of thermoplastic starch filled by wood and kenaf fiber, Journal of Biobased Materials and Bioenergy 3 (2009) 269-274.

[15] C.M.O. Müller, J.B. Laurindo, F. Yamashita, Effect of cellulose fibers addition on the mechanical properties and water vapor barrier of starch-based films, Food Hydrocolloids 23 (2009) 1328-1333.

[16] J. Castaño, S. Rodriguez-Llamazares, C. Carrasco, R. Bouza, Physical, chemical and mechanical properties of pehuen cellulosic husk and its pehuen-starch based composites, Carbohydrate Polymers 90 (2012) 1550-1556.

[17] S.K. Konar, R. Gu, M. Sain, Preparation and characterization of baked nitrile latex foam reinforced with biomasses, Industrial Crops and Products 42 (2013) 261-267.

[18] H. Ibrahim, M. Farag, H. Megahed, S. Mehanny, Characteristics of starch-based biodegradable composites reinforced with date palm and flax fibers, Carbohydrate Polymers 101 (2014) 11-19. 
[19] A.K. Behera, S. Avancha, R.K. Basak, R. Sen, B. Adhikari, Fabrication and characterizations of biodegradable jute reinforced soy based green composites, Carbohydrate Polymers 88 (2012) 329-335.

[20] L. Ludueña, A. Vázquez, V. Alvarez, Effect of lignocellulosic filler type and content on the behavior of polycaprolactone based eco-composites for packaging applications, Carbohydrate Polymers 87 (2012) 411-421.

[21] A.M. Idrovo Encalada, M.F. Basanta, E.N. Fissore, M.D. De'Nobili, A.M. Rojas, Carrot fiber (CF) composite films for antioxidant preservation: Particle size effect, Carbohydrate Polymers 136 (2016) 1041-1051.

[22] Associaton of Official Analytical Chemists (AOAC), 923.03 Proximate Analysis and Calculations Ash Determination (Ash) Flour en: K. Helrich (Ed.) Official methods of analysis of the Associaton of Official Analytical Chemists (AOAC), 2, Associaton of Official Analytical Chemists, Inc., Arlington, Virginia, USA, 1990, pp. 777.

[23] Associaton of Official Analytical Chemists (AOAC), 920.39 Lipids, Fats and Oils Analysis Total Fat Animal Feed en: Official methods of analysis of the Associaton of Official Analytical Chemists, 1, Associaaton of Official Analytical Chemists, Inc., Arlington, Virginia, USA, 1990, pp. 79.

[24] Associaton of Official Analytical Chemists (AOAC), 984.13 Protein (Crude) Determination in Animal Feed: Copper Catalyst Kjeldahl Method, en: K. Helrich (Ed.) Official methods of analysis of the Associaton of Official Analytical Chemists (AOAC), 1, Associaton of Official Analytical Chemists, Inc., Arlington, Virginia, USA, 1990, pp. 74.

[25] Associaton of Official Analytical Chemists (AOAC), 985.29 Total dietary fiber in foods. Enzimatic-gravimetric method, en: Official methods of analysis of the Associaton of Official Analytical Chemists (AOAC), Associaton of Official Analytical Chemists, Inc., Arlington, Virginia, USA, 1990.

[26] J.L. Guimarães, E. Frollini, C.G. da Silva, F. Wypych, K.G. Satyanarayana, Characterization of banana, sugarcane bagasse and sponge gourd fibers of Brazil, Industrial Crops and Products 30 (2009) 407-415.

[27] C.M. Rosell, E. Santos, C. Collar, Physico-chemical properties of commercial fibres from different sources: A comparative approach, Food Research International 42 (2009) 176-184.

[28] C. Dini, M.C. Doporto, M.A. García, S.Z. Viña, Nutritional profile and anti-nutrient analyses of Pachyrhizus ahipa roots from different accessions, Food Research International 54 (2013) 255-261.

[29] A.E. Duyvejonck, B. Lagrain, B. Pareyt, C.M. Courtin, J.A. Delcour, Relative contribution of wheat flour constituents to Solvent Retention Capacity profiles of European wheats, Journal of Cereal Science 53 (2011) 312-318.

[30] C.S. Gaines, Report of the AACC committee on soft wheat flour. Method 56-11, Solvent Retention Capacity Profile, AACC committee (2000).

[31] P.V.A. Bergo, R.A. Carvalho, P.J.A. Sobral, R.M.C. dos Santos, F.B.R. da Silva, J.M. Prison, J. Solorza-Feria, A.M.Q.B. Habitante, Physical properties of edible films based on cassava starch as affected by the plasticizer concentration, Packaging Technology and Science 21 (2008) 8589. 
[32] Y.P. Chang, A. Abd Karim, C.C. Seow, Interactive plasticizing-antiplasticizing effects of water and glycerol on the tensile properties of tapioca starch films, Food Hydrocolloids 20 (2006) 1-8.

[33] S. Chillo, S. Flores, M. Mastromatteo, A. Conte, L. Gerschenson, M.A. Del Nobile, Influence of glycerol and chitosan on tapioca starch-based edible film properties, Journal of Food Engineering 88 (2008) 159-168.

[34] M.C. Galdeano, S. Mali, M.V.E. Grossmann, F. Yamashita, M.A. García, Effects of plasticizers on the properties of oat starch films, Materials Science and Engineering C 29 (2009) 532-538.

[35] C.M.O. Müller, F. Yamashita, J.B. Laurindo, Evaluation of the effects of glycerol and sorbitol concentration and water activity on the water barrier properties of cassava starch films through a solubility approach, Carbohydrate Polymers 72 (2008) 82-87.

[36] D. Muscat, B. Adhikari, R. Adhikari, D.S. Chaudhary, Comparative study of film forming behaviour of low and high amylose starches using glycerol and xylitol as plasticizers, Journal of Food Engineering 109 (2012) 189-201.

[37] X. Qiao, Z. Tang, K. Sun, Plasticization of corn starch by polyol mixtures, Carbohydrate Polymers 83 (2011) 659-664.

[38] F.J. Rodriguez-Gonzalez, B.A. Ramsay, B.D. Favis, Rheological and thermal properties of thermoplastic starch with high glycerol content, Carbohydrate Polymers 58 (2004) 139-147.

[39] R. Sothornvit, J.M. Krochta, 23 - Plasticizers in edible films and coatings, en: J.H. Han (Ed.) Innovations in Food Packaging, Academic Press, London, UK, 2005, pp. 403-433.

[40] M.A. García, M.N. Martino, N.E. Zaritzky, Microstructural Characterization of Plasticized Starch-Based Films, Starch - Stärke 52 (2000) 118-124.

[41] B. Bird, W. Stewart, E. Lightfoot, Transport Phenomena, Revised 2nd Edition, John Wiley \& Sons, Inc., 2006.

[42] F. Irgens, Rheology and Non-Newtonian Fluids, 1st ed., Springer International Publishing, Cham, Switzerland, 2014.

[43] J.F. Steffe, Rheological Methods in Food Process Engineering, Freeman Press, East Lansing, USA, 1996.

[44] American Society for Testing and Materials (ASTM), Standard Test Methods for Water Vapor Transmission of Materials. ASTM E96/E96M, Annual Book of ASTM. Philadelphia, PA. (1996).

[45] L. Castillo, O. Lopez, C. Lopez, N. Zaritzky, M.A. Garcia, S. Barbosa, M. Villar, Thermoplastic starch films reinforced with talc nanoparticles, Carbohydrate Polymers 95 (2013) 664-674.

[46] American Society for Testing and Materials (ASTM), Standard Test Method for Haze and Luminous Transmittance of Transparent Plastics. ASTM D1003-00 Annual Book of ASTM. Philadelphia, PA. (2000).

[47] American Society for Testing and Materials (ASTM), Standard method for tensile properties of thin plastic sheeting. ASTM D882-00, ASTM Standards on Disc. ASTM, Philadelphia. 8 (2001) 9.

[48] C.I.G.L. Sarantópoulos, L.M. de Oliveira, M. Padula, L. Coltro, R.M. Vercelino Alves, E.E. Corrêa Garcia, Poropiedades Mecânicas, en: P.R. Citrângulo (Ed.) Embalagens Plásticas 
Flexíveis: Principais Polímeros e Avaliação de Propiedades, Centro de Tecnologia de Embalagem, Campinas, SP, Brasil, 2002, pp. 137-175.

[49] M. Mancini, M. Moresi, R. Rancini, Mechanical properties of alginate gels: empirical characterisation, Journal of Food Engineering 39 (1999) 369-378.

[50] J.A. Di Rienzo, F. Casanoves, M.G. Balzarini, L. Gonzalez, M. Tablada, C.W. Robledo, InfoStat, (2011).

[51] O.V. López, Desarrollo, caracterización y aplicación de envases biodegradables a partir de almidón, Universidad Nacional de La Plata, (2011).

[52] M.C. Doporto, Aprovechamiento integral de raíces de ahipa (Pachyrhizus ahipa) y sus productos derivados con fines alimentarios, Universidad Nacional de La Plata, (2014).

[53] M.C. Doporto, C. Dini, A. Mugridge, S.Z. Viña, M.A. García, Physicochemical, thermal and sorption properties of nutritionally differentiated flours and starches, Journal of Food Engineering 113 (2012) 569-576.

[54] L. Taiz, E. Zeiger, Cell Walls: Structure, Biogenesis, and Expansion, en: Plant Physiology, Sinauer Associates, Sunderland, Massachusetts, United States, 2002, pp. 313-338.

[55] M. George, M. Chae, D.C. Bressler, Composite materials with bast fibres: Structural, technical, and environmental properties, Progress in Materials Science 83 (2016) 1-23.

[56] M. Elleuch, D. Bedigian, O. Roiseux, S. Besbes, C. Blecker, H. Attia, Dietary fibre and fibrerich by-products of food processing: Characterisation, technological functionality and commercial applications: A review, Food Chemistry 124 (2011) 411-421.

[57] J.H. Han, A. Gennadios, Chapter 15 - Edible films and coatings: A review, en: J.H. Han (Ed.) Innovations in Food Packaging, Academic Press, London, 2005, pp. 239-262.

[58] X. Zhang, Q. Tong, W. Zhu, F. Ren, Pasting, rheological properties and gelatinization kinetics of tapioca starch with sucrose or glucose, Journal of Food Engineering 114 (2013) 255261.

[59] J. Perdomo, A. Cova, A.J. Sandoval, L. García, E. Laredo, A.J. Müller, Glass transition temperatures and water sorption isotherms of cassava starch, Carbohydrate Polymers 76 (2009) 305-313.

[60] F. Xie, E. Pollet, P.J. Halley, L. Avérous, Starch-based nano-biocomposites, Progress in Polymer Science 38 (2013) 1590-1628.

[61] A.U. Buranov, G. Mazza, Lignin in straw of herbaceous crops, Industrial Crops and Products 28 (2008) 237-259.

[62] O.V. López, M.A. García, N.E. Zaritzky, Film forming capacity of chemically modified corn starches, Carbohydrate Polymers 73 (2008) 573-581.

[63] P.S. Garcia, M.V.E. Grossmann, M.A. Shirai, M.M. Lazaretti, F. Yamashita, C.M.O. Müller, S. Mali, Improving action of citric acid as compatibiliser in starch/polyester blown films, Industrial Crops and Products 52 (2014) 305-312.

[64] S. Aila-Suarez, H.M. Palma-Rodriguez, A.I. Rodriguez-Hernandez, J.P. Hernandez-Uribe, L.A. Bello-Perez, A. Vargas-Torres, Characterization of films made with chayote tuber and potato starches blending with cellulose nanoparticles, Carbohydrate Polymers 98 (2013) 102107. 
[65] S.I. Park, K.S. Marsh, P. Dawson, Application of chitosan-incorporated LDPE film to sliced fresh red meats for shelf life extension, Meat Science 85 (2010) 493-499.

[66] L. Averous, N. Boquillon, Biocomposites based on plasticized starch: thermal and mechanical behaviours, Carbohydrate Polymers 56 (2004) 111-122.

[67] H. Kargarzadeh, N. Johar, I. Ahmad, Starch biocomposite film reinforced by multiscale rice husk fiber, Composites Science and Technology 151 (2017) 147-155. 


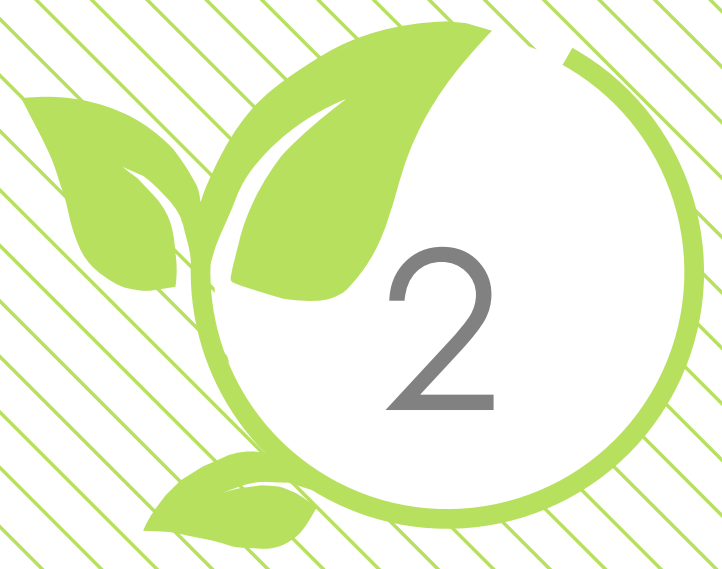

\section{Películas de almidón de mandioca reforzadas con bagazo de mandioca:}




\section{INTRODUCCIÓN}

En los últimos años, el uso de fibras naturales como refuerzos en polímeros y compuestos ha atraído mucha atención [6]. A pesar de su potencial como agentes de refuerzo, la incompatibilidad de las fibras naturales con matrices de polímeros hidrófobas, su tendencia a formar agregados durante el procesamiento, su pobre resistencia a la humedad, menor durabilidad, estabilidad térmica y estructural limitada, así como las dificultades para adaptar su incorporación en los procesos de fabricación convencionales, constituyen desafíos significativos para su implementación industrial [7-9]. Para optimizar las características de los materiales compuestos obtenidos es preciso tener en cuenta el tamaño del relleno empleado. El tamaño de partícula, así como la naturaleza química y las características superficiales del refuerzo afectan las interacciones entre el refuerzo y la matriz, lo cual repercute directamente sobre las propiedades de los materiales obtenidos [13].

Asimismo, resulta de particular interés el estudio de la biodegradabilidad de los materiales desarrollados, ya que si bien se asumen como materiales biodegradables, las investigaciones al respecto son aún incipientes. Como se mencionó anteriormente, los materiales biodegradables son aquellos capaces de ser degradados en ambientes naturales. Representan una nueva generación de materiales capaces de reducir significativamente el impacto ambiental en términos de consumo de energía y generación de residuos después de su utilización. Los materiales biodegradables se clasifican en función de su mecanismo de degradación:

Biodegradables: son aquellos materiales capaces de descomponerse en dióxido de carbono, metano, agua, componentes inorgánicos y biomasa, mediante la acción enzimática de microorganismos, que puede ser medida por tests estandarizados en un período específico de tiempo, en condiciones normalizadas de depósito. Las velocidades de biodegradación dependen enormemente del espesor y geometría de los artículos fabricados. Las 
velocidades altas de degradación se obtienen para films de bajo espesor, mientras que los artículos más gruesos: platos, bandejas, etc. pueden necesitar tiempos elevados para degradarse biológicamente.

Compostables: son aquellos que pueden ser biodegradados y desintegrados en un sistema de compostaje, el que debe cumplir determinados criterios de calidad tales como bajo contenido de metales pesados, ecotoxicidad y la no-generación de residuos visibles.

Hidrobiodegradables/Fotobiodegradables: son aquellos polímeros degradados por un proceso de dos etapas, que supone una etapa inicial de hidrólisis o fotodegradación, respectivamente, seguida por una segunda etapa que involucra una biodegradación.

Bioaerodegradables: son aquellos polímeros capaces de ser degradados sin necesidad de la acción de microorganismos, por lo menos inicialmente. Este proceso se conoce también como desintegración abiótica e incluye procesos parciales tales como disolución en agua y envejecimiento por luz o calor.

Los polímeros biodegradables se clasifican además en cuatro categorías principales basándose en su origen y producción:

Polímeros directamente extraídos de fuentes naturales: son polímeros naturales, fácilmente disponibles, extraídos de animales o vegetales. Algunos ejemplos son los polisacáridos (almidón, celulosa, quitosano, etc.) y las proteínas (caseína, gluten, etc.).

Polímeros producidos por síntesis química a partir de monómeros biológicos renovables: el mejor ejemplo es el ácido poliláctico (PLA), un poliéster obtenido a partir de monómeros de ácido láctico. 
Polímeros producidos por microorganismos o bacterias modificadas genéticamente: los principales polímeros de este grupo son los polihidroxialcanoatos (PHAs).

Polímeros sintéticos a partir de derivados del petróleo: el ejemplo más claro es la policaprolactona (PCL).

Otros polímeros degradables: plásticos fotobiodegradables, PVOH (polivinil alcohol), EVOH (etilvinil alcohol).

\section{OBJETIVOS}

- Analizar el efecto del tamaño de partícula de la carga sobre las propiedades de las películas de almidón de mandioca reforzadas con bagazo de la misma raíz.

- Evaluar la biodegradabilidad de los materiales obtenidos a base de almidón de mandioca reforzadas con bagazo.

\section{METODOLOGÍA Y TÉCNICAS EMPLEADAS}

\subsection{Materiales}

Las raíces de mandioca (Manihot esculenta) fueron proporcionadas por la Estación Experimental Montecarlo del INTA (Misiones, Argentina). El almidón y el bagazo se obtuvieron mediante el método explicado en el capítulo anterior (sección 3.1). El residuo fibroso se trituró y tamizó, separándolo en diferentes fracciones de tamaño de partícula: F: $<500 \mu \mathrm{m}$; G: $500-250 \mu \mathrm{m} ; \mathrm{M}: 250-53 \mu \mathrm{m}$; y P: $<53 \mu \mathrm{m}$. El bagazo de mandioca se caracterizó como se describió detalladamente en la sección 3.2 del capítulo I. 


\subsection{Preparación de películas}

Las suspensiones acuosas de almidón al $3 \% \mathrm{p} / \mathrm{p}$ con $1,5 \% \mathrm{p} / \mathrm{p}$ de diferentes fracciones de tamaño de la carga fibrosa, se gelatinizaron a $90{ }^{\circ} \mathrm{C}$ durante $20 \mathrm{~min}$. Se añadió glicerol como plastificante a las suspensiones gelatinizadas $(25 \%$ en relación al contenido de almidón), y las suspensiones se secaron más tarde en placas Petri en una estufa ventilada a $50^{\circ} \mathrm{C}$ durante $4 \mathrm{hs}$. Del mismo modo se prepararon películas control sin fibra para su comparación, unas con el mismo contenido de almidón ( $\left.C_{3}=3 \% \mathrm{p} / \mathrm{p}\right)$ y otras con el mismo contenido de sólidos que las películas reforzadas $\left(C_{4,5}=4,5 \% \mathrm{p} / \mathrm{p}\right)$. Este último control se incluyó con el fin de considerar los efectos del contenido de sólidos totales en las distintas propiedades del material.

\subsection{Caracterización de películas}

\subsubsection{Microscopía electrónica de barrido (SEM)}

La homogeneidad y el aspecto de las películas se examinaron mediante SEM, realizado en un microscopio electrónico FEI QUANTA 200 (Japón), según el procedimiento detallado en la sección 3.5.3 del capítulo I.

3.3.2. Espectrofotometría infrarroja por transformada de Fourier con reflectancia total atenuada (FTIR-ATR)

En general, la espectroscopía de transmisión de infrarrojo con transformada de Fourier (FTIR) se emplea en la caracterización de diferentes compuestos para identificar los grupos funcionales presentes en las muestras. Esta técnica es sensible a la estructura química de los compuestos, puesto que refleja las vibraciones características de los grupos de átomos comprometidos en la misma. El empleo de espectroscopía de transmisión de FTIR de muestras sólidas requiere la preparación de muestras delgadas y no muy absorbentes, por lo que típicamente debe prepararse una pastilla mezclando la muestra molida con $\mathrm{KBr}$ (compuesto transparente a la radiación infrarroja) para poder realizar la determinación. 
La espectrofotometría por FTIR-ATR, por otro lado, trabaja por reflexión en lugar de trasmisión por lo que resulta ideal para estudiar muestras gruesas con una alta absorción, que tienden a saturar el espectro y además no requieren una preparación previa de la muestra. El accesorio de ATR consta de un cristal ópticamente denso dentro del cual el haz de IR es reflejado y permite medir las atenuaciones producidas en el mismo a distintas frecuencias al entrar en contacto con la muestra.

Para este trabajo de investigación, los espectros IR de las películas plastificadas se midieron en un espectrómetro FTIR Nicolet-iS10 (Thermo Scientific, EEUU) con accesorio de reflexión total atenuada (ATR). Los espectros se tomaron en el intervalo de números de onda: $4000-400 \mathrm{~cm}^{-1}$ por acumulación de 64 exploraciones a una resolución de $4 \mathrm{~cm}^{-1}$. Los datos se analizaron utilizando el software Omnic 9 (Thermo Scientific, EEUU). La deconvolución espectral de los datos se realizó utilizando algoritmos de ajuste de curva.

\subsubsection{Capacidad de barrera UV y opacidad}

Los espectros de absorbancia (200 $-700 \mathrm{~nm})$ se registraron utilizando un espectrofotómetro U-1900 (HITACHI, Japón) y las propiedades de barrera óptica de los materiales se evalúo según métodos descriptos en la sección 3.5.5 del capítulo I.

\subsubsection{Permeabilidad al vapor de agua}

La permeabilidad al vapor de agua (WVP) se determinó de acuerdo con el método estándar ASTM F1249-89 descrito en la sección 3.5.4 del capítulo I.

\subsubsection{Propiedades mecánicas}

El comportamiento mecánico de las películas se evaluó mediante ensayos de tracción uniaxial según lo descripto en la sección 3.5.6 del capítulo I. Los resultados reportados corresponden al valor medio de cada propiedad mecánica. 


\subsubsection{Termosellado}

Las películas se termosellaron utilizando una termoselladora (HermePlas, Argentina) de alambre sobre piezas de películas de $8,7 \mathrm{~cm}$ de diámetro. En esta técnica, las mordazas se calientan a la temperatura de fusión por un breve impulso eléctrico potente. Antes de abrir las mordazas se esperó unos breves instantes para permitir que el cierre se enfriara, mejorando su fuerza.

El equipo de sellado funciona a $220 \mathrm{~V}$ y consta de un alambre conductor que permite alcanzar una temperatura fija de $154,3 \pm 8,5^{\circ} \mathrm{C}$ que se midió usando un termopar de tipo $\mathrm{K}$ conectado a un termómetro de registro de datos (TES-1307, Taiwan). El tiempo óptimo que permite obtener la mejor calidad de cierre fue determinado. Los tiempos ensayados variaban entre $0,83 \pm 0,05$ y $2,03 \pm 0,05 \mathrm{~s}$.

La resistencia al sellado térmico, que es un indicador de calidad del cierre, se evaluó mediante ensayos de tracción en el texturómetro descripto en la sección 3.5.6 del capítulo I. Se utilizó un sistema de agarre de tensión A/TG usando probetas de $7,6 \mathrm{~cm} \times 2,5 \mathrm{~cm}$ (Figura II.1).
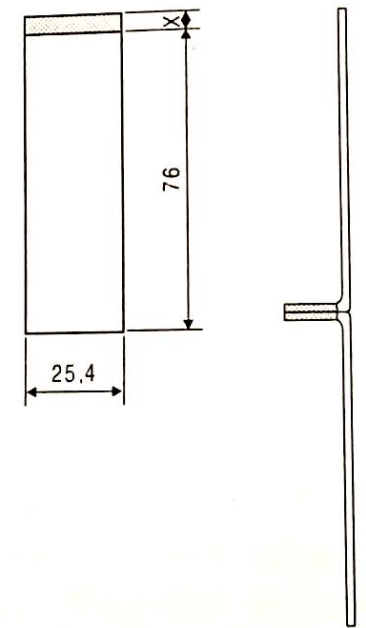

Figura II.1. Representación esquemática de probeta para ensayo de resistencia de ruptura de sello. 
Se registraron los patrones mecánicos de al menos diez replicados por muestra. Se calculó la resistencia a la tracción máxima y media, y los modos de falla se clasificaron según la norma ASTM F 88-00 [15].

\subsubsection{Biodegradación en suelo}

La desintegración bajo condiciones de compostaje en suelo se estudió en tierra fértil como sustrato, enterrando las muestras de $4 \mathrm{~cm}$ de diámetro contenidas en mallas de plástico de entramado fino a una profundidad de $5 \mathrm{~cm}$ desde la superficie a fin de asegurar la degradación aeróbica. Los recipientes $\left(220 \mathrm{~cm}^{3}\right)$ se acondicionaron a una temperatura y una humedad relativa controlada de $24{ }^{\circ} \mathrm{C}$ y $53 \% \mathrm{HR}$, respectivamente, tomadas como condiciones ambientales medias. Como agente de degradación se utilizó la propia microflora presente en la tierra utilizada, la cual presentaba las siguientes características y composición: Humedad: 35-40 \%, Cenizas: 40-45 \%, Relación $\mathrm{C} / \mathrm{N}$ : 7,7, Materia orgánica: $15-20 \%, \mathrm{pH}: 6,2$ y Conductividad eléctrica: 1,1 mS.cm ${ }^{-1}$. De acuerdo a la metodología descripta en la Norma ASTM D5988-03 se adicionó $1 \mathrm{~g}$ de compost cada $25 \mathrm{~g}$ de tierra. Las características fisicoquímicas y la composición del compost utilizado fueron: Humedad: 40-45 \%, Cenizas: $25-30 \%$, Relación C/N: 20-25, Materia orgánica: 25-30\%, pH: 6,0-6,5 y Conductividad eléctrica: $0,5-1,0 \mathrm{mS} \cdot \mathrm{cm}^{-1}$.

En todos los casos los recipientes se regaron diariamente con un rociador con el fin de mantener la humedad del suelo. El estudio de la biodegradación de las muestras se evaluó a través del seguimiento de la pérdida de peso de las muestras a lo largo del período de degradación. Varios autores han reportado que la variación del peso es un buen indicador de la degradabilidad de materiales poliméricos [16-18]. La pérdida de peso (\%) se determinó una vez que las muestras fueron desenterradas y cuidadosamente limpiadas con un cepillo para no dañar su estructura y minimizar los errores asociados a cuantificar masa debida a la presencia de partículas ajenas a la matriz. Se evaluaron distintos tiempos de exposición $(7,14,21,28,35$ y 42 días) para 
hacer un seguimiento del grado de avance de la degradación de los materiales. En todos los casos se realizaron inspecciones visuales de las películas luego de haberlas extraído de los recipientes a los distintos tiempos de ensayo y se tomaron fotografías de las mismas. Para comparar la velocidad de degradación de los materiales estudiados, se determinó el tiempo medio necesario para la degradación del $50 \%$ del material ( $\left.t_{50}\right)$, mediante el ajuste de los resultados obtenidos a la ecuación de Boltzmann de tipo sigmoidea [16]:

$$
D_{t}=\frac{D_{0}-D_{\infty}}{1+e^{\left(\frac{t-t_{50}}{d t}\right)}}+D_{\infty}
$$

Donde $D_{t}$ es el porcentaje de degradación evaluado por diferencia de peso con la condición inicial normalizada, $\mathrm{D}_{0}$ y $\mathrm{D}_{\infty}$ son los porcentajes de degradación iniciales y finales considerados como 0 y $100 \%$ respectivamente, t50 representa el tiempo necesario para la degradación del $50 \%$ de la muestra y dt es un parámetro empírico de ajuste que se relaciona con la velocidad de degradación.

\subsection{Análisis estadístico}

El análisis estadístico de resultados se realizó en forma análoga a lo descripto en la sección 3.6 del capítulo I.

\section{RESULTADOS Y DISCUSIÓN}

\subsection{Caracterización de las fracciones de bagazo de mandioca}

El bagazo de mandioca se fraccionó en función de su tamaño de partícula, presentando cada fracción composiciones diferentes. Cabe aclarar que si bien no se realizó la determinación química centesimal de cada fracción del residuo particulado, la microscopía electrónica de barrido de las mismas muestra las diferencias evidentes entre cada una (Figura II.2). 


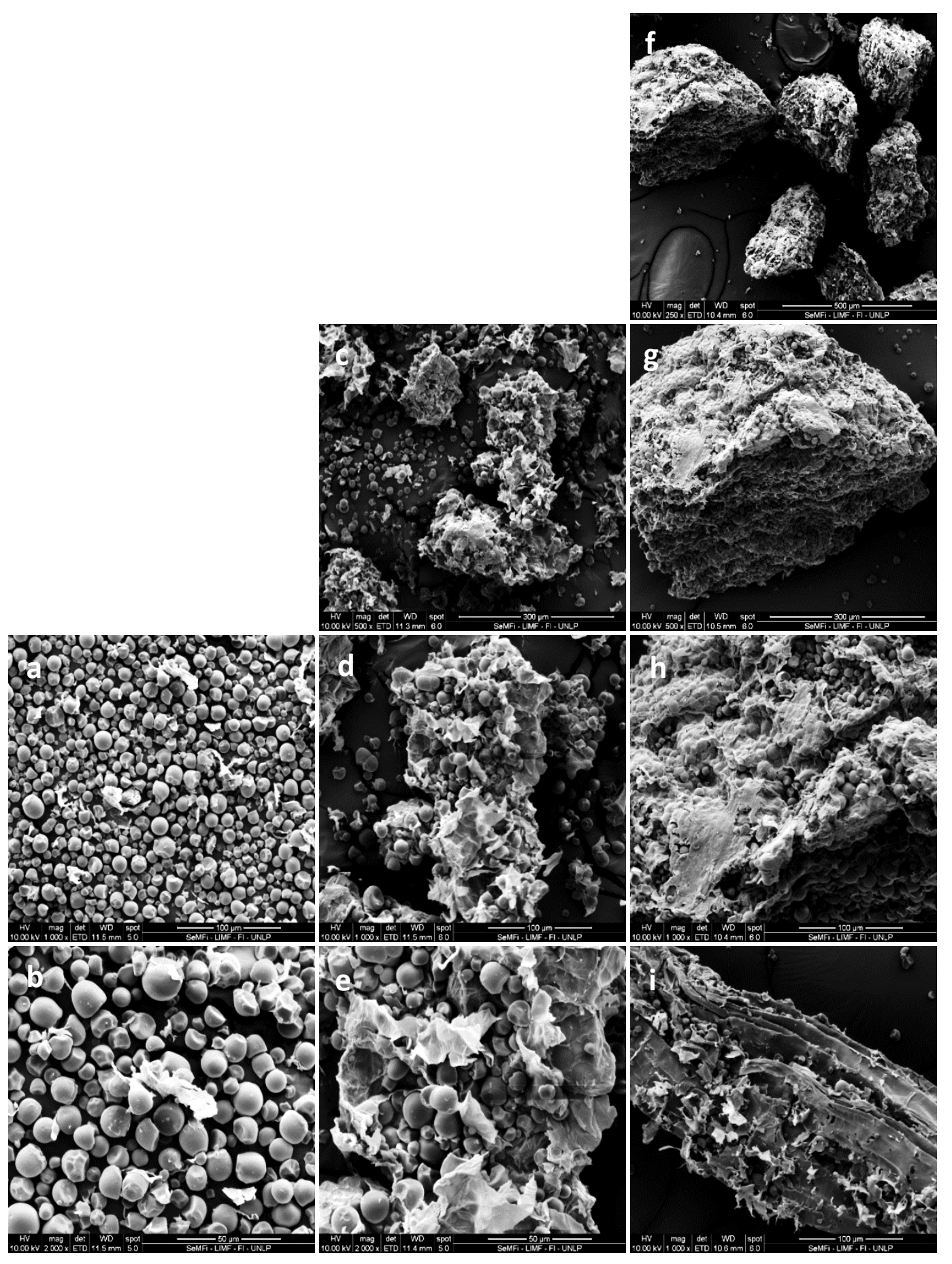

Figura II.2. Micrografía SEM de las distintas fracciones de bagazo de mandioca: fracción P a 1000x (a) y 2000x (b); fracción M a 500x (c), 1000x (d) y detalle a 2000x (e); y fracción G a 250x (f), 500x (g) y detalles a 1000x (h e i). 
En la fracción $\mathrm{P}$, donde se incluyen las partículas de tamaño menor a $53 \mu \mathrm{m}$, se observó un predominio de gránulos de almidón remanentes de la extracción (Figura II.2.a y b). Por otro lado, en la fracción $G$ correspondiente a partículas con tamaño mayor a $250 \mu \mathrm{m}$, prevalecen los restos del tejido vegetal parenquimatoso con gránulos de almidón ocluidos (Figura II.2.f, g, h e i). La fracción intermedia M (con partículas entre 250 y $53 \mu \mathrm{m}$ ) presenta una composición similar a la fracción G, diferenciándose en el tamaño de las fibras (Figura II.2.c). En esta fracción se observa una mayor proporción de almidón residual ocluido entre los restos de tejido celular (Figura II.2.d y e).

Los espectros de infrarrojo demuestran las diferencias composicionales de las distintas fracciones de tamaño de partícula analizadas (Figura II.3). Se ve que las partículas más pequeñas $(P)$ presentan bandas más agudas, indicando una composición más homogénea. Además, esta fracción muestra las bandas características del almidón de mandioca, con pequeñas variaciones en la frecuencia e intensidad de las bandas probablemente debido a la presencia de algún otro compuesto del tejido celular que se encuentre en bajas concentraciones. Se observa entonces una banda ancha a $3300 \mathrm{~cm}^{-1}$ asociada a las interacciones por puente de hidrógeno inter- e intramoleculares entre los grupos $\mathrm{O}-\mathrm{H}$ de los polisacáridos [1-4] y otra entre 2850 y $2930 \mathrm{~cm}^{-1}$ correspondiente a las vibraciones de estiramiento de enlaces $\mathrm{C}-\mathrm{H}$ en los grupos metilo y metileno de los mismos $[1,2,4,5]$. Como se detalla en la Tabla II .1, en la región $1700-1200 \mathrm{~cm}^{-1}$ se observan en el almidón las vibraciones asociadas al agua ligada y el agua "libre" en el material, sin embargo a medida que aumenta el tamaño de partícula de la fracción de residuo se comienzan a evidenciarse contribuciones de bandas propias de los compuestos de la pared celular del tejido parenquimatoso de la raíz, el cual se ha descripto en el capítulo anterior. Por un lado, se observa que los espectros de todas las fracciones de tamaño mayor a $53 \mu \mathrm{m}$, presentan una pequeña banda cercana a $1734 \mathrm{~cm}^{-1}$, la cual presenta mayor intensidad y menores frecuencias para la fracción $\mathrm{M}$ y todas las fracciones que la constituyen (Figura II.3.a). Esta 

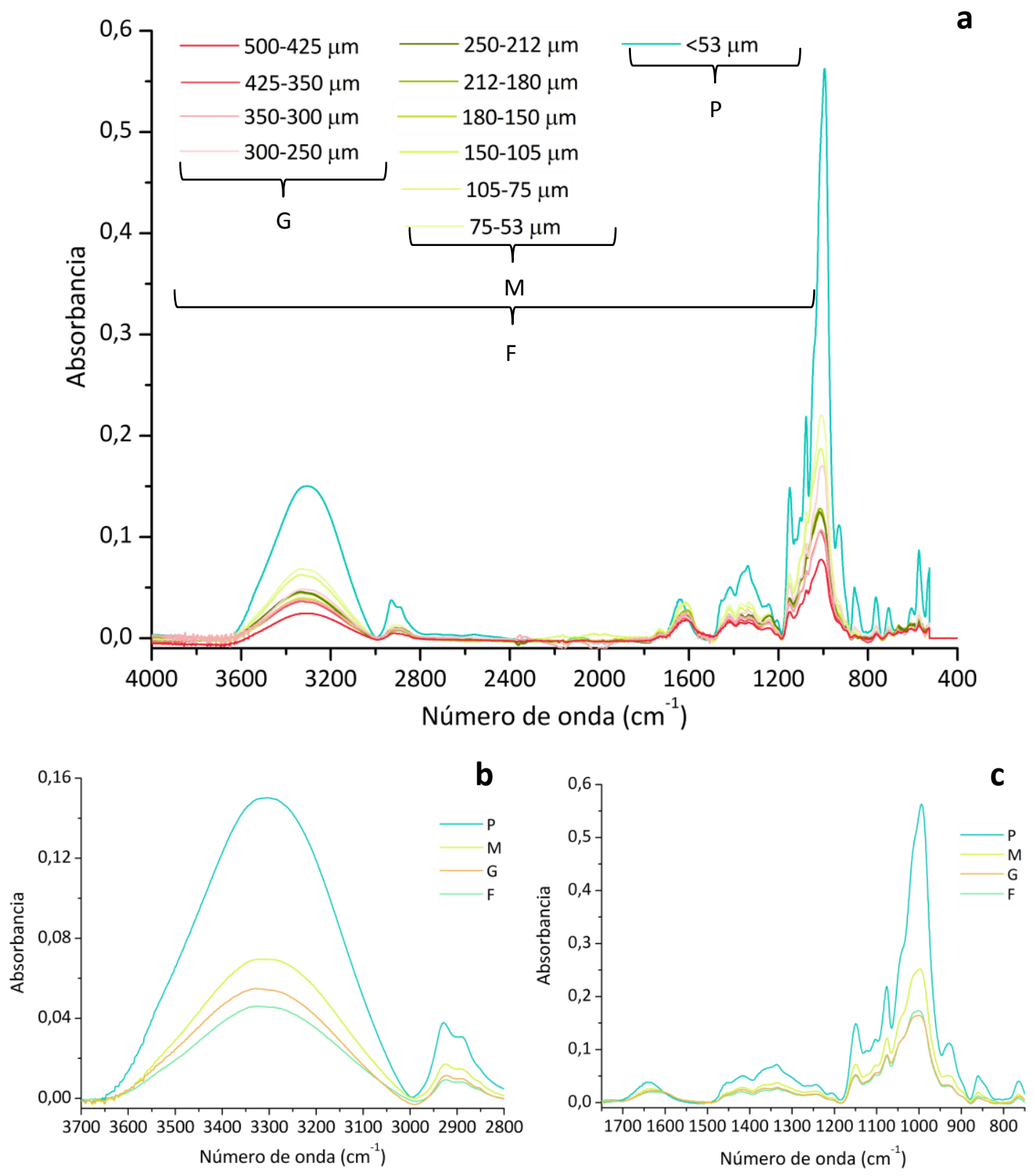

Figura II.3. Espectros FTIR-ATR de distintas fracciones de tamaño de partícula del bagazo molido empleado como relleno: a) FTIR de cada fracción de tamaño de partícula analizado; y fracciones empleadas como relleno (F, G, M y P) b) en la región $3700-2800 \mathrm{~cm}^{-1}$, y c) en la región $1750-750 \mathrm{~cm}^{-1}$. 


\section{Tabla II.1 - Asignación de bandas FTIR de almidón y subproductos de mandioca}

\section{Número de onda}

$\left(\mathrm{cm}^{-1}\right)$

Asignación de bandas

Referencias

3600-3000 Estiramiento O-H debido al contenido de agua y

carbohidratos (almidón, celulosa y lignina)

3610-3580 Estiramiento O-H comprometidos parcialmente en interacciones por puentes- $\mathrm{H}$

$3460 \quad$ Estiramiento $\mathrm{O}-\mathrm{H}$ de agua líquida (enlaces de puente de $\mathrm{H}$ moderados o débiles)

3270 Estiramiento O-H de agua líquida (interacciones de puente de $\mathrm{H}$ fuertes o extremadamente fuertes)

3000-2800 Estiramiento simétrico y asimétrico $\mathrm{C}-\mathrm{H}$

2959 Estiramiento asimétrico $\mathrm{C}-\mathrm{H}$ de grupos $-\mathrm{CH}_{3}$

2920 Estiramiento asimétrico $\mathrm{C}-\mathrm{H}$ de grupos $-\mathrm{CH}_{2}$

2872 Estiramiento simétrico $\mathrm{C}-\mathrm{H}$ de grupos $-\mathrm{CH}_{3}$

2850 Estiramiento simétrico $\mathrm{C}-\mathrm{H}$ de grupos $-\mathrm{CH}$

2930-2920 Enlaces de puente de $\mathrm{H}$ intermoleculares entre grupos fenólicos de la lignina

1750-1200 Plegado $\mathrm{O}-\mathrm{H}$ del agua e interacciones específicas

$1734 \quad \mathrm{C}=\mathrm{O}$ de grupos éster carboxílico en hemicelulosa y lignina

1690-70 O-H con fuerte interacción con agua ligada

$1652 \quad \mathrm{O}-\mathrm{H}$ en conglomerados de moléculas de agua con enlaces de puente de $\mathrm{H}$ de intensidad moderada y contribuciones de grupos carboxílicos del almidón

$1620 \quad \mathrm{C}=\mathrm{O}$ de amida I de proteínas

$1592 \quad \mathrm{O}-\mathrm{H}$ de agua "libre" sin enlaces de puente de $\mathrm{H}$

$1543 \quad \mathrm{NH}_{2}$ deformación de amida Il en proteínas

1598, 1514, Vibración de la estructura aromática base del

1464 y 1416 esqueleto de fenilpropano correspondiente a la lignina

1372 Plegado de $\mathrm{C}-\mathrm{H}$ en celulosa

1337 Vibración en el plano de $\mathrm{O}-\mathrm{H}$ en grupos alcohol

$1324 \quad$ Vibraciones de los grupos siringilo de la lignina

1200-800 Estiramiento -C-O-C y plegado -C-O-H en carbohidratos. Vibraciones de los anillos de piranosa

1164-1139 Vibraciones de los enlaces C-O-C del anillo glucosídico

1080-995 Vibraciones de los enlaces C-O-H del anillo

glucosídico

897 Plegado de $\mathrm{O}-\mathrm{H}$ en enlaces $\beta$-glucosídicos entre unidades de glucosa 
banda se atribuye a los grupos éster acetilo y urónico de las hemicelulosas y pectinas o al enlace éster del grupo carboxílico de los ácidos ferúlico y p-cumárico de la lignina y/o hemicelulosa $[3,11]$. En todas las fracciones se observa un pico ancho alrededor de $1651 \mathrm{~cm}^{-1}$ el cual se asocia, como han mencionado numerosos autores, a los modos de flexión del agua absorbida y a algunas contribuciones de los grupos carboxílicos de las pectinas y otros carbohidratos menores presentes en el bagazo $[4,5]$.

No obstante, a medida que aumenta el tamaño de partícula se observó el crecimiento de un hombro a $1538 \mathrm{~cm}^{-1}$ que se atribuye a la presencia de proteínas en dichas fracciones. Asimismo, para fracciones de tamaño mayor a $212 \mu \mathrm{m}$ aparece un segundo hombro a $1506 \mathrm{~cm}^{-1}$ que se atribuye al crecimiento de las contribuciones a la banda a $1514 \mathrm{~cm}^{-1}$ propio del estiramiento del esqueleto de anillos aromáticos de lignina (Tabla II.1 y Figura II.3). Tanto las fracciones M, G y $F$ como las menores que las componen presentaron bandas características de la celulosa y hemicelulosa con ciertos corrimientos debido a la superposición de bandas a: 1367, 927 y $897 \mathrm{~cm}^{-1}$, que se correlacionan con los picos 1372, 910 y $897 \mathrm{~cm}^{-1}$ explicados en la Tabla II.1.

4.2. Efecto del tamaño de partícula de refuerzo en los materiales compuestos

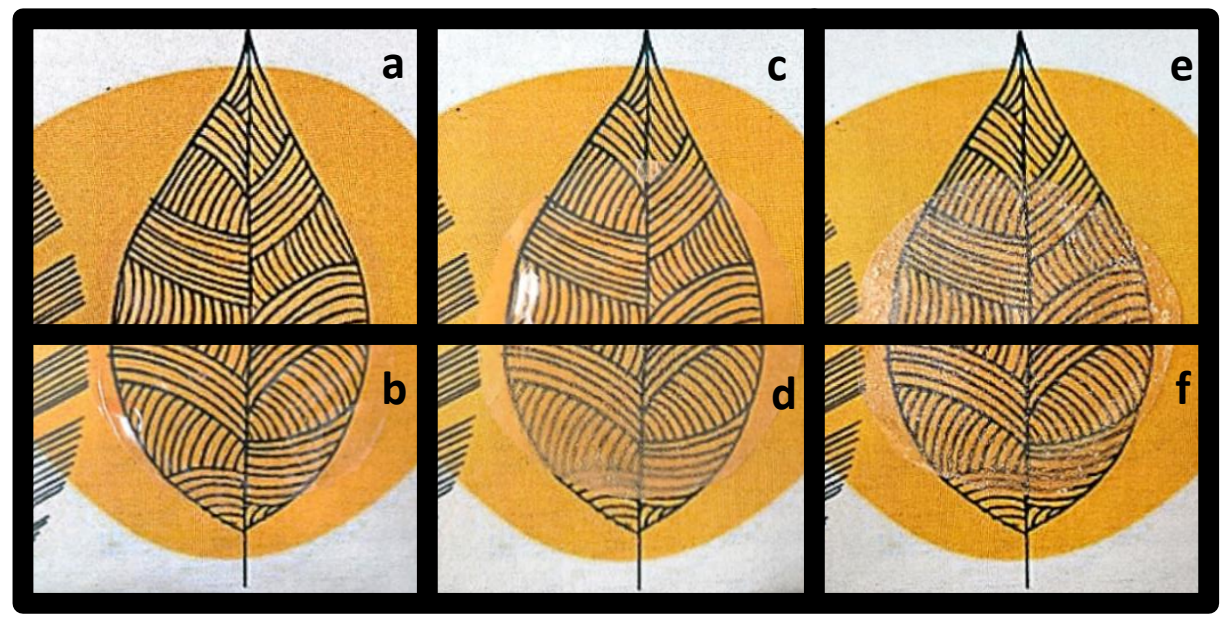

Figura II.4. Fotografías de películas de almidón de mandioca reforzadas con bagazo particulado de distintos tamaños: a) $C_{3}$; b) $C_{4,5}$; c) P; d) M; e) G; y f) F. 
Independientemente de su tamaño la matriz polimérica fue capaz de incorporar las partículas de relleno, dando lugar a películas continuas, que visualmente se diferenciaban fácilmente por su coloración y transparencia (Figura II.4). Las muestras control resultaron ser incoloras y translúcidas (Figura II.4.a y b), mientras que las películas reforzadas eran más opacas cuanto mayor era el tamaño del relleno empleado (Figura II.4.c, d, e y f).

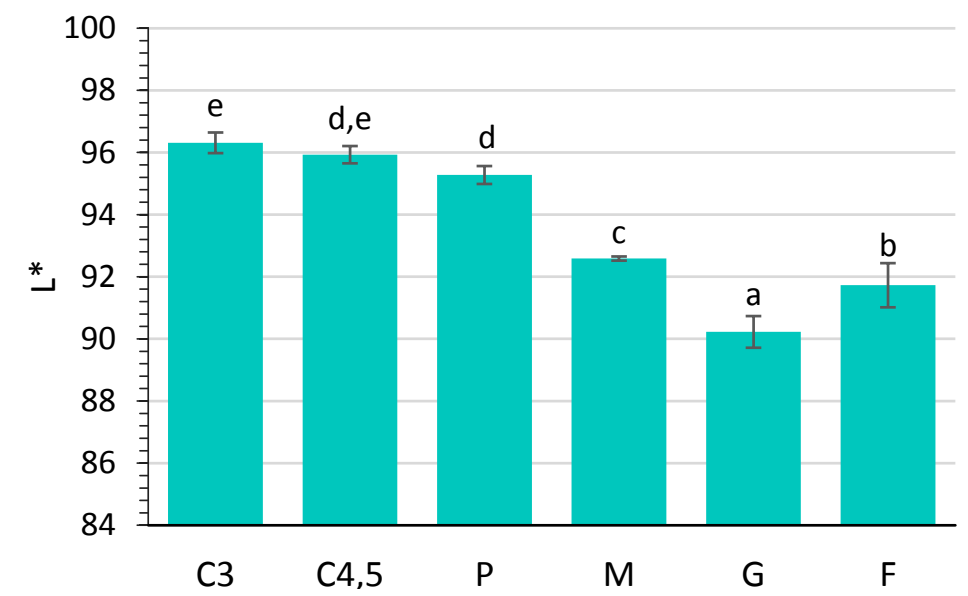

a

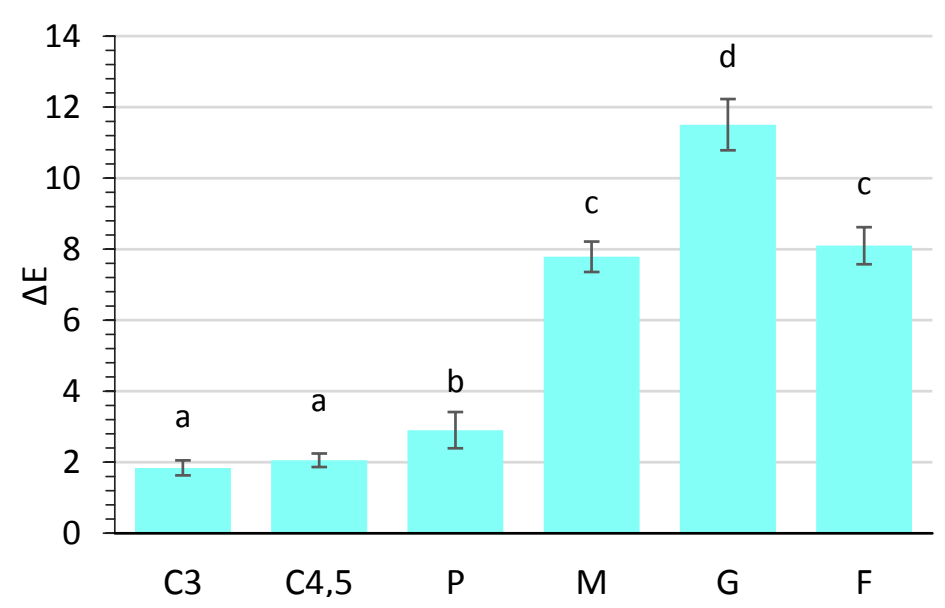

b

Figura II.5. Parámetros de color de películas de almidón con distinto tamaño de partícula de relleno: a) luminosidad $\left(L^{*}\right)$ y b) diferencia de color respecto al patrón $(\Delta E)$.

Las observaciones visuales se correlacionan con las determinaciones objetivas de parámetros de color: $\mathrm{L}^{*}, \mathrm{C}^{*}, \mathrm{~h}^{\circ}$ y $\Delta \mathrm{E}$. La luminosidad del material disminuyó con el agregado de partículas de mayor tamaño, no observándose diferencias significativas 
$(p>0,05)$ entre los controles y la películas reforzadas con P (Figura II.5.a). Las mayores diferencias de color se evidenciaron para las películas con G, F y M, respectivamente (Figura II.5.b). A este parámetro contribuyen además de las diferencias de luminosidad, las variaciones observadas en los parámetros de cromaticidad de las muestras (tono y saturación).

Las observaciones al SEM mostraron que en todos los casos la carga estaba completamente cubierta por la matriz de almidón (Figura II.6). No obstante, en los materiales que contenían partículas de bagazo mayores ( $G$ y F) las imágenes revelan la heterogeneidad en el espesor de las muestras, dando lugar a superficies más rugosas. De este modo, el espesor de los materiales aumentó con el tamaño de partícula del relleno: $92,7 \pm 8,8 ; 130,5 \pm 5,1 ; 124,5 \pm 7,7 ; 133,6 \pm 7,8 ; 184,2 \pm 13,6 ;$ y $177,5 \pm 20,1 \mu \mathrm{m}$ para las muestras $C_{3}, C_{4,5}, P, M, G$ y $F$, respectivamente.

No obstante, es de destacar que independientemente de la composición no se observaron poros ni grietas en la superficie de los materiales, lo cual afectaría drásticamente las características mecánicas y de barrera de los mismos.

Asimismo, los espectros de FTIR-ATR no mostraron diferencias sustanciales (Figura II.7), observándose los picos característicos del almidón como se detallan en la Tabla II.1. Así como las fracciones de bagazo, los espectros de las películas mostraron una banda ancha en la región 3500 - $3000 \mathrm{~cm}^{-1}$, correspondiente a las interacciones por puente de hidrógeno tanto entre los componentes de la matriz como con el agua ligada a la misma, evidenciando su compatibilidad. Desde ya los espectros de las películas presentaron una mayor área e intensidad de esta banda, debido al mayor número de interacciones involucradas en la formación de la matriz polimérica. Un análisis exhaustivo de los resultados obtenidos por esta técnica se expondrá en los capítulos subsiguientes. Las principales diferencias se observan en la región de la huella digital de los carbohidratos, en la cual se evidencian las vibraciones de los enlaces C-O-C y $\mathrm{C}-\mathrm{O}-\mathrm{H}$ del anillo glucosídico. En esta zona, las diferencias entre las 

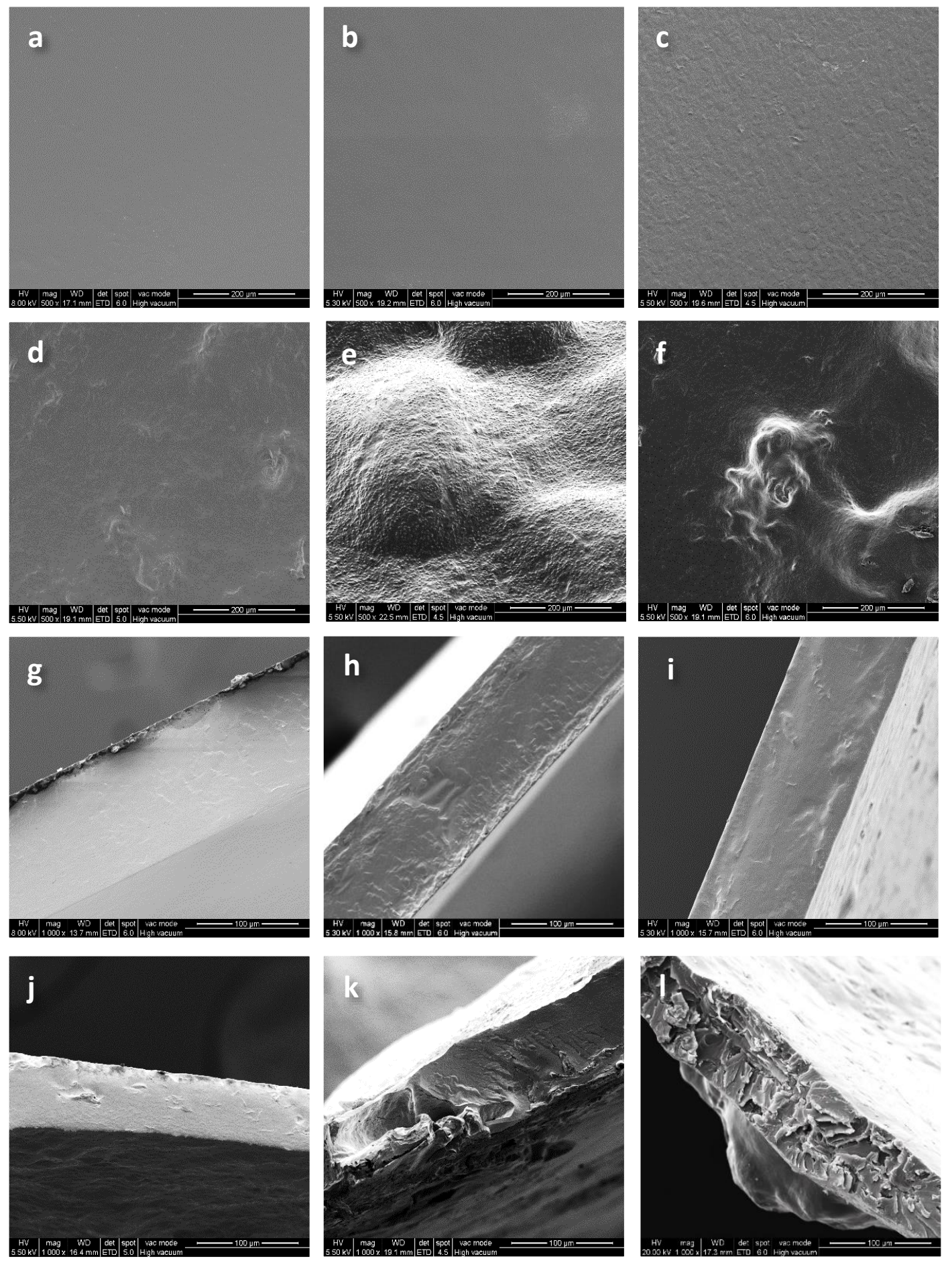

Figura II.6. Micrografías SEM de películas de almidón de mandioca reforzadas con fracciones de bagazo de distinto tamaño de partícula: imágenes de la superficie a 500x de muestras $C_{3}(a), C_{4,5}(b), P(c), M(d), G(e), y ~ F(f)$; y corte transversal $1000 x$ de muestras $C_{3}(g), C_{4,5}(h), P(i), M(j), G(k)$ y $F(I)$. 
muestras control y reforzadas (principalmente las fracciones $F, M$ y $G$ ) se atribuye a la presencia de los diferentes componentes de la pared celular: celulosa, hemicelulosa/arabinoxilanos, xiloglucanos, pectinas y lignina, entre otros. En esta región además es posible estimar la relación de fracción amorfa y cristalina de las películas a base de almidón, ya que algunos autores han indicado que existe una relación entre las intensidades de absorbancia relativas de los picos a 995 y $1047 \mathrm{~cm}^{-1}$ respecto al pico a $1017 \mathrm{~cm}^{-1}$ y el grado de cristalinidad en muestras de almidón [19-21]. En la Figura II.7 y la Tabla II.2 se observa que estas relaciones resultaron mayores para las muestras $P, G$ y $F$.

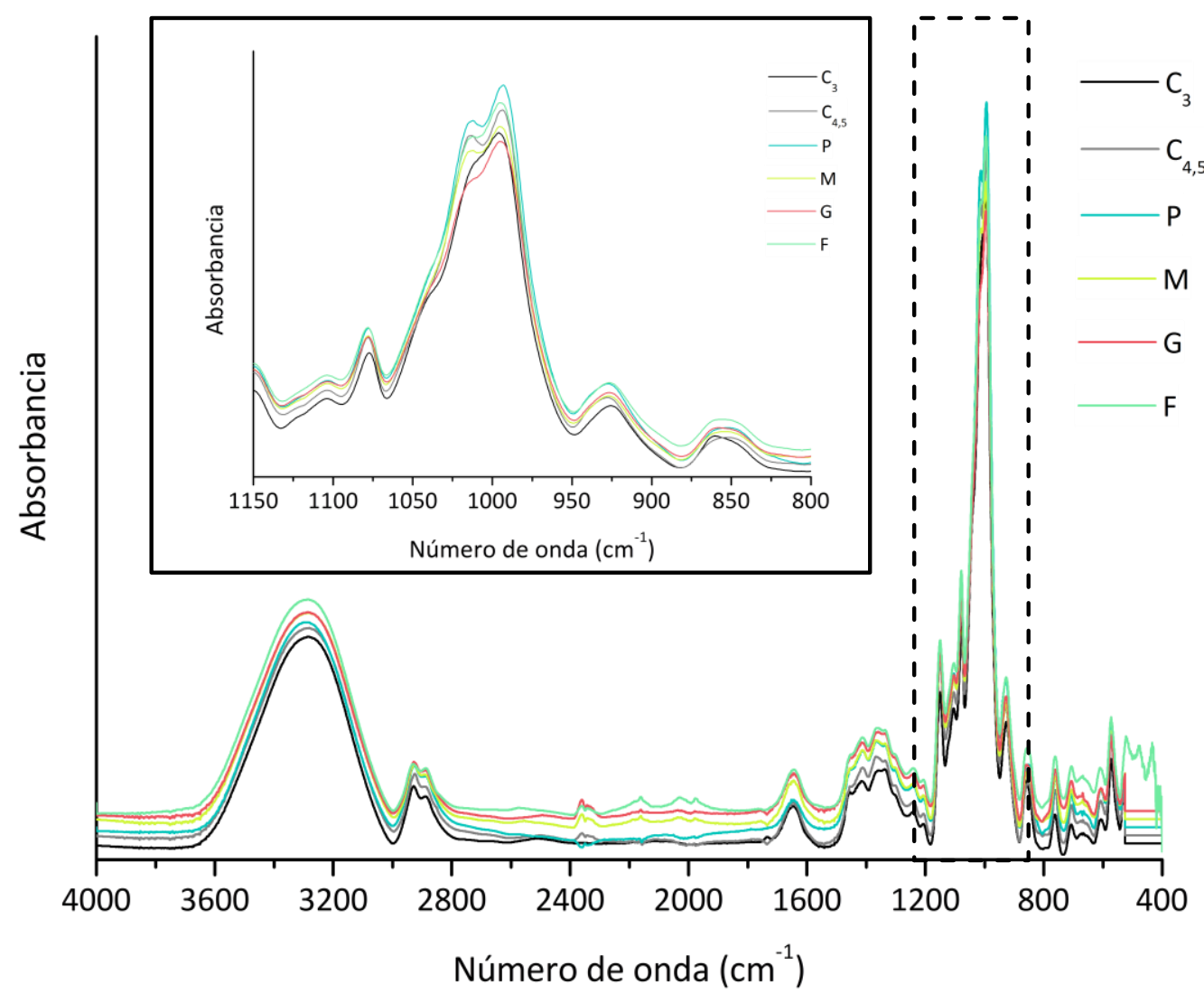

Figura II.7. Espectros FTIR-ATR de películas de almidón control $\left(C_{3}\right.$ y $\left.C_{4,5}\right)$ y reforzadas con distinto tamaño de carga $\left(P, M, G\right.$ y F), con cuadro de detalle de la región $800-1150 \mathrm{~cm}^{-1}$. 
Tabla II.2- Relación de picos a 995, 1047 respecto a $1017 \mathrm{~cm}^{-1}, y$ humedad de películas de almidón control $\left(C_{3}\right.$ y $\left.C_{4,5}\right)$ y reforzadas con distinto tamaño de carga $(P, M, G$ y $F)$

\begin{tabular}{cccc} 
FORMULACIÓN & $\mathbf{R}_{\mathbf{9 9 5} / 1017}$ & $\mathbf{R}_{\mathbf{1 0 4 7} / \mathbf{1 0 1 7}}$ & Humedad (\%) \\
\hline$C_{3}$ & $1,08 \pm 0,05^{\mathrm{a}}$ & $0,50 \pm 0,01^{\mathrm{a}}$ & $20,29 \pm 1,99^{\mathrm{b}}$ \\
$\mathrm{C}_{4,5}$ & $1,20 \pm 0,06^{\mathrm{bc}}$ & $0,50 \pm 0,01^{\mathrm{a}}$ & $12,53 \pm 1,68^{\mathrm{a}}$ \\
P & $1,26 \pm 0,03^{\mathrm{c}}$ & $0,51 \pm 0,02^{\mathrm{a}}$ & $12,64 \pm 0,19^{\mathrm{a}}$ \\
M & $1,10 \pm 0,06^{\mathrm{a}}$ & $0,49 \pm 0,02^{\mathrm{a}}$ & $13,65 \pm 1,83^{\mathrm{a}}$ \\
G & $1,17 \pm 0,04^{\mathrm{b}}$ & $0,62 \pm 0,06^{\mathrm{b}}$ & $11,16 \pm 0,06^{\mathrm{a}}$ \\
F & $1,16 \pm 0,01^{\mathrm{ab}}$ & $0,47 \pm 0,01^{\mathrm{a}}$ & $13,44 \pm 0,76^{\mathrm{a}}$ \\
\hline
\end{tabular}

Nota: Los valores reportados corresponden a la media \pm desviación estándar.

Letras diferentes dentro de la misma columna indican diferencias significativas $(p<0,05)$.

Sin embargo, estos resultados deben tomarse con cautela puesto que a las intensidades de los picos contribuyen no solo el almidón, sino también los componentes del tejido parenquimatoso.

En relación a las propiedades ópticas, los espectros UV-visible mostraron un aumento en la absorbancia de los materiales compuestos con la incorporación de la carga, siendo este incremento mayor para las películas G y $\mathrm{F}$ (Figura II.8).

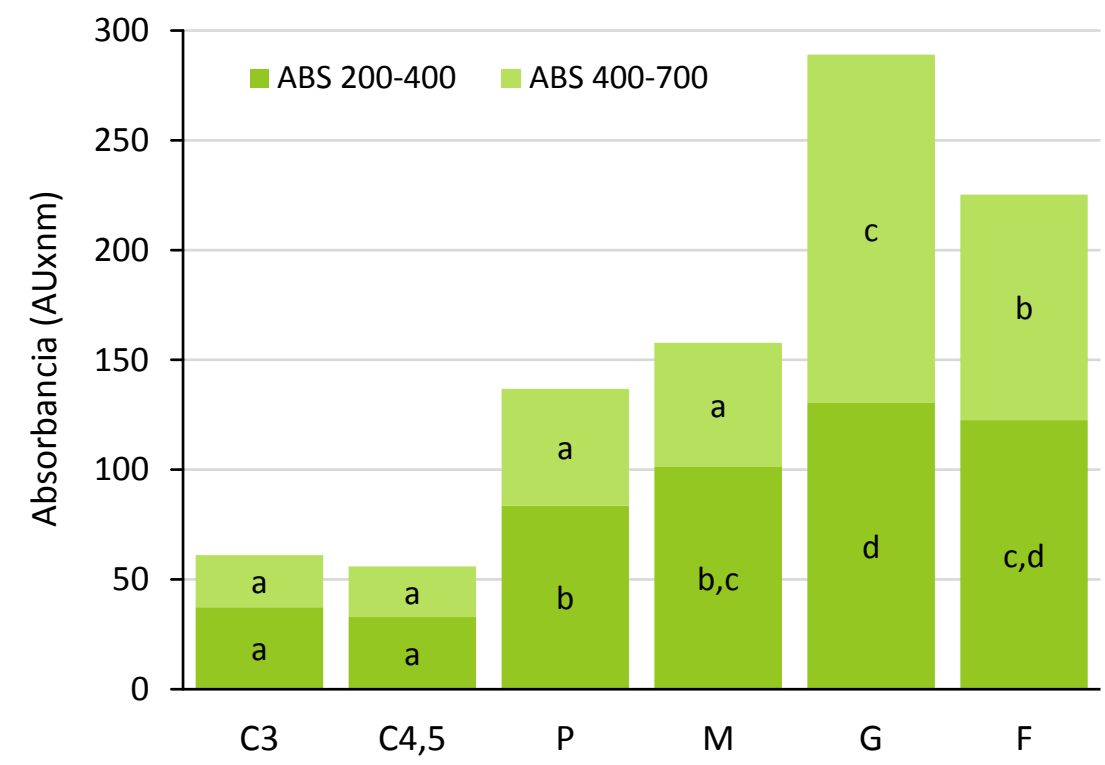

Figura II.8. Propiedades ópticas de las películas de almidón de mandioca reforzadas con fracciones de bagazo de distintos tamaños de partícula: capacidad de barrera a la radiación UV (ABS 200-400) y visible (ABS 400-700). 
Presumiblemente, dicho efecto resulta de una obstrucción física de la luz por las partículas la que está relacionada directamente con su tamaño. Además, el aumento de la capacidad de barrera UV de las películas compuestas podría atribuirse a la presencia de compuestos fenólicos propios de la lignina presente en los restos del tejido parenquimatoso predominante en las fracciones G, F y M del bagazo.

En comparación, la WVP de las películas fue significativamente $(p<0,05)$ mayor para las películas de gran tamaño de partículas (G), debido a los defectos inducidos en la matriz de almidón. De la misma manera, estos defectos que constituyen puntos de tensión en la material, podrían ser responsables de la disminución de la resistencia a la tracción y del módulo de elasticidad del mismo (Tabla II.3). La permeabilidad disminuye con el tamaño de partícula del relleno $(\mathrm{G}>\mathrm{M}>\mathrm{P}>\mathrm{C})$, resultando intermedio el comportamiento de las películas que contienen todas las fracciones del bagazo (F). El control con igual contenido de sólidos que los materiales compuestos $\left(C_{4,5}\right)$ presenta una WVP ligeramente mayor que el control $\mathrm{C}_{3}$.

\begin{tabular}{ccccc}
\hline Tabla II.3- Propiedades de las películas reforzadas con almidón de mandioca \\
FORMULACIÓN & $\begin{array}{c}\text { WVPx10 } \\
\text { (g/ } \mathbf{~ m ~ s ~ P a ) ~}\end{array}$ & $\begin{array}{c}\boldsymbol{\sigma}_{\max } \\
(\mathbf{M P a})\end{array}$ & $\begin{array}{c}\boldsymbol{\varepsilon}_{\max } \\
\mathbf{( \% )}\end{array}$ & $\begin{array}{c}\mathbf{E}_{\mathbf{c}} \\
(\mathbf{M P a})\end{array}$ \\
\hline $\mathrm{C}_{3}$ & $10,66 \pm 2,38^{\mathrm{a}}$ & $1,25 \pm 0,13^{\mathrm{a}}$ & $35,77 \pm 10,66^{\mathrm{c}}$ & $505 \pm 173^{\mathrm{ab}}$ \\
$\mathrm{C}_{4,5}$ & $15,39 \pm 2,04^{\mathrm{bc}}$ & $11,33 \pm 3,28 \mathrm{c}$ & $11,34 \pm 5,36^{\mathrm{ab}}$ & $757 \pm 38^{\mathrm{abc}}$ \\
$\mathrm{P}$ & $13,36 \pm 0,50^{\mathrm{ab}}$ & $16,25 \pm 2,38^{\mathrm{de}}$ & $7,53 \pm 1,16^{\mathrm{ab}}$ & $3028 \pm 701^{\mathrm{d}}$ \\
M & $17,93 \pm 2,30^{\mathrm{c}}$ & $20,15 \pm 5,33^{\mathrm{e}}$ & $13,08 \pm 5,35^{\mathrm{b}}$ & $1033 \pm 25^{\mathrm{bc}}$ \\
G & $35,77 \pm 1,49^{\mathrm{d}}$ & $6,68 \pm 1,73^{\mathrm{b}}$ & $5,70 \pm 2,14^{\mathrm{a}}$ & $195 \pm 18^{\mathrm{a}}$ \\
$\mathrm{F}$ & $14,61 \pm 0,72^{\mathrm{ab}}$ & $14,73 \pm 2,12^{\mathrm{d}}$ & $5,81 \pm 1,90^{\mathrm{a}}$ & $1247 \pm 35^{\mathrm{c}}$ \\
\hline
\end{tabular}

Nota: Los valores reportados corresponden a la media \pm desviación estándar. Letras diferentes dentro de la misma columna indican diferencias significativas $(p<0,05)$.

Como se muestra en la Tabla II.3, las películas con partículas F y P, por otro lado, mejoraron la resistencia mecánica del material aunque redujeron su flexibilidad, mientras que las partículas de carga de tamaño medio (M) reforzaron la matriz con un menor efecto sobre la elongación. Aunque las películas control de almidón $\left(C_{3}\right)$ mostraron un elevado porcentaje de elongación a la ruptura debido al efecto 
plastificante, sus propiedades mecánicas son pobres ${ }^{1}$. En general, y como era de esperar, las características mecánicas de las películas $\mathrm{P}$ y del control $\mathrm{C}_{4,5}$ resultaron similares debido al alto contenido de almidón de la fracción P. Esta misma tendencia se observó para las propiedades de barrera al vapor de agua (Tabla II.3).

Todas las películas se termosellaron con éxito por la técnica de impulso. La curva de esfuerzo-deformación típica obtenida para las películas de almidón de mandioca con un $1,5 \% \mathrm{p} / \mathrm{p}$ de bagazo y plastificadas con glicerol al $25 \% \mathrm{p} / \mathrm{p}$, se muestra en la Figura II.9.

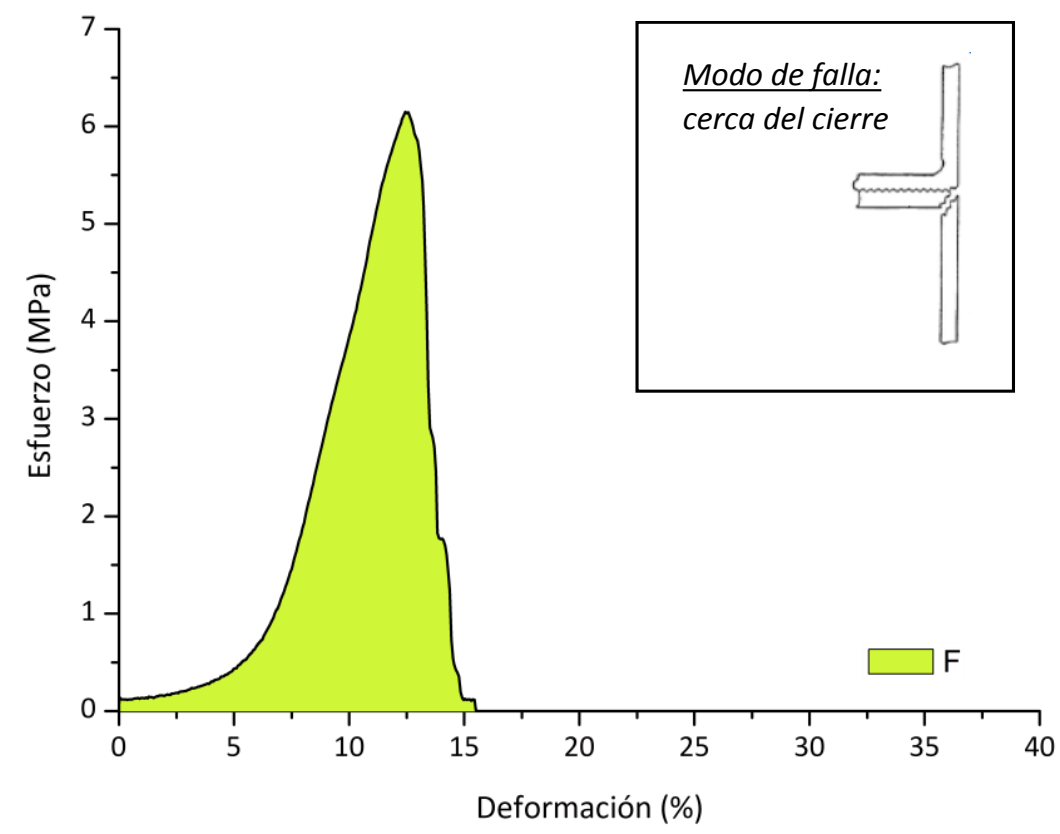

Figura II.9. Curva de esfuerzo-deformación de películas de almidón de mandioca reforzada con $1,5 \% \mathrm{p} / \mathrm{p}$ de bagazo (F) y termoselladas, sometidas a ensayos de tracción; y esquema del modo estándar de falla del cierre.

\footnotetext{
${ }^{1}$ Las diferencias entre los valores de las propiedades mecánicas del control $\left(C_{3}\right)$ y las muestras reforzadas con $1,5 \%$ de bagazo (F), respecto a los reportados para los mismos materiales en el capítulo I (referidos como $0 F G$ y $1,5 \mathrm{FG}$ en ese capítulo), se deben a las variaciones en el almidón extraído a partir de raíces tuberosas de distintos clones de mandioca cultivadas en la Estación Experimental Montecarlo del INTA (Misiones, Argentina). En particular la concentración de amilosa, principal constituyente de la matriz polimérica, puede variar según el clon utilizado entre un 10 y 21,6 \% [22].
} 
De acuerdo con los modos de falla estándar descriptos en la norma ASTM F 88-00 [15], las películas selladas se rompieron típicamente cerca del cierre indicando que la resistencia mecánica del sello es mayor que la del material. Sin embargo, las películas reforzadas presentaron, en general, mayor resistencia al sellado que el control. La Figura II.10 ejemplifica el modo de falla asociado a estos materiales, denominado ruptura cerca del cierre.

En comparación con los materiales sintéticos, las películas reforzadas con fibra exhibían menor resistencia al sellado, ya que los valores obtenidos fueron: 63,0 $\pm 11,6 \mathrm{MPa}$ y 4,0 $\pm 0,6 \mathrm{MPa}$, para polietileno de baja densidad (LDPE) y para las películas de almidón de mandioca reforzadas, respectivamente.

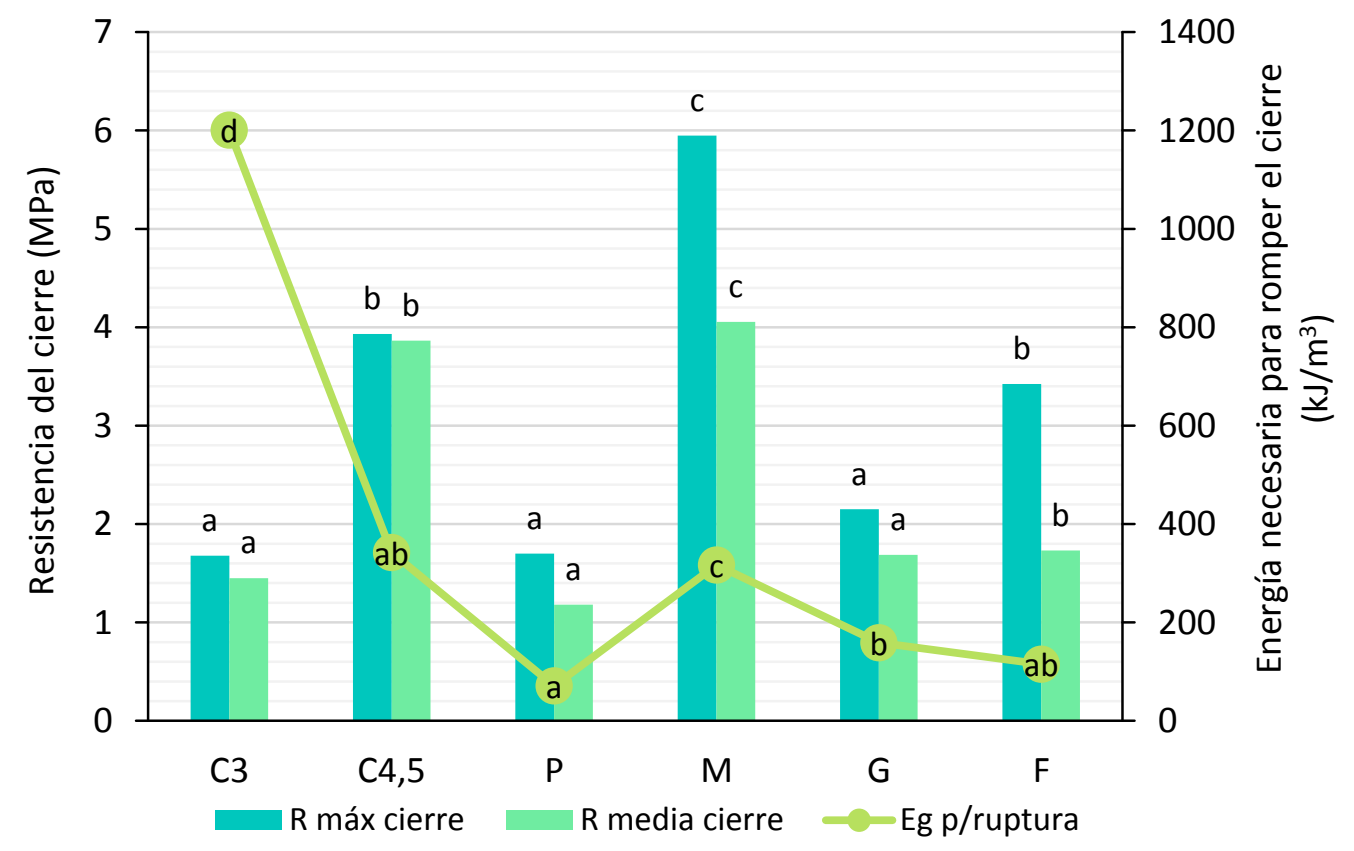

Figura II.10. Propiedades mecánicas de películas termoselladas de almidón de mandioca reforzadas con 1,5 \% de bagazo de diferente tamaño de partícula: sobre el eje izquierdo se indican valores registrados de resistencia máxima y media antes de la ruptura del cierre; y sobre el eje derecho, la energía necesaria total para romper el cierre. 
Cabe aclarar que las variaciones observadas en el comportamiento de las películas $C_{4,5}$ pueden explicarse considerando que el modo de falla no resultó uniforme en todos los casos, a pesar de que el número de replicados analizados para esta muestra fue superior al resto.

Considerando las potenciales aplicaciones agronómicas de las películas en estudio, otra propiedad importante para el desarrollo de materiales más sustentables es su biodegradabilidad. Si bien es sabido que los materiales a base de almidón son en esencia biodegradables, resulta relevante estudiar la cinética de dicho proceso puesto que la misma podría limitar ciertas aplicaciones, como por ejemplo la cobertura del suelo en cultivos de ciclo corto.

Se realizó un estudio integral del proceso de biodegradación, realizando un seguimiento fotográfico, gravimétrico y microscópico.

La Figura II.11 muestra la secuencia de fotografías de la biodegradación en suelo de las películas compuestas reforzadas con distinto tamaño de partícula y el control sin carga. En este ensayo solo se incluyó el control $C_{3}$ debido al elevado número de muestras que deben ser evaluadas y a que el comportamiento mecánico y las propiedades de barrera del control $C_{4,5}$ eran estadísticamente comparables al de las películas $P$.

En forma análoga se observó por microscopía electrónica de barrido que a los 15 días la degradación de las películas con partículas de menor tamaño ( $\mathrm{M}$ y P) y el control, se debe principalmente a la erosión y degradación mecánica de la muestra; mientras que en las películas $\mathrm{G}$ y $\mathrm{F}$ se observan las hifas que indican la colonización de los hongos provenientes del suelo (Figura II.12). No obstante a tiempos mayores todos los materiales ensayados presentaron una importante degradación microbiana. 


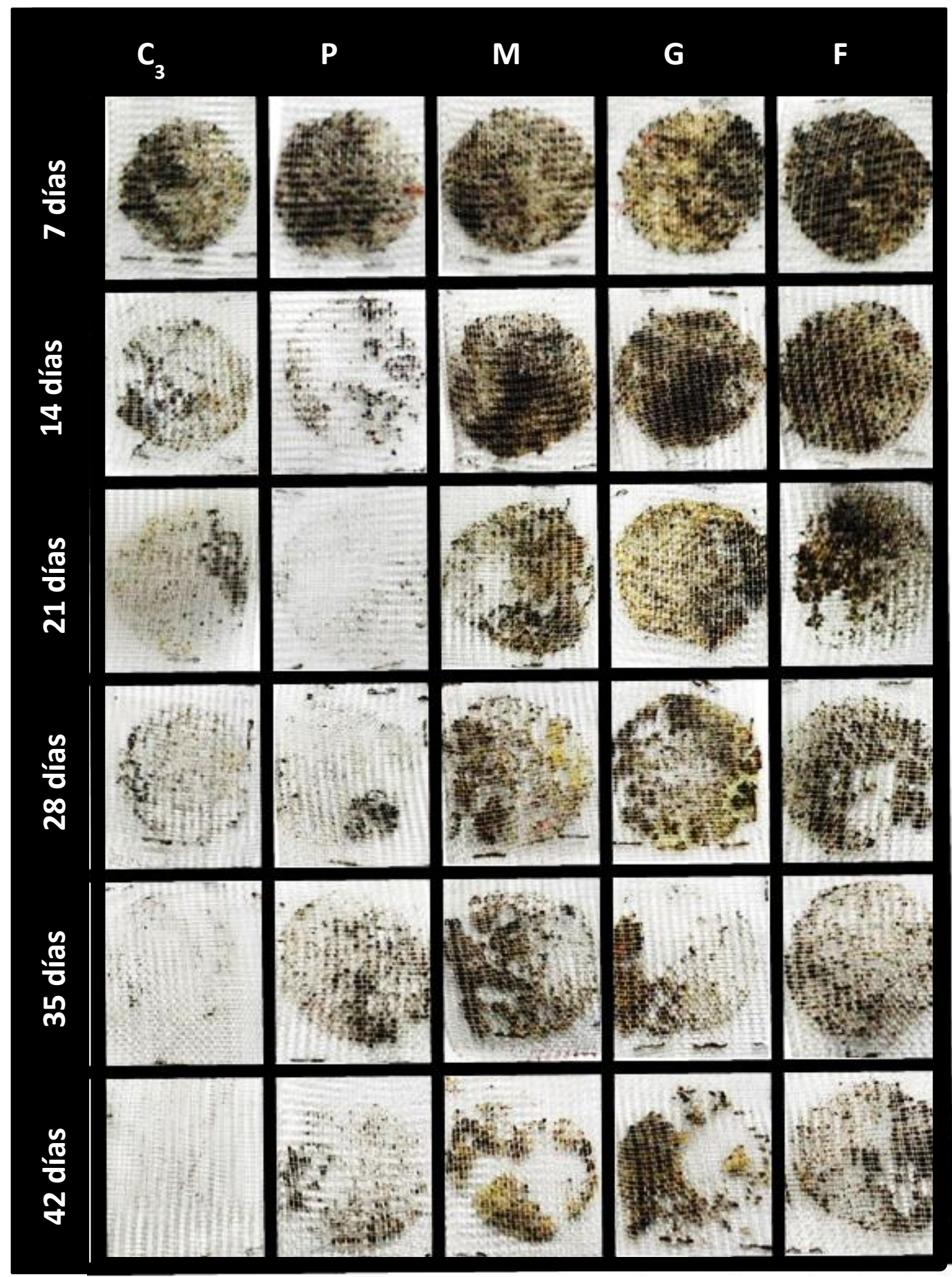

Figura II.11. Seguimiento fotográfico del proceso de biodegradación en suelo de las películas reforzadas con distinto tamaño de partícula de bagazo. 

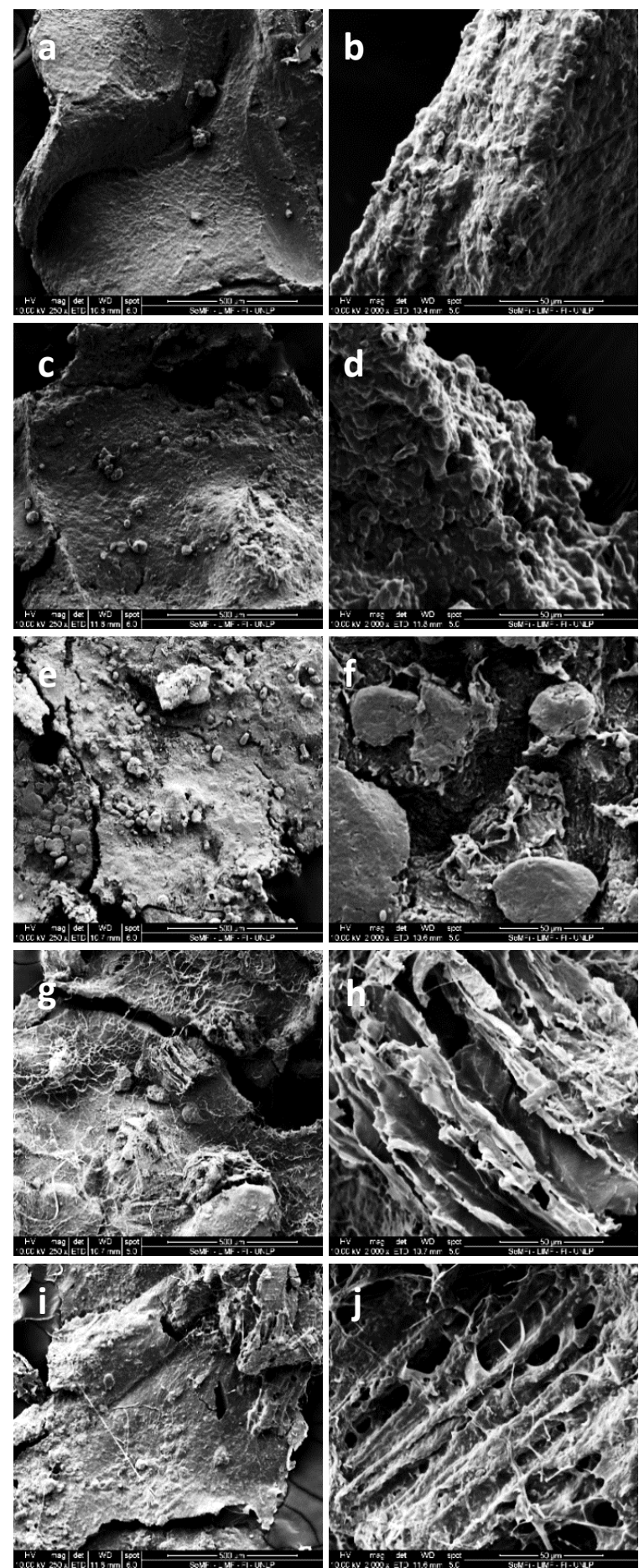

Figura II.12. Micrografía SEM de películas con distinto tamaño de partícula de relleno sometidas a condiciones de compostaje durante 15 días 250x y 1000x, respectivamente: $C_{3}(a, b) ; P(c, d) ; M(e, f) ; G(g, h) ; y F(i, j)$. 

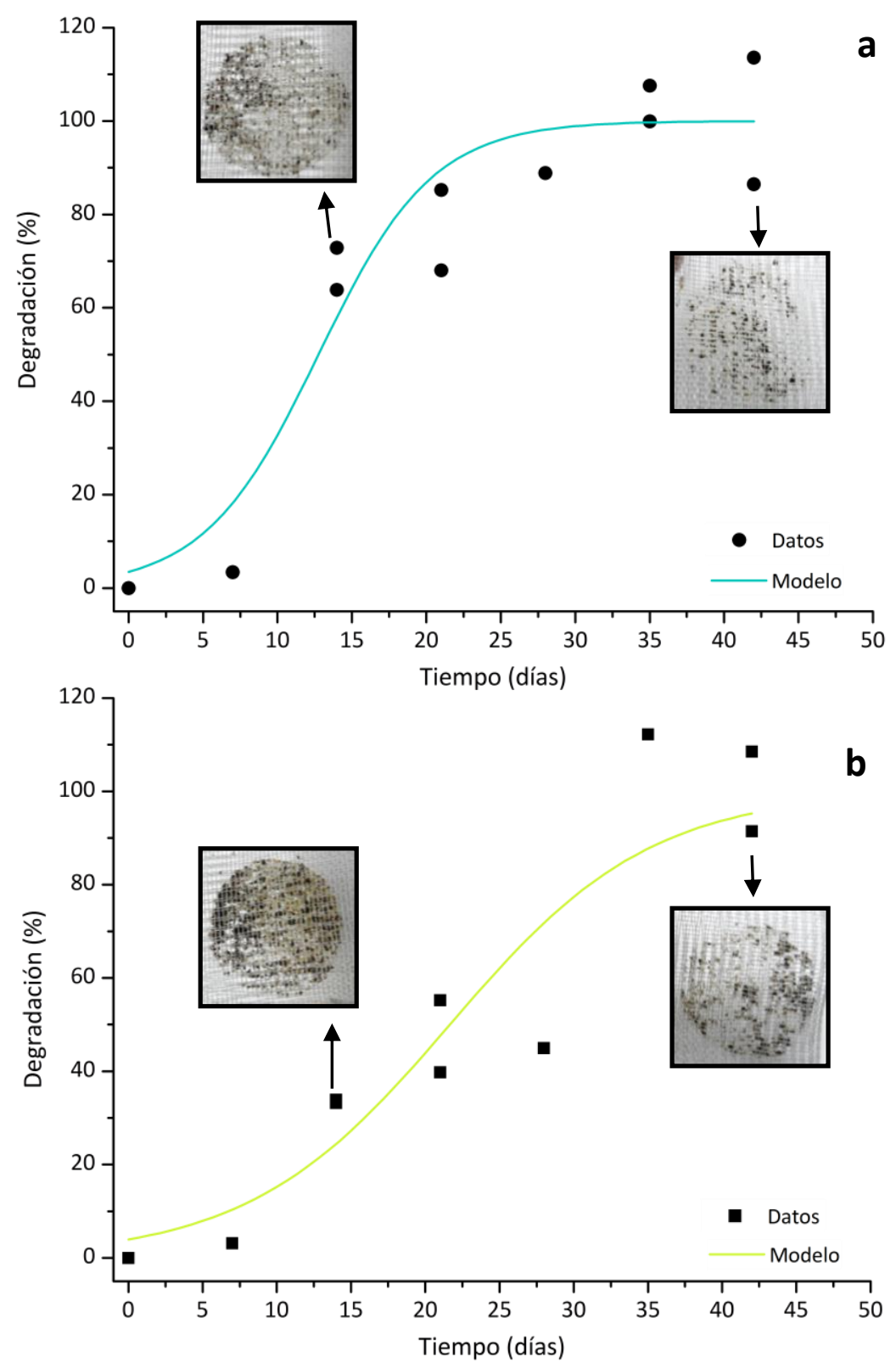

Figura II.13. Biodegradación en tierra de muestras control (a) y reforzadas con F (b) en función del tiempo y curva de ajuste al modelo de Boltzmann. Las fotografías correspondes a las muestras en las mallas de plástico a los 15 y 42 días de exposición.

En la Figura II.13 se muestran los datos de biodegradación en tierra de las películas de almidón de mandioca control y reforzadas con 1,5\% de bagazo. Con el objetivo de 
ejemplificar el grado de degradación de las muestras, en la misma figura se incluyen fotografías de los materiales desenterrados dentro de la malla plástica luego de 15 y 42 días de compostaje.

En la Tabla II.4 se detallan los valores resultantes del ajuste de los datos de pérdida de peso al modelo de Boltzmann. En todos los casos el ajuste resultó aceptable con un $r^{2}>0,8129$, aunque existe mayor dispersión a tiempos mayores. Los resultados indicaron que las películas reforzadas con partículas de bagazo mayores a $53 \mu \mathrm{m}$ ( $M, G$ y F) presentan un tiempo medio de degradación $t_{50}$ significativamente mayor $(p<0,05)$ que el de las películas control o P. Por otro lado, el parámetro empírico de ajuste $d t$, el cual se relaciona inversamente con la velocidad de degradación del material, presenta un comportamiento análogo, indicando una degradación retardada de los materiales reforzados: $M, G$ y $F$.

Tabla II.4- Parámetros de biodegradación de materiales a base de almidón de mandioca y distinto tamaño de partícula de bagazo de mandioca

\begin{tabular}{cccc} 
FORMULACIÓN & $\begin{array}{c}\mathbf{t}_{50} \\
\text { (días) }\end{array}$ & $\begin{array}{c}\mathbf{d t} \\
\text { (días) }\end{array}$ & $\mathbf{r}^{\mathbf{2}}$ \\
\hline $\mathrm{C}_{3}$ & $14,51 \pm 1,36^{\mathrm{a}}$ & $5,91 \pm 1,33^{\mathrm{a}}$ & 0,9099 \\
$\mathrm{P}$ & $12,41 \pm 2,09^{\mathrm{a}}$ & $4,09 \pm 1,72^{\mathrm{a}}$ & 0,8129 \\
M & $24,82 \pm 1,55^{\mathrm{b}}$ & $10,68 \pm 1,53^{\mathrm{b}}$ & 0,9312 \\
$\mathrm{G}$ & $23,80 \pm 2,35^{\mathrm{b}}$ & $11,33 \pm 2,58^{\mathrm{b}}$ & 0,8238 \\
$\mathrm{~F}$ & $25,88 \pm 1,54^{\mathrm{b}}$ & $10,23 \pm 1,36^{\mathrm{b}}$ & 0,9242 \\
\hline
\end{tabular}

Nota: Los valores reportados corresponden a la media \pm desviación estándar. Diferentes letras dentro de la misma columna indican diferencias significativas $(p<0,05)$.

Dichos resultados se correlacionan con los obtenidos de composición del material e imágenes SEM del bagazo, puesto que indican que la fracción $P$ se encuentra constituida básicamente por almidón remanente del proceso de extracción y por tanto presenta un comportamiento similar a la película control. En comparación con otros polímeros biodegradables, otros autores han reportado tiempos medios de biodegradabilidad similares e incluso menores para materiales compuestos de PLAPHB reforzados con nanocristales de celulosa [16] o PLA reforzado con arcillas [23]. 
Estos resultados indicarían la potencialidad de estos materiales con fines agronómicos, puesto que se garantiza la degradación del material en el suelo, característica primordial en aplicaciones como por ejemplo cobertura de suelo o macetas de replantación.

\section{CONCLUSIONES}

En resumen, el tamaño de partícula de carga tuvo un efecto sustancial sobre las propiedades mecánicas, de barrera y ópticas de los materiales compuestos basados en almidón de mandioca. Como era de esperar, las películas reforzadas con un tamaño de partícula inferior a $500 \mu \mathrm{m}(\mathrm{F})$ mostraron un comportamiento intermedio al de las películas que contenían rellenos con diferentes fracciones del bagazo $(G, M$ y $P)$, probablemente debido a una combinación de sus efectos individuales sobre la matriz. Por lo tanto, una mayor capacidad de barrera UV-visible se atribuye a partículas de carga grandes; mientras que las propiedades mecánicas mejoradas resultan principalmente de partículas de tamaño medio, y las partículas pequeñas reducen la WVP respecto al control $\left(C_{3}\right)$.

Todas las películas a base de almidón de mandioca fueron selladas por la técnica de impulso, ampliamente utilizada en el caso de materiales sintéticos flexibles [24]. Las películas selladas se rompían típicamente cerca del cierre, según el modo de falla estándar, indicando que la resistencia mecánica del sello es mayor que el de la película.

Además, los materiales probaron ser biodegradables observándose que en menos de 50 días todas las películas de almidón (reforzadas y no reforzadas) presentan un alto grado de degradación en suelo; aunque en este caso las matrices reforzadas mostraron un deterioro más lento. Estos resultados son relevantes para las potenciales aplicaciones agronómicas de estos materiales, ya sea como plásticos de cobertura o matrices de liberación de componentes activos. 
Asimismo, la naturaleza biodegradable de estos materiales y su capacidad para ser sellados térmicamente, podría conducir al desarrollo de envases para aplicaciones alimentarias específicas, tales como la conservación de productos orgánicos.

\section{BIBLIOGRAFÍA}

[1] Y. Zhang, J.H. Han, Mechanical and thermal characteristics of pea starch films plasticized with monosaccharides and polyols, J. Food Sci. 71 (2006) 109-118.

[2] J. Piermaria, A. Bosch, A. Pinotti, O. Yantorno, M.A. Garcia, A.G. Abraham, Kefiran films plasticized with sugars and polyols: Water vapor barrier and mechanical properties in relation to their microstructure analyzed by ATR/FT-IR spectroscopy, Food Hydrocolloids 25 (2011) 1261-1269.

[3] A.M. Idrovo Encalada, M.F. Basanta, E.N. Fissore, M.D. De'Nobili, A.M. Rojas, Carrot fiber (CF) composite films for antioxidant preservation: Particle size effect, Carbohydr. Polym. 136 (2016) 1041-1051.

[4] R. Bodirlau, C.-A. Teaca, I. Spiridon, Influence of natural fillers on the properties of starchbased biocomposite films, Compos. Part B-Eng. 44 (2013) 575-583.

[5] D. Ahuja, A. Kaushik, M. Singh, Simultaneous extraction of lignin and cellulose nanofibrils from waste jute bags using one pot pre-treatment, International journal of biological macromolecules (2017).

[6] A. Shalwan, B.F. Yousif, In State of Art: Mechanical and tribological behaviour of polymeric comopistes based on natural fibres, Mater. Des. 48 (2013) 14-24.

[7] Z.N. Azwa, B.F. Yousif, A.C. Manalo, W. Karunasena, A review on the degradability of polymeric composites based on natural fibres, Mater. Des. 47 (2013) 424-442.

[8] D.B. Dittenber, H.V.S. GangaRao, Critical review of recent publications on use of natural composites in infrastructure, Compos. Part A-Appl. S. 43 (2012) 1419-1429.

[9] A.K. Mohanty, M. Misra, L.T. Drzal, Sustainable Bio-Composites from Renewable Resources: Opportunities and Challenges in the Green Materials World, Journal of Polymers and the Environment 10 (2002) 19-26.

[10] S. Yao, S. Nie, Y. Yuan, S. Wang, C. Qin, Efficient extraction of bagasse hemicelluloses and characterization of solid remainder, Bioresour Technol 185 (2015) 21-27.

[11] A. Kaushik, M. Singh, G. Verma, Green nanocomposites based on thermoplastic starch and steam exploded cellulose nanofibrils from wheat straw, Carbohydr. Polym. 82 (2010) 337-345.

[12] N. Abidi, L. Cabrales, C.H. Haigler, Changes in the cell wall and cellulose content of developing cotton fibers investigated by FTIR spectroscopy, Carbohydr. Polym. 100 (2014) 9-16.

[13] Z. Yao, J.Y.Y. Heng, S. Lanceros-Méndez, A. Pegoretti, X. Ji, E. Hadjittofis, M. Xia, W. Wu, J. Tang, Study on the surface properties of colored talc filler (CTF) and mechanical performance of CTF/acrylonitrile-butadiene-styrene composite, Journal of Alloys and Compounds 676 (2016) 513-520. 
[14] C.I.G.L. Sarantópoulos, L.M. de Oliveira, M. Padula, L. Coltro, R.M. Vercelino Alves, E.E. Corrêa Garcia, Poropiedades Mecânicas, en: P.R. Citrângulo (Ed.) Embalagens Plásticas Flexíveis: Principais Polímeros e Avaliação de Propiedades, Centro de Tecnologia de Embalagem, Campinas, SP, Brasil, 2002, pp. 137-175.

[15] A.S.f.T.a.M. (ASTM), Standard Test Method for Seal Strength of Flexible Barrier Materials. ASTM F88-00, ASTM Standards on Disc. ASTM, Philadelphia, PA. 15.09 (2001).

[16] M.P. Arrieta, E. Fortunati, F. Dominici, E. Rayón, J. López, J.M. Kenny, PLA-PHB/cellulose based films: Mechanical, barrier and disintegration properties, Polym. Degrad. Stab. 107 (2014) 139-149.

[17] T. Ishigaki, W. Sugano, A. Nakanishi, M. Tateda, M. Ike, M. Fujita, The degradability of biodegradable plastics in aerobic and anaerobic waste landfill model reactors, Chemosphere 54 (2004) 225-233.

[18] L. Ludueña, A. Vázquez, V. Alvarez, Effect of lignocellulosic filler type and content on the behavior of polycaprolactone based eco-composites for packaging applications, Carbohydr. Polym. 87 (2012) 411-421.

[19] J.J.G. van Soest, H. Tournois, D. de Wit, J.F.G. Vliegenthart, Short-range structure in (partially) crystalline potato starch determined with attenuated total reflectance Fouriertransform IR spectroscopy, Carbohydr. Res. 279 (1995) 201-214.

[20] P. Rubens, J. Snauwaert, K. Heremans, R. Stute, In situ observation of pressure-induced gelation of starches studied with FTIR in the diamond anvil cell, Carbohydr. Polym. 39 (1999) 231-235.

[21] I. Capron, P. Robert, P. Colonna, M. Brogly, V. Planchot, Starch in rubbery and glassy states by FTIR spectroscopy, Carbohydr. Polym. 68 (2007) 249-259.

[22] C. Dini, M.C. Doporto, S.Z. Viña, M.A. García, Cassava flour and starch as differentiated ingredients for gluten free products, en: F.P. Molinari (Ed.) Cassava: Production, Nutritional Properties and Health Effects, Nova Science Publishers, Hauppauge, NY, USA, 2014.

[23] P. Stloukal, S. Pekarova, A. Kalendova, H. Mattausch, S. Laske, C. Holzer, L. Chitu, S. Bodner, G. Maier, M. Slouf, M. Koutny, Kinetics and mechanism of the biodegradation of PLA/clay nanocomposites during thermophilic phase of composting process, Waste Manag 42 (2015) 3140.

[24] A.L. Brody, K.S. Marsh, The Wiley Encyclopedia of Packaging Technology, Wiley, 1997. 

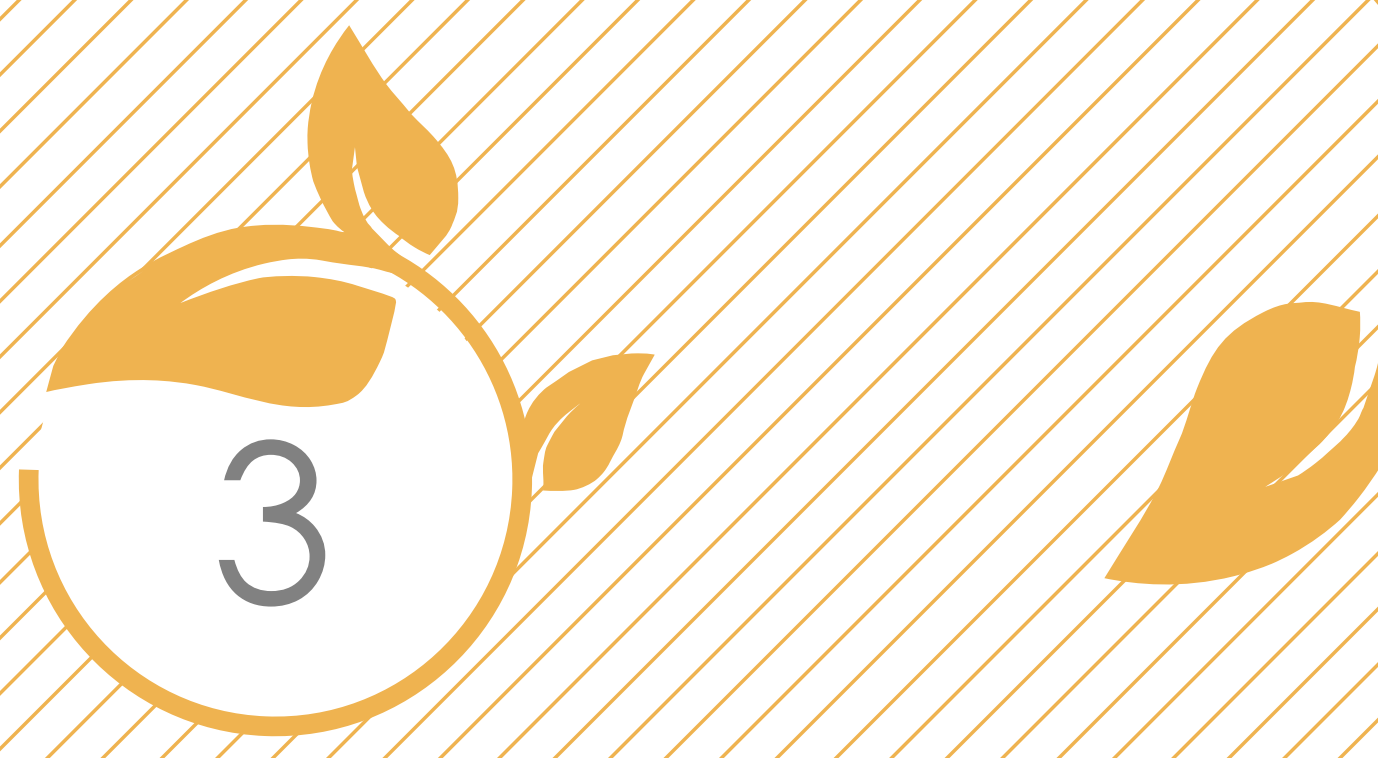

Películas de almidón de mandioca
reforzadas con residuos de mandioca:

\section{ALMIDÓN TERMOPLÁSTICO \\ REFORZADO CON \\ BAGAZO Y CÁSCARA}




\section{INTRODUCCIÓN}

El bagazo de mandioca es un subproducto de la industria del procesamiento de la mandioca, es un material fibroso que contiene aproximadamente $40 \%$ (base seca) de fibra. Por fermentación del bagazo de mandioca pueden obtenerse derivados no alimenticios tales como pululano [1] o n-butanol [2], y productos alimenticios tales como piensos nutricionalmente mejorados [3] o aromatizantes [4]. El uso de la fibra obtenida a partir del bagazo de mandioca ha sido estudiado como relleno natural destinado a reforzar biomateriales, modificando su hidrofobicidad y propiedades finales [5-7]. Las fibras derivadas del bagazo de mandioca son también atractivas como aditivos alimentarios, pero no se han reportado informes sobre el uso de piel o cáscara de mandioca (de aquí en adelante denominada cáscara) como relleno de matrices poliméricas.

Debido a su carácter renovable y biodegradable, las fibras lignocelulósicas han despertado un gran interés en las últimas décadas, y están siendo estudiadas como alternativas sustentables a las fibras sintéticas tradicionales comúnmente utilizadas como material de refuerzo. El campo de aplicación de los materiales compuestos es muy amplio y abarca desde la industria de aeronáutica y automotriz hasta la producción de envases, cada una con características y requerimientos específicos.

Asimismo, en vistas de su amplia disponibilidad y su carácter renovable, los materiales termoplásticos obtenidos por la plastificación del almidón se encuentran entre las alternativas más prometedoras para el desarrollo de biomateriales [8-10]. La comprensión de los diferentes procesos implicados en la transformación del almidón en un polímero termoplástico ha avanzado considerablemente en los últimos años [11-14]. Hoy en día, el almidón termoplástico (TPS) es una opción interesante en aplicaciones que no requieren excesiva durabilidad a largo plazo ni rendimiento mecánico elevado. 
Sin embargo, y como se mencionó anteriormente, el procesamiento de materiales a base de almidón es más difícil que el correspondiente a los polímeros sintéticos, puesto que implica múltiples reacciones químicas y físicas, tales como la difusión del agua, la expansión de los gránulos, la gelatinización, la descomposición, la fusión y la cristalización $[12,15]$. Bajo condiciones de alta presión y tensión de cizalla el almidón puede gelatinizarse a menores contenidos de humedad. A diferencia de la gelatinización de una suspensión de almidón descripta previamente, en estas condiciones la disrupción de la estructura cristalina de los gránulos de almidón se produce por la ruptura mecánica de los enlaces intramoleculares [16, 17]. En estas condiciones aumenta la movilidad de los gránulos de almidón, presentando un comportamiento viscoelástico similar a las mezclas de polímeros termoplásticos sintéticos, y en ese sentido este tipo de procesamiento del almidón se asemeja a un mezclado en "fundido" [12], que en este trabajo de Tesis denominaremos plastificación para diferenciarlo de la gelatinización convencional. Durante la plastificación, algunas de las moléculas poliméricas se liberan de la estructura granular [18]. Por lo tanto, el TPS presenta regiones amorfas altamente plastificadas y algunas regiones granulares residuales, dependiendo la cantidad de cada fase en una mezcla dada del tiempo y las condiciones de procesamiento. Consecuentemente las propiedades de los materiales obtenidos resultarán radicalmente distintas según el procesamiento empleado $[12,16,19]$. Por ejemplo, el moldeo por compresión de almidón conduce a materiales sinterizados relativamente frágiles, mientras que mediante moldeo por inyección de TPS de almidones nativos se obtienen materiales amorfos con propiedades mecánicas mejoradas [20]. No obstante, a fin de su potencial utilización como material alternativo a los termoplásticos sintéticos convencionales, las propiedades mecánicas del TPS deben ser mejoradas.

El refuerzo de la matriz termoplástica con fibras lignocelulósicas naturales es una buena opción para aumentar su resistencia mecánica y preservar así el carácter renovable y biodegradable del material compuesto. A este respecto, Azwa y col. [21] y 
Shalwan y Yousif [22] han revisado extensamente el uso de fibras naturales como materiales de refuerzo en matrices biodegradables. Sin embargo, el uso de subproductos industriales como relleno y/o soporte está todavía en estudio. En este contexto, las fibras de celulosa aisladas de la pasta de madera [11], el bagazo de caña de azúcar [23], el yute [24], el algodón [25], y el salvado de trigo [26] se han incorporado en matrices de hidrocoloides. Slavutsky y Bertuzzi [27] informaron que la adición de nanocristales de celulosa obtenidos del bagazo de caña de azúcar ayudó a mejorar las propiedades de barrera al vapor de agua de películas a base de almidón.

Sin embargo, existen algunas desventajas asociadas con el uso de fibras naturales como refuerzo de compuestos poliméricos, tales como su incompatibilidad con matrices de polímeros hidrófobos, tendencia a formar agregados durante el procesamiento, pobre resistencia a la humedad y al fuego, temperaturas de procesamiento limitadas, menor durabilidad, variaciones en calidad y precio según el productor y región de origen, y dificultad para su incorporación directa en sistemas de fabricación estándares [21, 28]. Por lo tanto, para evaluar la capacidad de las fibras naturales como rellenos de materiales poliméricos, es necesario obtener una comprensión global de sus características inherentes y su composición.

\section{OBJETIVOS}

- Obtener materiales compuestos de almidón de mandioca termoplástico con los subproductos de la extracción de almidón de mandioca (cáscara y bagazo) como rellenos naturales.

- Comparar la composición y características de ambos rellenos.

- Estudiar el efecto de la incorporación de los rellenos sobre la microestructura de los biocompuestos y consecuentemente sobre sus propiedades mecánicas y de barrera. 


\section{METODOLOGÍA Y TÉCNICAS EMPLEADAS}

\subsection{Materiales utilizados: obtención y caracterización}

Se empleó el almidón de mandioca y sus subproductos del proceso de extracción obtenidos a partir de raíces cultivadas y proporcionadas por la Estación Experimental INTA Montecarlo (Misiones, Argentina), según el proceso descripto en la sección 3.1 del capítulo I. La caracterización fisicoquímica de los materiales empleados como relleno: cáscara $(C)$ y bagazo $(B)$ de la raíz tuberosa de mandioca se realizaron según métodos descriptos en la sección 3.2 del capítulo I.

\subsection{Preparación de películas y materiales compuestos}

\subsubsection{Preparación de mezclas}

Se prepararon mezclas de almidón de mandioca, glicerol (30\%p/p), agua destilada (45 \%p/p) y residuos $(0,5$ y $1,5 \% p / p)$, según valores optimizados en un trabajo previo [29]. La concentración de los componentes se expresó en g por 100 g de almidón (base seca). Las formulaciones se denominaron: TPS; TPS-C0,5; TPS-C1,5; TPS-B0,5 y TPS-B1,5, donde $C$ se refiere a la cáscara y $B$ al bagazo, y los números indican la concentración de la carga. Los subproductos se mezclaron previamente con el almidón para conseguir una buena dispersión dentro de la matriz. A continuación, se añadieron el glicerol y el agua destilada, y las muestras se mezclaron y acondicionaron a $25{ }^{\circ} \mathrm{C}$ durante $24 \mathrm{hs}$. Las mezclas se procesaron en una mezcladora experimental de tornillos Brabender Plastograph (Brabender, Alemania) a $140{ }^{\circ} \mathrm{C}$ y $50 \mathrm{rpm}$ durante $15 \mathrm{~min}$. Se registraron las curvas de torque $(\mathrm{N} \mathrm{m})$ en función del tiempo de procesamiento.

Además se evaluó la degradación térmica de los biocompuestos desarrollados. Los análisis termogravimétricos (TGA) se llevaron a cabo en equipo específico de la línea Discovery (TA Instrument, EEUU). Las muestras, previamente acondicionadas a $25^{\circ} \mathrm{C} \mathrm{y}$ $60 \%$ de humedad relativa (HR), se calentaron de 30 a $700{ }^{\circ} \mathrm{C}$ a una velocidad de calentamiento de $10{ }^{\circ} \mathrm{C} / \mathrm{min}$, empleando un flujo de aire de $40 \mathrm{~mL} / \mathrm{min}$. A partir de la 
primera derivada de las curvas registradas de pérdida de peso versus temperatura, se obtuvieron las temperaturas máximas de descomposición de cada componente para cada formulación.

\subsubsection{Preparación de películas por termocompresión}

Las películas de almidón termoplástico compuestas se obtuvieron por termocompresión utilizando una prensa hidráulica, siguiendo las condiciones de procesamiento reportadas por Castillo y col. [30]. Las mezclas fueron acondicionadas previamente a $25{ }^{\circ} \mathrm{C}$ y $60 \% \mathrm{HR}$ durante 48 hs y fueron moldeadas a $140{ }^{\circ} \mathrm{C}$ de temperatura y $150 \mathrm{~kg} / \mathrm{cm}^{2}$ de presión durante $6 \mathrm{~min}$. Posteriormente, las películas fueron acondicionadas nuevamente a $25^{\circ} \mathrm{C}$ y $60 \% \mathrm{HR}$ durante al menos 48 hs previo a su caracterización.

3.4. Caracterización de películas biodegradables y materiales compuestos

\subsubsection{Espesor}

Se determinó el espesor de cada espécimen como se detalló en la sección 3.5.1 del capítulo I.

\subsubsection{Humedad}

El contenido de humedad se determinó según lo descrito en la sección 3.5.2 del capítulo I.

\subsubsection{Microscopía electrónica de barrido (SEM)}

Para observar las muestras por microscopía electrónica de barrido en alto vacío las películas fueron preparadas como se detalló en la sección 3.5.3 del capítulo I.

3.4.4. Espectroscopía de infrarrojo con transformada de Fourier (FTIR) Los espectros se obtuvieron utilizando un espectrofotómetro FTIR Thermo Nicolet Nexus (Nexus, EEUU). Las las mezclas plastificadas de almidón termoplástico, molidas 
hasta polvo fino, se mezclaron con $\mathrm{KBr}$ (CAS\# 7758-02-3, Sigma-Aldrich) al 3 \%p/p. La mezcla se prensó y se obtuvo una pastilla transparente. Se obtuvieron espectros de 100 barridos acumulados con una resolución de $4 \mathrm{~cm}^{-1}$ en el intervalo de $4000-400 \mathrm{~cm}^{-1}$.

\subsubsection{Análisis termo-mecánico: DMA y MDSC}

En esta sección las temperaturas de transición vítrea de los materiales ensayados se determinaron por calorimetría diferencial de barrido modulado (MDSC) utilizando un calorímetro de barrido diferencial Q100 controlado por el módulo TA 5000 (TA Instruments, EEUU). Aproximadamente $8 \mathrm{mg}$ de muestra previamente acondicionados a $25{ }^{\circ} \mathrm{C}$ y $60 \% \mathrm{HR}$ se pesaron en cápsulas de aluminio herméticas para evitar la pérdida de agua, usando una cápsula vacía como valor de referencia. Las muestras se calentaron de -100 a $200{ }^{\circ} \mathrm{C}$ a una velocidad de calentamiento de $10^{\circ} \mathrm{C} / \mathrm{min}$, bajo una atmósfera de $\mathrm{N}_{2}$ operando con un caudal de $20 \mathrm{~mL} / \mathrm{min}$. Para la modulación de la señal se utilizó un período de $40 \mathrm{~s}$ y una amplitud de $0,5^{\circ} \mathrm{C}$. A partir de los termogramas se obtuvieron los siguientes parámetros: temperatura de inicio (To), temperatura de pico $(\mathrm{Tm})$ y entalpía asociada a esta transición térmica $(\Delta \mathrm{Hm})$.

Las temperaturas e intensidades de los fenómenos de relajación para las películas de TPS fueron determinadas por DMA. Las mediciones se llevaron a cabo en un equipo térmico dinámico - mecánico Q800 (TA Instruments, EEUU) con un sistema de enfriamiento de nitrógeno líquido utilizando pinzas de tensión uniaxial (ver sección 3.5.6 del capítulo I). Se llevaron a cabo barridos de frecuencia múltiple a una amplitud fija mientras se producía el calentamiento de la muestra entre -100 y $100{ }^{\circ} \mathrm{C}$ a una velocidad de $5{ }^{\circ} \mathrm{C} / \mathrm{min}$. Se registraron y analizaron las curvas de módulo de almacenamiento $\left(E^{\prime}\right)$ y módulo de pérdida ( $\left.E^{\prime \prime}\right)$ y las curvas de tangente del ángulo de desfasaje ( $\tan \delta$ ) en función de la temperatura, utilizando el software Universal Analysis 2000. Las temperaturas de los procesos de relajación asociados a las temperaturas de transición vítrea $(\mathrm{Tg})$, se determinaron a partir de los puntos de 
inflexión de las curvas del módulo de almacenamiento, así como el pico máximo tanto en las curvas del módulo de pérdida como de $\tan \delta$.

\subsubsection{Permeabilidad al vapor de agua}

La permeabilidad al vapor de agua (WVP) se determinó de acuerdo con el método estándar ASTM F1249-89 [31] utilizando un equipo de permeabilidad PERMATRAN $\mathrm{W}^{\circledR}$ Model3/33 (Mocon Inc., EEUU). Las muestras de película se colocaron en una celda de prueba que se divide en dos cámaras separadas por la muestra ensayada. La cámara interior está llena de nitrógeno (medio gaseoso) y la cámara exterior con vapor de agua (gas de prueba). Las moléculas de agua difunden a través de la película a la cámara interior y se registra la permeabilidad del vapor de agua por un sensor en la cámara adyacente. Las mediciones se realizaron a $25{ }^{\circ} \mathrm{C}$ con un gradiente ascendente de presión parcial de vapor de agua. Además se emplearon mascarillas de aluminio precortadas para dejar un área expuesta de película de $5 \mathrm{~cm}^{2}$. Los resultados se expresaron en $\mathrm{g} / \mathrm{m} \mathrm{s}$ Pa.

\subsubsection{Propiedades ópticas}

Las características de color y la capacidad de barrera UV-visible se determinaron siguiendo los procedimientos explicados en la sección 3.5.5 del capítulo I. Los resultados de barrera UV-visible fueron normalizados a un espesor de película de $200 \mu \mathrm{m}$.

\subsubsection{Propiedades mecánicas}

El comportamiento mecánico de las películas de TPS se evaluó realizando ensayos cuasi-estáticos en estado uniaxial utilizando un analizador dinámico-mecánico Q800 (TA Instruments, EEUU) como se detalla en la sección 3.5.6 del capítulo I. En este caso, los ensayos se realizaron a $25^{\circ} \mathrm{C}$ desde $0,1 \mathrm{~N}$ hasta ruptura de la muestra utilizando una velocidad de desplazamiento constante de $0,3 \mathrm{~N} / \mathrm{min}$ y una fuerza de precarga de 0,1 a $0,5 \mathrm{~N}$. 


\subsection{Análisis estadístico}

El análisis estadístico de resultados se realizó en forma análoga a lo descripto en la sección 3.6 del capítulo I.

\section{RESULTADOS Y DISCUSIÓN}

\subsection{Caracterización de los subproductos de la mandioca}

El procesamiento de los tubérculos de mandioca produce principalmente dos subproductos: el bagazo y la cáscara. La cáscara podría representar entre el 5 y el $15 \%$ de las raíces [32] y se obtiene después de que los tubérculos han sido desinfectados y pelados manual o mecánicamente. Dependiendo de la variedad de mandioca analizada, pueden contener altas cantidades de glucósidos cianogénicos y tienen un contenido proteico más alto que otras partes del tubérculo. Sin embargo, la especie empleada en este trabajo de Tesis corresponde a una variedad dulce, que no contiene niveles detectables de glucósidos cianogénicos [33]. Por otro lado, el bagazo de mandioca es un residuo fibroso sólido (alrededor del 11,34 \pm 0,50 \% del total en base húmeda) que permanece después de que el almidón ha sido extraído [32]. La calidad y apariencia de estos subproductos varían con la edad de la planta, el tiempo transcurrido desde la cosecha, así como el equipo industrial y el método utilizados para la cosecha [34]. Los subproductos de las raíces tuberosas son rápidamente fermentables, por lo que debieron ser estabilizados por secado a $50{ }^{\circ} \mathrm{C}$. La composición química de los residuos de mandioca se muestra en la Tabla III.1.

La cáscara de mandioca está mayormente compuesta por fibra (55\%), de la cual casi un $24 \%$ corresponde a lignina; mientras que el bagazo consiste en aproximadamente un $96 \%$ de carbohidratos, principalmente almidón y restos del tejido celular parenquimatoso, como se ha descripto en el capítulo I. Asimismo, la cáscara de mandioca se caracteriza por un mayor contenido de proteínas, cenizas y lípidos. 


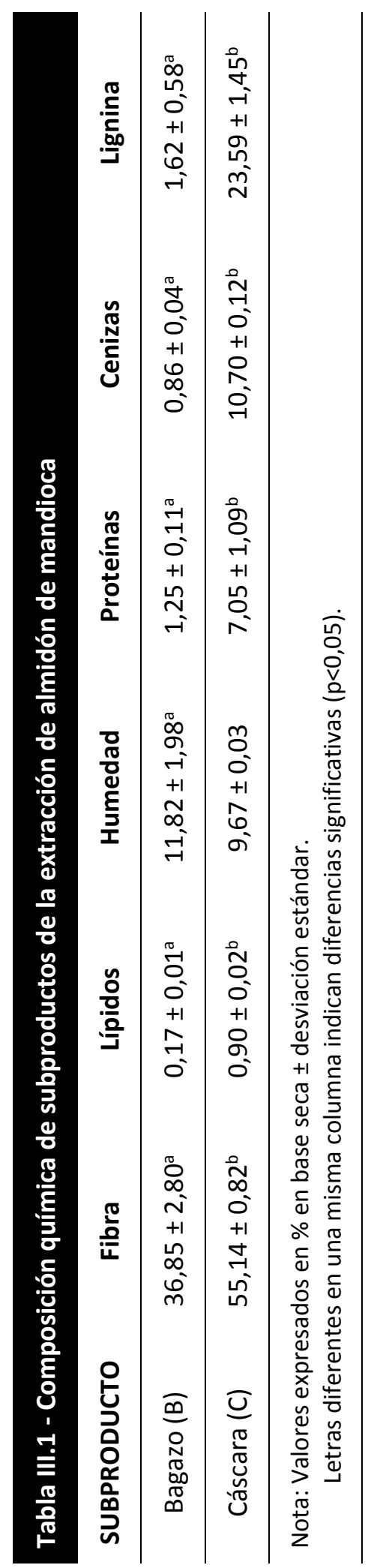


Cabe destacar que los resultados obtenidos están dentro del rango de los valores reportados para cáscara de mandioca seca utilizada como alimento de animales [35-37].

La caracterización morfológica al SEM del bagazo de mandioca se muestra en la Figura III.1a, donde se pueden observar los gránulos de almidón rodeados por paredes celulares remanentes del tejido parenquimatoso. Los gránulos de almidón identificados exhibieron formas redondas y poligonales, tal como se describió en el capítulo II. La morfología de la cáscara de mandioca es similar a la del bagazo, aunque se puede observar una mayor contribución de componentes lignocelulósicos (Figura III.1b), como era de esperar considerando su composición química (Tabla III.1).

Además, ambos residuos presentaron una distribución heterogénea del tamaño de partícula: las cáscaras revelaron una mayor contribución de partículas más grandes (principalmente $300 \mu \mathrm{m}$ ); mientras que en el bagazo predominan partículas de tamaño inferior a $53 \mu \mathrm{m}$ (Figuras III.1a y b).

La capacidad de retención de solventes se utiliza generalmente para evaluar harinas, aunque en el presente trabajo se ha propuesto con el fin de estudiar la capacidad de interacción de los subproductos con diferentes disolventes complementando su caracterización fisicoquímica. En general, la cáscara de mandioca exhibió mayor capacidad de retención que el bagazo para todos los solventes ensayados (Figura III.2), siendo estos resultados concordantes con su composición química (Tabla III.1). En el caso de la cáscara, la capacidad de retención de carbonato de sodio, que se ha relacionado con el contenido de almidón dañado [38], fue similar a la capacidad de retención de agua, que se ha correlacionado con el contenido total de fibra dietaria [39]. La cáscara de mandioca también presentó mayor capacidad de retención de sacarosa que de otros solventes, lo que sugiere una mayor proporción de componentes relacionados con la fibra dietaria soluble [40]. Con respecto a la capacidad de retención 

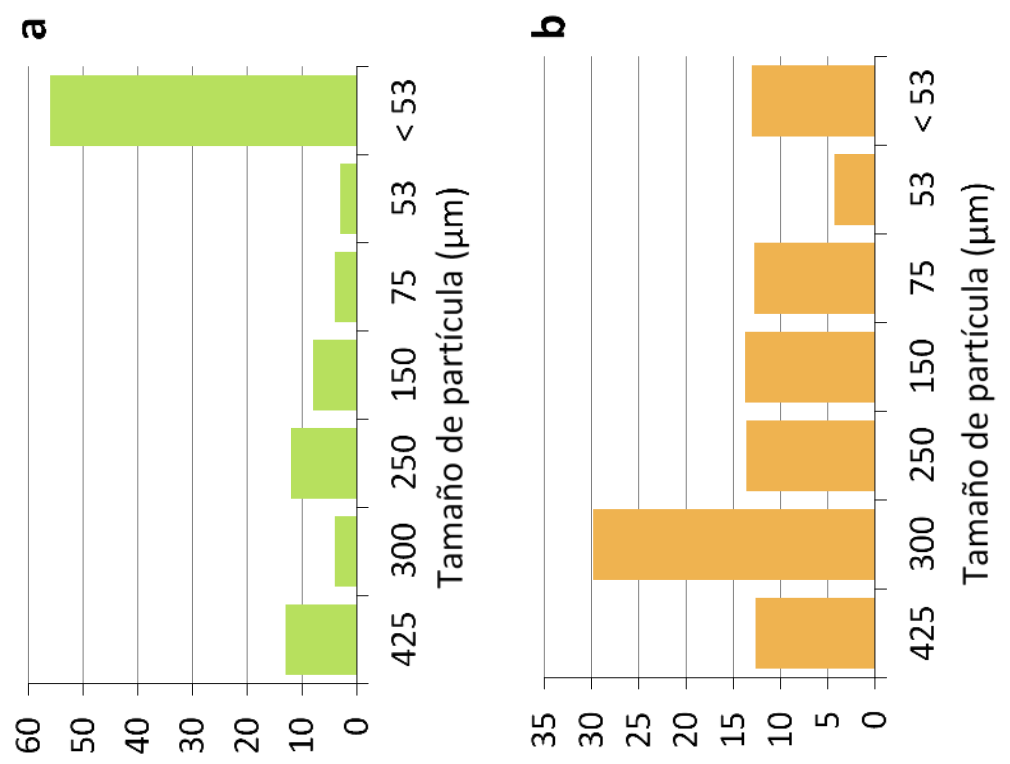

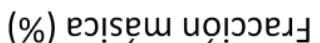

(\%) е!़sęu uọıวед
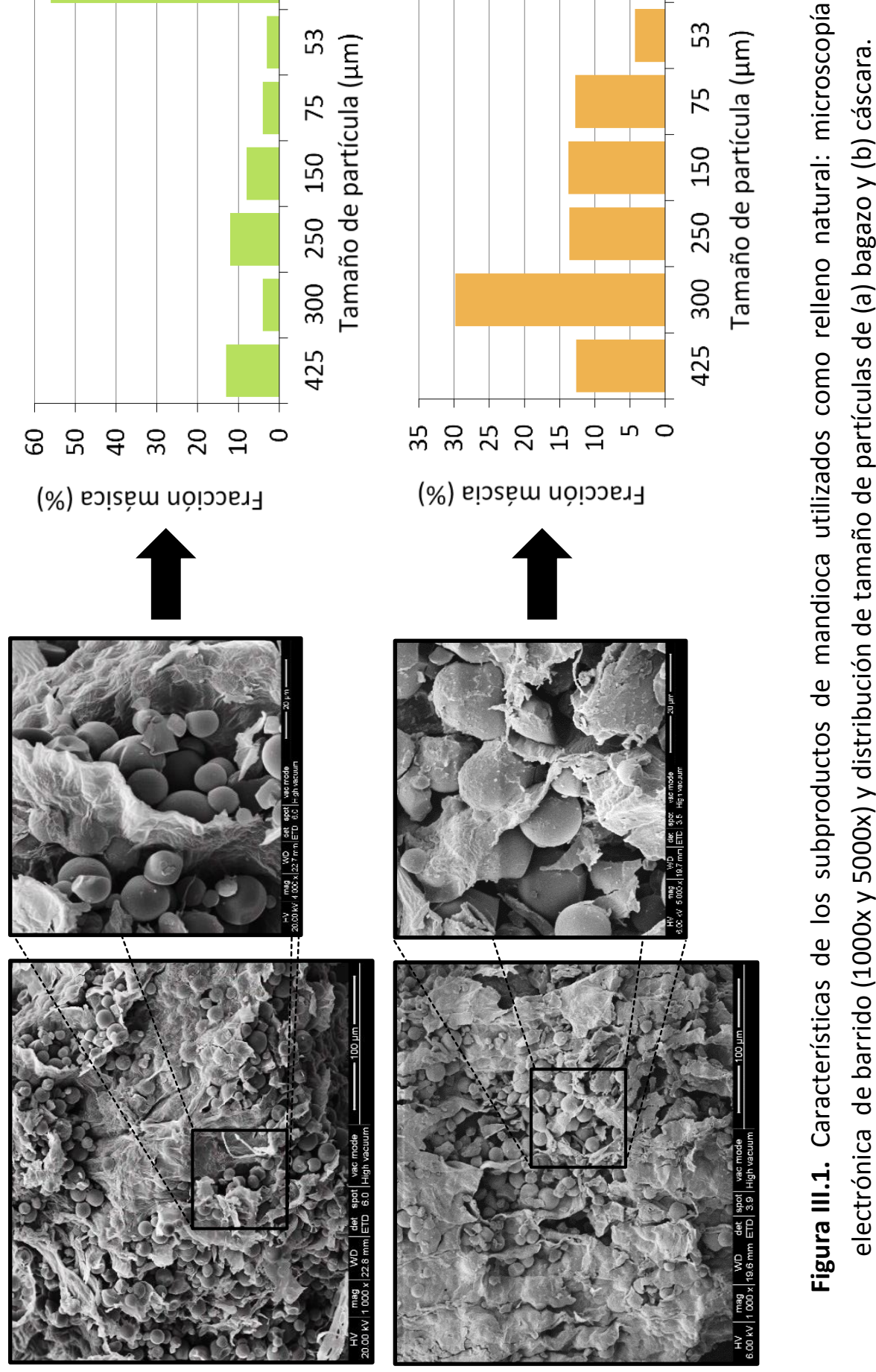
de ácido láctico, los valores más altos observados en la cáscara que en el bagazo podrían explicarse considerando su mayor contenido proteínico (Tabla III.1).

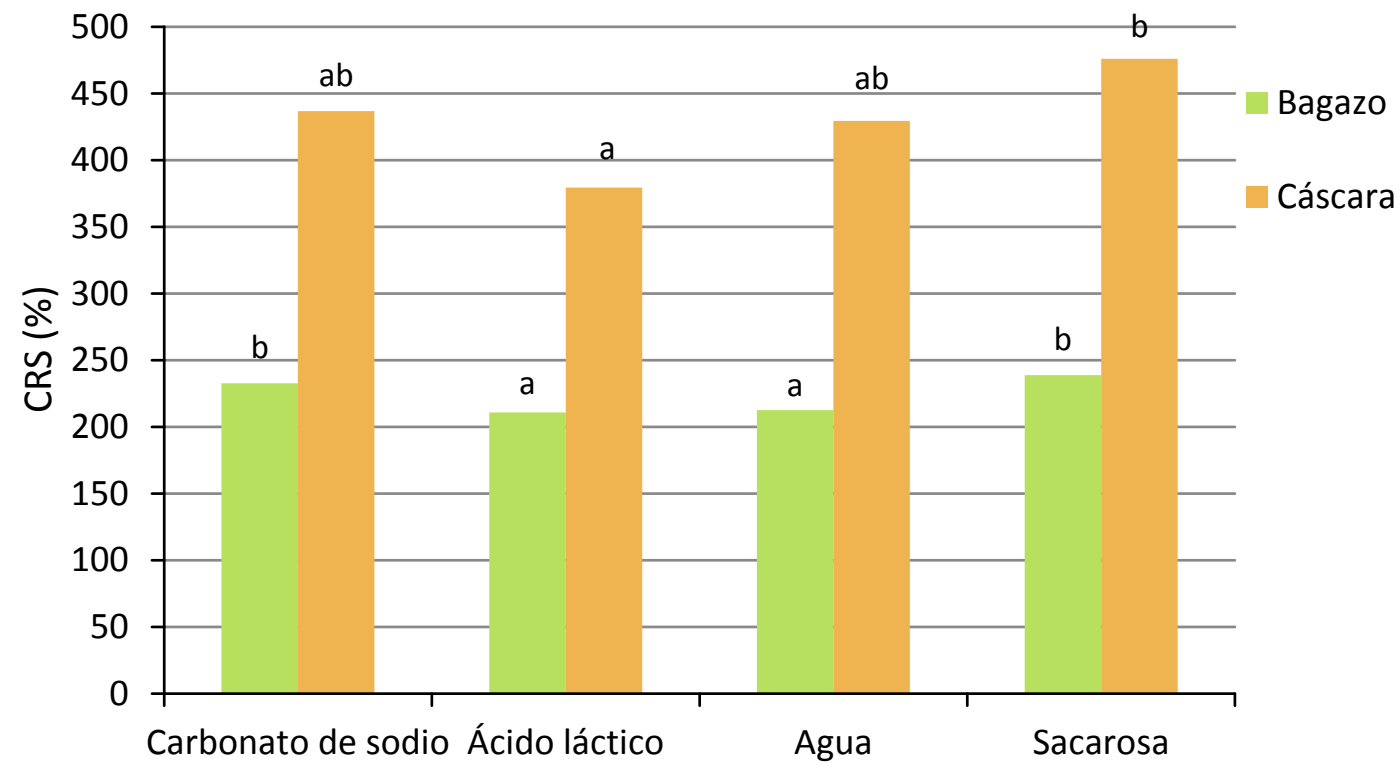

Figura III.2. Capacidad de retención de solventes de subproductos de mandioca. ${ }^{1}$

\subsection{Procesamiento del almidón termoplástico}

Cabe aclarar que las concentraciones empleadas para la preparación de biocompuestos a base de almidón de mandioca termoplástico y subproductos de su extracción se eligieron en base a los contenidos de carga optimizados por el grupo de trabajo en materiales compuestos a base de $\operatorname{TPS}$ con otros rellenos $[29,41]$. No obstante, con el fin de comparar los efectos del procesamiento sobre las propiedades de los materiales obtenidos y teniendo en cuenta los altos contenidos de almidón residual del bagazo (ver sección 4.4 del capítulo I), se realizó una prueba empleando la misma relación de sólidos entre almidón y bagazo empleadas en la preparación de películas por casting estudiadas en el capítulo I para la preparación de películas de TPS

\footnotetext{
${ }^{1}$ Las letras indican diferencias significativas $(p<0,05)$ entre medidas del mismo residuo, puesto que para todos los solventes evaluados las diferencias observadas entre ambos subproductos fueron significativos $(p<0,05)$.
} 
por termocompresión. Dado que no fue posible procesar algunas mezclan en la mezcladora y que la mayoría de las películas obtenidas en este caso no resultaron uniformes en las condiciones de operación empleadas, se decidió utilizar concentraciones de carga menores para el estudio de materiales compuestos de TPS con bagazo y cáscara de mandioca.
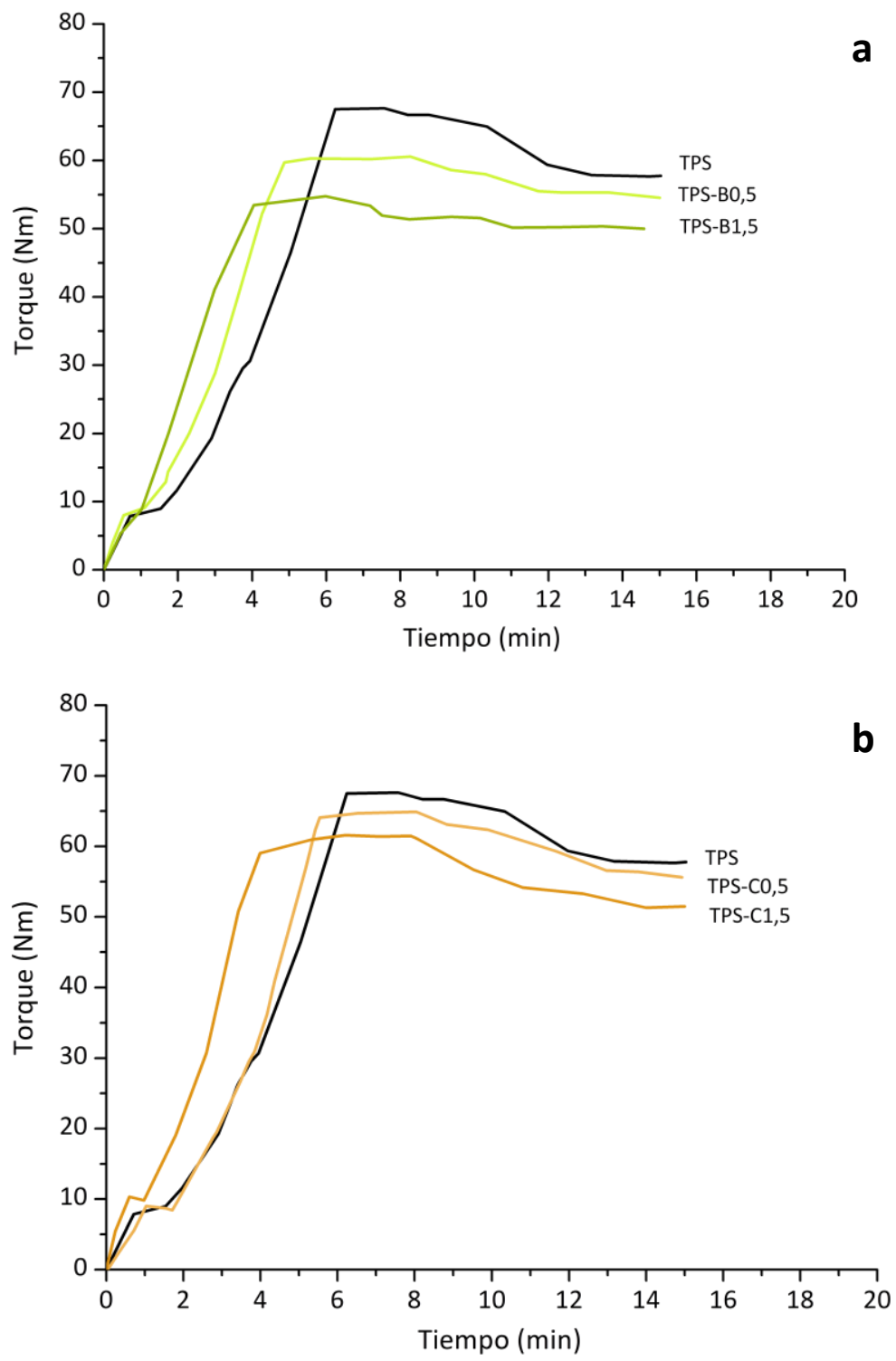

Figura III.3. Curvas de torque en función del tiempo de procesamiento obtenido para mezclas de TPS de mandioca control y aquellas que contienen 0,5 y $1,5 \% \mathrm{p} / \mathrm{p}$ de material de refuerzo respecto al contenido de almidón: (a) bagazo y (b) cáscara. 
Como ya se mencionó, las características de los materiales termoplásticos a base de almidón dependen fuertemente de las condiciones y tiempos de procesamiento, por ello es importante estudiar cómo se comportan las distintas mezclas durante el mismo. La Figura III.3 muestra las curvas de torque en función del tiempo de mezcla en el proceso de plastificación y mezclado en fundido de los biocompuestos desarrollados. Según Corradini y col. [42], el torque aumenta hasta un máximo en las etapas iniciales de procesamiento durante la plastificación de polímeros y luego disminuyen, alcanzando una meseta con un valor de estabilización, prácticamente constante.

Particularmente, en el caso de mezclas de almidón ensayadas, las curvas presentaron un pico de plastificación amplio e intenso, el torque aumentó hasta un valor máximo y se redujo a un valor estable en el tiempo. Al comienzo del procesamiento, el torque aumenta rápidamente debido al debilitamiento de la interacción entre las moléculas de almidón y el hinchamiento de los gránulos [43]. Luego, los cristales de almidón se funden bajo la acción de la fuerza mecánica de cizallamiento y el calor, disminuyendo los valores de torque. Finalmente, la masa fundida de almidón se homogeniza y el torque tiende a estabilizarse. Mościcki y col. [44] reportaron curvas de plastificación similares para el procesamiento de almidón de papa termoplástico, aunque emplearon mayores contenidos de plastificante y condiciones de procesamiento ligeramente diferentes.

Con la incorporación de las cargas, se pudo observar que la presencia de bagazo y cáscara de la mandioca no afectó el perfil de plastificación del almidón termoplástico. La Tabla III.2 muestra los parámetros característicos asociados al proceso de plastificación y fusión del almidón. La energía de plastificación se calculó como la integral bajo las curvas, desde el momento en que el torque comienza a aumentar hasta el momento en que se alcanza el punto máximo [18]. Esta región del proceso de mezclado está asociada a la difusión del plastificante dentro de las moléculas poliméricas. La inclusión de bagazo y cáscara en las formulaciones de TPS condujo a 
una reducción de la energía de plastificación, evidenciando una termodinámica más favorable del proceso de difusión de plastificante en los gránulos de almidón en presencia de los subproductos de mandioca [18].

Tabla III.2 - Parámetros del proceso de plastificación de biocompuestos a base de almidón termoplástico (TPS) con 0,5 y 1,5\%p/p de cáscaras (C) y bagazo (B)

\begin{tabular}{cccccc} 
BIOCOMPUESTO & TPS & TPS-C0,5 & TPS-C1,5 & TPS-B0,5 & TPS-B1,5 \\
\hline $\begin{array}{c}\text { Energía de } \\
\text { plastificación } \\
\text { (Nm min) }\end{array}$ & 165,95 & 131,15 & 103,73 & 125,98 & 103,99 \\
\hline $\begin{array}{c}\text { Torque máximo } \\
(\mathrm{Nm})\end{array}$ & 67,49 & 64,1 & 59,05 & 59,70 & 53,46 \\
\hline $\begin{array}{c}\text { Torque de } \\
\text { estabilización } \\
(\mathrm{Nm})\end{array}$ & 57,76 & 55,91 & 51,28 & 54,52 & 50,08 \\
\hline
\end{tabular}

Además, los compuestos reforzados presentaron menor torque máximo y tiempo para completar la etapa de plastificación que el TPS control. Estos resultados indicaron que la adición de residuos mejoró la capacidad de procesar el almidón bajo las condiciones operativas empleadas [43]. Por último, la incorporación tanto del bagazo como de la cáscara condujeron a una reducción del torque de torsión de estabilización alcanzado al final del procesamiento que podría asociarse a una disminución de la viscosidad de la mezcla fundida de TPS [18].

La degradación térmica y la estabilidad de materiales a base de almidón durante el procesamiento son cuestiones importantes tanto desde perspectivas académicas como industriales [19]. El análisis termogravimétrico (TGA) ha sido la técnica más utilizada para estudiar la estabilidad térmica y la descomposición del almidón de diferentes fuentes [45-47]. El conocimiento de la temperatura degradación y modo de descomposición por calor son altamente recomendados en la optimización del proceso de producción de termoplásticos [13]. La deshidratación y la descomposición se han considerado generalmente como los dos procesos principales asociados con 
los mecanismos de degradación del almidón $[12,19]$. Aunque las degradaciones de los polímeros se estudian habitualmente bajo atmósferas inertes, la degradación en un entorno de oxígeno o aire es igualmente importante. Por lo tanto, se estudió la degradación oxidativa térmica de los biocompuestos de TPS con el fin de proporcionar información relevante sobre cómo se comportan estos materiales en condiciones atmosféricas más realistas $[48,49]$.

La Figura III.4 muestra la pérdida de peso en función de la temperatura de calentamiento, así como las primeras derivadas correspondientes a los materiales compuestos desarrollados. Junto con el aumento de la temperatura, se producen varias reacciones de estado sólido y transiciones de fase, tales como fusión, evaporación y sublimación, así como condensación química, descomposición y finalmente carbonización a muy altas temperaturas [50]. Como puede observarse, todas las curvas presentaron un comportamiento similar, mostrando que se producen cuatro etapas de pérdida de peso, lo que indica que la adición de los subproductos de la mandioca no modificó las curvas TGA de los compuestos de TPS (Figura III.4).

Cada etapa corresponde a un pico en la curva de la derivada primera que representa un evento separado en un rango de temperatura particular. La pérdida de peso correspondiente a la desorción del agua, que generalmente comienza justo por encima de la temperatura ambiente $\left(\sim 70^{\circ} \mathrm{C}\right)$, no se observó en ninguno de los biocompuestos. Este resultado podría ser indicativo del bajo contenido de agua absorbida por el material. Resultados similares fueron reportados por Mano y col. [13] para mezclas de almidón termoplástico y un polímero sintético. El proceso de degradación observado alrededor de $150^{\circ} \mathrm{C}$ se podría atribuir a la pérdida de glicerol, como ha sido informado previamente por otros autores $[13,51]$. La pérdida de peso más sustancial, que ocurre alrededor de $318^{\circ} \mathrm{C}$, se asoció con la degradación de las moléculas constitutivas del almidón. Durante este proceso, se crean enlaces éter y estructuras no saturadas por reacciones de condensación térmica entre los grupos hidroxilo de las cadenas de 

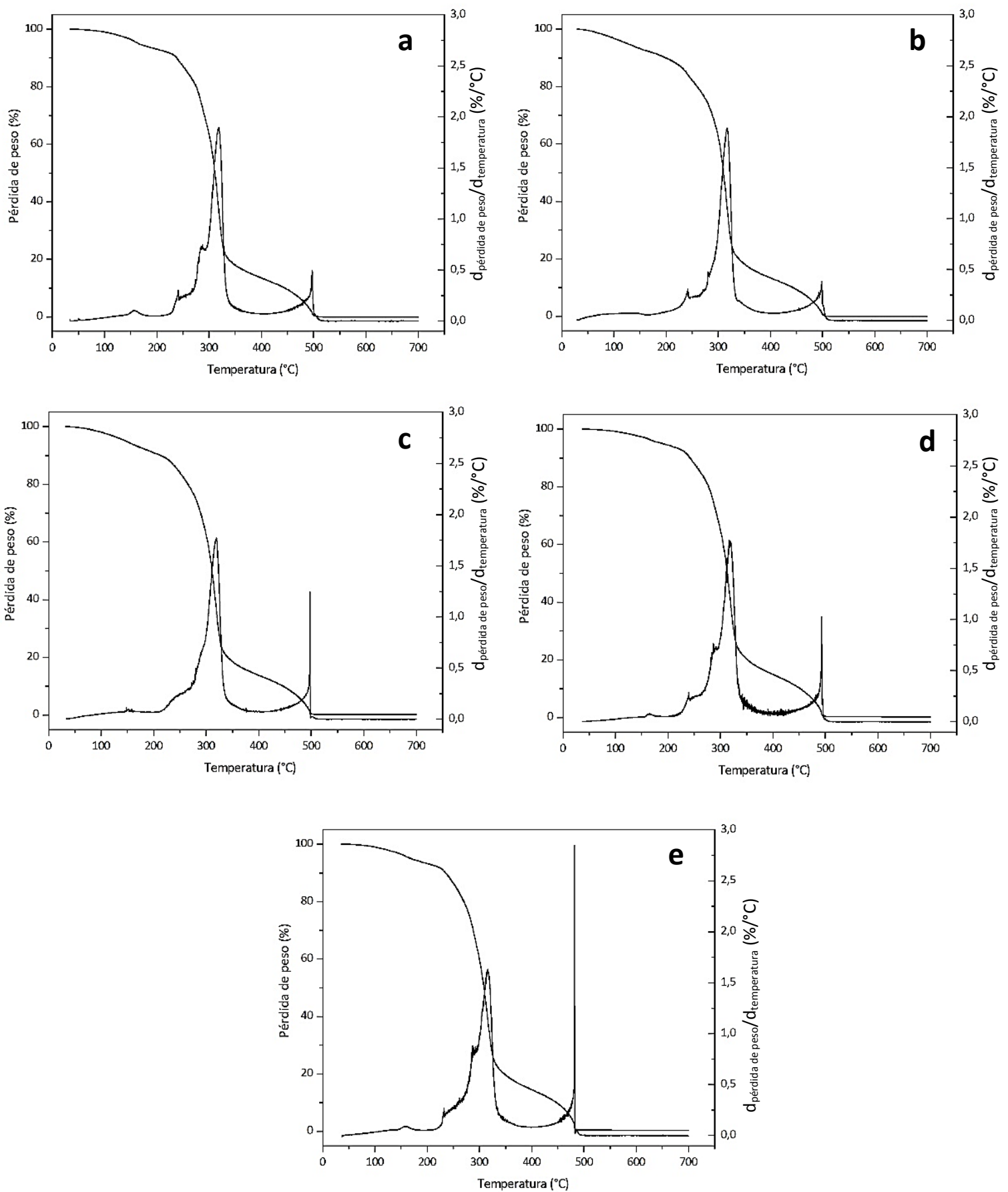

Figura III.4. Pérdida de peso en función de la temperatura de calentamiento y curvas de la primera derivada de biocompuestos a base de almidón de mandioca y sus subproductos: a) TPS; b) TPS-B0,5; c) TPS-B1,5; d) TPS-C0,5; y e) TPS-C1,5. 
los constituyentes del almidón, con eliminación del agua y otras moléculas pequeñas y por deshidratación de los grupos hidroxilo en el anillo glucosídico [52]. El hombro en el pico de degradación del almidón puede deberse a la diferente velocidad de degradación de la amilosa y la amilopectina. La estructura lineal de la amilosa da lugar a grupos hidroxilo más expuestos, mientras que la estructura ramificada de la amilopectina dificulta el acceso a estos grupos funcionales. La última etapa de pérdida de peso, que se observó alrededor de $490{ }^{\circ} \mathrm{C}$, se atribuyó a las reacciones de combustión de los residuos carbonosos en presencia de oxígeno, formando gases simples como $\mathrm{CO}, \mathrm{CO}_{2}$ y $\mathrm{H}_{2} \mathrm{O}$. Esta etapa de descomposición adicional denominada "combustión incandescente" se produce cuando la degradación térmica ocurre en la atmósfera de oxígeno $[19,53]$.

\subsection{Caracterización microestructural de los compuestos de TPS}

La espectroscopía FTIR se utilizó para investigar los cambios en la estructura del TPS a un nivel molecular de corto alcance y para identificar las posibles interacciones entre el almidón, el glicerol y los rellenos empleados. Yin y col. [54] destacaron que cuando se mezclan dos o más sustancias, las interacciones químicas entre los componentes se evidencian a través de cambios en las bandas espectrales características de los grupos funcionales que participan en dichas interacciones. La Figura III.5 muestra los espectros FTIR correspondientes al residuo de la mandioca, la matriz de TPS control y los biocompuestos que contienen los rellenos con distintas concentraciones. De los compuestos puros se detectaron y asignaron bandas características. Las principales diferencias entre los espectros de ambos subproductos son la presencia del pico a $1518 \mathrm{~cm}^{-1}$, señal típica de la lignina (ver Tabla II.1 del capítulo II), así como el ancho y posición de la banda alrededor de $3400 \mathrm{~cm}^{-1}$. Estos resultados se relacionan con las diferencias en la composición química, como se ha descrito anteriormente, principalmente a los contenidos de proteína y lignina en la cáscara de mandioca (Tabla III.1). 


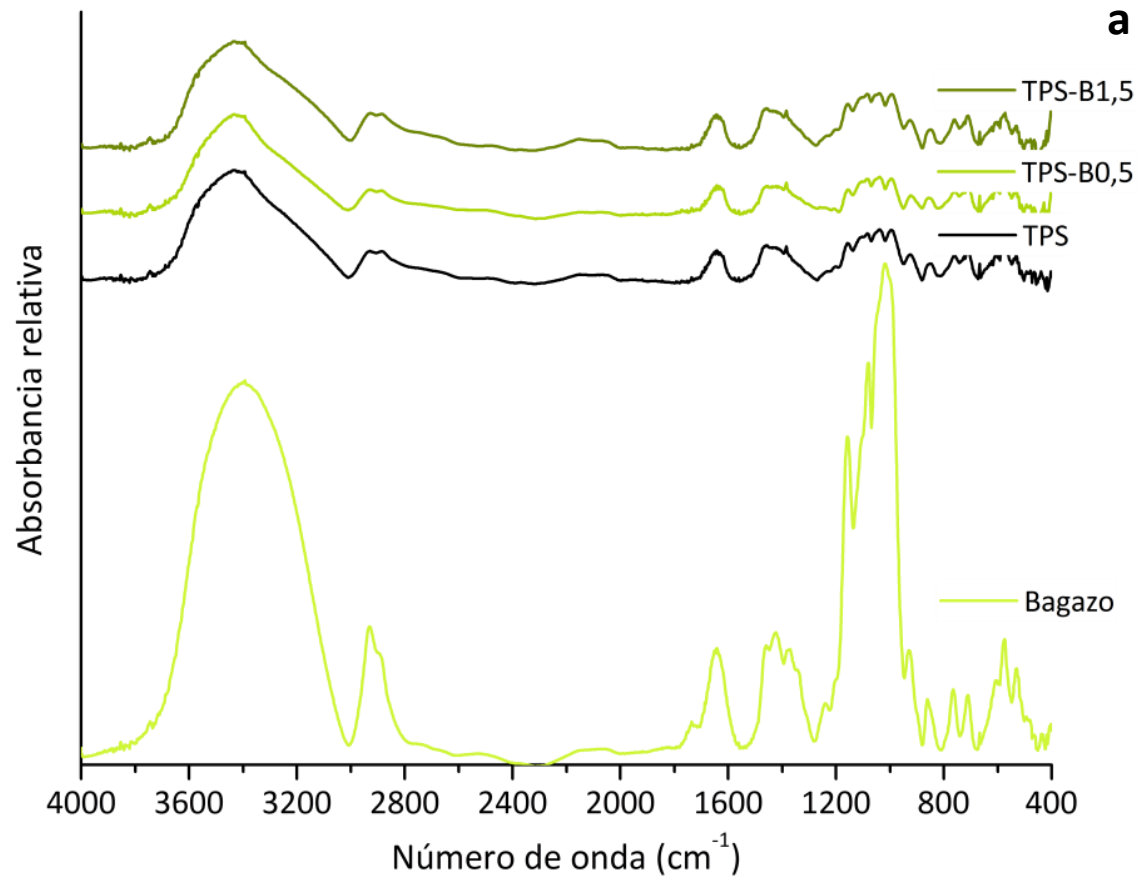

a

, 5 
Los compuestos de TPS de mandioca presentaron bandas correspondientes a los grupos funcionales distintivos del almidón y el glicerol. El pico ancho observado alrededor de $3400 \mathrm{~cm}^{-1}$ se asocia al estiramiento de los grupos $\mathrm{O}-\mathrm{H}$. Las bandas identificadas a 2929 y $2881 \mathrm{~cm}^{-1}$ se atribuyen al estiramiento de $\mathrm{C}-\mathrm{H}$. El pico a $1642 \mathrm{~cm}^{-1}$ se asignó al modo de plegado del agua absorbida. Los picos cerca de $1420 \mathrm{~cm}^{-1}$ se asignan a la unión de $\mathrm{O}-\mathrm{H}$, mientras que los picos a 1155 y $1040 \mathrm{~cm}^{-1} \mathrm{se}$ atribuyeron al estiramiento del enlace $\mathrm{C}-\mathrm{O}$ del grupo $\mathrm{C}-\mathrm{O}-\mathrm{H}$ en el almidón de mandioca y al estiramiento del enlace $\mathrm{C}-\mathrm{O}$ del grupo $\mathrm{C}-\mathrm{O}-\mathrm{C}$ en el anillo de anhidroglucosa, respectivamente $[55,56]$. Adicionalmente, el pico detectado a $1456 \mathrm{~cm}^{-1}$ fue atribuido al glicerol [57]. El espectro del TPS compuesto presentó las señales correspondientes principalmente a la matriz de TPS, independientemente del subproducto de mandioca incorporado.

Además, las intensidades de las bandas de relleno en los compuestos de TPS fueron relativamente débiles debido a su baja concentración en las formulaciones. La banda situada a $3421 \mathrm{~cm}^{-1}$ viró a 3408 y $3412 \mathrm{~cm}^{-1}$ para TPS que contenían bagazo y cáscara al 0,5\%, respectivamente. En los biocompuestos que contenían 1,5\% de bagazo de mandioca, el pico mencionado se desplazó a $3396 \mathrm{~cm}^{-1}$, cuanto mayor es el contenido de relleno mayor es el desplazamiento, mientras que en el caso de la cáscara de mandioca se desplazó a $3418 \mathrm{~cm}^{-1}$. Estos cambios podrían atribuirse a las interacciones por enlaces puente de hidrógeno entre grupos hidroxilo del almidón de mandioca y grupos específicos de lignina, celulosa y hemicelulosa de los subproductos. Bodirlau y col. [58] enfatizaron que estas interacciones de unión puente de hidrógeno ocurren posiblemente entre grupos hidroxilo y carbonilo en el almidón y grupos carbonilo, hidroxilo y éter en la lignina e hidroxilo en componentes celulósicos.

Así, los resultados de FTIR revelaron cambios en la matriz de TPS debido a los subproductos de la mandioca los que se atribuyeron principalmente a la interacción química entre las moléculas de almidón y de material de relleno por formación de 
enlaces puente de hidrógeno que se favorecen durante el procesamiento de las mezclas. Del mismo modo, considerando que la cáscara de mandioca contiene un $7 \%$ de proteínas, la presencia de grupos $-\mathrm{NH}_{2}$ podría contribuir a potenciar las interacciones puente de hidrógeno de las mezclas, lo que permite explicar los cambios observados. Sin embargo, el pico característico de la lignina a $1518 \mathrm{~cm}^{-1}$, identificado en el espectro de la cáscara pura, no pudo ser detectado en compuestos que contenían este subproducto, probablemente debido a su baja concentración (Figura III.5).

Una vez que las mezclas de TPS de mandioca fueron sometidas a compresión térmica, se obtuvieron películas. Las imágenes obtenidas de las películas de TPS de mandioca (Figura III.6a) mostraron superficies homogéneas, lo cual indica que durante el procesamiento de las mezclas de almidón los gránulos de almidón se termoplastificaron completamente. La dispersión de los materiales de carga se estudió mediante la técnica SEM, detectándose que las partículas de relleno cerca de la superficie se encontraban recubiertas por la matriz de almidón plastificado (Figuras III.6.b y c). Esta observación es indicativa de una buena adhesión de los rellenos naturales a la matriz.
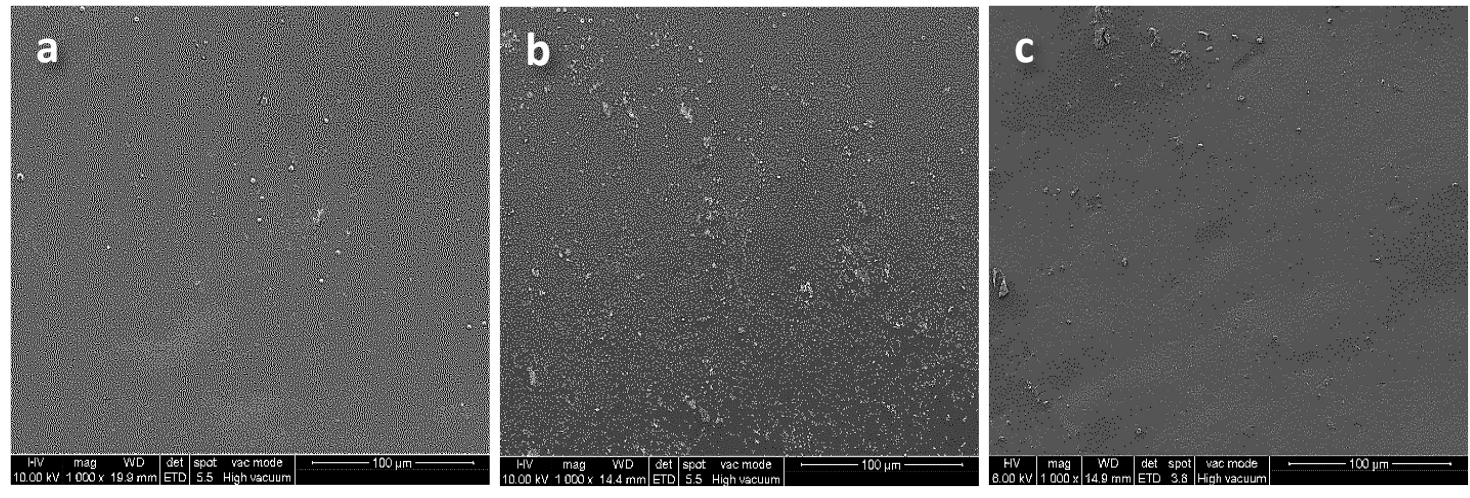

Figura III.6. Imágenes por microscopía electrónica de barrido de la superficie de películas de almidón termoplástico de mandioca (1000x): (a) TPS, (b) TPS-C0,5 y (c) TPS-B0,5. 
Los resultados de la microscopía SEM se correlacionan con aquellos obtenidos por FTIR. Ma y col. [59] también observaron el mismo efecto en películas de TPS que contenían microfibras de algodón y las atribuyeron a la fuerte interacción entre las fibras y la matriz. No obstante, la presencia de bagazo y cáscara parece aumentar ligeramente la rugosidad de la superficie, dando lugar a una menor homogeneidad. Este efecto fue más evidente en las formulaciones que contenían cáscara como relleno, a pesar de las bajas concentraciones utilizadas (Figura III.6b), probablemente debido al mayor contenido de partículas de mayor tamaño (Figura III.1b). Una tendencia similar fue informada por Bodirlau y col. [58] en el estudio de biocompuestos a base de almidón con micropartículas químicamente modificadas de fibras de queratina, celulosa o lignina.

\subsection{Propiedades térmicas}

Las propiedades térmicas del material (temperatura de transición vítrea y temperatura de fusión) fueron estudiadas por DMTA y DSC, respectivamente. Los ensayos DMTA de TPS de mandioca y sus biocompuestos muestran dos transiciones claras: la primera, a temperaturas más bajas $\left(\operatorname{Tg}_{1}\right)$, se atribuye a una fase rica en glicerol; mientras que la segunda, por lo general por encima de la temperatura ambiente $\left(\operatorname{Tg}_{2}\right)$, se considera la transición propia del TPS (Figura III.7).

Se observó un aumento en esta segunda temperatura de transición para los materiales de TPS reforzados con los subproductos de mandioca, resultando este desplazamiento más alto para aquellos que contenían cáscara como relleno. Otros autores han informado comportamientos similares en TPS de maíz reforzado con fibras naturales [60, 61]. Las temperaturas de transición vítrea más altas podrían ser indicativas de las interacciones de tipo puente de hidrógeno más fuertes entre el material de refuerzo y la matriz, en concordancia con los desplazamientos observados por FTIR en la banda situada alrededor de $3400 \mathrm{~cm}^{-1}$. Además, se observó una disminución de la intensidad máxima de $\tan \delta$ en ambas películas de TPS reforzado que, según Gironès y col. [60], 
indica que la presencia de carga promueve la inhibición de los procesos de relajación, conduciendo así a sistemas más rígidos.

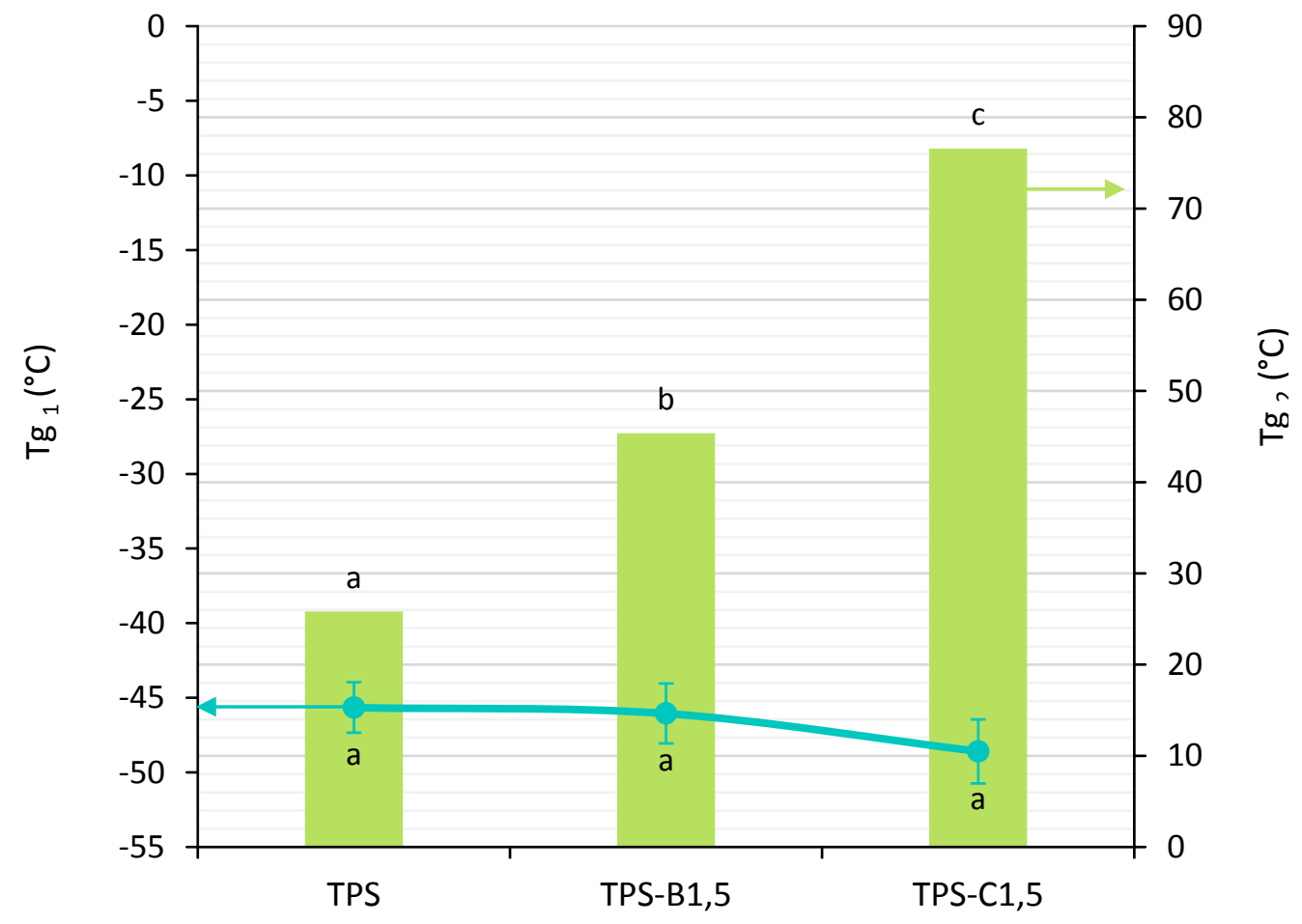

Figura III.7. Temperaturas de transición vítrea $\left(\operatorname{Tg}_{1}\right.$ y $\left.\operatorname{Tg}_{2}\right)$ de películas TPS con bagazo de mandioca y cáscaras como material de relleno determinadas por DMA.

Además, la transición de fusión de las películas de TPS aparece como un único pico endotérmico marcado (Figura III.8). EI TPS reforzado mostró un proceso de fusión menos cooperativo que el TPS de mandioca, posiblemente debido al gran número de interacciones involucradas en las matrices con más componentes. Por otra parte, las películas de TPS con la cáscara de mandioca al 1,5\% presentaron una temperatura de pico más alta, que se correlaciona con la mayor temperatura de transición vítrea $\left(\operatorname{Tg}_{2}\right)$ observada para este material. 


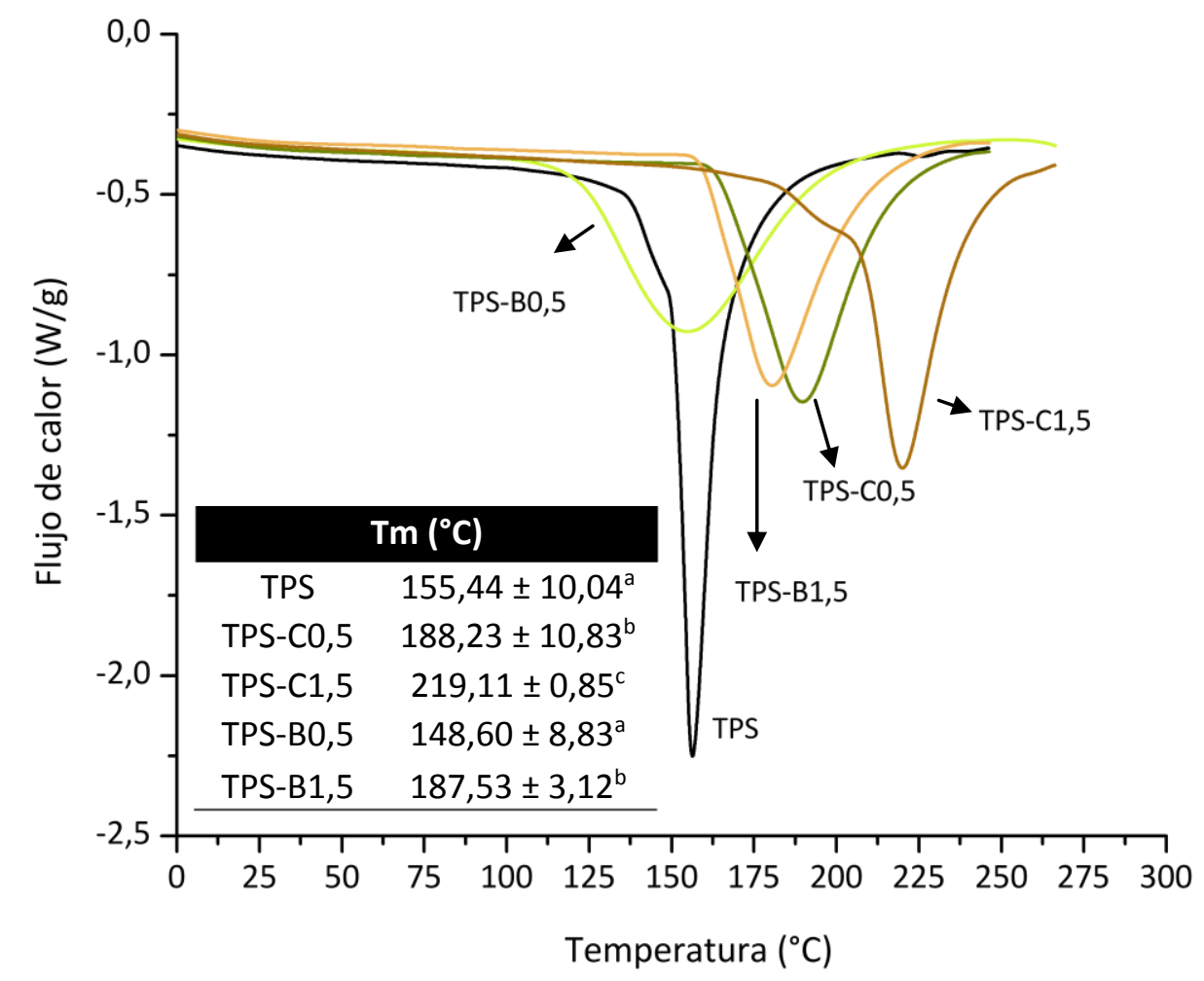

Figura III.8. Termogramas de DSC y temperaturas de fusión Tm de películas TPS con bagazo de mandioca y cáscaras como material de relleno.

\subsection{Propiedades ópticas}

El aspecto general de todas las películas de TPS estudiadas fue homogéneo y transparente, con un ligero tono amarronado. El efecto de la adición de la carga sobre los parámetros de color de las películas plastificadas se muestra en la Tabla III.3. Por un lado, el parámetro de luminosidad $\left(L^{*}\right)$ disminuyó significativamente $(p<0,05)$ con el contenido de cáscara mientras que el parámetro chroma $\left(C^{*}\right)$ y la diferencia de color $(\Delta \mathrm{E})$ aumentó. El cambio en el tono $\left(\mathrm{h}^{\circ}\right)$, sin embargo, disminuyó ligeramente con este relleno (C). Bodirlau y col. [58] enfatizaron que los tamaños de partícula de carga mayores que la longitud de onda visible obstaculizan la luz, minimizando la transparencia de las películas biocompuestas a base de almidón, siendo el mayor 


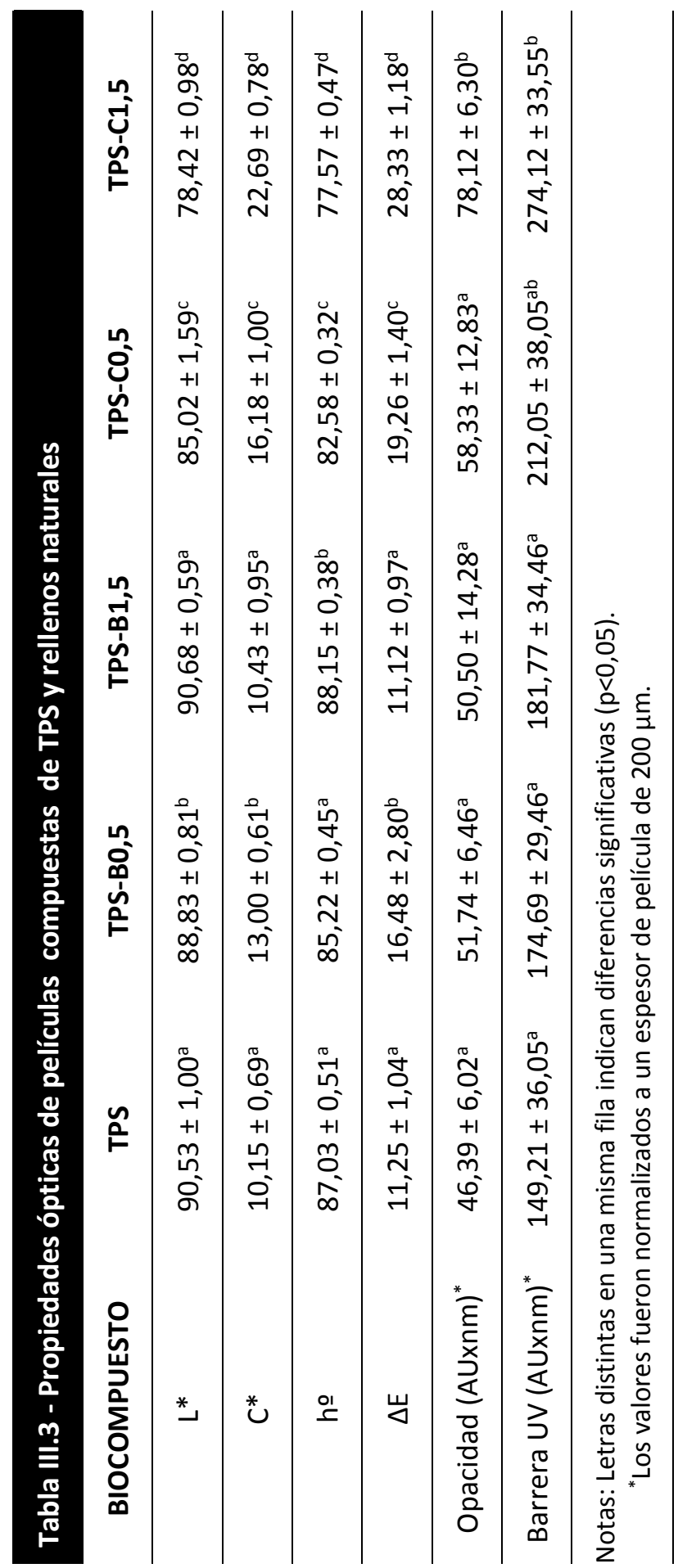


efecto debido a la presencia de lignina. Por consiguiente, cuanto mayor sea el tamaño de partícula menor será la transmisión de luz. Esto explica por qué los materiales que contenían la cáscara de la mandioca, con tamaños de partícula mayores que la del bagazo, presentaron valores de luminosidad más bajos y valores de opacidad mayores a la misma concentración de carga (Tabla III.3). Por otro lado, el TPS compuesto que contenía bagazo presentó un efecto moderado, siendo los parámetros de color similares a los del TPS. Los resultados se correlacionan con la composición química de la carga, que como se describió anteriormente, exhibe una proporción importante de carbohidratos, principalmente almidón. Conforme con el incremento de color de las muestras reforzadas de TPS, se observó un aumento en la absorbancia a través de la región UV del espectro de películas de TPS cuando se añaden los subproductos de mandioca a la matriz de almidón (Figura III.9).

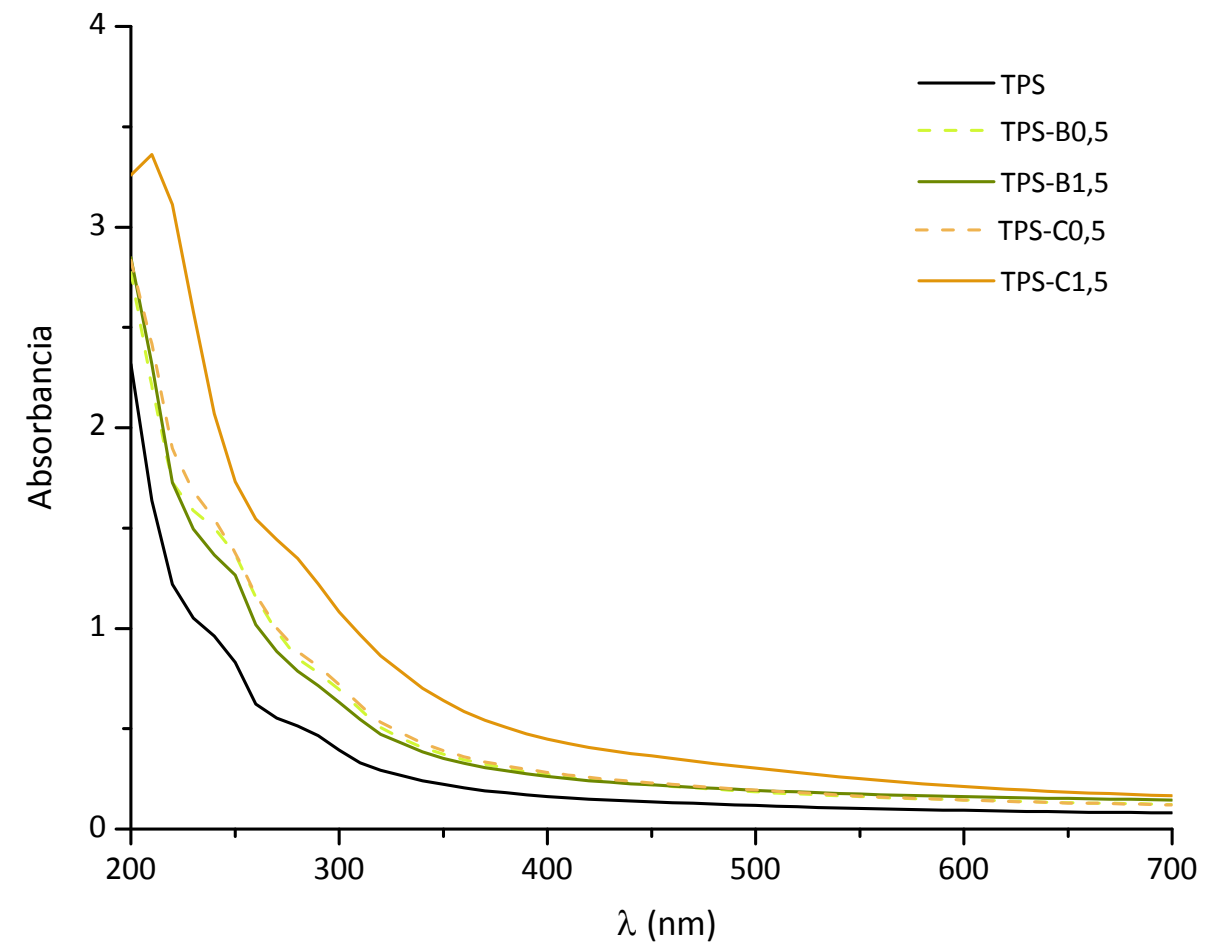

Figura III.9. Espectros de UV-vis de películas de TPS que contienen subproductos de la extracción de almidón de mandioca como cargas naturales. 
Mbey y col. [62] informaron una tendencia similar para las películas compuestas de almidón de mandioca y caolinita. El estudio de la capacidad de absorción de luz UV de las películas biodegradables es especialmente relevante para determinar sus posibles aplicaciones como material de empaque. La Figura III.9 muestra los espectros UV-vis obtenidos para las películas plastificadas estudiadas. Para estimar la capacidad de barrera UV de las películas reforzadas, se calculó el área bajo la curva en la región UV (200 - 400 nm). Como era de esperar, este parámetro aumentó con el contenido de relleno, aunque la cáscara tuvo un efecto de bloqueo más importante que el bagazo. El aumento de la capacidad de barrera UV de las películas de TPS reforzadas con cáscara de mandioca podría atribuirse principalmente a los componentes fenólicos de la lignina [63]. Del mismo modo, la opacidad se calculó a partir del espectro visible (400 - $700 \mathrm{~nm}$ ) y presentó una tendencia similar aunque menos pronunciada (Tabla III.3).

\subsection{Propiedades mecánicas y de barrera}

La incorporación de agentes de refuerzo a los materiales a base de almidón termoplástico, busca mejorar sus propiedades mecánicas finales. La Figura III.10 muestra los perfiles mecánicos característicos correspondientes a películas de TPS de mandioca y los materiales biocompuestos que contienen los subproductos de mandioca, obtenidos mediante ensayos cuasiestáticos de tensión uniaxial. Como puede verse la adición de los rellenos no modificó el comportamiento dúctil de las películas de TPS. La Tabla III.4 muestra las propiedades mecánicas obtenidas a partir de curvas de tensión-deformación. Como se puede observar, la incorporación de ambos subproductos de mandioca como agentes de refuerzo de la matriz de TPS condujo a películas más fuertes, aunque se usaron concentraciones bajas de carga. Este resultado fue evidenciado por el incremento en la resistencia máxima a la tracción y los valores de módulo elástico de las películas de TPS debido a la adición de subproductos (Tabla III.4). 
Tabla III.4 - Propiedades mecánicas de los materiales compuestos a base de TPS mandioca

\begin{tabular}{ccccc} 
BIOCOMPUESTO & $\begin{array}{c}\mathbf{E}_{\mathbf{c}} \\
(\mathbf{M P a})\end{array}$ & $\begin{array}{c}\boldsymbol{\sigma}_{\max } \\
(\mathbf{M P a})\end{array}$ & $\begin{array}{c}\boldsymbol{\varepsilon}_{\max } \\
\mathbf{( \% )}\end{array}$ & $\begin{array}{c}\text { Espesor } \\
(\boldsymbol{\mu m})\end{array}$ \\
\hline TPS & $38,78 \pm 4,26^{\mathrm{a}}$ & $1,68 \pm 0,37^{\mathrm{a}}$ & $11,03 \pm 2,58^{\mathrm{a}}$ & $200,53 \pm 7,43^{\mathrm{a}}$ \\
TPS-B0,5 & $45,71 \pm 1,52^{\mathrm{b}}$ & $1,79 \pm 0,67^{\mathrm{a}}$ & $10,98 \pm 2,72^{\mathrm{a}}$ & $183,53 \pm 4,42^{\mathrm{b}}$ \\
TPS-B1,5 & $82,71 \pm 4,89^{\mathrm{c}}$ & $4,35 \pm 0,52^{\mathrm{b}}$ & $15,69 \pm 1,43^{\mathrm{b}}$ & $192,39 \pm 11,67^{\mathrm{a}, \mathrm{b}}$ \\
TPS-C0,5 & $64,71 \pm 0,13^{\mathrm{d}}$ & $3,45 \pm 0,11^{\mathrm{c}}$ & $11,65 \pm 1,26^{\mathrm{a}}$ & $187,35 \pm 23,60^{\mathrm{ab}}$ \\
TPS-C1,5 & $63,98 \pm 5,85^{\mathrm{d}}$ & $2,96 \pm 0,38^{\mathrm{d}}$ & $11,65 \pm 2,75^{\mathrm{a}, \mathrm{b}}$ & $193,13 \pm 8,89^{\mathrm{ab}}$ \\
\hline
\end{tabular}

Nota: Letras distintas en una misma columna indican diferencias significativas $(p<0,05)$.

Aunque los materiales compuestos con $0,5 \% \mathrm{p} / \mathrm{p}$ de bagazo exhiben valores mayores de esfuerzo máximo y módulo elástico, las diferencias fueron solo significativas $(p<0,05)$ en el caso del módulo elástico $(E c)$. Por otro lado, la presencia de 1,5\%p/p de bagazo dio lugar a un aumento importante $(p<0,05)$ en las propiedades mecánicas. En este sentido, el esfuerzo máximo a la ruptura de los compuestos TPS-B1,5 resultó 128 $\%$ más alto que el valor correspondiente de la matriz de TPS; mientras que el módulo elástico de las películas de almidón aumentó 2,6 veces con incorporación de bagazo de 1,5\%p/p. La naturaleza fibrosa del bagazo, así como el contenido remanente de almidón podría ser responsable de la capacidad de refuerzo de este relleno orgánico. Estos resultados están de acuerdo con los reportados por varios autores de películas a base de almidón reforzadas con fibras de diferentes orígenes [58, 60, 64-67]. Este aumento significativo en la rigidez de las películas de TPS podría atribuirse principalmente a la adhesión intrínseca entre el relleno y la matriz debido a las estructuras químicas similares del almidón y el bagazo [59]. Específicamente, Vallejos y col. [67] también subrayaron que la adición de fibras de bagazo mejoró considerablemente la rigidez de los materiales a base de almidón de maíz termoplástico. Por otra parte, las películas de TPS que contenían bagazo de 1,5\%p/p exhibían un mayor módulo elástico que aquellas con la misma cantidad de cáscara, evidenciando la mayor eficacia del bagazo como material de refuerzo (Tabla III.4). Este 
resultado podría atribuirse principalmente a dos contribuciones. En primer lugar, puede asociarse al mayor contenido de almidón residual en el bagazo que en la cáscara, lo que contribuye al desarrollo de una estructura de matriz más densa. Por otra parte, la diferencia en el contenido de fibra en ambos subproductos podría ser el otro factor responsable de su capacidad de refuerzo diferencial. En particular, la presencia de $1,5 \% \mathrm{p} / \mathrm{p}$ de cáscara de mandioca en TPS se asocia a una disminución en el módulo elástico con respecto a los biocompuestos que contienen 0,5\%p/p. Este comportamiento podría estar relacionado con el mayor contenido de partículas más grandes, lo que condujo a un material menos homogéneo (Figura III.6b), y podría promover defectos estructurales.

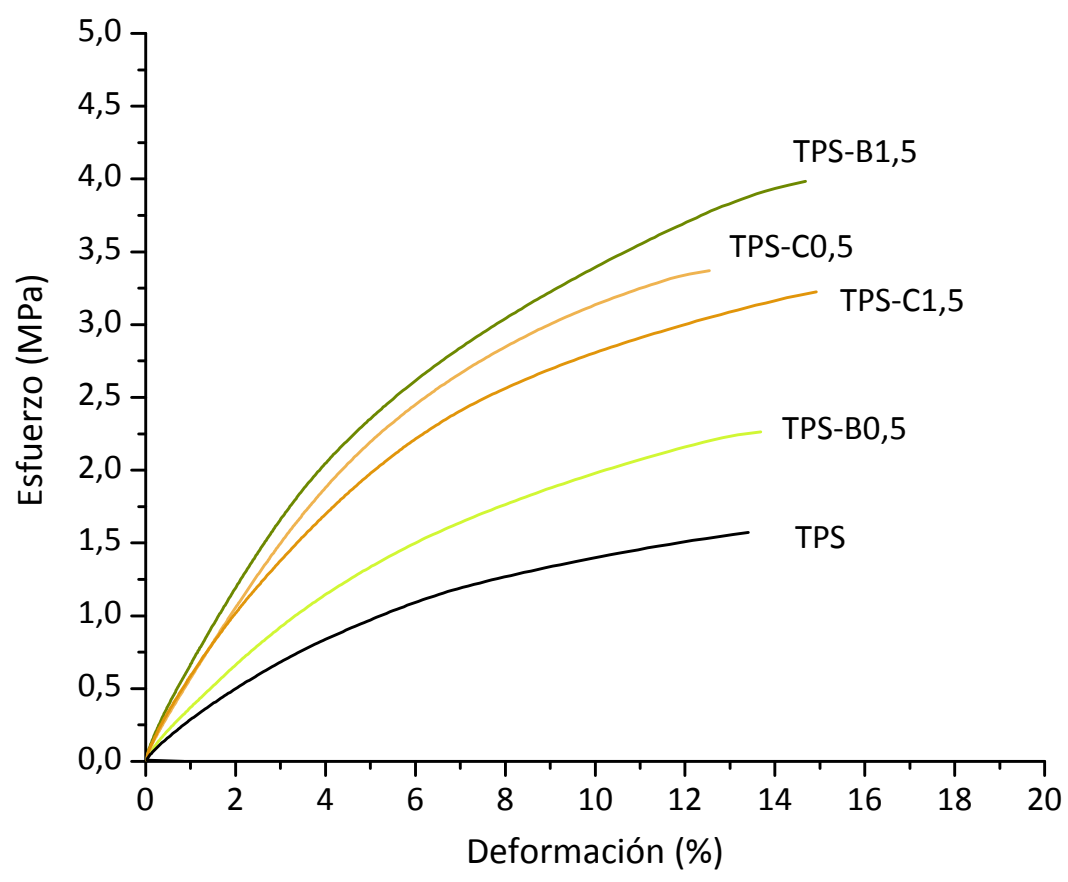

Figura III.10. Curvas de esfuerzo-deformación de películas de TPS de mandioca con y sin rellenos naturales obtenidas por ensayos de tensión uniaxial en DMA.

Con respecto a la elongación en la ruptura, la adición de 0,5%p/p de bagazo no afectó significativamente $(p>0,05)$ esta propiedad mecánica de las películas de TPS (Figura III.10). Sin embargo, la incorporación de la concentración ensayada más alta de 
este subproducto aumentó alrededor del $42 \%$ los valores de elongación del TPS. Este resultado podría atribuirse a la orientación y dispersión del bagazo en la matriz de TPS, atribuida a la eficiencia del proceso de fusión y termocompresión, mejorando la capacidad del material para deformarse hasta la fractura. El hecho de que la ductilidad de las películas TPS aumente con la presencia de bagazo es un aspecto positivo debido a que esta propiedad mecánica es relevante para el procesamiento industrial y potenciales aplicaciones. Asimismo, aunque la adición de la cáscara a un 1,5\%p/p condujo a un incremento en los valores de deformación de las películas de almidón, este efecto no fue significativo ( $p>0,05)$ (Figura III.10).

Como una de las funciones principales de los materiales para envases es impedir la transferencia de humedad de la atmósfera al producto, la WVP debe ser tan baja como sea posible. Debido al carácter hidrófilo del almidón, los materiales a base de TPS tienen pobres propiedades de barrera al vapor de agua y una alternativa para superar esta limitación es incorporar diferentes cargas, como ya se mencionó. En este respecto, varios autores han reportado la reducción de la WVP de materiales basados en almidón mediante la adición de diferentes rellenos naturales, especialmente fibras de diversos orígenes $[56,68]$. La Figura III.11 muestra el efecto de la presencia de bagazo y cáscara sobre la WVP de películas de TPS de mandioca.

El valor obtenido para las películas de TPS de mandioca fue similar al de los materiales basados en almidones de diferentes orígenes botánicos. López y col. [41] informaron que las películas de TPS de maíz, desarrolladas por mezcla en estado fundido y termocompresión, presentaron una WVP de $1,36 \times 10^{-10} \mathrm{~g} / \mathrm{m} \mathrm{s} \mathrm{Pa}$; y Phan y col. [69] enfatizaron que las películas de almidón de arroz nativo tenían una WVP de $1,67 \times 10^{-10} \mathrm{~g} / \mathrm{m}$ s Pa. Por otra parte, las películas a base de almidón de mandioca y de maíz plastificadas con glicerol al 1,5\% obtenidas por casting exhibieron valores WVP de 1,4 y $1,2 \times 10^{-10} \mathrm{~g} / \mathrm{m}$ s Pa, respectivamente [70]. Además, Han [71] informó un valor de $1,12 \times 10^{-10} \mathrm{~g} / \mathrm{m}$ s Pa para las películas de almidón de mandioca. Contrariamente a 


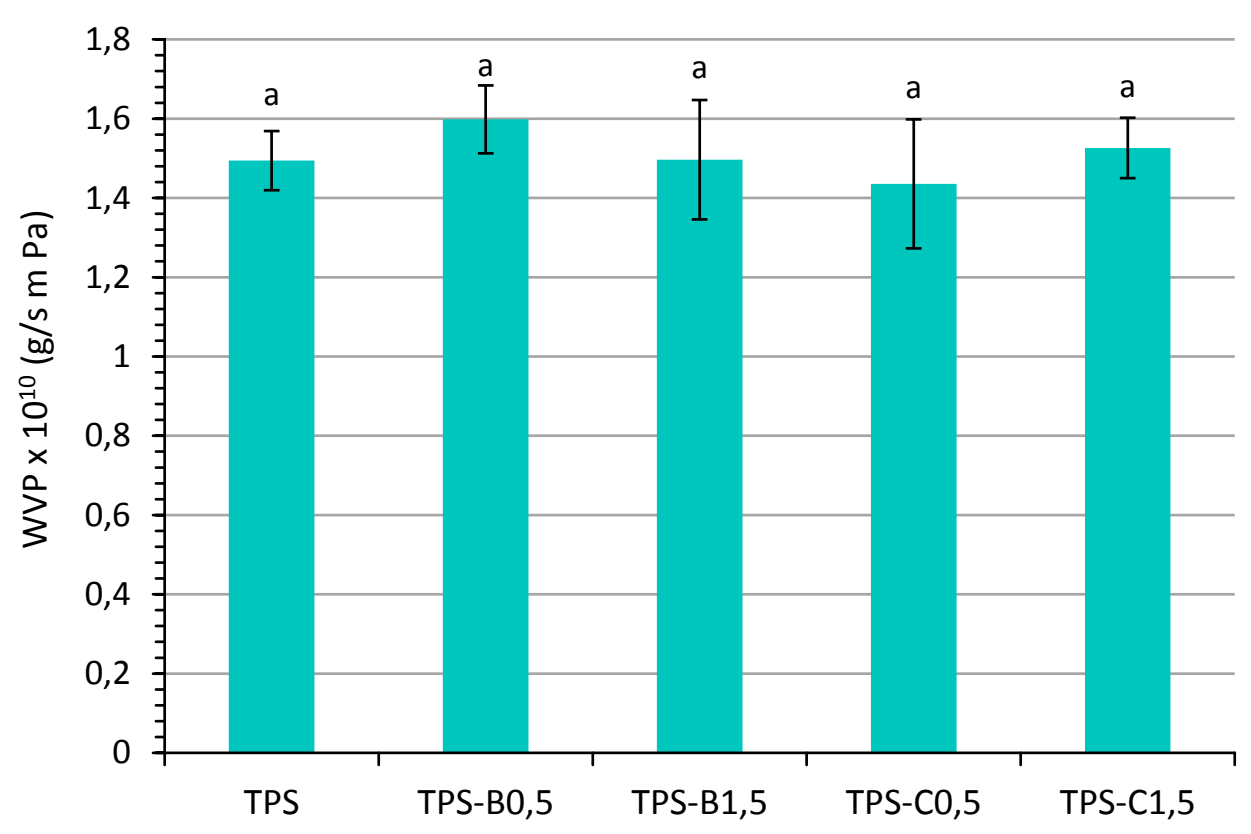

Figura III.11. Permeabilidad al vapor de agua (WVP) de películas de TPS que contienen subproductos de mandioca como rellenos naturales.

lo esperado, no se observaron influencias significativas $(p>0,05)$ sobre la WVP de películas con la incorporación de subproductos de mandioca. Sin embargo, cuando se desarrollaron películas de almidón de mandioca que contenían 0,75, 1,5 y 3 \% de bagazo de mandioca por casting, discutidas en el capítulo I, se observó un aumento en WVP. Este resultado revela un efecto claro del método de procesamiento sobre las propiedades finales de los materiales desarrollados, especialmente sobre la propiedad de barrera al vapor de agua. Este comportamiento podría atribuirse a dos factores de compensación. En primer lugar, es bien sabido que la presencia de carga aumenta la tortuosidad de la vía de las moléculas de agua, disminuyendo los valores de WVP. Por otro lado, el método de procesamiento podría favorecer la generación de huecos y defectos estructurales en la matriz lo que facilita el transporte de las moléculas de agua, incrementando la WVP. La compensación de estos dos factores ayuda a explicar los resultados obtenidos. 


\section{CONCLUSIONES}

En este capítulo se caracterizaron y compararon los subproductos de la extracción de almidón de mandioca: bagazo y cáscara. Se observó que la cáscara contenía mayores cantidades de fibra y proteína que el bagazo, siendo el almidón el componente principal del último. La composición química determinó la capacidad de retención de solventes de los subproductos de la mandioca, resultados que se correlacionan debidamente. Por otra parte, la cáscara presentó una mayor proporción de partículas más grandes, lo que afectó a la morfología SEM del TPS, sus propiedades mecánicas, y de barrera.

Bajo las condiciones de procesamiento ensayadas las interacciones entre almidón y relleno se vieron favorecidas, lo que conduce a menores energías de mezcla requeridas, que fueron evidenciadas por menores valores de torque registrados. La compatibilidad entre matriz y relleno fue la esperada, debido a su similar naturaleza química, la cual fue demostrada por análisis de FTIR y TGA.

Asimismo, las propiedades térmicas de los compuestos de TPS se correlacionan con los desplazamientos de banda observados por FTIR. Los incrementos observados en la segunda transición vítrea $\left(\operatorname{Tg}_{2}\right)$ y el punto de fusión $(\mathrm{Tm})$ se atribuyen a que la composición global de la matriz de los materiales compuestos es más heterogénea y por tanto existen una mayor diversidad de interacciones entre los componentes.

Además, la adición de las cargas aumentó la capacidad de barrera UV y la opacidad de los materiales TPS, especialmente aquellos que contienen cáscara, siendo este efecto dependiente de la concentración de relleno empleado.

A pesar de la baja concentración utilizada, ambos subproductos refuerzan las matrices de TPS, siendo el bagazo el material de relleno más eficiente debido a su alto contenido en almidón residual y menor proporción de partículas de mayor tamaño. No obstante 
los resultados obtenidos son apreciablemente menores a los de otros biomateriales como el PLA o PCL.

A priori los materiales obtenidos podrían emplearse para envases por ejemplo de sales y mezclas de fertilizantes dosificados que pueden disolverse in-situ para su aplicación sin tener residuos excesivos. De este modo, en el presente trabajo de Tesis se propone un enfoque integral del uso de las raíces de mandioca, puesto que se desarrollaron biocompuestos de TPS de mandioca y los componentes restantes de la extracción de almidón (cáscara y bagazo) como agentes de refuerzo.

No obstante, se necesitan estudios adicionales considerando concentraciones de carga más altas, optimización de condiciones de procesamiento y modificaciones químicas para mejorar las propiedades finales y ampliar el campo de aplicación de estos biocompuestos.

\section{BIBLIOGRAFÍA}

[1] K.R. Sugumaran, P. Jothi, V. Ponnusami, Bioconversion of industrial solid waste-cassava bagasse for pullulan production in solid state fermentation, Carbohydr. Polym. 99 (2014) 2230.

[2] C. Lu, J. Zhao, S.T. Yang, D. Wei, Fed-batch fermentation for n-butanol production from cassava bagasse hydrolysate in a fibrous bed bioreactor with continuous gas stripping, Bioresour. Technol. 104 (2012) 380-387.

[3] C. Sriherwanto, C. Koob, B. Bisping, Cassava bagasse fermented by Rhizopus spp. for potential use as animal feed, New Biotechnol. 25 (2009).

[4] P. Christen, A. Bramorski, S. Revah, Characterization of volatile compounds produced by Rhizopus strains grown on agro-industrial solid wastes, Bioresour. Technol. 71 (2000) 211-215.

[5] D. Pasquini, E.d.M. Teixeira, A.A.d.S. Curvelo, M.N. Belgacem, A. Dufresne, Extraction of cellulose whiskers from cassava bagasse and their applications as reinforcing agent in natural rubber, Ind. Crops Prod. 32 (2010) 486-490.

[6] E.d.M. Teixeira, A.A.S. Curvelo, A.C. Corrêa, J.M. Marconcini, G.M. Glenn, L.H.C. Mattoso, Properties of thermoplastic starch from cassava bagasse and cassava starch and their blends with poly (lactic acid), Ind. Crops Prod. 37 (2012) 61-68. 
[7] E.d.M. Teixeira, D. Pasquini, A.A.S. Curvelo, E. Corradini, M.N. Belgacem, A. Dufresne, Cassava bagasse cellulose nanofibrils reinforced thermoplastic cassava starch, Carbohydr. Polym. 78 (2009) 422-431.

[8] L. Averous, N. Boquillon, Biocomposites based on plasticized starch: thermal and mechanical behaviours, Carbohydr. Polym. 56 (2004) 111-122.

[9] M.A. Shirai, J.B. Olivato, P.S. Garcia, C.M. Muller, M.V. Grossmann, F. Yamashita, Thermoplastic starch/polyester films: effects of extrusion process and poly (lactic acid) addition, Materials science \& engineering. C, Materials for biological applications 33 (2013) 4112-4117.

[10] L. Yu, K. Dean, L. Li, Polymer blends and composites from renewable resources, Prog. Polym. Sci. 31 (2006) 576-602.

[11] A.L. da Róz, A.J.F. Carvalho, A. Gandini, A.A.S. Curvelo, The effect of plasticizers on thermoplastic starch compositions obtained by melt processing, Carbohydr. Polym. 63 (2006) 417-424.

[12] H. Liu, F. Xie, L. Yu, L. Chen, L. Li, Thermal processing of starch-based polymers, Prog. Polym. Sci. 34 (2009) 1348-1368.

[13] J.F. Mano, D. Koniarova, R.L. Reis, Thermal properties of thermoplastic starch/synthetic polymer blends with potential biomedical applicability, J. Mater. Sci. Mater. M. 14 (2003) 127135.

[14] F. Xie, E. Pollet, P.J. Halley, L. Avérous, Starch-based nano-biocomposites, Prog. Polym. Sci. 38 (2013) 1590-1628.

[15] R.L. Whistler, J.R. Daniel, Carbohydrates, en: O.R. Fennema (Ed.) Food Chem, Marcel Dekker, Inc., New York, NY, USA, 1985, pp. 70-137.

[16] A. Mohammadi Nafchi, M. Moradpour, M. Saeidi, A.K. Alias, Thermoplastic starches: Properties, challenges, and prospects, Starch/Staerke 65 (2013) 61-72.

[17] J.W. Donovan, Phase transitions of the starch-water system, Biopolymers 18 (1979) 263275.

[18] A. Córdoba, N. Cuéllar, M. González, J. Medina, The plasticizing effect of alginate on the thermoplastic starch/glycerin blends, Carbohydr. Polym. 73 (2008) 409-416.

[19] X. Liu, Y. Wang, L. Yu, Z. Tong, L. Chen, H. Liu, X. Li, Thermal degradation and stability of starch under different processing conditions, Starch/Staerke 65 (2013) 48-60.

[20] M.E. Cagiao, D.R. Rueda, R.K. Bayer, F.J. Baltà Calleja, Structural changes of injection molded starch during heat treatment in water atmosphere: Simultaneous wide and small-angle X-ray scattering study, J. Appl. Polym. Sci. 93 (2004) 301-309.

[21] Z.N. Azwa, B.F. Yousif, A.C. Manalo, W. Karunasena, A review on the degradability of polymeric composites based on natural fibres, Mater. Des. 47 (2013) 424-442.

[22] A. Shalwan, B.F. Yousif, In State of Art: Mechanical and tribological behaviour of polymeric comopistes based on natural fibres, Mater. Des. 48 (2013) 14-24.

[23] E. Chiellini, P. Cinellia, A. Cortia, E.R. Kenawy, Composite films based on waste gelatin: thermal-mechanical properties and biodegradation testing, Polym. Degrad. Stab. 73 (2001) 549-555. 
[24] O.A. Khondker, U.S. Ishiaku, A. Nakai, H. Hamada, A novel processing technique for thermoplastic manufacturing of unidirectional composites reinforced with jute yarns, Compos. Part A-Appl. S. 37 (2006) 2274-2284.

[25] L. Ludueña, A. Vázquez, V. Alvarez, Effect of lignocellulosic filler type and content on the behavior of polycaprolactone based eco-composites for packaging applications, Carbohydr. Polym. 87 (2012) 411-421.

[26] L. Famá, L. Gerschenson, S. Goyanes, Starch-vegetable fibre composites to protect food products, Carbohydr. Polym. 75 (2009) 230-235.

[27] A.M. Slavutsky, M.A. Bertuzzi, Water barrier properties of starch films reinforced with cellulose nanocrystals obtained from sugarcane bagasse, Carbohydr. Polym. 110 (2014) 53-61.

[28] D.B. Dittenber, H.V.S. GangaRao, Critical review of recent publications on use of natural composites in infrastructure, Compos. Part A-Appl. S. 43 (2012) 1419-1429.

[29] L. Castillo, O. Lopez, C. Lopez, N. Zaritzky, M.A. Garcia, S. Barbosa, M. Villar, Thermoplastic starch films reinforced with talc nanoparticles, Carbohydrate Polymers 95 (2013) 664-674.

[30] L. Castillo, O. Lopez, C. Lopez, N. Zaritzky, M.A. Garcia, S. Barbosa, M. Villar, Thermoplastic starch films reinforced with talc nanoparticles, Carbohydr. Polym. 95 (2013) 664-674.

[31] A.S.f.T.a.M. (ASTM), Standard Test Methods for Water Vapor Transmission Rate Through Plastic Film and Sheeting Using a Modulated Infrared Sensor. ASTM F1249-89, Annual Book of ASTM. Philadelphia, PA. (1989) 5.

[32] S.O. Aro, V.A. Aletor, O.O. Tewe, J.O. Agbede, Nutritional potentials of cassava tuber wastes: A case study of a cassava starch processing factory in south-western Nigeria., Livest. Res. Rural Dev. 22 (2010).

[33] C. Dini, M.C. Doporto, S.Z. Viña, M.A. García, Cassava Flour and Starch As Differentiated Ingredients for Gluten Free Products, en: F.P. Molinari (Ed.) Food and Beverage Consumption and Health: Cassava Production, Nutritional Properties and Health Effects, Nova Science Publishers, Inc., New York, 2014, pp. 87-114.

[34] M. Leonel, S.B. Sarmento, M.P. Cereda, F.L. Cãmara, Extração e caracterização de amido de jacatupé (Pachyrhizus ahipa), Ciênc. Tecnol. Aliment. 23 (2003) 362-365.

[35] F.O. Ahamefule, G.O. Eduok, A. Usman, K.U. Amaefule, B.E. Obua, S.A. Oguike, Blood biochemistry and haematology of weaner rabbits fed sundried, ensiled and fermented cassava peel based diets., Pakistan J. Nutr. 5 (2006) 248-253.

[36] S.O. Aro, V.A. Aletor, Proximate composition and amino acid profile of differently fermented cassava tuber wastes collected from a cassava starch producing factory in Nigeria, Livest. Res. Rural Dev. 24 (2012).

[37] W. Kosoom, N. Charoenwattanasakun, Y. Ruangpanit, S. Rattanatabtimtong, S. Attamangkune, Physical, chemical and biological properties of cassava pulp, Proc. of the 47th Kasetsart University Annual Conference, Kasetsart, 2009.

[38] C.S. Gaines, Report of the AACC committee on soft wheat flour. Method 56-11, Solvent Retention Capacity Profile, AACC committee (2000). 
[39] A.E. Duyvejonck, B. Lagrain, E. Dornez, J.A. Delcour, C.M. Courtin, Suitability of solvent retention capacity tests to assess the cookie and bread making quality of European wheat flours, LWT - Food Sci. Technol. 47 (2012) 56-63.

[40] C. Dini, M.C. Doporto, M.A. García, S.Z. Viña, Nutritional profile and anti-nutrient analyses of Pachyrhizus ahipa roots from different accessions, Food Res. Int. 54 (2013) 255-261.

[41] O.V. López, L.A. Castillo, M.A. García, M.A. Villar, S.E. Barbosa, Food packaging bags based on thermoplastic corn starch reinforced with talc nanoparticles, Food Hydrocolloids 43 (2015) 18-24.

[42] E. Corradini, A.J.F. De Carvalho, A.A. Da Silva Curvelo, J.A. Marcondes Agnelli, L.H. Capparelli Mattosso, Preparation and Characterization of Thermoplastic Starch/Zein Blends, Mater. Res. 10 (2007) 227-231.

[43] X. Qiao, Z. Tang, K. Sun, Plasticization of corn starch by polyol mixtures, Carbohydr. Polym. 83 (2011) 659-664.

[44] L. Mościcki, M. Mitrus, A. Wójtowicz, T. Oniszczuk, A. Rejak, L. Janssen, Application of extrusion-cooking for processing of thermoplastic starch (TPS), Food Res. Int. 47 (2012) 291299.

[45] P. Aggarwal, D. Dollimore, A comparative study of the degradation of different starches using thermal analysis Talanta 43 (1996) 1527- 1530

[46] R.M.D. Soares, A.M.F. Lima, R.V.B. Oliveira, A.T.N. Pires, V. Soldi, Thermal degradation of biodegradable edible films based on xanthan and starches from different sources, Polym. Degrad. Stab. 90 (2005) 449-454.

[47] A.A.A. Soliman, N.A. El-Shinnawy, F. Mobarak, Thermal behaviour of starch and oxidized starch, Thermochimica Acta 296 (1997) 149-153.

[48] I. Acar, G.S. Pozan, S. Özgümüş, Thermal oxidative degradation kinetics and thermal properties of poly(ethylene terephthalate) modified with poly(lactic acid), J. Appl. Polym. Sci. 109 (2008) 2747-2755.

[49] J.D. Peterson, S. Vyazovkin, C.A. Wight, Kinetics of the Thermal and Thermo-Oxidative Degradation of Polystyrene, Polyethylene and Poly(propylene), Macromol. Chem. Phys. 202 (2001) 775-784.

[50] K. Pielichowski, J. Njuguna, Thermal Degradation of Polymeric Materials, Rapra Technology Limited, Shropshire, UK, 2005.

[51] D. Vega, M.A. Villar, M.D. Failla, E.M. Vallés, Thermogravimetric analysis of starch-based biodegradable blends, Polym. Bull. 37 (1996) 229-235.

[52] R.A. Ruseckaite, A. Jimenez, Thermal degradation of mixtures of polycaprolactone with cellulose derivates., Polym. Degrad. Stab. 8 (2003) 353-358.

[53] E. Rudnik, G. Matuschek, N. Milanov, A. Kettrup, Thermal properties of starch succinates, Thermochimica Acta 427 (2005) 163-166.

[54] Y.J. Yin, K.D. Yao, G.X. Cheng, J.B. Ma, Properties of polyelectrolyte complex films of the chitosan and gelatin., Polym. Int. 48 (1999) 429-433. 
[55] K. Kaewtatip, J. Thongmee, Effect of kraft lignin and esterified lignin on the properties of thermoplastic starch, Mater. Des. 49 (2013) 701-704.

[56] J. Prachayawarakorn, S. Chaiwatyothin, S. Mueangta, A. Hanchana, Effect of jute and kapok fibers on properties of thermoplastic cassava starch composites, Mater. Des. 47 (2013) 309315.

[57] Y. Zhang, J.H. Han, Mechanical and thermal characteristics of pea starch films plasticized with monosaccharides and polyols, J. Food Sci. 71 (2006) 109-118.

[58] R. Bodirlau, C.-A. Teaca, I. Spiridon, Influence of natural fillers on the properties of starchbased biocomposite films, Compos. Part B-Eng. 44 (2013) 575-583.

[59] X. Ma, J. Yu, J.F. Kennedy, Studies on the properties of natural fibers-reinforced thermoplastic starch composites, Carbohydr. Polym. 62 (2005) 19-24.

[60] J. Gironès, J.P. López, P. Mutjé, A.J.F. Carvalho, A.A.S. Curvelo, F. Vilaseca, Natural fiberreinforced thermoplastic starch composites obtained by melt processing, Compos. Sci. Technol. 72 (2012) 858-863.

[61] P. Müller, K. Renner, J. Moczo, E. Fekete, B. Pukanszky, Thermoplastic starch/wood composites: interfacial interactions and functional properties, Carbohydr. Polym. 102 (2014) 821-829.

[62] J.A. Mbey, S. Hoppe, F. Thomas, Cassava starch-kaolinite composite film. Effect of clay content and clay modification on film properties, Carbohydr. Polym. 88 (2012) 213-222.

[63] A.U. Buranov, G. Mazza, Lignin in straw of herbaceous crops, Ind. Crops Prod. 28 (2008) 237-259.

[64] M. Gáspár, Z. Benkő, G. Dogossy, K. Réczey, T. Czigány, Reducing water absorption in compostable starch-based plastics, Polym. Degrad. Stab. 90 (2005) 563-569.

[65] Y. Lu, L. Weng, X. Cao, Morphological, thermal and mechanical properties of ramie crystallites-reinforced plasticized starch biocomposites, Carbohydr. Polym. 63 (2006) 198-204.

[66] C.M.O. Müller, J.B. Laurindo, F. Yamashita, Effect of cellulose fibers addition on the mechanical properties and water vapor barrier of starch-based films, Food Hydrocolloids 23 (2009) 1328-1333.

[67] M.E. Vallejos, A.A.S. Curvelo, E.M. Teixeira, F.M. Mendes, A.J.F. Carvalho, F.E. Felissia, M.C. Area, Composite materials of thermoplastic starch and fibers from the ethanol-water fractionation of bagasse, Ind. Crops Prod. 33 (2011) 739-746.

[68] W.N. Gilfillan, D.M.T. Nguyen, P.A. Sopade, W.O.S. Doherty, Preparation and characterisation of composites from starch and sugar cane fibre, Ind. Crops Prod. 40 (2012) 4554.

[69] T.D. Phan, F. Debeaufort, D. Luu, A. Voilley, Functional Properties of Edible Agar-Based and Starch-Based Films for Food Quality Preservation, J. Agric. Food Chem. 53 (2005) 973-981.

[70] O.V. López, M.A. García, Starch films from a novel (Pachyrhizus ahipa) and conventional sources: Development and characterization, Mater. Sci. Eng., C 32 (2012) 1931-1940.

[71] J.H. Han, Edible Films and Coatings: A Review, en: J.H. Han (Ed.) Innovations in Food Packaging, Academic Press London, UK, 2014, pp. 213-255. 


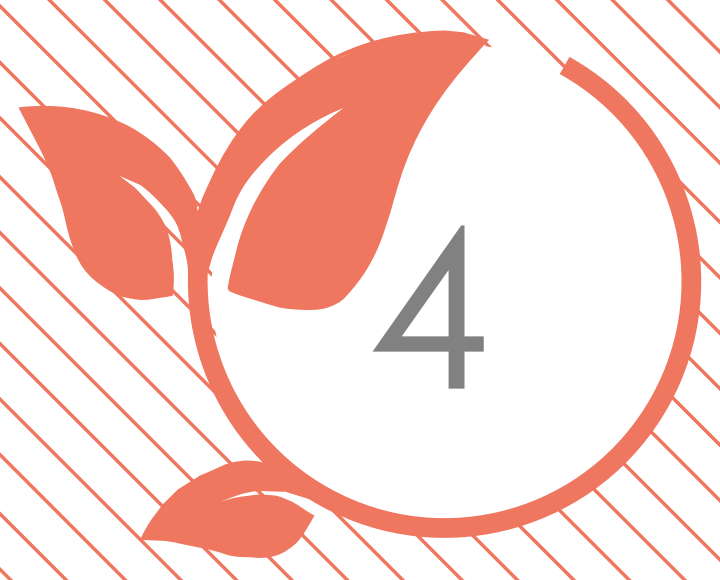

Películas de almidón de mandioca reforzadas con bagazo de mandioca:

\section{FUNCIONALIZACIÓN}




\section{INTRODUCCIÓN}

En general, los plastificantes se incluyen en las formulaciones de materiales poliméricos con dos propósitos principales: como agentes de procesamiento auxiliares y como modificadores de las propiedades finales del producto [1]. En el primer caso, los plastificantes reducen la temperatura de procesamiento, previenen la adherencia en los moldes y aumentan la humectación. En el segundo caso, aumentan la resistencia térmica; mejoran las propiedades mecánicas; y disminuyen la temperatura de transición vítrea. Se ha aceptado que el mecanismo de acción de los plastificantes implica la reducción de las fuerzas intermoleculares a lo largo de las cadenas poliméricas, aumentando así el volumen libre y los movimientos de la cadena. Sin embargo, la selección del plastificante depende de su compatibilidad, eficiencia y permanencia en la matriz polimérica [1].

Cabe destacar que la plastificación es particularmente importante en las películas de biopolímeros, ya que la deshidratación de estas estructuras produce películas cohesivas fuertes con propiedades mecánicas y de barrera deficientes [2]. Dado que la mayoría de los plastificantes contienen grupos hidrófilos, estos compuestos pueden interactuar mediante enlaces tipo puente de hidrógeno no sólo con la matriz polimérica sino también con moléculas de agua del ambiente, aumentando por lo tanto la absorción de humedad de las películas [3]. En cuanto a los materiales a base de almidón, se han realizado numerosos estudios sobre diferentes plastificantes para evaluar su rendimiento, siendo los polialcoholes -especialmente el glicerol-, los más utilizados [4-14].

En comparación con los polialcoholes la urea presenta una fuerte hidrofilicidad debido a su estructura química -contiene dos grupos amino y un grupo carbonilo- y una fuerte tendencia a cristalizar. Se ha utilizado para la plastificación de materiales a base de 
almidón [8, 15-17], así como de celulosa [18], poli (alcohol vinílico) [19] y proteína de soja [20].

Con respecto a la plastificación externa, existe una cantidad máxima de plastificante que las matrices a base de hidrocoloides pueden admitir, la cual está limitada por la tendencia del plastificante a migrar hacia la superficie del material. En lo que respecta a las películas plastificadas con glicerol, la migración se evidencia por la apariencia oleosa de la superficie de éstas $[21,22]$, mientras que cuando se utiliza urea como plastificante, puede ocurrir cristalización superficial de la misma [17]. Consiguientemente, se han reportado varios estudios sobre el efecto del contenido de plastificante en matrices biopoliméricas, siendo un contenido de alrededor de $30 \% \mathrm{p} / \mathrm{p}$ en base seca el máximo reportado tanto para glicerol como para urea en materiales a base de almidón $[13,17,21,23]$. Asimismo, se han encontrado referencias sobre mezclas de plastificantes empleadas con el objetivo de extender los límites de migración, por ejemplo, urea/formaldehído y urea/etanolamina $[15,16]$. El uso de mezclas de glicerol-urea, en particular, se ha descripto en películas de TPS [24, 25]. No obstante, considerando la inestabilidad térmica de la urea, su implementación en materiales a base de almidón resulta más apropiada en films obtenidos por casting. Hasta nuestro mayor conocimiento no se ha publicado ninguna investigación sobre el efecto de la mezcla de urea y glicerol en las películas de almidón de mandioca obtenidas por casting.

Además, el uso de urea en el desarrollo de materiales funcionales podría ser de especial interés para aplicaciones industriales agronómicas, tales como sistemas de liberación controlada de fertilizantes.

Si bien la funcionalización de materiales biodegradables mediante el agregado de compuestos activos es una opción de amplia demanda en el área farmacéutica y biomédica, las aplicaciones agronómicas informadas resultan escasas, debido a que la 
mayoría de los materiales estudiados en tales casos aún no cuentan con precios competitivos que justifiquen su desarrollo. El almidón por su parte, como se ha remarcado anteriormente, es un polímero biodegradable de bajo costo, que resulta de interés para el estudio de su potencial como matriz de liberación controlada, por ejemplo de fertilizantes.

El diseño de materiales funcionalizados permite entonces la liberación controlada del componente activo y consecuentemente su dosificación. Es necesario, cuando se trabaja con estos materiales evaluar la cinética de liberación del compuesto activo. En general, los estudios referidos a la liberación controlada se han desarrollado en su mayoría en substratos líquidos y muy pocos en condiciones reales de aplicación.

Por lo tanto, en este capítulo se exponen los resultados obtenidos respecto a la eficiencia como plastificante tanto del glicerol como de la urea en matrices de almidón de mandioca obtenidas por casting; $y$, por otro lado, el efecto del contenido de urea sobre biocompuestos de almidón y bagazo de mandioca, la cinética de biodegradación en suelo y la liberación del compuesto activo de los mismos.

\section{OBJETIVOS}

- Evaluar el comportamiento de la urea, el glicerol y su mezcla como plastificantes para las películas de almidón de mandioca con y sin relleno de bagazo de mandioca.

- Estudiar la microestructura y las propiedades mecánicas y de barrera de las películas funcionalizadas.

- Analizar la biodegradación y la cinética de liberación en suelo del compuesto activo. 


\section{METODOLOGÍA Y TÉCNICAS EMPLEADAS}

\subsection{Materiales}

En estos ensayos se utilizó almidón nativo de mandioca de la Cooperativa de Productores de Jardín América Ltda. (Misiones, Argentina). Como plastificantes se utilizaron reactivos de grado analítico: glicerol (CAS\# 56-81-5, Anedra, Argentina) y urea (CAS\# 57-13-6, Biopack, Argentina). El bagazo de mandioca se obtuvo como fue descripto en la sección 3.1 del capítulo I y se utilizó la fracción molida y tamizada con tamaños de partícula menores a $500 \mu \mathrm{m}$.

\subsection{Preparación de películas y materiales compuestos}

Se prepararon películas nativas de almidón de mandioca por moldeo y se plastificaron con: glicerol, urea o su mezcla 50:50 (p/p). La relación de plastificantes y almidón (p/p) fue de 25:100. Las películas se denominaron como sigue: control $\left(C_{0}\right)$ las muestras sin plastificante; $25 \mathrm{G}$ las muestras plastificadas solo con glicerol; $12,5 \mathrm{GU}$ las muestras plastificadas con la mezcla 50:50 de urea y glicerol; y $25 \mathrm{U}$ las muestras plastificadas solo con urea. Todas las suspensiones acuosas de almidón al 3 \%p/p se gelatinizaron como se ha explicado previamente, a $90{ }^{\circ} \mathrm{C}$ durante $20 \mathrm{~min}$, posteriormente se agregaron los plastificantes a temperatura ambiente. Aproximadamente $20 \mathrm{~g}$ de las suspensiones formadoras de película se colocaron en placas de Petri (diámetro 8,7 cm) y posteriormente se secaron en estufa con convección forzada (GMX 9203A PEET LAB, EEUU) a $50^{\circ} \mathrm{C}$ durante 4 hs. Previo a su caracterización las películas se acondicionaron a $20^{\circ} \mathrm{C}$ y $65 \% \mathrm{HR}$ durante al menos $48 \mathrm{hs}$.

Las películas que contenían bagazo como material de relleno se prepararon de forma análoga, con $1,5 \% \mathrm{p} / \mathrm{p}$ previo a la gelatinización y contenidos de urea variable de 0 a $50 \%$ p/p en base seca, como se detalla en la Tabla IV.1. 
Tabla IV.1- Contenido de plastificante - expresado en porcentaje en peso respecto al contenido de almidón - de las formulaciones empleadas para los materiales eco-compatibles a base de almidón de mandioca desarrollados

\begin{tabular}{ccc} 
MUESTRA & GLICEROL & UREA \\
\hline $0 \% \mathrm{U}$ & 25 & 0 \\
$12,5 \% \mathrm{U}$ & 12,5 & 12,5 \\
$25 \% \mathrm{U}$ & 0 & 25 \\
$37,5 \% \mathrm{U}$ & 0 & 37,5 \\
$50 \% \mathrm{U}$ & 0 & 50 \\
\hline
\end{tabular}

\subsection{Caracterización de los materiales obtenidos}

\subsubsection{Humectabilidad y contenido de humedad}

\subsubsection{Contenido de humedad y aw}

El contenido de humedad de las películas se determinó gravimétricamente midiendo la pérdida de peso de las películas al secarse en una estufa a $105{ }^{\circ} \mathrm{C}$ hasta peso constante. Los valores reportados corresponden al valor medio de tres determinaciones.

La actividad de agua de las películas se determinó a $25{ }^{\circ} \mathrm{C}$ usando un equipo de medición de actividad acuosa AquaLab serie 4TEV (Decagon Devices Inc., EEUU) con un sensor de punto de rocío y una precisión de $\pm 0,015$. Se midieron al menos tres replicados para cada muestra.

\subsubsection{Absorción de agua}

La absorción de agua se cuantificó gravimétricamente en películas de $2 \mathrm{~cm} \times 2 \mathrm{~cm}$ expuestas a una atmósfera controlada de humedad relativa del $100 \%$ y $20{ }^{\circ} \mathrm{C}$. Las películas se secaron previamente hasta peso constante en una atmósfera de $\mathrm{CaCl}_{2}$ anhidro con una precisión de $\pm 0,0001 \mathrm{~g}$. Las curvas de captación de agua se ajustaron al modelo experimental de Elizalde y col. [26]: 


$$
q=(Q * t) /(B+t)
$$

Donde $\mathrm{q}$ y $\mathrm{Q}$ son agua absorbida en el tiempo $(\mathrm{t})$ y en el equilibrio respectivamente, $\mathrm{y}$ $B$ es el tiempo necesario para que las muestras absorban la mitad del valor de equilibrio. La materia seca se determinó gravimétricamente mediante secado en estufa a $105^{\circ} \mathrm{C}$. Cada muestra se midió al menos por triplicado.

\subsubsection{Hidrofilicidad}

La afinidad de las películas por el agua, se evaluó mediante medidas estáticas de ángulo de contacto, usando un goniómetro estándar Modelo 250 de Ramé-Hart (EEUU). Se liberó una pequeña gota de agua destilada y desionizada de 2-3 $\mu \mathrm{L}$ en la superficie de la película, luego se calculó el ángulo de contacto a partir de una imagen digital tomada tan pronto como la gota había alcanzado la muestra. Se tomaron diez repeticiones por cada muestra de película.

\subsubsection{Propiedades ópticas y de barrera al vapor de agua}

La evaluación de las propiedades ópticas y de barrera al vapor de agua se realizó según los métodos descriptos en las secciones 3.5.5 y 3.5.4 del capítulo I, respectivamente.

\subsubsection{Microestructura de la película y propiedades mecánicas}

\subsubsection{Espectroscopia de infrarrojo por transformada de Fourier (FTIR)}

Los espectros IR de las películas plastificadas se midieron en un espectrómetro FTIR Nicolet-iS10 (Thermo Scientific, EEUU) con accesorio de reflexión total atenuada (ATR), como se describió en la sección 3.3.2 del capítulo II. La deconvolución espectral de los datos se realizó utilizando algoritmos de ajuste de curva en las siguientes regiones: $3700-2800 \mathrm{~cm}^{-1}, 1700-1500 \mathrm{~cm}^{-1}$ y $1200-900 \mathrm{~cm}^{-1}$, como se describió en un trabajo de Rivero y col. [3]. 


\subsubsection{Calorimetría diferencial de barrido modulada (MDSC)}

Las propiedades térmicas de las películas plastificadas se estudiaron por MDSC como se describió en la sección 3.3.5 del capítulo III. Se obtuvieron las curvas correspondientes al flujo calórico y la capacidad calorífica en función de la temperatura de calentamiento. Dado que se realizaron ensayos modulados, la señal de flujo de energía se puede dividir en una componente reversible (relacionada con la capacidad calorífica) y una componente no reversible (asociada al ruido y la línea de base). Por lo tanto, el límite de detección de la temperatura de transición vítrea, medida a través de la capacidad calorífica (señal reversible), se incrementa sustancialmente [27]. La temperatura de transición vítrea se definió como el punto de inflexión de la transición observada en los termogramas usando el software Universal Analysis (TA Instruments, EEUU), analizando todas las muestras al menos por triplicado.

\subsubsection{Ensayos mecánicos}

Las propiedades mecánicas de las películas estudiadas se evaluaron mediante pruebas de tracción utilizando un texturómetro TA.XT2i-Stable Micro Systems (Reino Unido) como se detalla en la sección 3.5.6 del capítulo I. Además, se determinó el espesor de las películas como se ha descripto anteriormente.

\subsubsection{Microscopía electrónica de barrido (SEM)}

Además, algunas de las probetas sometidas a los ensayos de tracción se montaron en tacos de bronce y se recubrieron con una capa de oro $(40-50 \mathrm{~nm})$ para ser estudiadas por SEM con un microscopio FEI QUANTA 200 SEM (Japón) con un detector de electrones Apollo 40. Todas las muestras se analizaron utilizando un voltaje de aceleración de 10 kV bajo alto vacío.

\subsubsection{Biodegradación en suelo}

La desintegración bajo condiciones de compostaje en suelo se estudió como 
se describe en la sección 3.3.7 del capítulo II. Considerando que el número de tratamientos a evaluar era mayor y que se había demostrado que las películas a base de almidón de mandioca reforzadas con 1,5 \% de bagazo se degradaban en un tiempo menor a 50 días, se decidió evaluar los siguientes tiempos de exposición: 15, 30 y 45 días, para hacer un seguimiento del grado de avance de la degradación de los materiales. En todos los casos se realizaron inspecciones visuales de las películas luego de haberlas extraído de los recipientes a los distintos tiempos de ensayo y se tomaron fotografías de las mismas. Para comparar la velocidad de degradación de los materiales estudiados, se determinó el tiempo medio necesario para la degradación del $50 \%$ del material (t50), mediante el ajuste de los resultados obtenidos a la ecuación de Boltzmann [28].

\subsubsection{Liberación controlada de urea}

La liberación de urea en suelo de las películas de almidón estudiadas se realizó por diferencia entre el contenido inicial de urea y el restante en la película biodegrada a los distintos tiempos de almacenamiento. La concentración de urea en las muestras se cuantificó por el método enzimático de ureasa-salicilato (BioSystems, España). Brevemente, se pulverizaron en un mortero $70 \mathrm{mg}$ de muestras de película previamente secadas en estufa de vacío a $50^{\circ} \mathrm{C}$ hasta peso constante, y se disolvieron en $1 \mathrm{~mL}$ de agua. El método utiliza la enzima ureasa para hidrolizar urea y el amoníaco producido reacciona con hipoclorito alcalino y salicilato sódico en presencia de un catalizador para formar indofenol un compuesto coloreado que se cuantifica espectrofotométricamente a $600 \mathrm{~nm}$. El complejo coloreado se midió en un espectrofotómetro UV mini 1240 UV-vis (Shimadzu, Japón), realizando las diluciones necesarias para el rango de resolución del kit. Las medidas se realizaron al menos por duplicado y los resultados se expresaron como porcentaje de liberación, considerando el contenido inicial de urea de las películas en estudio. 


\subsection{Análisis estadístico}

Así como en los anteriores ensayos realizados se llevó a cabo el análisis multifactorial de los resultados según lo descripto en la sección 3.6 del capítulo I.

\section{RESULTADOS Y DISCUSIÓN}

4.1. Efecto del tipo plastificante sobre películas de almidón de mandioca Dado que ambos plastificantes evaluados presentan un carácter hidrofílico, la susceptibilidad al agua de las películas se estudió mediante diferentes pruebas simples: contenido de humedad, actividad del agua, absorción de agua y ángulo de contacto. Los resultados se muestran en la Figura IV.1.

El contenido de agua de las muestras poliméricas osciló entre 15 y $21 \%$, con diferencias significativas $(p<0,05)$ entre las tres películas analizadas. A pesar de que todas las muestras contenían la misma cantidad de plastificante $(25 \% \mathrm{p} / \mathrm{p})$, la adición de urea resultó en un menor contenido de humedad, indudablemente debido a la mayor higroscopicidad del glicerol [29]. No obstante, no se detectaron diferencias significativas en los valores de aw de las películas, que varió entre 0,655 y 0,648.

Asimismo, su comportamiento de absorción de agua fue similar (Figura IV.1). Se observó un ajuste relativamente bueno $\left(r^{2}>0,888\right)$ de los datos experimentales al modelo de Elizalde y col. [26], de los cuales se obtuvieron los parámetros Q y B. Todas las películas alcanzaron un valor de equilibrio similar (Q), aunque las películas plastificadas sólo con urea (25U) presentaron una menor tasa inicial de absorción de agua (Q/B).

Por otro lado, la medición del ángulo de contacto mostró una tendencia opuesta al contenido de agua. Esta técnica es una herramienta útil para determinar el carácter hidrófobo o hidrófilo de la superficie de la película: los ángulos de contacto bajos 
$\left(\Theta<90^{\circ}\right)$ corresponden a superficies que son más mojables, por el contrario, las superficies hidrófobas muestran valores altos $\left(\Theta>90^{\circ}\right)$ de este parámetro. Todas las películas presentaron valores de ángulo de contacto bajos (Figura IV.1), siendo las más bajas las de las películas que contenían urea, aunque no se observaron diferencias significativas $(p>0,05)$. Los valores reportados para las películas basadas en almidón de maíz confirman la naturaleza hidrófila de estos materiales, aunque la comparación de los valores de los ángulos de contacto resulta difícil, ya que depende fuertemente de los aditivos, su matriz polimérica y la forma de obtención del material [30].

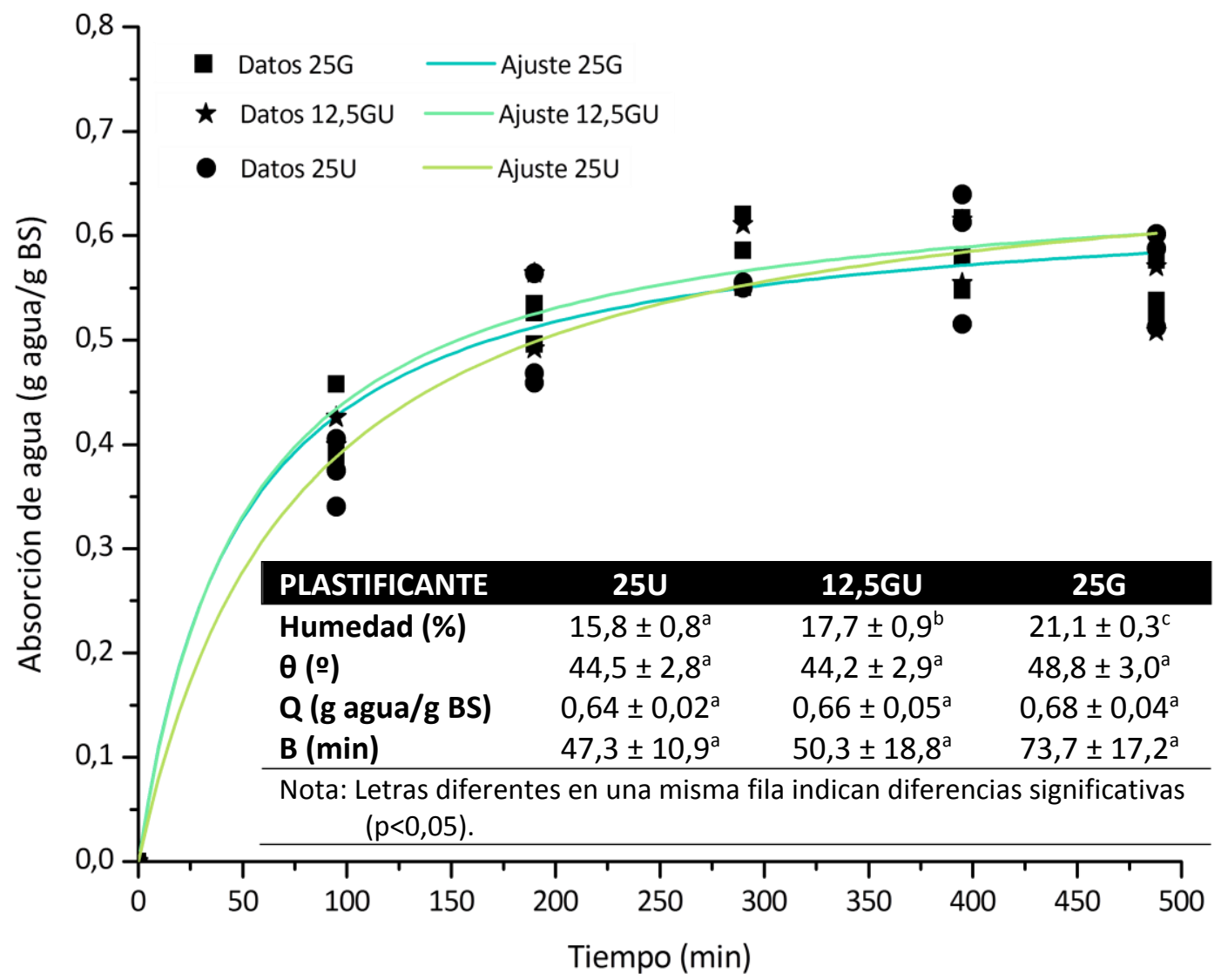

Figura IV.1. Curvas de absorción predictivas (líneas continuas) y experimentales (puntos) a 100 \%HR de películas a base de almidón de mandioca plastificadas con: glicerol (25G), urea $(25 \mathrm{U})$ y la mezcla de ambos (12,5GU). En la tabla incorporada se resumen los parámetros del modelo, el contenido de agua y el ángulo de contacto de las muestras. 
A pesar de que las películas plastificadas con $25 \mathrm{G}$ presentaron valores WVP medios más altos que los plastificados con $12,5 \mathrm{GU}$ y $25 \mathrm{U}\left(10,3 \pm 0,9 \times 10^{-11} \mathrm{~g} / \mathrm{m} \mathrm{s} \mathrm{Pa}\right.$, $9,9 \pm 1,0 \times 10^{-11} \mathrm{~g} / \mathrm{m} \mathrm{s}$ Pa y $9,2 \pm 0,5 \times 10^{-11} \mathrm{~g} / \mathrm{m} \mathrm{s} \mathrm{Pa}$, respectivamente), no hubieron diferencias significativas $(p>0,05)$. Estos resultados están de acuerdo con otros trabajos publicados, considerando que todas las muestras contenían la misma cantidad total de plastificante [1]. Como ya se mencionó, los plastificantes interfieren con la asociación de las cadenas poliméricas disminuyendo la rigidez del retículo, produciendo una estructura de la matriz menos ordenada, tal efecto tiene gran impacto en la permeabilidad de las películas. En comparación con las películas de almidón de mandioca sin plastificar, la WVP disminuye con un $25 \%$ de plastificante, ya que se obtienen películas más homogéneas y compactas sin poros ni grietas evidenciadas por SEM $[21,23]$, como se discutió en el capítulo I.

Respecto a la capacidad de barrera UV-visible, los valores obtenidos fueron: $65,06 \pm 2,4$ AUxnm; 73,87 $\pm 2,3$ AUxnm; y 67,94 $\pm 1,1$ AUxnm para 25G, $12,5 \mathrm{GU}$ y $25 \mathrm{U}$ respectivamente. Debido a que la urea absorbe radiación en la región ultravioleta, la capacidad de barrera UV (200 - $400 \mathrm{~nm}$ ) fue mayor para las películas plastificadas con urea: $36,88 \pm 1,4 \mathrm{AUxnm} ; 45,84 \pm 3,8 \mathrm{AUxnm}$; y 46,90 \pm 0,94 AUxnm para 25G, 12,5GU y $25 \mathrm{U}$, respectivamente. Por el contrario, las muestras que contenían glicerol mostraron una mayor absorción en la región visible (400 - $700 \mathrm{~nm})$. En las películas plastificadas con la mezcla de ambos plastificantes, ambas contribuciones son relevantes y por lo tanto, $12,5 \mathrm{GU}$ presentó la mayor absorción total de luz $(200-700 \mathrm{~nm})$.

Los espectros de FTIR para los componentes puros: almidón (A), glicerol (G), urea (U), y la mezcla 50:50 de los anteriores (50:50GU), se muestran en la Figura IV.2. La urea exhibe bandas de absorción características en dos regiones principales: 3700 $3000 \mathrm{~cm}^{-1}$ (estiramiento del enlace amida $\mathrm{N}-\mathrm{H}$ ) y $1700-1300 \mathrm{~cm}^{-1}$ (plegado del enlace amida $\mathrm{N}-\mathrm{H}$ y estiramiento de grupo carbonilo). El glicerol, por el contrario, tiene una 
banda ancha entre 3700 - $3000 \mathrm{~cm}^{-1}$ (estiramiento y flexión del grupo O-H) y los picos característicos de enlaces C-H en la región de $3000-2800 \mathrm{~cm}^{-1}$ y $1500-1200 \mathrm{~cm}^{-1}$. La mezcla de urea y glicerol muestra las bandas características de absorción de los componentes individuales, aunque se observaron variaciones en los máximos de los picos hacia mayor es números de onda, especialmente en la región de 3700 $3000 \mathrm{~cm}^{-1}$, representativa de las interacciones a través de puentes de $\mathrm{H}$ de ambos componentes. Por otra parte, el espectro del almidón de mandioca nativo presenta una banda ancha entre $3700-3000 \mathrm{~cm}^{-1}$ que corresponde al estiramiento y flexión de los grupos oxhidrilo, otro pico a $1650 \mathrm{~cm}^{-1}$ asociado al estiramiento de $\mathrm{O}-\mathrm{H}$ en moléculas de agua con enlaces $\mathrm{H}$ moderadamente fuertes y las bandas características de las vibraciones de estiramiento C-O-C y las vibraciones de flexión $\mathrm{C}-\mathrm{O}-\mathrm{H}$ en los anillos piranósicos- glucosídicos a $1200-900 \mathrm{~cm}^{-1}$ [31, 32].

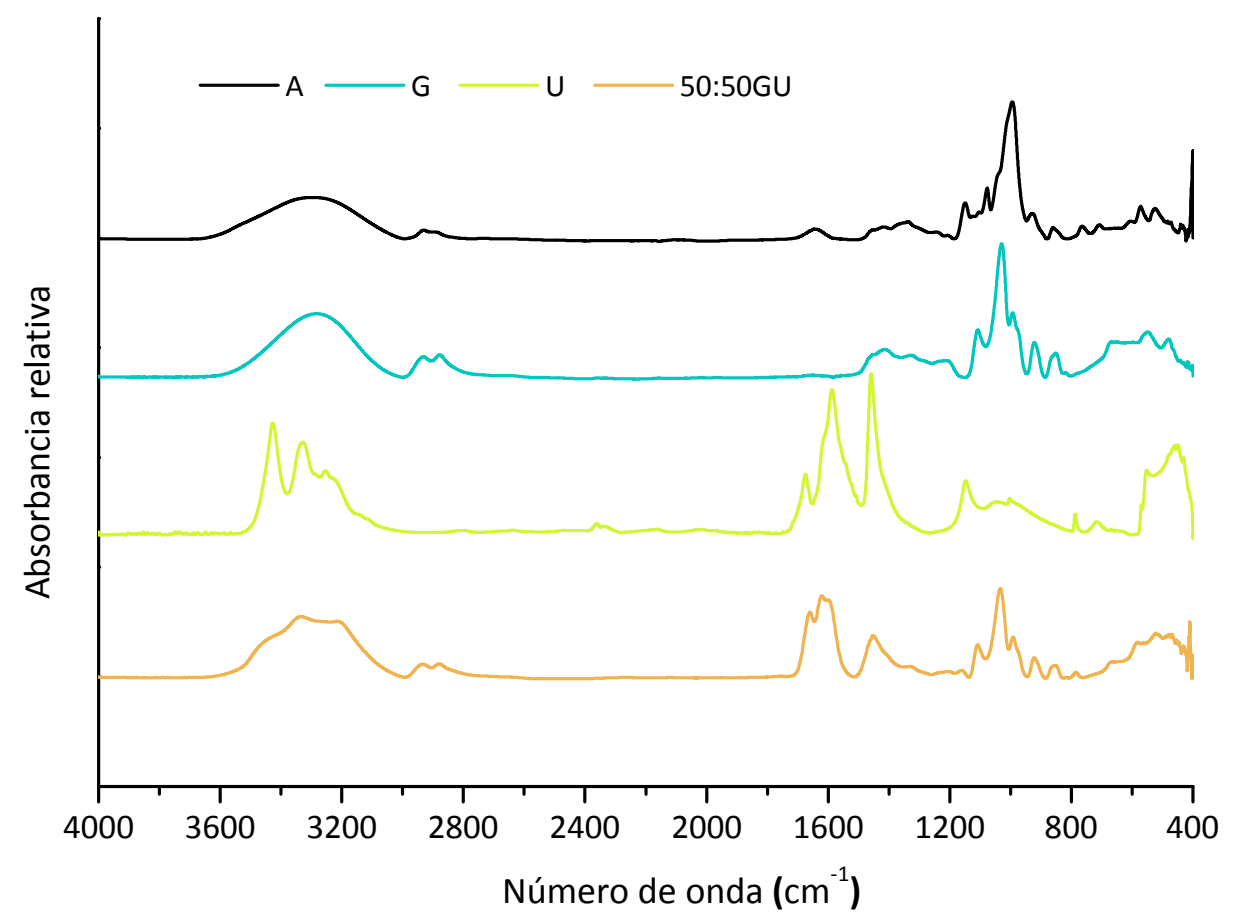

Figura IV.2. Espectros ATR-FTIR de componentes de película: almidón (A), glicerol (G), urea (U) y su mezcla 50:50 (50:50GU). 
Del mismo modo, los espectros de películas plastificadas con glicerol, urea y la mezcla de ambos revelaron las bandas características de los componentes puros. Sin embargo, se observaron variaciones en los picos de intensidad y localización, lo que indica interacciones distintivas entre los componentes. Las diferencias principales se mostraron en las regiones de $3700-3000 \mathrm{~cm}^{-1}, 3000-2800 \mathrm{~cm}^{-1}, 1700-1500 \mathrm{~cm}^{-1} \mathrm{y}$ 1200 - $900 \mathrm{~cm}^{-1}$. La Tabla IV.2 muestra los picos de absorción más importantes en cada ventana espectral.

\begin{tabular}{|c|c|c|c|c|}
\hline PLASTIFICANTE & $C_{0}$ & 25G & $12,5 \mathrm{GU}$ & $25 U$ \\
\hline & $3297,0(1)$ & $3281,9(1)$ & $3203,4(0,41)$ & $3199,6(0,48)$ \\
\hline \multirow[t]{2}{*}{$3700-3000 \mathrm{~cm}^{-1}$} & -- & -- & $3346,2(0,41)$ & $3343,2(0,34)$ \\
\hline & -- & -- & $3467,1(0,18)$ & $3458,8(0,18)$ \\
\hline \multirow{3}{*}{$3000-2800 \mathrm{~cm}^{-1}$} & $2886,0(0,36)$ & $2884,4(0,58)$ & $2881,3(0,43)$ & $2884,1(0,40)$ \\
\hline & -- & -- & $2914,6(0,26)$ & $2914,0(0,30)$ \\
\hline & $2931,1(0,64)$ & $2936,3(0,42)$ & $2938,1(0,31)$ & $2940,2(0,30)$ \\
\hline \multirow{3}{*}{$1700-1500 \mathrm{~cm}^{-1}$} & -- & -- & $1593,8(0,25)$ & $1587,6(0,32)$ \\
\hline & $1643,7(1)$ & $1651,5(1)$ & $1628,5(0,45)$ & $1623,8(0,40)$ \\
\hline & -- & -- & $1664,8(0,30)$ & $1663,9(0,28)$ \\
\hline \multirow{7}{*}{$1200-900 \mathrm{~cm}^{-1}$} & $929,3(0,15)$ & $924,0(0,13)$ & $926,5(0,12)$ & $929,3(0,11)$ \\
\hline & $989,4(0,23)$ & $993,9(0,31)$ & $993,4(0,28)$ & $993,0(0,28)$ \\
\hline & $1016,7(0,16)$ & $1018,1(0,10)$ & $1017,4(0,09)$ & $1016,3(0,11)$ \\
\hline & $1046,6(0,12)$ & $1042,0(0,17)$ & $1041,5(0,17)$ & $1041,7(0,16)$ \\
\hline & $1078,9(0,06)$ & $1079,4(0,04)$ & $1079,1(0,05)$ & $1078,9(0,04)$ \\
\hline & $1107,4(0,12)$ & $1106,9(0,14)$ & $1106,6(0,13)$ & $1105,7(0,13)$ \\
\hline & $1152,0(0,16)$ & $1153,6(0,14)$ & $1152,3(0,16)$ & $1151,3(0,18)$ \\
\hline
\end{tabular}

Nota: En el caso de bandas deconvolucionadas, cada valor informado corresponde a la posición máxima y, entre paréntesis, la contribución relativa al área total de la banda.

Por un lado, el glicerol, las películas no plastificadas $\left(C_{0}\right)$ y las $25 \mathrm{G}$ revelaron una banda de absorción amplia e intensa en la región de $3700-3000 \mathrm{~cm}^{-1}$ centrada en $3281 \mathrm{~cm}^{-1}$, que está asignada a vibraciones de estiramiento y flexión del grupo O-H (Figura IV.3a), como ya se mencionó. Las películas que contienen urea por otro lado, presentaron tres contribuciones importantes en esta región: aproximadamente 3200, 3345 y $3452 \mathrm{~cm}^{-1}$ (Figura IV.3a). Estas últimas se atribuyen a los picos característicos del estiramiento del 
enlace N-H del grupo amida de la urea $\left(3254,3327\right.$ y $\left.3427 \mathrm{~cm}^{-1}\right)$, aunque los cambios significativos observados indican, como era de esperar, que estos grupos N-H están implicados en las interacciones puente- $\mathrm{H}$ dentro de la matriz. Las contribuciones individuales de cada uno de estos picos a la banda dependen del contenido de urea, resultando las áreas relativas de los picos a 3200 y $3345 \mathrm{~cm}^{-1}$ los más afectados (Tabla IV.2).

En la región espectral entre $3000-2800 \mathrm{~cm}^{-1}$ la urea no revela ninguna señal característica, mientras que el glicerol tiene una banda con dos picos claros a 2937 y $2875 \mathrm{~cm}^{-1}$ (Figura IV.3a). Las películas control de almidón y las plastificadas con glicerol presentan una banda análoga a pesar de que las intensidades relativas cambian debido a la presencia de los grupos metileno del glicerol (Tabla IV.2). Además, en las películas que contienen urea estas bandas se desdoblan en tres contribuciones con intensidades relativas similares, lo que indica que el entorno químico de los grupos C-H cambia en presencia de urea, afectando a su transición vibracional (Figura IV.3a y Tabla IV.2).

En los espectros FTIR, las películas que contienen urea presentan tres señales similares en términos de posición de pico y contribución relativa en la región comprendida entre $1700-1500 \mathrm{~cm}^{-1}$ pero con mayor absorbancia en las muestras de $25 \mathrm{U}$ (Figura IV.3b). Los desplazamientos observados con respecto a los picos de la urea pura indican la existencia de interacciones tanto entre plastificante y matriz como plastificante y agua en el material. Wang y col. [17] publicaron resultados similares en películas de almidón de maíz oxidado plastificadas con urea, siendo el pico a $1659 \mathrm{~cm}^{-1}$ atribuido al estiramiento $\mathrm{C}=\mathrm{O}$ (región amida-I) y el de $1626 \mathrm{~cm}^{-1}$ asignado a la flexión del grupo N-H (región amida-II). Tanto en las películas control como en las de 25G se observó una sola contribución en esta región, asociada con los enlaces $\mathrm{O}-\mathrm{H}$ de las moléculas de agua que interactúan con la matriz (Figura IV.3b y Tabla IV.2). 

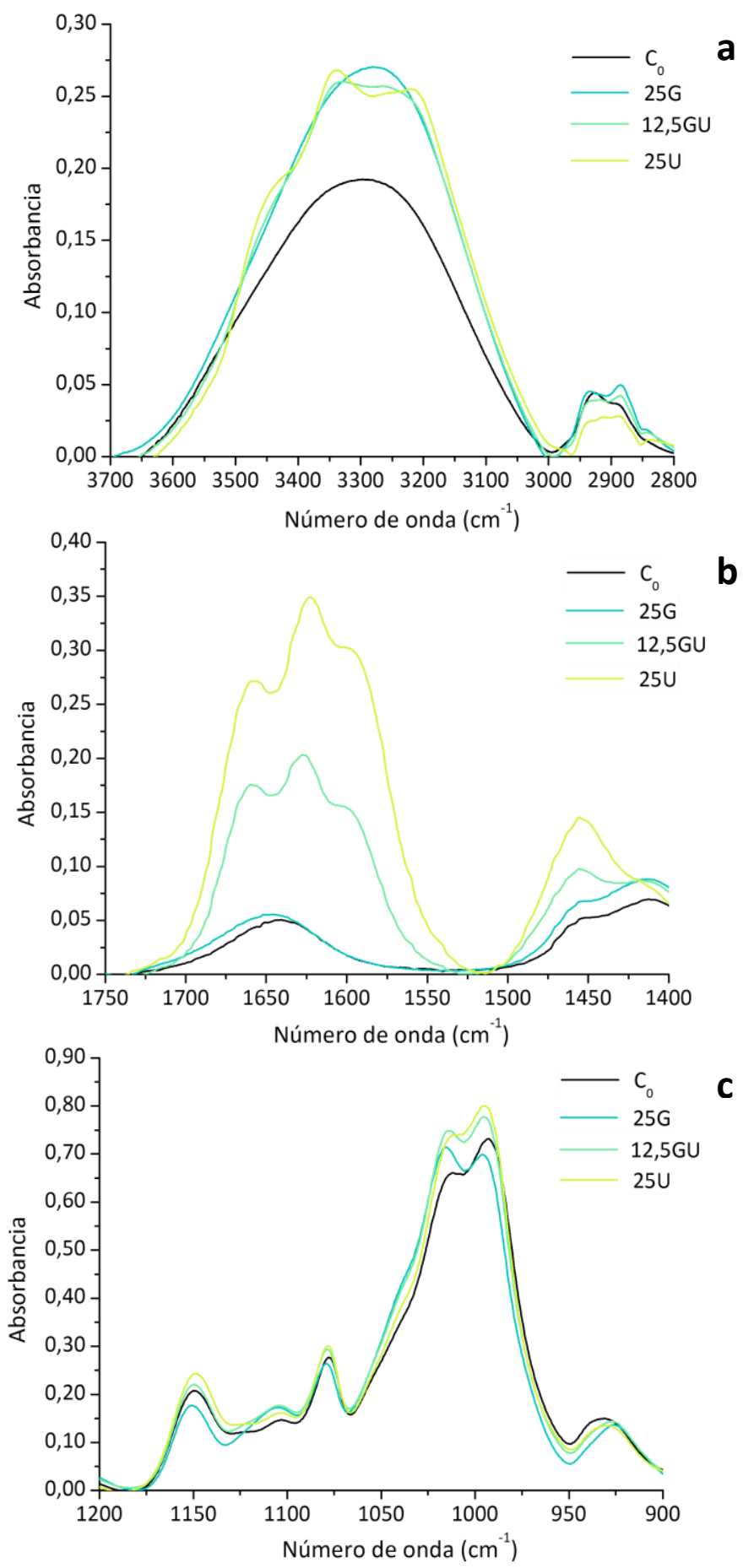

Figura IV.3. Espectros ATR-FTIR de películas a base de almidón de mandioca: control no plastificado $\left(\mathrm{C}_{0}\right)$, plastificado con $25 \%$ de glicerol (25G), $12,5 \%$ de glicerol y $12,5 \%$ de urea $(12,5 \mathrm{GU})$ y $25 \%$ de urea $(25 \mathrm{U})$. Se muestran tres regiones principales:

a) $3700-2800 \mathrm{~cm}^{-1}$; b) $1750-1400 \mathrm{~cm}^{-1}$; y c) $1200-900 \mathrm{~cm}^{-1}$. 
La Figura IV.3b también muestra un aumento en la intensidad del pico localizado a $1455 \mathrm{~cm}^{-1}$ con el aumento del contenido de urea, que se correlaciona con el estiramiento del enlace C-N en la estructura de la urea. Wang y col. [17] correlacionaron la relación de la absorbancia de este pico con la absorbancia del pico de $2930 \mathrm{~cm}^{-1}$, respecto al contenido de urea superficial del material ya que habían observado migración de este plastificante a la superficie de películas de almidón de papa cuando sus concentraciones excedieron el $30 \% \mathrm{p} / \mathrm{p}$. A pesar de que la relación A1455/A2930 se duplicó en las muestras de 12,5GU a 25U, no se observó cristalización superficial de urea en ninguna de las dos muestras, probablemente debido a que los contenidos de urea evaluados estaban por debajo de los reportados por Wang y col. [17] para la migración de urea.

Como se muestra en la Figura IV.3c, en la región de la huella digital del espectro todos los componentes de las películas absorben, presentando picos e intensidades distintivas. Como en esta región las principales contribuciones están relacionadas con la matriz de almidón, no se observaron variaciones espectrales mayores. Además, las bandas en esta región del espectro infrarrojo resultan principalmente de modos de vibración de enlaces C-O y C-C altamente acoplados, por lo que la asignación de bandas individuales resulta difícil [33]. Las principales contribuciones encontradas se muestran en la Tabla IV.2.

Los picos entre 990 y $1030 \mathrm{~cm}^{-1}$ se atribuyeron al estiramiento de los anillos de anhidroglucosa $\mathrm{C}-\mathrm{C}, \mathrm{C}-\mathrm{O}, \mathrm{C}-\mathrm{H}$ y $\mathrm{COH}[16,34]$, mientras que los de alrededor de 1150 y $1080 \mathrm{~cm}^{-1}$ fueron asignados al estiramiento de C-O-H en el almidón [35]. Las ligeras desviaciones detectadas en los máximos de los picos se atribuyeron a la interacción plastificante-almidón.

Además, muchos autores han subrayado que tanto las relaciones de absorbancia de los picos a 995 como $1047 \mathrm{~cm}^{-1}$ con relación a $1022 \mathrm{~cm}^{-1}$ podrían ser indicativas del grado 
de cristalinidad del almidón $[33,34,36]$. En este respecto las muestras plastificadas, independientemente del tipo de plastificante, presentaron relaciones menores que el control sin plastificar, lo cual podría indicar que la inclusión de plastificante promueve la disminución de la cristalinidad del almidón. Sin embargo, dado que estas relaciones mostraron comportamientos opuestos en las muestras analizadas, este criterio no sería adecuado para estimar la cristalinidad de las películas obtenidas. Tal comportamiento podría atribuirse al hecho de que el haz IR en modo ATR sólo puede pasar a través de la superficie superior de la película medida y que, adicionalmente, tanto el glicerol como la urea (aunque esta última en menor medida) tienen contribuciones en esta región.

Las mediciones de MDSC permitieron estudiar las transiciones de relajación de las películas desarrolladas (Tabla IV.3). Se observó una disminución significativa $(p<0,05)$ en la temperatura de transición vítrea de las películas de almidón de mandioca plastificadas con urea (25U), siendo este efecto menos importante en la coplastificación con glicerol $(12,5 \mathrm{GU})$. La reducción de la Tg se considera un indicativo de la eficacia de plastificación [1], por lo tanto los resultados indican que la urea es un plastificante más eficiente que el glicerol y su mezcla para este tipo de matrices.

\begin{tabular}{|c|c|c|c|c|c|}
\hline PLASTIFICANTE & $\operatorname{Tg}\left({ }^{\circ} \mathrm{C}\right)$ & To $\left({ }^{\circ} \mathrm{C}\right)$ & $\operatorname{Tm}\left({ }^{\circ} \mathrm{C}\right)$ & $\operatorname{Tf}\left({ }^{\circ} \mathrm{C}\right)$ & $\Delta \mathrm{H}(\mathrm{mJ} / \mathrm{mg})$ \\
\hline $25 \mathrm{U}$ & $13,6 \pm 1,0^{a}$ & $79,7 \pm 6,1^{\mathrm{a}}$ & $122,8 \pm 3,7^{\mathrm{a}}$ & $182,6 \pm 1,2^{a}$ & $277,0 \pm 29,2^{b}$ \\
\hline $12,5 \mathrm{GU}$ & $35,0 \pm 1,2^{b}$ & $129,2 \pm 2,6^{b}$ & $142,8 \pm 6,7^{b}$ & $187,5 \pm 2,4^{a}$ & $145,0 \pm 1,9^{a}$ \\
\hline $25 \mathrm{G}$ & $37,8 \pm 0,5^{b}$ & $118,7 \pm 1,7^{b}$ & $138,5 \pm 4,3^{b}$ & $185,4 \pm 6,8^{a}$ & $184,1 \pm 31,0^{a}$ \\
\hline
\end{tabular}

Los termogramas de las películas también mostraron diferencias en el pico endotérmico característico de la vaporización de agua de las películas de almidón 
(Tabla IV.3). Estas variaciones en las temperaturas de inicio (To) y pico (Tm), así como la energía total del proceso $(\Delta \mathrm{Hm})$ se atribuyeron a la superposición de la fusión de la urea $\left(\mathrm{Tm}=133,5^{\circ} \mathrm{C}\right.$ y $\left.\Delta \mathrm{Hm}=244,2 \mathrm{~J} / \mathrm{g}\right)$ y la vaporización del agua en las películas de almidón plastificadas con urea, en comparación con las plastificadas con glicerol. Sin embargo, no se observaron diferencias significativas entre las muestras de $12,5 \mathrm{GU}$ y 25G, presumiblemente debido a sus diferencias en el contenido de humedad (Figura IV.1).

El comportamiento mecánico de las películas a base de almidón depende en gran medida de su composición y grosor. Todas las películas estudiadas tenían un espesor promedio de alrededor de 65 - $70 \mu \mathrm{m}$, sin diferencias significativas $(p>0,05)$ entre las muestras.

La Figura IV.4 presenta los perfiles de esfuerzo-deformación de las películas estudiadas. Como era de esperar, el comportamiento mecánico de las películas fue marcadamente afectado por el tipo de plastificante. Las películas plastificadas con urea (25U) resultaron más flexibles y resistentes que las plastificadas con el mismo contenido de glicerol (25G).

Se observó un aumento significativo $(p<0,05)$ en la elongación a la ruptura $(75,80 \%$ y $47,24 \%$, para $25 \mathrm{U}$ y $25 \mathrm{G}$ respectivamente) y tenacidad del material $\left(1740,37 \mathrm{~kJ} / \mathrm{m}^{3}\right.$ y $1090,86 \mathrm{~kJ} / \mathrm{m}^{3}$, para $25 \mathrm{U}$ y $25 \mathrm{G}$ respectivamente), aunque no se observaron diferencias significativas en la resistencia a la tracción máxima a la ruptura. El módulo elástico de los materiales siguió una tendencia similar (28,61 MPa y 14,30 MPa, respectivamente), por lo que se puede concluir que en términos de resistencia mecánica, la urea es un plastificante más eficiente que el glicerol, probablemente debido a la diferencia de tamaño molecular entre ambos plastificantes [1]

Cuando se añaden ambos plastificantes a la matriz, el perfil mecánico resultante está entre el de un material flexible y el de uno tenaz -flexible, que exhibe 

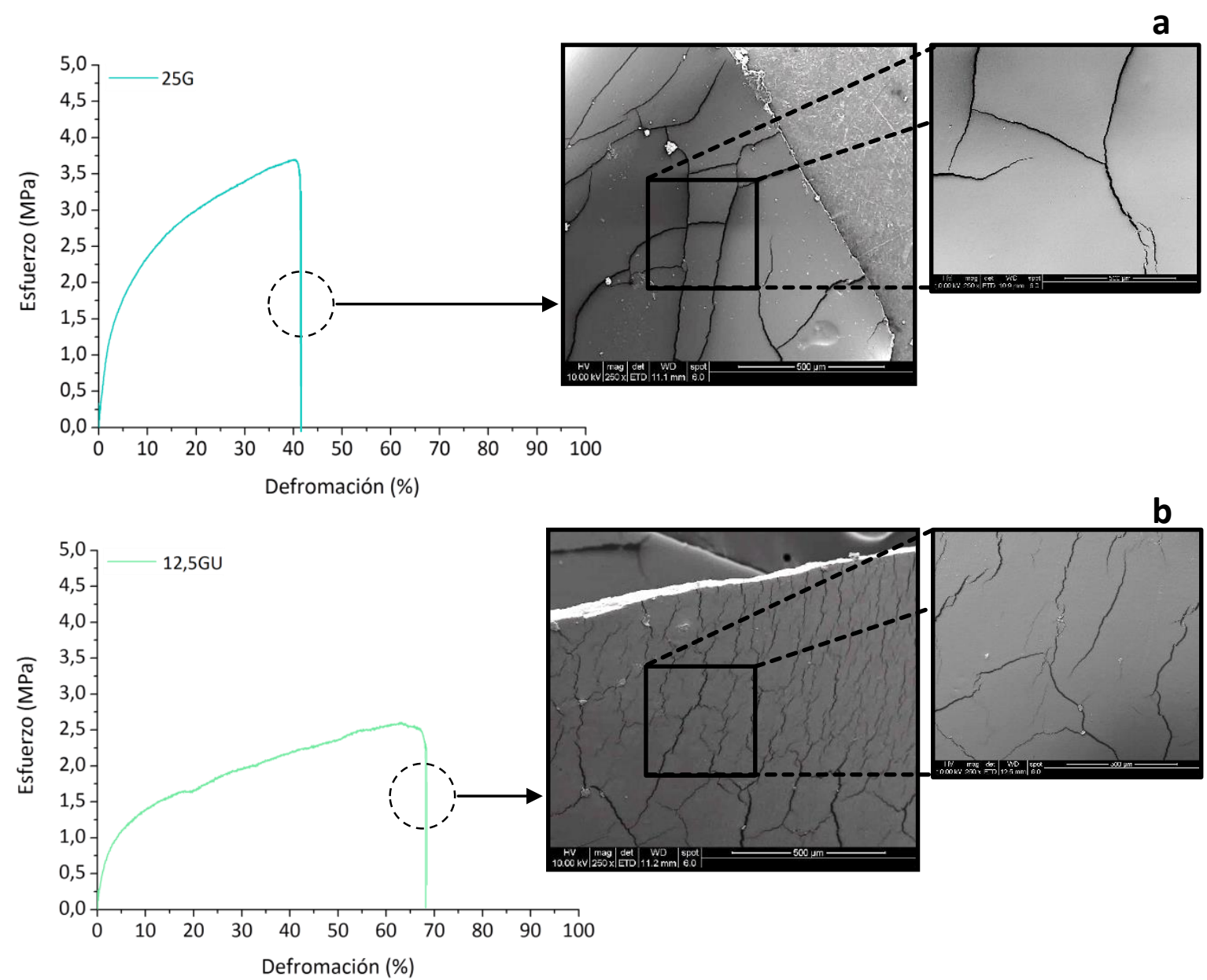

b

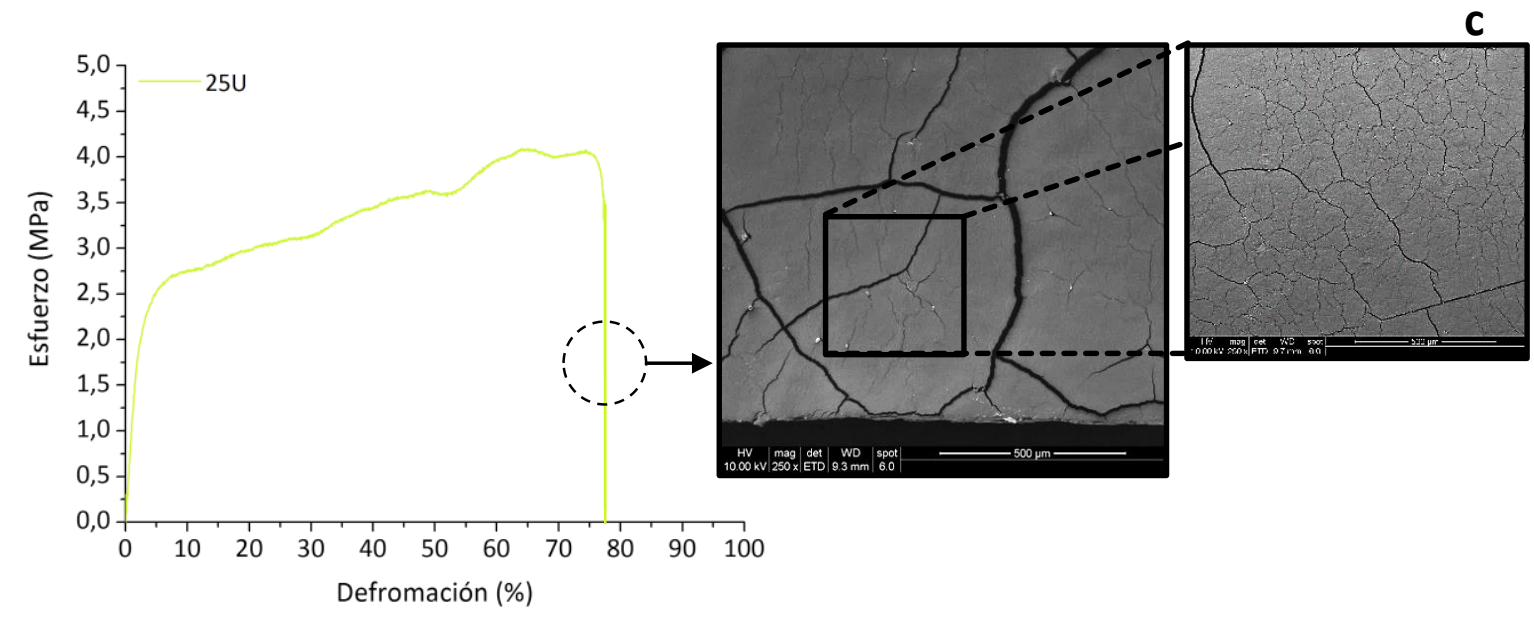

Figura IV.4. Curvas de tensión-deformación por tracción y micrografía SEM de películas de almidón de mandioca plastificadas y fracturadas con: a) $25 \%$ de glicerol (25G); b) 12,5\% de glicerol y $12,5 \%$ de urea (12,5GU); y c) $25 \%$ de urea (25 U). 
características peores que el de las películas con un único plastificante. A pesar de que no hay diferencias significativas $(p>0,05)$ en la elongación de la matriz a la ruptura entre muestras de $25 \mathrm{U}$ y $12,5 \mathrm{GU}$, tanto la resistencia máxima como la tenacidad de estas últimas son significativamente menores $(p<0,05)$ que las de las películas plastificadas ya sea con urea o glicerol ( $25 \mathrm{U}$ y $25 \mathrm{G}$, respectivamente).

Además, se estudió, mediante la técnica SEM, la topografía de la superficie y las secciones transversales de las películas sometidas a los ensayos de tracción. La Figura IV.4 muestra el extremo de la fractura de las películas de almidón de mandioca que contienen diferentes tipos de plastificante. Se observaron grietas o microfisuras en la superficie de los materiales en la dirección en la que se propagó la fractura de la muestra. Sin embargo, las películas con la adición de urea presentaron grietas más pequeñas en diferentes direcciones probablemente debido a la estructura más amorfa de la matriz plastificada.

Asimismo, debe resaltarse que no se detectó migración ni cristalización superficial de urea. Las microfisuras observadas en estos especímenes se deben al estiramiento no elástico de las películas que contienen urea (cuadro de detalle en las Figuras IV.4b yc). Estos resultados evidenciaron una vez más la estructura más flexible y resistente de las películas de $25 \mathrm{U}$, gracias al desarrollo de interacciones entre la urea y el almidón de la matriz, como fue confirmado por ATR-FTIR.

4.2. Materiales compuestos de almidón y bagazo de mandioca funcionalizados con urea: efecto del contenido de plastificante

Con el fin de explorar las potenciales aplicaciones agronómicas de las películas biodegradables a base de almidón de mandioca estudiadas en el presente trabajo de Tesis, se procedió a evaluar el efecto de la funcionalización de este eco-material con urea como compuesto activo. En esta sección se detallan los resultados obtenidos en el análisis del contenido de urea como plastificante y compuesto activo de materiales 

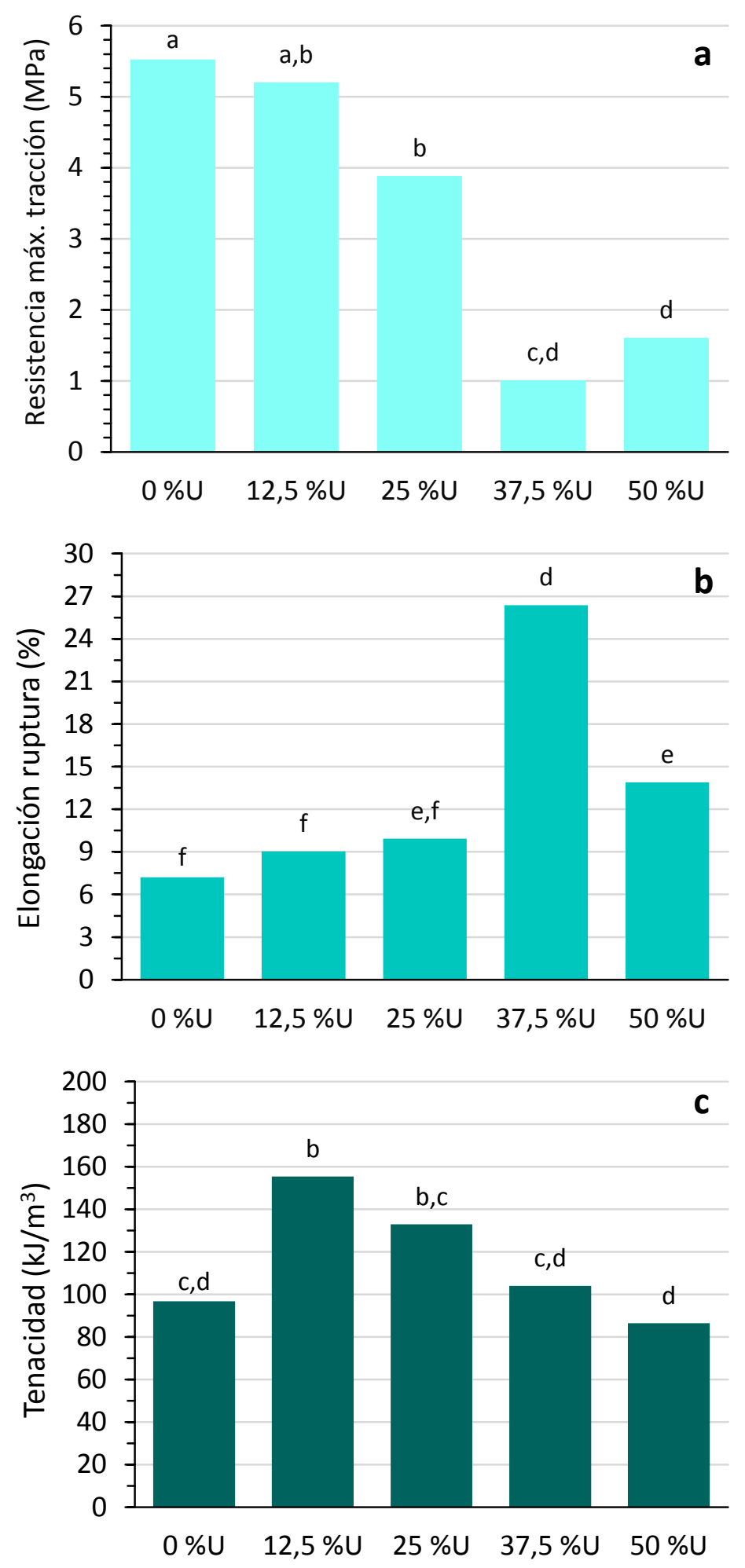

Figura IV.5. Comportamiento mecánico de películas a base de almidón de mandioca funcionalizadas con fibra y urea sometidas a ensayos de tracción. 
reforzados con bagazo de mandioca. La composición y nomenclatura de las películas estudiadas se detallan en la Tabla IV.1 en la sección 3.

Como se mencionó anteriormente, el comportamiento mecánico de las películas a base de almidón depende fuertemente de su composición, siendo la incorporación de plastificante y del relleno los factores más importantes [37, 38].

En la Figura IV.5 se presentan los resultados obtenidos para las películas reforzadas con bagazo con distintos contenidos de urea. Se observa que, a pesar de contener plastificante, el comportamiento del control $(0 \% \mathrm{U}$, que esencialmente contiene un $25 \%$ de glicerol- denominado anteriormente 25G-) corresponde a un material resistente debido a la presencia de fibra en la matriz, con el agregado de urea el material se vuelve más dúctil y flexible ya que aumenta significativamente la elongación y disminuye la resistencia del material. Cuando se comparan los comportamientos mecánicos de las películas que contienen la misma cantidad de plastificante $(0,12,5$ y $25 \%$ de urea) se comprueba nuevamente que la urea es un plastificante más efectivo para la matriz con bagazo que el glicerol o que la mezcla de ambos, como se observó en las películas de almidón sin refuerzo.
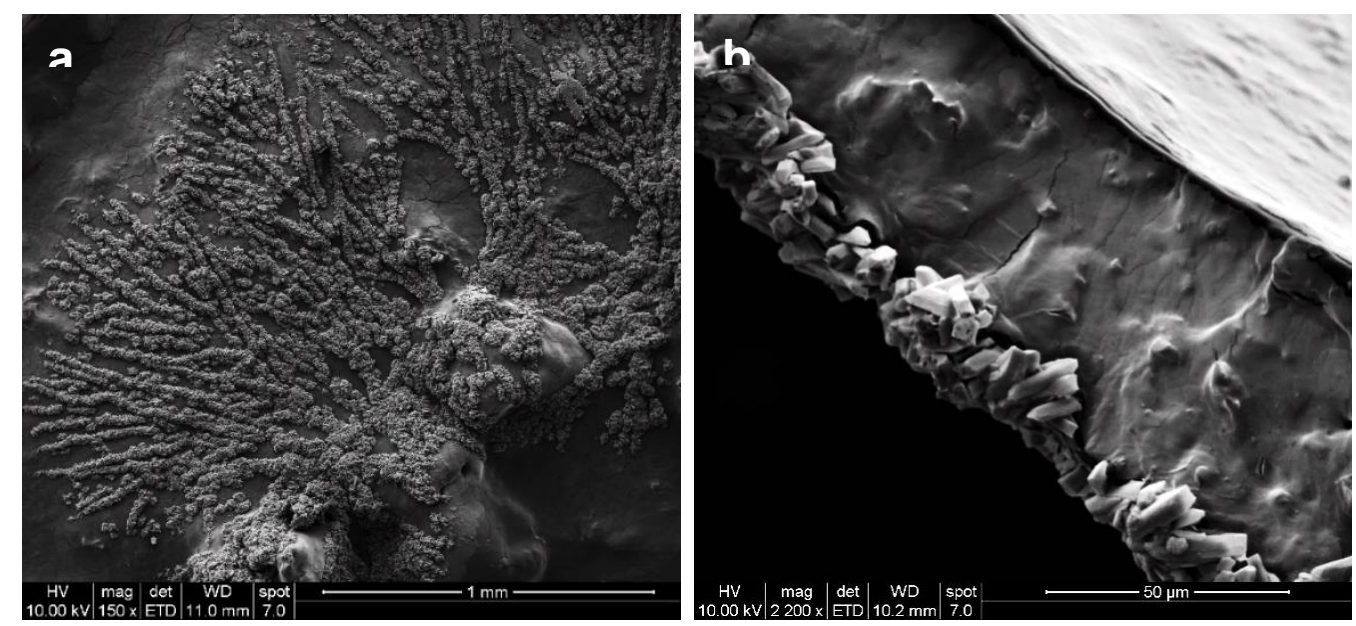

Figura IV.6. Morfología de: a) la superficie (150x), y b) un corte transversal (2000x) de películas de almidón de mandioca reforzadas con fibras plastificadas con $50 \%$ de urea. 
A simple vista se observó en las películas con 50 \% de urea la expulsión del aditivo de la matriz y su cristalización sobre la superficie de la película, la que fue más evidente sobre la cara expuesta al aire durante el secado. En la Figura IV.6 pueden apreciarse los cristales de urea sobre las películas $50 \% \mathrm{U}$ observadas por la técnica SEM. Estas observaciones permiten explicar el comportamiento mecánico de las películas con $50 \%$ de urea en relación con las que contenían 37,5 \%.

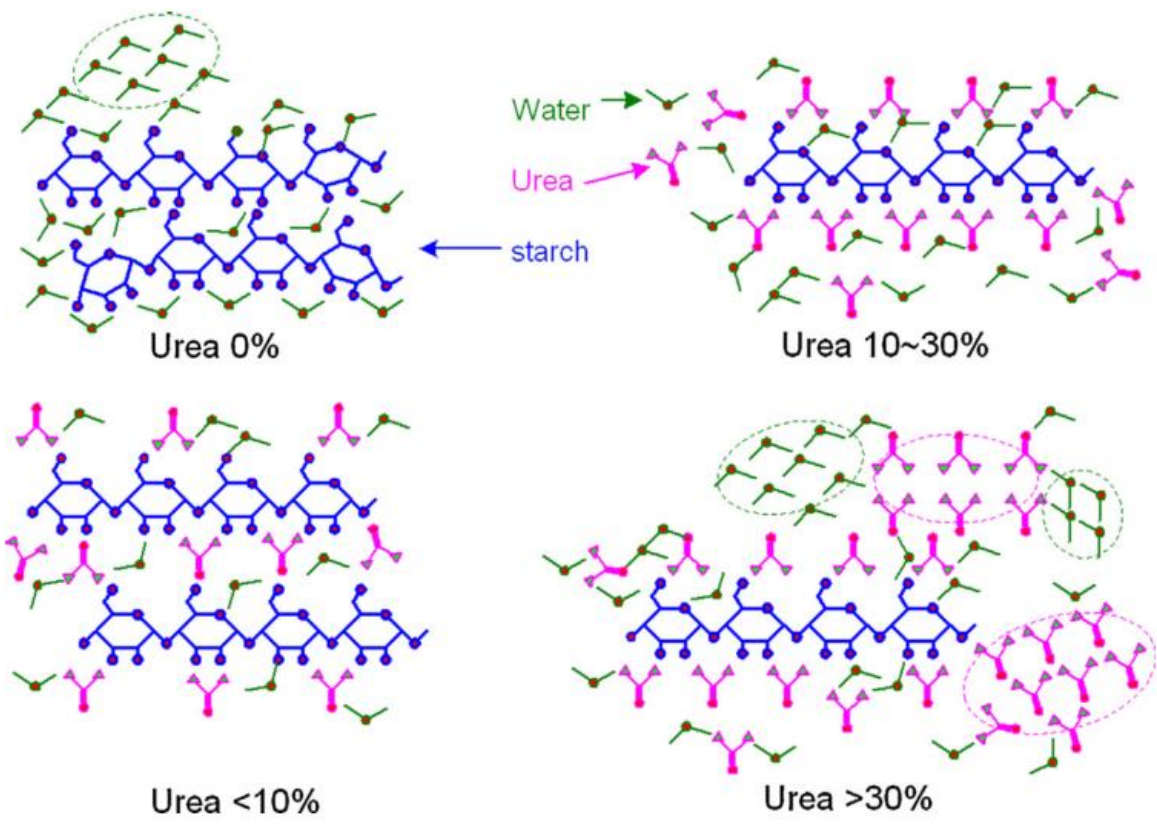

Figura V.7. Modelo esquemático propuesto por Wang y col. [39] de las formas de interacción entre las moléculas de almidón (azul), agua (verde) y urea (rosa), en la matriz de materiales a base de almidón con distintos contenidos de urea.

Wang y col. [17] propusieron un modelo que representa esquemáticamente los estados de la urea en películas de almidón de maíz oxidado (Figura IV.7). Con contenidos menores al $10 \%$ indicaron que la urea se encuentra incorporada a la matriz (plastificación interna); con concentraciones mayores la urea no está tan comprometida en la estructura y ejerce un efecto de plastificación de la matriz aumentando su capacidad de absorción de agua. Consecuentemente disminuye la 
resistencia mecánica y aumenta la elongación a la ruptura del material (plastificación externa). A concentraciones mayores al $37,5 \%$, en el caso de películas a base de almidón de mandioca reforzadas, se produjo una separación de fase macroscópica de la película debido a la sobresaturación de urea en la matriz de almidón, lo que se evidenció al SEM, afectándose el comportamiento mecánico del material.

Las curvas de ajuste de los datos de hinchamiento de las películas de almidón de mandioca con urea y bagazo estudiadas se muestran en la Figura IV.8. Se observó un buen ajuste $\left(r^{2}>0,989\right)$ de los datos experimentales al modelo empírico de Elizalde y col. [26], a partir del cual se estimaron los parámetros Q y B relacionados con el contenido de agua en el estado estacionario y el tiempo necesario para que se absorba el $50 \%$ de dicho valor, respectivamente (Tabla IV.4).

\begin{tabular}{|c|c|c|c|}
\hline MUESTRA & $\mathrm{Q}$ (g agua/g BS) & $B(\min )$ & $r^{2}$ \\
\hline $0 \% U$ & $0,43 \pm 0,007^{b}$ & $17,35 \pm 3,53^{b}$ & 0,99421 \\
\hline $12,5 \% \mathrm{U}$ & $0,45 \pm 0,008^{c}$ & $3,51 \pm 3,23^{a}$ & 0,99272 \\
\hline $25 \% U$ & $0,41 \pm 0,008^{a}$ & $7,66 \pm 4,06^{a}$ & 0,98985 \\
\hline $37,5 \% \mathrm{U}$ & $0,53 \pm 0,006^{d}$ & $18,82 \pm 2,50^{b}$ & 0,99720 \\
\hline $50 \% U$ & $0,82 \pm 0,018^{e}$ & $49,96 \pm 4,03^{c}$ & 0,99431 \\
\hline
\end{tabular}

Nota: Se presentan los valores medio \pm la desviación standard.

Letras diferentes en una misma columna indican diferencias significativas $(p<0,05)$.

En general, ambos parámetros aumentan con el contenido de urea, debido a la naturaleza hidrofílica de este compuesto. Las películas que incluían glicerol en su formulación absorbieron la misma cantidad de agua, siendo el término B de la muestra con $12,5 \%$ de urea mucho menor que para la película con $25 \%$ de glicerol. Las películas con $50 \%$ de urea presentaron los valores más altos de $B$ y $Q$, probablemente debido a que la urea expulsada de la matriz y cristalizada sobre la superficie de la película, como se observó al SEM, aumenta considerablemente la hidrofilicidad del material. 

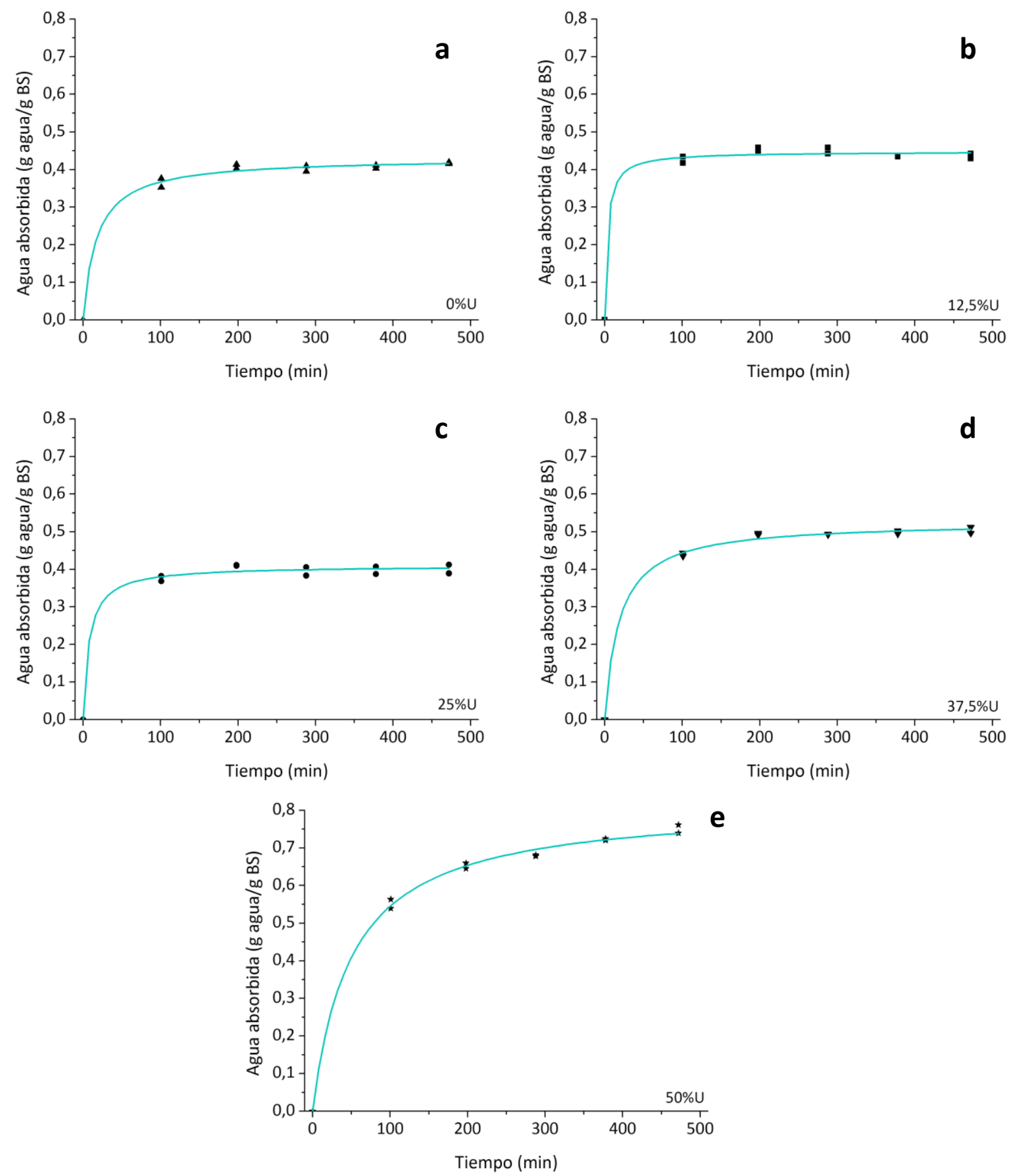

Figura IV.8. Datos experimentales y curva de ajuste para absorción de agua en función del tiempo de películas de almidón con bagazo y distintas concentraciones de urea:

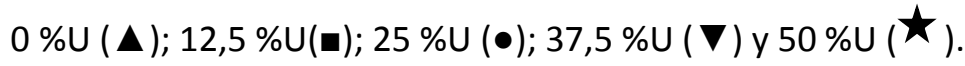


La velocidad de biodegradación de un material polimérico depende de varios factores, incluyendo su área superficial, actividad microbiana del medio, $\mathrm{pH}$, temperatura, humedad y la presencia de otros nutrientes. Entre las características del material que afectan tal velocidad se incluyen su composición química, peso molecular y cristalinidad, entre otras. Los microorganismos colonizan la superficie de los polímeros, secretando enzimas, las que hidrolizan los enlaces poliméricos generando oligómeros, dímeros que subsecuentemente son llevados a sus formas monoméricas los que son lo suficientemente pequeños para atravesar la membrana plasmática. Luego son metabolizados produciendo a través del ciclo de Krebs de los ácidos tricarboxílicos: dióxido de carbono y agua en condiciones aeróbicas o metano en condiciones anaerobias.

Los resultados indican que la cinética de biodegradación en suelo aumentó con el contenido de urea del material. Las películas con $50 \%$ de urea registraron a los 15 días una degradación del $57 \%$ de las muestras. Dicho comportamiento se ajustó satisfactoriamente $\left(r^{2}>0,94\right)$ con el modelo de Boltzmann el que permitió estimar el tiempo necesario para la degradación del $50 \%$ del material $\left(t_{50}\right)$ y el parámetro empírico de ajuste (dt) porcentaje que se relaciona con la velocidad de degradación del material (Tabla IV.5).

\begin{tabular}{|c|c|c|c|}
\hline MUESTRA & $\mathbf{t}_{50}$ (días) & dt (días) & $r^{2}$ \\
\hline $0 \% \mathrm{U}$ & $33,18 \pm 8,60^{\mathrm{bcd}}$ & $1,80 \pm 4,87^{a}$ & 0,99366 \\
\hline $12,5 \% \mathrm{U}$ & $32,95 \pm 1,86^{d}$ & $4,03 \pm 2,09^{a}$ & 0,93939 \\
\hline $25 \% U$ & $24,64 \pm 0,59^{b}$ & $4,07 \pm 0,36^{a}$ & 0,99340 \\
\hline $37,5 \% U$ & $27,33 \pm 1,44^{c}$ & $6,68 \pm 1,32^{\mathrm{a}}$ & 0,95391 \\
\hline $50 \% U$ & $14,40 \pm 0,60^{a}$ & $4,02 \pm 1,39^{a}$ & 0,98714 \\
\hline
\end{tabular}

Nota: Se presentan los valores medio \pm la desviación standard. Letras diferentes en una misma columna indican diferencias significativas $(p<0,05)$. 
No se observaron diferencias en los $t_{50}$ de las películas que contenían glicerol en su formulación ( $0 \%$ y $12,5 \% U$ ). La muestra con $50 \%$ de urea fue la que más rápido se degradó (menor $t_{50}$ ), probablemente debido a que la menor resistencia mecánica y el mayor hinchamiento de la matriz (Tabla IV.4) favorecen la erosión y desintegración del material. Las películas conteniendo 25 y $37,5 \%$ de urea tuvieron tiempos de degradación media similares si bien se observó la mayor velocidad inicial de degradación para las muestras con $37,5 \%$ de urea. En comparación con otros materiales biodegradables las películas de almidón reforzadas aditivadas con urea se degradaron más lentamente que las formuladas con PLA, PHB y nanocelulosa cristalina estudiadas por Arrieta y col. [28], ya que para estos materiales se encontraron valores de $t_{50}$ entre 13,7 y 7 días.

Así, las películas de almidón de mandioca reforzadas y funcionalizadas con urea cumplen con la reglamentación que permite la certificación y etiquetado de productos "OK Biodegradable" o "Compostable" para los cuales se debe garantizar su degradación completa bajo condiciones de técnicas industriales en un plazo no mayor a 12 semanas [40].

A partir de estos materiales eco-compatibles podrían desarrollarse macetas biodegradables, las que se caracterizan por su degradación en un período corto y transformación en materia orgánica, que puede ser utilizada por la planta. Con este fin, resulta imprescindible estudiar la liberación controlada de urea al suelo. Como ya se mencionó, en general los estudios referidos a la liberación controlada se han desarrollado en su mayoría en simulantes líquidos y muy pocos han sido realizados en condiciones reales de aplicación [41, 42].

La Figura IV.9 muestra que las películas con $50 \%$ de urea registraron a los 15 días una liberación del $95 \%$ del compuesto activo. No se observaron diferencias entre las muestras con contenidos de urea a partir de 37,5 \%. Hacia los 30 días la liberación se 
consideró completa independientemente de la formulación del material. Se ha propuesto que el mecanismo de liberación de compuestos activos desde una matriz polimérica sigue en general tres etapas: la inicial durante la cual casi no se observa liberación, a la que se denomina período de retardo, la fase de liberación constante y finalmente la disminución gradual de la velocidad de liberación hasta alcanzar el estado estacionario.

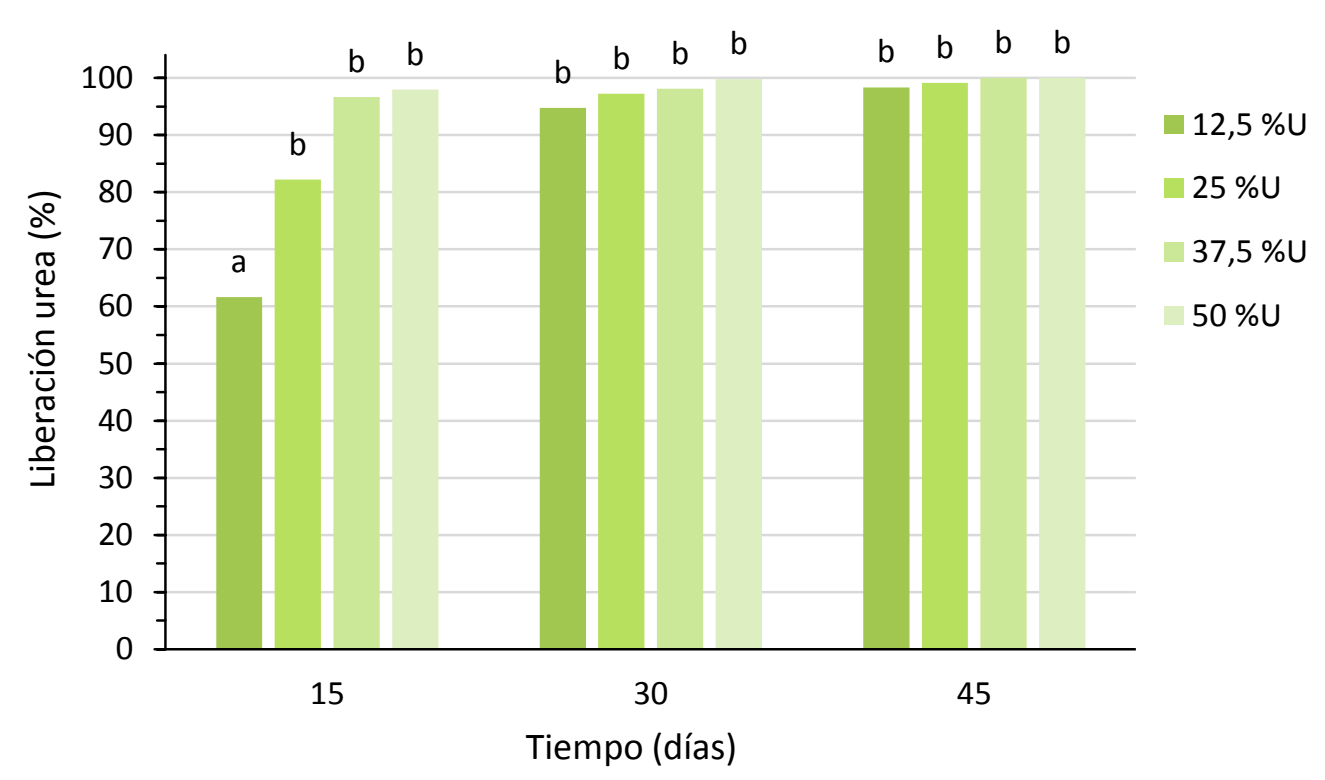

Figura IV.9. Porcentaje de liberación de urea en suelo de las películas de almidón de mandioca funcionalizadas a los 15,30 y 45 días bajo condiciones de compostaje.

Como era de esperar, los resultados obtenidos de liberación en suelo se correlacionan con los de biodegradación y los de capacidad de absorción de agua de las películas ya que estos procesos ocurren en forma simultánea. Peppas y Brannon-Peppas [43] propusieron que la primera etapa del proceso de liberación es la penetración de agua, el hinchamiento de la matriz, seguido por un mecanismo que tiene en general dos contribuciones principales: la difusión y la liberación por relajación y erosión de la matriz polimérica. 
En general la liberación controlada de fertilizantes encapsulados depende de la temperatura y humedad del suelo; por lo tanto, una mayor liberación se producirá cuando estos factores aumentan, lo que coincide con el incremento de las necesidades de las plantas. Una situación similar sería de esperar en las películas funcionalizadas, las que podrían considerarse como alternativas viables para el aumento de los rendimientos de cultivos de ciclo corto. Se ha indicado que, la urea es crucial en las primeras etapas de desarrollo, por lo que la liberación completa del fertilizante a tiempos cortos permitiría que este nutriente se encuentre rápidamente disponible para el cultivo.

\section{CONCLUSIONES}

En este capítulo se vio que la urea, el glicerol y su mezcla son plastificantes compatibles para matrices a base de almidón de mandioca, sin detectar la migración superficial de los plastificantes ensayados. A pesar de que todas las muestras contenían la misma cantidad de plastificante ( $25 \% \mathrm{p} / \mathrm{p})$, la adición de urea dio como resultado un menor contenido de humedad de la película. Sin embargo, otras propiedades relacionadas con la interacción con el agua, tales como la actividad acuosa de las películas, el hinchamiento y el ángulo de contacto fueron similares para todos los materiales ensayados. Del mismo modo, las propiedades de barrera al vapor de agua no se vieron afectadas por el tipo de plastificante utilizado.

Las películas que contenían urea mostraron propiedades ópticas mejoradas, especialmente la capacidad de barrera UV, ya que este plastificante exhibe una transición electrónica en esta región espectral. Las películas de almidón de mandioca plastificadas con la mezcla presentaron la mayor absorción UV-vis (200-700 nm), lo cual es relevante considerando las potenciales aplicaciones de la película. 
Las interacciones plastificante-polímero así como aquellas que implican moléculas de agua se evidenciaron por los cambios de las posiciones e intensidades de los pico observados en los espectros ATR-FTIR, particularmente aquellos dentro de las regiones $3700-2800 \mathrm{~cm}^{-1}, 1750-1400 \mathrm{~cm}^{-1}$ y $1200-900 \mathrm{~cm}^{-1}$. El desplazamiento observado a frecuencias más bajas a $3300 \mathrm{~cm}^{-1}$, sugirió una interacción de enlace puente de $\mathrm{H}$ más fuerte entre los grupos $\mathrm{O}-\mathrm{H}$ del almidón y $\mathrm{N}-\mathrm{H}$ de la urea que entre los pares de $\mathrm{O}-\mathrm{H}$. Asimismo, la eficiencia de la urea como plastificante se demostró tanto por la disminución de los valores de Tg como por la mejora de las propiedades mecánicas. Por el contrario, la coplastificación de las películas de almidón con la mezcla de glicerol y urea dio como resultado un comportamiento mecánico más pobre.

En cuanto a las películas reforzadas con bagazo y funcionalizadas con urea, de los resultados expuestos puede concluirse que la estructura y propiedades de las películas de almidón de mandioca reforzadas dependen fuertemente del contenido de urea incorporado. Este aditivo además de funcionalizar la matriz actúa como un plastificante más efectivo aún que el glicerol, como se evidencia en el estudio de las propiedades mecánicas de las películas desarrolladas. El contenido máximo de urea que puede incluirse en la matriz es del 37,5 \% ya que con concentraciones mayores se evidencia la expulsión del aditivo y su cristalización superficial. Los resultados obtenidos de liberación controlada de urea en suelo se correlacionan con los de biodegradación y de capacidad de absorción de agua de las películas ya que estos procesos ocurren en forma simultánea.

Así las películas reforzadas con agregado de urea permiten dosificar la liberación de nutrientes en el suelo en coincidencia con las demandas del cultivo según su estado fenológico; por lo que se espera que proporcionen una alta eficiencia en el uso de este nutriente y que se minimicen los efectos adversos sobre el ambiente. 


\section{BIBLIOGRAFÍA}

[1] R. Sothornvit, J.M. Krochta, 23 - Plasticizers in edible films and coatings, en: J.H. Han (Ed.) Innovations in Food Packaging, Academic Press, London, UK, 2005, pp. 403-433.

[2] M.G.A. Vieira, M.A. da Silva, L.O. dos Santos, M.M. Beppu, Natural-based plasticizers and biopolymer films: A review, European Polymer Journal 47 (2011) 254-263.

[3] S. Rivero, L. Damonte, M.A. García, A. Pinotti, An Insight into the Role of Glycerol in Chitosan Films, Food Biophysics 11 (2016) 117-127.

[4] P.V.A. Bergo, R.A. Carvalho, P.J.A. Sobral, R.M.C. dos Santos, F.B.R. da Silva, J.M. Prison, J. Solorza-Feria, A.M.Q.B. Habitante, Physical properties of edible films based on cassava starch as affected by the plasticizer concentration, Packag. Technol. Sci. 21 (2008) 85-89.

[5] M.C. Galdeano, S. Mali, M.V.E. Grossmann, F. Yamashita, M.A. García, Effects of plasticizers on the properties of oat starch films, Mater. Sci. Eng., C 29 (2009) 532-538.

[6] A.N. Ghebremeskel, C. Vemavarapu, M. Lodaya, Use of surfactants as plasticizers in preparing solid dispersions of poorly soluble API: selection of polymer-surfactant combinations using solubility parameters and testing the processability, Int J Pharm 328 (2007) 119-129.

[7] H. Liu, D. Chaudhary, G. Ingram, J. John, Interactions of hydrophilic plasticizer molecules with amorphous starch biopolymer-an investigation into the glass transition and the water activity behavior, J. Polym. Sci., Part B: Polym. Phys. 49 (2011) 1041-1049.

[8] X. Ma, J. Yu, The Effects of Plasticizers Containing Amide Groups on the Properties of Thermoplastic Starch, Starch/Staerke 56 (2004) 545-551.

[9] S. Mali, L.S. Sakanaka, F. Yamashita, M.V.E. Grossmann, Water sorption and mechanical properties of cassava starch films and their relation to plasticizing effect, Carbohydr. Polym. 60 (2005) 283-289.

[10] A.P. Mathew, A. Dufresne, Plasticized Waxy Maize Starch: Effect of Polyols and Relative Humidity on Material Properties, Biomacromolecules 3 (2002) 1101-1108.

[11] M. Rodríguez, J. Osés, K. Ziani, J.I. Maté, Combined effect of plasticizers and surfactants on the physical properties of starch based edible films, Food Res. Int. 39 (2006) 840-846.

[12] T.M. Stein, S.H. Gordon, R.V. Greene, Amino acids as plasticizers, Carbohydr. Polym. 39 (1999) 7-16.

[13] R.A. Talja, H. Helén, Y.H. Roos, K. Jouppila, Effect of various polyols and polyol contents on physical and mechanical properties of potato starch-based films, Carbohydr. Polym. 67 (2007) 288-295.

[14] Y. Zhang, J.H. Han, Mechanical and thermal characteristics of pea starch films plasticized with monosaccharides and polyols, J. Food Sci. 71 (2006) 109-118.

[15] X.F. Ma, J.G. Yu, Y.B. Ma, Urea and formamide as a mixed plasticizer for thermoplastic wheat flour, Carbohydr. Polym. 60 (2005) 111-116.

[16] X.F. Ma, J.G. Yu, J.J. Wan, Urea and ethanolamine as a mixed plasticizer for thermoplastic starch, Carbohydr. Polym. 64 (2006) 267-273. 
[17] J.L. Wang, F. Cheng, P.X. Zhu, Structure and properties of urea-plasticized starch films with different urea contents, Carbohydr. Polym. 101 (2014) 1109-1115.

[18] S. Wang, X. Peng, L. Zhong, S. Jing, X. Cao, F. Lu, R. Sun, Choline chloride/urea as an effective plasticizer for production of cellulose films, Carbohydr. Polym. 117 (2015) 133-139.

[19] X. Jiang, B. Tan, X. Zhang, D. Ye, H. Dai, X. Zhang, Studies on the properties of poly(vinyl alcohol) film plasticized by urea/ethanolamine mixture, J. Appl. Polym. Sci. 125 (2012) 697-703.

[20] X. Mo, X. Sun, Thermal and mechanical properties of plastics molded from urea-modified soy protein isolates, J. Am. Oil Chem. Soc. 78 (2001) 867-872.

[21] O.V. López, M.A. García, N.E. Zaritzky, Film forming capacity of chemically modified corn starches, Carbohydr. Polym. 73 (2008) 573-581.

[22] R. Sothornvit, D.S. Reid, J.M. Krochta, Plasticizer effect on the glass transition temperature of beta-lactoglobulin films, Trans. ASAE 45 (2002) 1479-1484.

[23] F. Versino, M.A. García, Cassava (Manihot esculenta) starch films reinforced with natural fibrous filler, Ind. Crops Prod. 58 (2014) 305-314.

[24] F. Ivanič, D. Jochec-Mošková, I. Janigová, I. Chodák, Physical properties of starch plasticized by a mixture of plasticizers, European Polymer Journal (2017).

[25] P. Rychter, M. Kot, K. Bajer, D. Rogacz, A. Siskova, J. Kapusniak, Utilization of starch films plasticized with urea as fertilizer for improvement of plant growth, Carbohydr. Polym. 137 (2016) 127-138.

[26] B.E. Elizalde, A.M.R. Pilosof, G.B. Bartholomai, Empirical Model for Water Uptake and Hydration Rate of Food Powders by Sorption and Baumann Methods, J. Food Sci. 61 (1996) 407409.

[27] P. de Meuter, H. Rahier, B. Van Mele, The use of modulated temperature differential scanning calorimetry for the characterisation of food systems, Int. J. Pharm. 192 (1999) 77-84.

[28] M.P. Arrieta, E. Fortunati, F. Dominici, E. Rayón, J. López, J.M. Kenny, PLA-PHB/cellulose based films: Mechanical, barrier and disintegration properties, Polym. Degrad. Stab. 107 (2014) 139-149.

[29] C.M.O. Müller, F. Yamashita, J.B. Laurindo, Evaluation of the effects of glycerol and sorbitol concentration and water activity on the water barrier properties of cassava starch films through a solubility approach, Carbohydr. Polym. 72 (2008) 82-87.

[30] M.A. Bertuzzi, E.F. Castro Vidaurre, M. Armada, J.C. Gottifredi, Water vapor permeability of edible starch based films, J. Food Eng. 80 (2007) 972-978.

[31] X. Ma, J. Yu, K. He, N. Wang, The Effects of Different Plasticizers on the Properties of Thermoplastic Starch as Solid Polymer Electrolytes, Macromol. Mater. Eng. 292 (2007) 503-510.

[32] J. Piermaria, A. Bosch, A. Pinotti, O. Yantorno, M.A. Garcia, A.G. Abraham, Kefiran films plasticized with sugars and polyols: Water vapor barrier and mechanical properties in relation to their microstructure analyzed by ATR/FT-IR spectroscopy, Food Hydrocolloids 25 (2011) 1261-1269. 
[33] P. Rubens, J. Snauwaert, K. Heremans, R. Stute, In situ observation of pressure-induced gelation of starches studied with FTIR in the diamond anvil cell, Carbohydr. Polym. 39 (1999) 231-235.

[34] I. Capron, P. Robert, P. Colonna, M. Brogly, V. Planchot, Starch in rubbery and glassy states by FTIR spectroscopy, Carbohydr. Polym. 68 (2007) 249-259.

[35] W. Shujun, Y. Jiugao, Y. Jinglin, Preparation and characterization of compatible thermoplastic starch/polyethylene blends, Polym. Degrad. Stab. 87 (2005) 395-401.

[36] J.J.G. van Soest, H. Tournois, D. de Wit, J.F.G. Vliegenthart, Short-range structure in (partially) crystalline potato starch determined with attenuated total reflectance Fouriertransform IR spectroscopy, Carbohydr. Res. 279 (1995) 201-214.

[37] A. Shalwan, B.F. Yousif, In State of Art: Mechanical and tribological behaviour of polymeric comopistes based on natural fibres, Mater. Des. 48 (2013) 14-24.

[38] R.N. Tharanathan, Biodegradable films and composite coatings: past, present and future, Trends Food Sci. Technol. 14 (2003) 71-78.

[39] J.L. Wang, F. Cheng, P.X. Zhu, Structure and properties of urea-plasticized starch films with different urea contents, Carbohydr Polym 101 (2014) 1109-1115.

[40] C. Stareter, Pruebas sobre diversas características de las macetas biodegradables., Horticultura: Revista de Industria Distribución y Socioeconomía Hortícola 180 (2004) 38-47.

[41] O.V. López, L. Giannuzzi, N.E. Zaritzky, M.A. García, Potassium sorbate controlled release from corn starch films, Mater. Sci. Eng., C 33 (2013) 1583-1591.

[42] S. Rivero, L. Giannuzzi, M.A. García, A. Pinotti, Controlled delivery of propionic acid from chitosan films for pastry dough conservation, J. Food Eng. 116 (2013) 524-531.

[43] N.A. Peppas, L. Brannon-Peppas, Water diffusion and sorption in amorphous macromolecular systems and foods, J. Food Eng. 22 (1994) 189-210. 


\section{INTRODUCCIÓN}

Las investigaciones relacionadas a la funcionalización de materiales biodegradables mediante el agregado de compuestos activos es una opción de amplia demanda en el área farmacéutica y biomédica, siendo escasas las aplicaciones agronómicas. Se ha informado el uso de materiales compuestos biodegradables como macetas [1] y cobertura del suelo (mulching) [2, 3]. Esta última permite controlar el crecimiento de malezas, reduce la erosión, mantiene la humedad y temperatura del suelo mejorando la productividad de los cultivos. Empero, su remoción implica un costo adicional a la producción, así como una fuente de contaminación ambiental. Al respecto el uso de materiales eco-compatibles permitiría reducir los problemas de contaminación asociados a esta práctica como ser la recolección y/o reciclado. Consecuentemente, el desarrollo de películas a base de almidón es una alternativa viable para ésta y otras aplicaciones de interés agronómico, ya que se trata de materiales biodegradables, procedentes de un recurso renovable y relativo bajo costo. Briassoulis [4] señaló la importancia del estudio de la resistencia mecánica de los materiales destinados a este fin, así se ha propuesto como estrategia para mejorar el comportamiento mecánico de las películas biodegradables la incorporación de rellenos [5-8].

Los materiales biodegradables que se utilicen con fines agrícolas deberían cumplir con tres requisitos críticos de diseño: lograr un buen comportamiento mecánico, conservarlo durante su aplicación en condiciones de campo y lograr una biodegradación del $100 \%$ en el suelo preferentemente antes de la siguiente estación de cultivo [5]. Para ser parte de sistemas agrícolas sostenibles, la biodegradación in situ de los materiales de mulching debe ocurrir dentro de un plazo razonable (menor a 2 años según lo propuesto por la nueva norma ASTM D5988-12 de biodegradación en suelo) y la calidad del suelo no debe verse afectada negativamente [6]. En el estudio de los materiales con aplicaciones agronómicas, es de particular importancia su comportamiento frente a la radiación solar, especialmente la radiación 
fotosintéticamente activa (PAR) transmitida por el material en el rango de longitudes de onda de $400-700 \mathrm{~nm}$. Esta radiación se asocia a la necesaria para la fotosíntesis, que es el proceso básico en el desarrollo de cultivos [7]. Como consecuencia, la cantidad de radiación PAR transmitida por el material, tiene gran importancia en relación con el crecimiento del cultivo y contribuye a la elección del mismo. Asimismo, debido a la exposición prolongada a los agentes climáticos, principalmente a la radiación solar, las películas ya sean sintéticas o naturales-biodegradables presentan alteraciones en sus propiedades físicas y mecánicas las que limitan su vida útil. Por tanto resulta primordial evaluar la performance de los materiales en el tiempo, expuestos a condiciones climáticas que se asemejen a las reales.

Por otra parte, el diseño de materiales funcionalizados permite la liberación controlada del componente activo incluido en la formulación y consecuentemente su dosificación. Sin embargo aplicaciones en el área agronómica que incluyan fertilizantes han sido poco desarrolladas hasta el momento, encontrándose sólo información referida al encapsulado de urea $[9,10]$ o a su inclusión en matrices mixtas [11]. El uso de sistemas de liberación controlada de fertilizantes surge como una alternativa para un uso racional y adecuado de nutrientes, lo que repercute en la eficiencia de uso de cada elemento nutritivo y en el aumento en la productividad con menor costo e impacto ambiental; constituyendo un recurso hacia una agricultura más limpia y sustentable. Así se pretende mitigar los problemas derivados del uso excesivo de fertilizantes en los cultivos, siendo el más importante la contaminación de las aguas por nitratos [12]. Los nuevos sistemas de producción agrarios con una menor utilización de agroquímicos, necesitan tecnologías innovadoras que permitan asegurar los rendimientos y la calidad de los productos agrícolas, a la vez que minimicen los efectos negativos sobre el ambiente. En este sentido, es necesario desarrollar nuevos métodos para reducir la cantidad de agroquímicos que entran en el medio ambiente, ayudando a mantener la actividad biológica en un nivel deseable. La inclusión de urea en la formulación de películas biodegradables permitiría la liberación gradual del fertilizante, minimizando 
la contaminación del suelo y el agua asociada con la sobredosificación en contraposición con la forma tradicional de aplicación [10].

\section{OBJETIVOS}

- Estudiar el efecto del almacenamiento bajo condiciones controladas de las películas a base de almidón de mandioca reforzadas con bagazo, para distintos contenidos de relleno.

- Evaluar la resistencia en condiciones ambientales reales de los materiales control y reforzados.

- Evaluar la estabilidad de los materiales reforzados y funcionalizados con urea durante el almacenamiento.

- $\quad$ Analizar el efecto del material sobre el crecimiento de plantines de tomate, en su etapa de desarrollo inicial.

\section{METODOLOGÍA Y TÉCNICAS EMPLEADAS}

\subsection{Materiales utilizados}

Para los materiales de cobertura se empleó almidón de mandioca extraído de raíces tuberosas cultivadas en la Estación Experimental Agropecuaria perteneciente al INTA Montecarlo (Misiones, Argentina) y el remanente de la extracción del almidón (bagazo) como se describió en las secciones 3.1 y 3.2 del capítulo I. Mientras que por cuestiones de disponibilidad, para el estudio de los materiales funcionalizados y el ensayo bajo condiciones reales de exposición, se utilizó almidón nativo de mandioca obtenido de la Cooperativa de Productores de Jardín América Ltda. (Misiones, Argentina); el mismo bagazo ya caracterizado; y glicerol (CAS\# 56-81-5, Anedra, Argentina) y urea (CAS\# 57-13-6, Biopack, Argentina) como aditivos. 
3.2. Preparación de películas y materiales compuestos para cobertura Se prepararon suspensiones acuosas de almidón de mandioca ( $3 \% \mathrm{p} / \mathrm{p})$ con agregado de bagazo $(0 ; 0,75$ y $1,5 \% \mathrm{p} / \mathrm{p})$ y plastificadas con glicerol como se describió en la sección 3.4.2 del capítulo I.

\subsubsection{Almacenamiento bajo condiciones ambientales controladas}

Las películas se almacenaron en una cámara bajo condiciones controladas de humedad y temperatura ( $53 \% \mathrm{HR}$ y $24^{\circ} \mathrm{C}$ ), expuestos a ciclos de luz y oscuridad de 16 y 8 hs respectivamente con el fin de reproducir las condiciones de exposición normal a la luz solar (fotoperíodo). El efecto del almacenamiento durante 60 días se evaluó mediante distintas técnicas que se nombraran brevemente puesto que la mayoría ya han sido descriptas previamente a lo largo del trabajo de Tesis:

\subsubsection{Difracción de rayos $X(D R X)$}

La espectroscopia de difracción de rayos $\mathrm{X}$ de un material semicristalino, como el almidón, se caracteriza por la presencia de picos de absorción y una zona de contribución amorfa, que cuanto mayor resulta esta zona menor por tanto será el grado de cristalinidad de la muestra (Figura V.1). Los materiales obtenidos a partir de almidón presentan en general una contribución de la región amorfa importante, puesto que el gránulo de almidón ha sido desestructurado durante el proceso de gelatinización. No obstante, la retrogradación natural del almidón, que puede observarse también en los materiales a base de este compuesto, se puede identificar por un aumento en el grado de cristalinidad de los mismos. Por tanto, con el fin de estudiar las variaciones en el grado de cristalinidad de las muestras almacenadas se realizaron ensayos de difracción de rayos $X$ (DRX) en un difractómetro Philips PW 1390 (Holanda) empleando radiación CuK $\alpha(\lambda=1,5418 \AA ̊$ ) y filtro de Ni para valores de $2 \theta$ entre $2^{\circ}$ y $60^{\circ}$. Las condiciones de operación utilizadas 
fueron: $40 \mathrm{kV}$ de tensión, $40 \mathrm{~mA}$ de corriente, un paso de $0,04^{\circ} \mathrm{y}$ una velocidad de barrido de $2 \% \mathrm{~min}$.

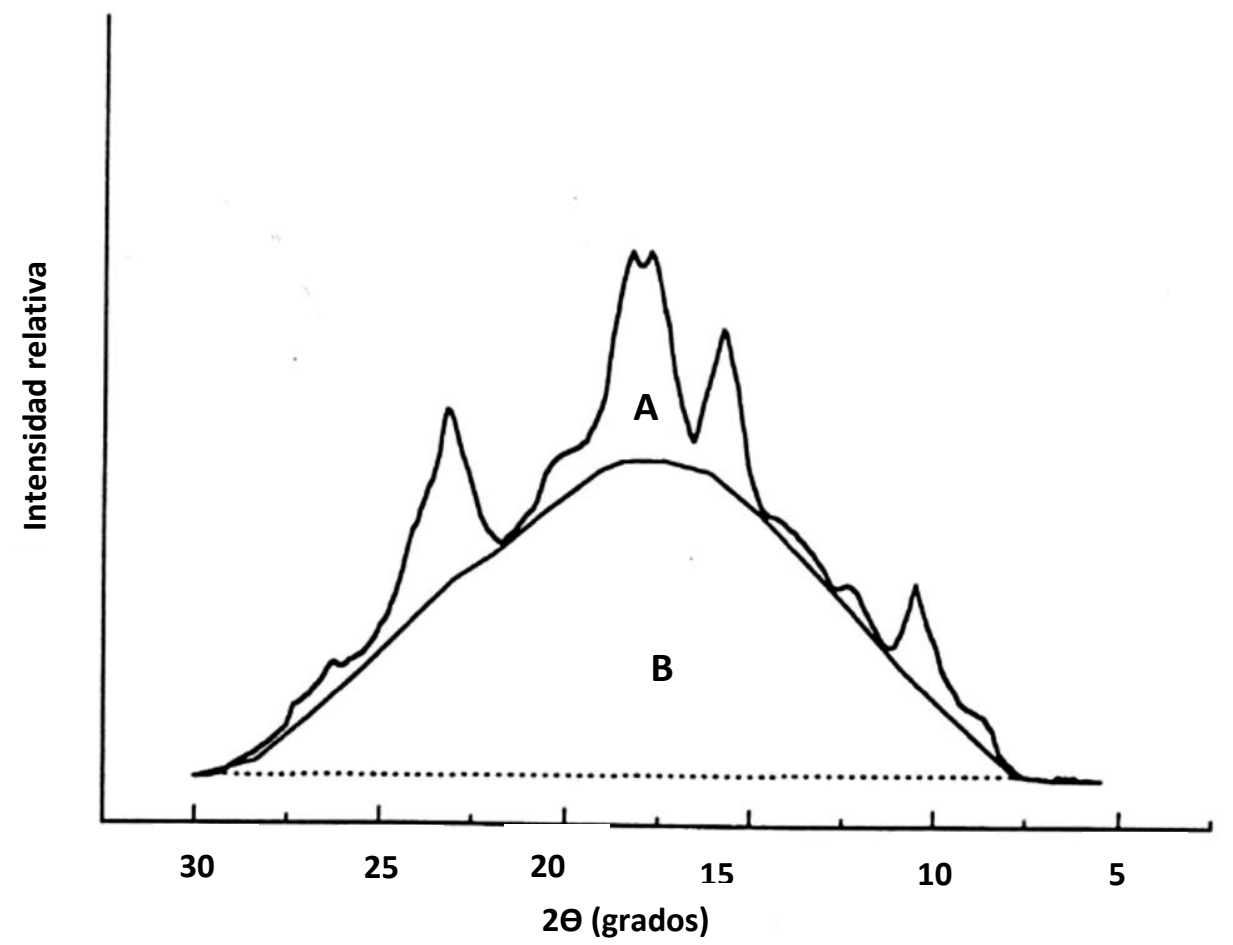

Figura V.1. Difractorgrama típico de un material semicristalino: región cristalina $(A)$ y región amorfa $(B)$.

La cristalinidad se estimó por integración de las áreas de los picos de absorción (que se atribuye a las regiones cristalinas) relativa al área total del espectro [13]. El grado de cristalinidad de una muestra se calcula como sigue:

$$
X c(\%)=A_{c} / A_{T} * 100
$$

Donde $\mathrm{X}_{\mathrm{C}}$ representa el grado de cristalinidad, $\mathrm{A}_{\mathrm{C}}$ corresponde al área de picos de absorción y AT el área total del difractograma, determinadas luego del suavizado de las curvas para eliminar el ruido, en el programa OriginPro 8 (OriginLab Corporation, EEUU). 


\subsubsection{Análisis termo-mecánico dinámico: DMA}

Como se describió en la sección 3.3.5 del capítulo III, se estudiaron las temperaturas de transición vítrea de los materiales obtenidos mediante ensayos modulados de frecuencia sobre probetas rectangulares de $3 \mathrm{~cm} \times 6 \mathrm{~mm}$.

\subsubsection{Propiedades ópticas y mecánicas}

Las medidas de color superficial y de capacidad de barrera a la luz en la región UVvisible se realizaron en forma análoga a lo descripto en la sección 3.5.5 del capítulo I.

También se evaluó el comportamiento mecánico de las películas mediante ensayos cuasi-estáticos de tracción en un analizador dinámico mecánico (DMA Q800, TA Instruments, EEUU) como se describe en la sección 3.5.6 del capítulo I.

\subsubsection{Solubilidad}

La solubilidad de las películas se determinó en agua desionizada a 25 y $100^{\circ} \mathrm{C}$. Muestras de películas de $2 \mathrm{~cm} \times 3 \mathrm{~cm}$ se pesaron (peso seco inicial) y se colocaron en vasos de precipitados que contenían $80 \mathrm{~mL}$ de agua desionizada. Las muestras fueron mantenidas con agitación constante a $200 \mathrm{rpm}$ durante 1 hora a la temperatura correspondiente $\left(25\right.$ y $100^{\circ} \mathrm{C}$ ). Luego, fueron recuperadas por filtración y secadas en una estufa a $60^{\circ} \mathrm{C}$ hasta peso constante (peso seco final). El porcentaje total de materia soluble (\% de solubilidad) fue calculado de la siguiente manera:

$$
\text { Solubilidad }(\%)=\frac{(\text { Peso seco inicial }- \text { Peso seco final })}{\text { Peso seco } \text { inicial }} * 100
$$

Todas las muestras se analizaron al menos por duplicado.

\subsubsection{Almacenamiento bajo condiciones ambientales reales}

Se evaluó el desempeño de los materiales desarrollados frente a condiciones ambientales reales. En esta instancia se evaluaron las películas de almidón de mandioca reforzadas con $1,5 \% \mathrm{p} / \mathrm{p}$ de bagazo plastificadas con $0,75 \% \mathrm{p} / \mathrm{p}$ de glicerol $\mathrm{y}$ 
se compararon con el control sin bagazo. El ensayo se llevó a cabo durante un período de 21 días en el mes de octubre de 2016, registrándose las condiciones meteorológicas: temperatura media $\left({ }^{\circ} \mathrm{C}\right)$ y precipitaciones totales $(\mathrm{mm} / \mathrm{día})$.

\subsubsection{Humedad}

Se estudió la humedad tanto de los materiales estudiados como del suelo cubierto como se describe en la sección 3.5.2 del capítulo I.

\subsubsection{Espectroscopía de infrarrojo con transformada de Fourier} (FTIR)

Con el fin de analizar variaciones en las interacciones de los componentes de la matriz con la degradación ambiental se realizaron ensayos de espectroscopía FTIR-ATR como se describió en la sección 3.3.2 del capítulo II.

\subsubsection{Difracción de rayos $X(D R X)$}

La retrogradación de la matriz de almidón con el tiempo se estudió por medio de ensayos de DRX análogos a los descriptos en la sección 3.2.1.1 de este capítulo, aunque por cuestiones de disponibilidad el equipo usado en este caso fue un difractómetro X'Pert Pro Analytical Model PW3040/60 (PANalytical, Países Bajos) empleando radiación CuK $\alpha(\lambda=1,5418 \AA$ ) en las mismas condiciones antes descriptas.

\subsubsection{Propiedades ópticas}

Se estudió el efecto del tratamiento en las propiedades ópticas de los materiales desarrollados, mediante la evaluación del color y espectroscopia UV-visible como se describió en la sección 3.5.5 del capítulo I. A partir de los espectros de absorción obtenidos en un espectrofotómetro U-1900 (HITACHI, Japón) entre 200 y 700 nm, se determinó en este caso el valor de transmisividad en el intervalo PAR, es decir, la cantidad de radiación PAR transmitida por el material de cobertura se calculó como el valor promedio ponderado de la transmitancia (\%) en el rango de 400 a 700 nm [14]. 


\subsubsection{Propiedades mecánicas}

Dada la aplicación del material la comparación de las propiedades mecánicas se realizó mediante ensayos de punción en un texturómetro TA.XT2i - Stable Micro Systems (Reino Unido) empleando un punzón cilíndrico de $3 \mathrm{~mm}$ de diámetro a una velocidad de deformación de $1 \mathrm{~mm} / \mathrm{s}$. Se registraron las curvas de fuerza (N) vs. deformación $(\mathrm{mm})$ y a partir de las mismas se calculó la fuerza máxima a la ruptura, la deformación a la ruptura y el área bajo la curva $(\mathrm{N} \mathrm{mm})$ que se asocia a la energía necesaria para perforar el material [15].

\subsection{Preparación de películas y materiales compuestos funcionalizados} Se prepararon películas de almidón de mandioca al $3 \% p / p$ con agregado de 1,5\%p/p de bagazo y distintas concentraciones de urea, según se detalla en la sección 3.2 del capítulo IV.

\subsubsection{Almacenamiento en condiciones controladas}

Con el fin de evaluar la estabilidad de los materiales formulados, se estudió el efecto del almacenamiento durante 30 días sobre las propiedades mecánicas de las películas reforzadas con $1,5 \%$ de bagazo y funcionalizadas con urea. Se realizaron ensayos de tracción como se describió en la sección 3.5.8 del capítulo I, y se obtuvieron los difractogramas de rayos $\mathrm{X}$ para evaluar la retrogradación del almidón en la matriz y la posible cristalización de urea en la superficie del material (ver sección 3.2.1.1 de este capítulo). Además se determinó la variación en el contenido de humedad de las muestras (ver sección 3.5.3 del capítulo I).

\subsubsection{Efecto del material sobre el crecimiento de plantines}

\subsubsection{Elección del tipo de semilla y sustrato}

Se realizaron ensayos de poder de germinación sobre placas de Petri y papel de filtro en incubadora, y se comparó la velocidad de crecimiento de semillas de pimiento 
sweet-banana (Capsicum annuum, nombre comercial 'Banana pepper'), pimiento redbell (Capsicum annum, nombre comercial 'Bell pepper'), berenjena (Solarium melonguena) y tomate perita (Licopersycum esculentum).

El ensayo en placa se llevó a cabo con 22 semillas de cada especie sobre placas de Petri y papel de filtro, el cual se mantuvo húmedo durante todo el ensayo en estufa a $27^{\circ} \mathrm{C}$.

Por otro lado, las pruebas de germinación en suelo se realizaron sobre dos sustratos: tierra fértil, constituida por una mezcla 25:1 de tierra negra (Humedad 35-40\%; Cenizas 40-45\%; pH 4,0-6,2; MO 15-20\%; C/N 7,7; CE 1,1 dS/m) y compost orgánico (Humedad 40-45\%; Cenizas 35-40\%; pH 6,0-6,5; MO 20-25\%; C/N 30-35; CE 0,5-1,0 dS/m); y mezcla profesional GrowMix ${ }^{\circledR}$ Multipro $^{\mathrm{TM}}$, compuesta por turba de musgo Sphagnum de fibras medias, perlita, compost de corteza, cal calcita, cal dolomita y agentes humectantes perlita (pH 5,2-5,8; Humedad 55-60\%; MO 85-90\%; CE 0,3-0,45 dS/m; Porosidad 80-85\%; Capacidad de retención de agua 60\%), todos productos Terrafertil, Argentina.

Se sembraron 20 celdas de $23 \mathrm{~cm}^{3}$ por cada variedad de semilla, la mitad con $15 \mathrm{~g}$ de tierra $(\mathrm{T})$ por celda y la otra mitad con $5 \mathrm{~g}$ de mezcla comercial $(\mathrm{M})$ de manera tal de completar el volumen de la celda en formas iguales. Por cada celda se sembraron 2 semillas de cada especie.

3.3.2.2. Capacidad de campo del sustrato y cantidad de agua de riego La capacidad de retención de agua del suelo depende de su composición, densidad y porosidad. Para evitar pérdidas por exceso o falta de riego, se determinó la capacidad de campo del sustrato empleado para siembra de manera de alcanzar el crecimiento óptimo de los plantines. Teniendo en cuenta esto se puede definir la capacidad de campo (Wc) como la cantidad de agua contenida en un suelo bien drenado que se almacena y es retenida en el perfil en contra de la fuerza de la gravedad, considerando que el agua que se aplica en exceso drena y se pierde de la región radicular como 
percolación profunda [16]. Sin embargo, este parámetro no tiene en cuenta la fracción de agua absorbida por las raíces de la planta. Consecuentemente, el valor de la capacidad de campo es un índice cualitativo del límite superior de agua que se ha

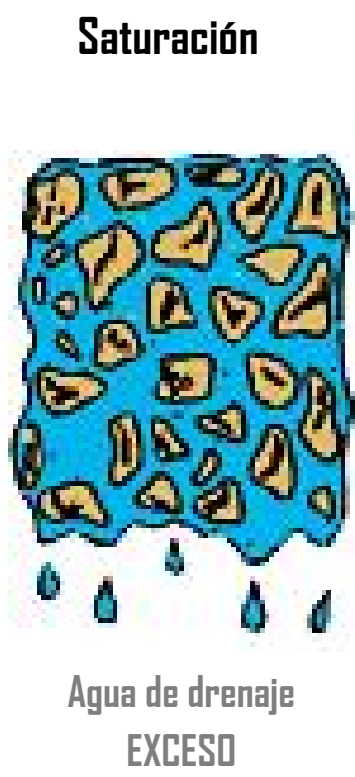

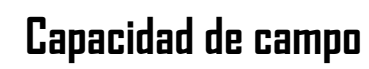

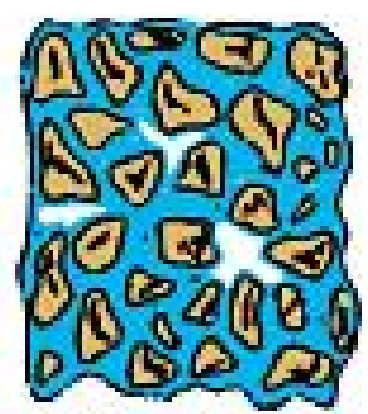

Agua capilar HUMEDAD APRDVECHABLE

\section{Punto de marchitez} permanente

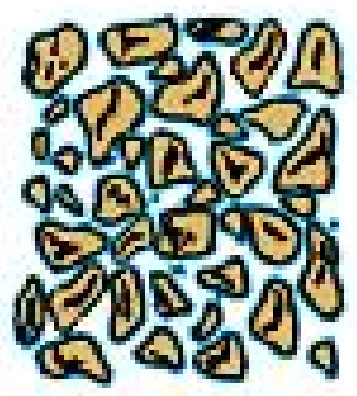

Agua higroscópica

DÉFICIT

Figura V.2. Esquema del estado del agua en el suelo.

Adaptado de INTA-Ediciones [17].

Para determinar la cantidad de agua que debía suministrarse durante el crecimiento de los plantines, de manera de evitar carencia o exceso de agua que podrían limitar el desarrollo de los plantines, se determinó la capacidad de campo del sustrato en las celdas de cultivo en las condiciones del invernadero $\left(25^{\circ} \mathrm{C}\right.$ y $45 \%$ de humedad relativa) durante un período de 7 días, tiempo al que se observó la estabilización de dicho parámetro. El riego se realizó en forma diaria utilizando 15 celdas para determinar la capacidad de campo y regando el resto de las celdas con un $80 \%$ del volumen determinado, puesto que las buenas prácticas recomiendan este nivel de riego para evitar marchitamiento de la raíz. Cada día de medición también se determinó la humedad de al menos 3 de las celdas regadas antes y después del riego. Asimismo se 
midió la temperatura del suelo antes y después del riego, para asegurar que la raíz tampoco pudiera sufrir estrés térmico.

Para determinar la capacidad de campo, se empleó un método sencillo el cual consistió en agregar sucesivamente alícuotas de $100 \mu \mathrm{L}$ de agua a una celda con 5 gr de sustrato (suficiente para llenar una celda de siembra al ras), hasta que se observara percolación de la primer gota de agua en exceso.

\subsubsection{Macetas biodegradables para speedling}

Se prepararon macetas con un volumen de $23 \mathrm{~cm}^{3}$ y $5,5 \mathrm{~cm}$ de altura a partir de películas control (U0), con $25 \%$ de urea (U25) y 37,5\% de urea (U375), así como otras obtenidas a partir de papel kraft recubierto con las mismas suspensiones filmogénicas (P0, P25 y P375, respectivamente). En el caso de los materiales soportados, las suspensiones filmogénicas se aplicaron como recubrimiento sobre papel kraft con una relación de moldeo igual a la descripta en la sección 3.4 del capítulo I, y bajo las mismas condiciones de secado y acondicionamiento.

En estos sistemas se evaluó el efecto de la liberación de fertilizante sobre el crecimiento de semillas de tomate en bandejas de speedling para la producción de plantines, comparándolo con controles sin película.

El ensayo se llevó a cabo bajo invernadero $\left(25^{\circ} \mathrm{C}\right.$ y $45 \%$ de humedad relativa) en bandejas multicelda de polietileno con 256 celdas por bandeja utilizando semillas de tomate perita (Lycopersicum esculentum) comercializadas por Florensa (Italia). Como sustrato se utilizó la mezcla comercial GrowMix ${ }^{\circledR}$ Multipro $^{\mathrm{TM}}$ (Terrafertil, Argentina) cuya composición fue descripta en la sección anterior.

El riego se realizó en base a los resultados obtenidos para la capacidad de campo del sustrato y se realizó un seguimiento diario de las muestras, hasta observar que los plantines poseían al menos 4 hojas verdaderas. 
3.3.2.4. Material de liberación controlada in situ para crecimiento de plantines

Se prepararon platines de tomate perita (Lycopersicum esculentum) de Florensa ${ }^{\mathrm{TM}}$ (Italia) en bandejas de speedling de polietileno con celdas de $23 \mathrm{~cm}^{3}$. A pesar de que el producto especificaba un poder germinativo del $88 \%$ se evaluó el mismo en las condiciones de trabajo seleccionadas. Para ello se sembraron 32 celdas con 2 semillas de tomate en $5 \mathrm{~g}$ del sustrato profesional (GrowMix ${ }^{\circledR}$ Multipro $^{\mathrm{TM}}$, Terrafertil, Argentina) cada una. Al cabo de 5 días se cuantificó el número de semillas que habían brotado para calcular el poder germinativo según:

$$
\text { GERM. \% }=\frac{\# \text { semillas germindas }}{\# \text { semillas sembradas }} * 100
$$

Considerando el poder germinativo de las semillas empleadas se sembraron 256 celdas con una semilla de tomate perita Florensa ${ }^{\mathrm{TM}}$, a fin de obtener al cabo de 14 días al menos 144 plantines de tomate con $2 / 3$ hojas verdaderas para ser trasplantados a macetas plásticas de polietileno № 10 (capacidad de $250 \mathrm{~cm}^{3}$ ). El ensayo de crecimiento medio (período vegetativo) también fue llevado a cabo en invernadero por cuestiones de disponibilidad y posibilidad de controlar las condiciones de luz, temperatura y humedad del medio. En estas condiciones se mantuvieron durante todo el período de crecimiento ciclos de luz y oscuridad de 16:8 horas, una temperatura media de $25,6 \pm 1,8{ }^{\circ} \mathrm{C}$ y humedad relativa ambiente de $45 \pm 8 \%$.

Como medio de crecimiento se usó una mezcla 10:20:1 de sustrato profesional GrowMix $^{\circledR}$ Multipro $^{\mathrm{TM}}$, tierra negra y compost orgánico, todos productos nacionales (Terrafertil, Argentina).

Se empleó un diseño experimental completamente aleatorizado con 16 repeticiones por tratamiento, los cuales fueron 7 en total y se describirán más adelante. 

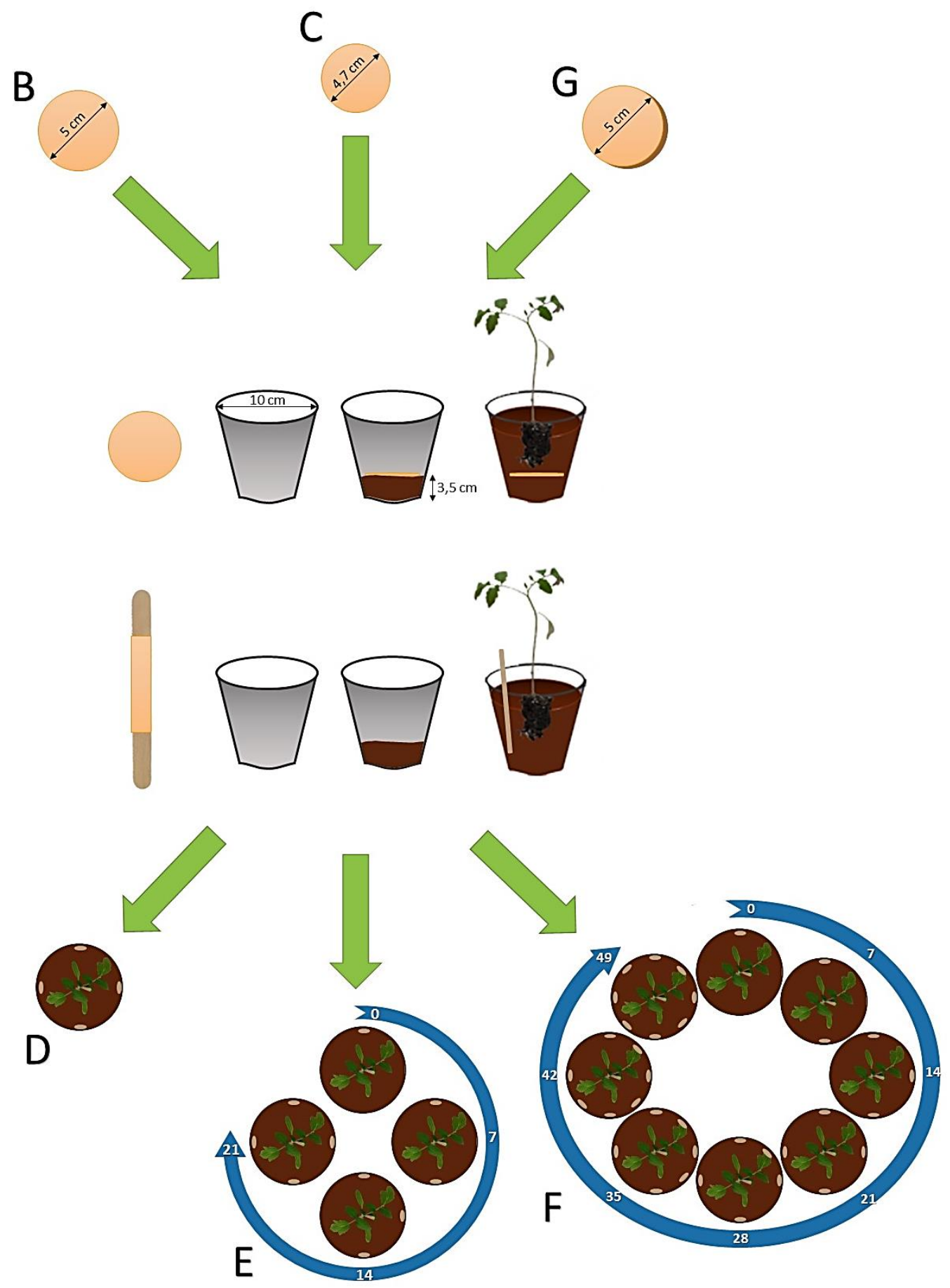

Figura V.3. Esquema de preparación de tratamientos con película de almidón de mandioca funcionalizadas con urea. 
Se realizaron dos extracciones de muestra: una a los 28 días del trasplante y otra a los 56 días (46 y 74 días desde la siembra, respectivamente). El objetivo de la primera extracción consistía en analizar el efecto del soporte, la dosificación y la/s dirección/es de difusión del fertilizante en el medio, mientras que la segunda extracción permitió comparar el efecto de la aplicación dosificada del fertilizante.

Los requerimientos del macronutriente se estimaron a partir de datos bibliográficos, considerándose una demanda de aproximadamente $30 \mathrm{~kg} \mathrm{~N} / \mathrm{ha}$ a los 28 días del trasplante para cultivos con un rendimiento de 90 ton/ha de tomate [18]. Considerando que la urea aporta un 46 \% de nitrógeno, se determinó un requerimiento de $50 \mathrm{mg} \mathrm{N}$ a los 28 días desde el trasplante, y $100 \mathrm{mg} \mathrm{N}$ a los 56 días. Cabe aclarar que para los tratamientos con extracción a los 28 días se estimó el aporte de $\mathrm{N}$ a partir del material considerando este requerimiento y una liberación completa al cabo de este tiempo (como se demostró en el capítulo IV). Así los tratamientos ensayados con extracción a los 28 días desde el trasplante fueron: A) control; B) disco de $5 \mathrm{~cm}$ de diámetro de película $25 \%$ urea; C) disco de 4,7 cm de diámetro de película 37,5 \% urea; D) 4 bastones con película $25 \%$ de urea en simultáneo; E) bastones con película $25 \%$ de urea colocados de a uno por semana (en total 4 que equivalen a $50 \mathrm{mg}$ de urea); y G) disco de papel kraft de $5 \mathrm{~cm}$ de diámetro recubierto con la suspensión filmogénica conteniendo 25 \% urea (idéntica a la muestra P25 descripta en la sección 3.3.2.3). Mientras que a los 56 días del trasplante fueron: A) control; y F) bastones con película $25 \%$ de urea colocados de a uno por semana (en total 8 que equivalen a $100 \mathrm{mg}$ de urea).

Como se muestra en el esquema Figura V.3 los discos de películas empleados en los tratamientos $B, C$ y $\mathrm{G}$ se enterraron a 3,5 cm desde la base de la maceta para asegurar que al momento del trasplante la radícula no se encuentre en contacto directo con el material. Por otro lado, los bastones a los que se hace referencia en los tratamientos D, E y F corresponden a soportes de madera balsa a los cuales se les fijó con un adhesivo 
comercial porciones de película de $5 \mathrm{~cm} \times 1 \mathrm{~cm}$ ubicadas en el soporte de manera tal que quedaran suspendidas a 3,5 cm desde la base maceta (misma altura a la que fueron enterrados los discos de los tratamientos $B, C$ y $G$ ). Los mismos fueron colocados como se muestra en la Figura V.3.

\subsubsection{Parámetros de crecimiento de la planta}

Además de las extracciones a los 28 y 56 días desde el trasplante, se realizó un seguimiento fotográfico semanal del crecimiento de los plantines. En cada extracción se analizaron al menos 8 plantas de tomate. Las plantas se descalzaron con extremo cuidado para no dañarlas, desarmando el terrón de sustrato hasta descubrir la raíz. Las raíces se lavaron con agua corriente para desprender los restos de sustrato adheridos a las mismas. Luego se colocaron sobre una superficie blanca provista de una escala milimetrada y un patrón de dimensiones conocidas, y se fotografiaron. Con la grilla provista se determinó la altura del tallo $(A T, \mathrm{~cm})$ y la longitud de raíz $(\mathrm{LR}, \mathrm{cm})$ y se midió el diámetro basal del tallo (DBT, $\mathrm{mm}$ ) utilizando un calibre milimetrado digital (Fowler ProMax, EEUU). Las hojas fueron separadas una a una y colocadas sobre la placa blanca, utilizando un soporte a una distancia fija y luz artificial (para asegurar condiciones similares de exposición), y se tomaron fotografías para luego determinar el área foliar total $\left(\mathrm{AF}, \mathrm{cm}^{2}\right)$ y cuantificar el número de hojas $(\mathrm{NH}, \#)$ mediante el procesamiento de imágenes con el Software libre ImageJ (Image Processing and Analisys in Java, National Institutes of Health, EEUU). De la parte aérea se separaron hojas y tallos, y las raíces limpias se secaron con papel absorbente y se registraron los pesos frescos (PFH, PFT, PFR respectivamente). El peso de materia seca de las hojas, tallos y raíz (PSH, PST, PSR respectivamente) se determinó también con una balanza analítica Mettler Toledo AB204-S (EEUU) con una precisión de $\pm 0,1 \mathrm{mg}$, una vez realizado el secado en estufa a $65^{\circ} \mathrm{C}$ bajo vacío hasta peso constante [19]. Por último se determinaron la relación vástago/raíz (V/R) y hoja/tallo $(H / T)$ en fresco y en seco, y 
el contenido porcentual de materia seca total (MS\%), como parámetros de crecimiento $[20,21]$.

\subsubsection{Contenido de clorofila y carotenoides totales}

Los pigmentos fotosintéticos son sustancias fundamentales para la vida de organismos vegetales. Como bien se conoce estos pigmentos se encuentran en los cloroplastos de las células vegetales y permiten absorber la energía de la luz solar empleada en la fijación de carbono. Estos compuestos en distinta proporción y con estructura química muy diferentes, se presentan en forma de porfirinas (Clorofila $a, b$ y $c$ ), carotenoides, antocianinas y flavonoides. En las hojas de las plantas superiores el contenido total de pigmentos incluye Clorofila- $a$, Clorofila- $b$ y carotenoides que son necesarios para los proceso de fotosíntesis [22]. Tanto la Clorofila-a (pigmento mayoritario) como la Clorofila- $b$ (pigmento accesorio) son componentes fundamentales de la membrana fotosintética del tejido vegetal, y su relación $(a / b)$ varía aproximadamente entre 3 y 1.

Los pigmentos fotosintéticos son compuestos orgánicos (Figura V.4) que pueden ser extraídos del tejido vegetal acuosos con solventes orgánicos, tales como acetona, metanol, etanol, dimetilsulfóxido (DMSO), dimetilformamida (DMF), entre otros; siendo más eficiente la extracción a partir de DMF $[22,24]$. Consiguientemente, en este trabajo de Tesis se determinó el contenido de Clorofila- $a\left(\mathrm{Chl}_{\mathrm{a}}\right)$, Clorofila- $b\left(\mathrm{Chl}_{\mathrm{b}}\right)$, y carotenoides totales $\left(\mathrm{C}_{\mathrm{x}+\mathrm{c}}\right)$ por extracción con $\mathrm{N}, \mathrm{N}$-dimetilformamida (DMF CAS\# 6812-2, Anedra, Argentina) como solvente y posterior medida espectrofotométrica, determinando el contenido de cada pigmento según parámetros especificados por Wellburn y Lichtenihaler [25] y ratificados por Porra [26]:

$$
\begin{gathered}
C_{a}=12 * A_{663,8}+3,11 * A_{646,8} \\
C_{b}=20,78 * A_{646,8}-4,88 * A_{663,8} \\
C_{x+c}=\left(1000 * A_{480}-1,12 * C h l_{a}-53,78 * C h l_{b}\right) / 245
\end{gathered}
$$


Donde $\mathrm{C}_{\mathrm{a}}, \mathrm{C}_{\mathrm{b}}$ y $\mathrm{C}_{\mathrm{x}+\mathrm{c}}$ son las concentraciones de Clorofila $a$ y $b$, y carotenoides totales expresados en $\mathrm{A}_{663,8}, \mathrm{~A}_{646,8}$ y $\mathrm{A}_{480}$ representan la absorbancia de la muestra a 663,8, 646,8 y $480 \mathrm{~nm}$, respectivamente.

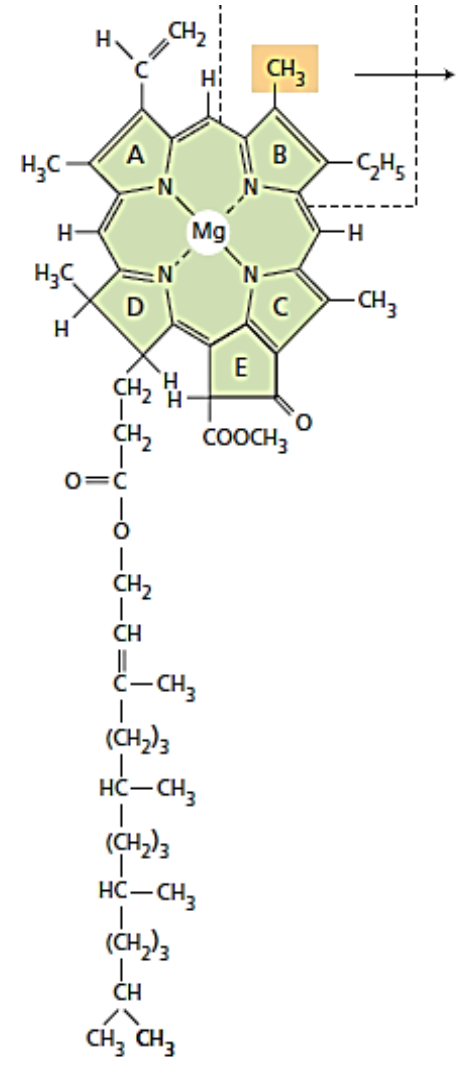

Clorofila-a

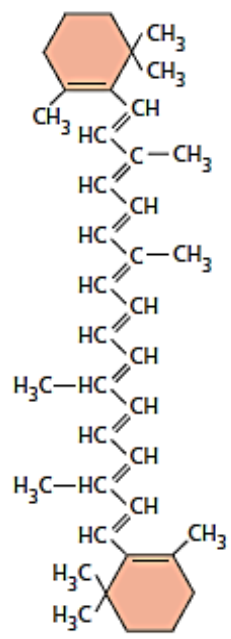

$\beta$-Caroteno

Figura V.4. Estructura química de: a) Clorofila- $a$; b) Clorofila- $b$; y c) $\beta$-caroteno. Adaptado de Taiz y Zeiger [23].

Los ensayos se realizaron al menos por cuadruplicado, tomando 9 discos de $3 \mathrm{~mm}$ de diámetro de distintas hojas de una planta (equivalente a aproximadamente $250 \mathrm{mg}$ de muestra). La extracción de los compuestos coloreados se realizó con $5 \mathrm{~mL}$ de DMF durante 24 hs a $4{ }^{\circ} \mathrm{C}$. Se centrifugaron las muestras durante $10 \mathrm{~min}$ a $4500 \mathrm{rpm}$ (Rolco CM 2036, Argentina) y se midió la absorbancia de la misma a 663,8, 646,8 y 480 nm en un espectrofotómetro U-1900 (HITACHI, Japón). 
Los resultados se expresaron como $\mu \mathrm{g}$ de pigmento por unidad de peso (g) y de área de hoja $\left(\mathrm{cm}^{2}\right)$.

\subsubsection{Contenido de nitrógeno}

Se realizó un ensayo preliminar analizando el contenido de nitrógeno de las hojas, tallos y raíces de plantas de tomate, según la técnica descripta en el capítulo I. En función de los resultados obtenidos (menor aporte de $\mathrm{N}$ proveniente de los tallos) se continuó determinando el contenido de nitrógeno de las hojas y de la raíz de las plantas tratadas por la técnica de Micro Kjeldahl. La primera etapa consiste en la digestión de la muestra (con un contenido mínimo de $750 \mu \mathrm{g}$ de $\mathrm{N}$ ) con $5 \mathrm{~mL}$ de ácido sulfúrico concentrado $\left(\mathrm{H}_{2} \mathrm{SO}_{4} 98 \%\right.$, CAS\# 7664-93-9, Anedra, Argentina) y $1 \mathrm{~g}$ de catalizador (10 g de $\mathrm{Na}_{2} \mathrm{SO}_{4}+1 \mathrm{~g}$ de $\mathrm{CuSO}_{4}$, CAS\# 7757-82-6 y 7758-98-7 respectivamente, ambos productos Anedra, Argentina). El contenido de nitrógeno de la muestra se determina por colorimetría, puesto que los iones amonio obtenidos en la digestión, reaccionan con salicilato de sodio $\left(\mathrm{C}_{7} \mathrm{H}_{5} \mathrm{NaO}_{3}, \mathrm{CAS \#} 54-21-7\right.$, Riedel-de Haën, Alemania) e hipoclorito de sodio ( $\mathrm{NaClO}$ con 6-14\% de cloro activo, CAS\# 7681-52-9, Merck, Alemania), en presencia del catalizador nitroprusiato de sodio ( $\mathrm{Na}_{2}\left[\mathrm{Fe}(\mathrm{CN})_{5} \mathrm{NO}\right]$, CAS\# 13755-38-9, Anedra, Argentina) para formar un indofenol $\left(\mathrm{C}_{12} \mathrm{H}_{9} \mathrm{NO}_{2}\right)$ verde según:

$$
\mathrm{NH}_{4}^{+}+\mathrm{C}_{7} \mathrm{H}_{5} \mathrm{NaO}_{3}+\mathrm{NaClO} \stackrel{\text { Nitroprusiato }}{\longrightarrow} \mathrm{C}_{12} \mathrm{H}_{9} \mathrm{NO}_{2}
$$

La intensidad del color formado, absorbancia leída a $660 \mathrm{~nm}$, es proporcional a la concentración de nitrógeno en la muestra ensayada [27, 28]. Este método requiere una curva de calibración con albumina para la cual se empeló albumina bovina $96 \%$ de pureza (CAS\# 9048-46-8, Sigma-Aldrich, EEUU).

Las muestras se analizaron al menos por duplicado y los resultados se expresaron en forma porcentual en base seca y como mg de $\mathrm{N}$ totales por planta. 


\subsection{Análisis estadístico}

Así como en los anteriores ensayos realizados se realizó el análisis multifactorial (ANAVA) y la comparación de medias a través del test de las diferencias mínimas cuadradas (LSD) de Fisher, utilizando un nivel de significación de $\alpha=0,05$ y el Software estadístico InfoStat [29]. Además, dado el gran número de variables evaluadas en el último ensayo y con el fin de analizar la interdependencia y variabilidad de los resultados obtenidos, se llevó a cabo un Análisis por Componentes Principales (ACP). Para el ACP se empleó el Software estadístico InfoStat antes mencionado considerando dos componentes. Del análisis realizado se informó el gráfico Biplot y el valor del coeficiente de correlación cofenética obtenidos, este último es indicativo de la calidad del agrupamiento de las variables en función de los componentes.

\section{RESULTADOS Y DISCUSIÓN}

\subsection{Material de cobertura}

En el capítulo I se estudió el efecto del relleno sobre las propiedades de los materiales compuestos. A partir de estos resultados se procedió a evaluar el efecto del almacenamiento sobre dichos materiales comparándose con las condiciones iniciales, con el fin de evaluar su potencialidad como material de cobertura de suelos, entre otros. Por lo tanto, en esta sección se reiterarán algunos datos ya detallados con el fin de explicar los resultados obtenidos en esta etapa.

\subsubsection{Almacenamiento en condiciones controladas}

Las suspensiones filmogénicas estudiadas dieron lugar a películas con un color levemente amarronado, cuya intensidad varió con el contenido de relleno. Las películas conteniendo $3 \%$ de fibra resultaron excesivamente coloreadas y heterogéneas, por lo que fueron descartadas para ensayos posteriores. Por otro lado, las películas no reforzadas presentaron una superficie más homogénea y visualmente más translúcida. 
Dichas características se observan en los elevados valores de luminosidad (L), y los parámetros de color chroma $\left(\mathrm{C}^{*}\right)$ y tono $\left(\mathrm{h}^{\circ}\right)$; en la Tabla V.1 se muestra una variación significativa $(p<0,05)$ en los parámetros de color entre las películas control sin fibra (OFG), y con $0,75 \%(0,75 F G)$ y $1,5 \% p / p$ de fibra $(1,5 F G)$.

Sin embargo, pasados 60 días de almacenamiento bajo foto-ciclos periódicos, se evidenció un comportamiento opuesto entre las películas control y las muestras reforzadas: las películas sin fibra se tornaron más opacas, lo cual se evidencia en la mayor diferencia de color con las películas a tiempo inicial (Tabla V.1). Por el contrario, las películas reforzadas $(0,75 F G$ y $1,5 F G)$ visualmente se vieron decoloradas aunque la diferencia de color respecto a la condición inicial fue significativamente menor $(p<0,05)$ que para las muestras control (Tabla V.1).

\begin{tabular}{|c|c|c|c|c|}
\hline \multirow{2}{*}{ TIEMPO } & \multirow{2}{*}{ PARÁMETRO } & \multicolumn{3}{|c|}{$\begin{array}{r}\text { FORMULACIÓN } \\
\end{array}$} \\
\hline & & OFG & $0,75 F G$ & $1,5 F G$ \\
\hline \multirow{3}{*}{0 días } & $L^{*}$ & $93,65 \pm 0,73^{\mathrm{b} / \mathrm{D}}$ & $92,56 \pm 0,19^{\mathrm{ab} / \mathrm{BC}}$ & $91,73 \pm 0,72^{\mathrm{a} / \mathrm{AB}}$ \\
\hline & $C^{*}$ & $3,63 \pm 0,05^{\mathrm{a} / \mathrm{B}}$ & $5,97 \pm 0,10^{b / D}$ & $8,05 \pm 0,10^{c / E}$ \\
\hline & ho & $89,70 \pm 0,11^{\mathrm{a} / \mathrm{B}}$ & $91,25 \pm 0,03^{b / D}$ & $91,59 \pm 0,22^{\mathrm{b} / \mathrm{D}}$ \\
\hline \multirow{4}{*}{60 días } & $\mathrm{L}^{*}$ & $95,71 \pm 0,06^{c / E}$ & $92,89 \pm 0,04^{b / C D}$ & $91,10 \pm 0,15^{\mathrm{a} / \mathrm{A}}$ \\
\hline & $C^{*}$ & $3,11 \pm 0,05^{\mathrm{a} / \mathrm{A}}$ & $5,47 \pm 0,07^{b / c}$ & $7,99 \pm 0,18^{c / E}$ \\
\hline & ho & $88,52 \pm 0,03^{\mathrm{a} / \mathrm{A}}$ & $91,26 \pm 0,45^{\mathrm{b} / \mathrm{D}}$ & $90,57 \pm 0,08^{b / c}$ \\
\hline & $\Delta E$ & $2,13 \pm 0,05^{\mathrm{b} /-}$ & $0,60 \pm 0,08^{\mathrm{a} /-}$ & $0,66 \pm 0,13^{\mathrm{a} /-}$ \\
\hline \multicolumn{5}{|c|}{$\begin{array}{l}\text { Nota: La variación de color }(\Delta E) \text { se determinó en relación a los valores iniciales. } \\
\text { Letras minúsculas diferentes dentro de una misma fila indican diferencias significativas } \\
(p<0,05) \text { entre muestras en un mismo tiempo, mientras que letras mayúsculas indican } \\
\text { diferencias significativas }(p<0,05) \text { entre muestras considerando tiempo y contenido de } \\
\text { bagazo. }\end{array}$} \\
\hline
\end{tabular}

Como se mencionó anteriormente, un parámetro relevante en las aplicaciones agronómicas es la estimación de la radiación fotosintéticamente activa (PAR) transmitida por el material en el rango de longitudes de onda $400-700 \mathrm{~nm}$. El agregado 


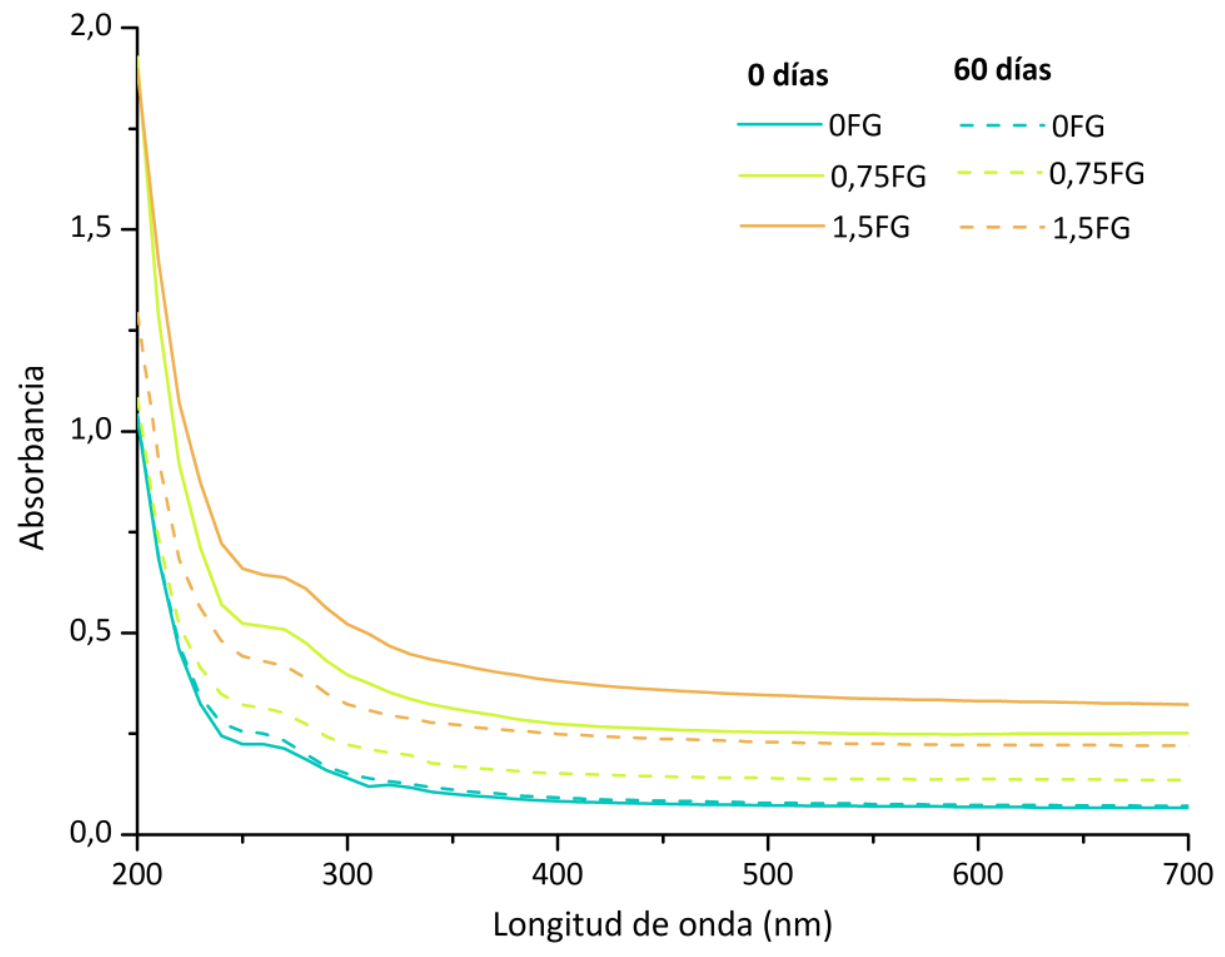

\begin{tabular}{ccccc}
\hline \multicolumn{4}{c}{ Capacidad de barrera UV y en la región PAR (visible) } \\
\multirow{2}{*}{ TIEMPO } & $\begin{array}{c}\text { ABSORBANCIA } \\
\text { (AUxnm) }\end{array}$ & OFG & $\mathbf{0 , 7 5 F G}$ & $\mathbf{1 , 5 F G}$ \\
\cline { 3 - 5 } & PAR & $22,5 \pm 1,5^{\mathrm{a} / \mathrm{A}}$ & $78,7 \pm 3,3^{\mathrm{b} / \mathrm{C}}$ & $102,6 \pm 0,2^{\mathrm{c} / \mathrm{D}}$ \\
\multirow{2}{*}{0 días } & UV & $43,4 \pm 0,08^{\mathrm{a} / \mathrm{A}}$ & $105,5 \pm 3,5^{\mathrm{b} / \mathrm{DE}}$ & $122,6 \pm 6,7^{\mathrm{c} / \mathrm{E}}$ \\
\hline \multirow{2}{*}{60 días } & PAR & $31,0 \pm 10,9^{\mathrm{a} / \mathrm{A}}$ & $54,0 \pm 17,0^{\mathrm{b} / \mathrm{B}}$ & $66,6 \pm 2,7^{\mathrm{c} / \mathrm{BC}}$ \\
& UV & $52,3 \pm 8,6^{\mathrm{a} / \mathrm{AB}}$ & $75,0 \pm 22,5^{\mathrm{b} / \mathrm{BC}}$ & $81,3 \pm 1,7^{\mathrm{c} / \mathrm{CD}}$ \\
\hline
\end{tabular}

Nota: Letras minúsculas diferentes dentro de una misma fila indican diferencias significativas $(p<0,05)$ entre muestras en un mismo tiempo, mientras que letras mayúsculas indican diferencias significativas $(p<0,05)$ entre muestras considerando tiempo y contenido de bagazo.

Figura V.5. Espectros de absorción UV-visible de las películas de almidón plastificadas con distinta concentración de bagazo: $0 \%(\mathrm{OFG}) ; 0,75 \%(0,75 \mathrm{FG})$; y 1,5\% (1,5FG) al tiempo inicial (línea completa) y luego de 60 días de almacenamiento (línea punteada), y tabla con parámetros de barrera óptica de los mismos materiales.

de fibra a las formulaciones aumentó la absorción tanto en este rango del espectro UVvisible como en la región UV (200-400 nm), siendo la opacidad un $700 \%$ y $400 \%$ mayor 
para las muestras 1,5FG respecto al control (Figura V.5). Durante el almacenamiento las películas control mostraron un aumento de la opacidad aunque, contrario a lo esperado considerando los resultados colorimétricos, este incremento no resultó significativo $(p>0,05)$. Por el contrario, las películas reforzadas registraron una disminución significativa $(p<0,05)$ de la absorbancia en ambas regiones, atribuida a la decoloración observada anteriormente (Figura V.5). Como se observa en la Tabla inserta, este efecto resultó levemente mayor en las muestras $0,75 \mathrm{FG}$ que en las 1,5FG.

El contenido de humedad de las películas plastificadas disminuyó levemente con el agregado de bagazo, aunque la diferencia solo resultó significativa $(p<0,05)$ entre las películas control y las que contenían $1,5 \%$ de bagazo. Luego del almacenamiento controlado, las películas de almidón se hidrataron, sin embargo este efecto solo fue significativo para las muestras control $(p<0,05)$ mostrando una variación en la humedad del material desde $18,8 \pm 0,02 \%$ a $21,9 \pm 1,4 \%$.

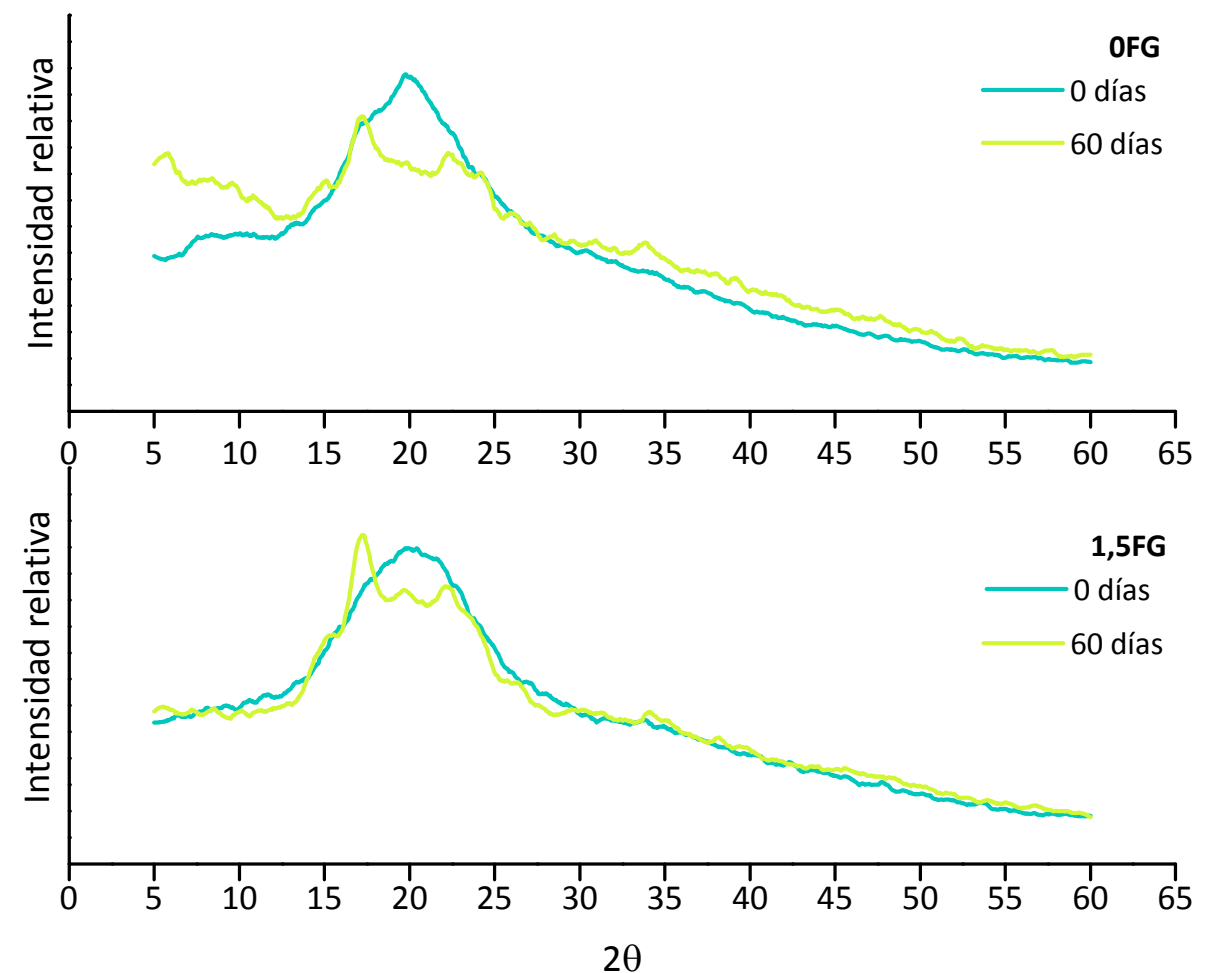

Figura V.6. Difractograma de películas de almidón plastificadas control (OFG) y reforzadas con $1,5 \%$ de bagazo (1,5FG), a tiempo inicial (0 días) y final (60 días). 
El estudio por difracción de rayos X (DRX) de las muestras control (OFG) y con $1,5 \%$ de fibra $(1,5 F G)$ muestra que las películas de almidón de mandioca con y sin fibra presentan un grado de cristalinidad bajo que inicialmente (0 días) no difieren significativamente $(p>0,05)$ entre sí: $3,57 \pm 0,83 \%$ y 3,38 $\pm 1,25 \%$, respectivamente. Sin embargo, luego del almacenamiento (60 días) ambas formulaciones presentaron un aumento significativo de este parámetro $(p<0,05)$ como era de esperarse debido a la retrogradación del almidón en la matriz (Figura V.6). No obstante los valores obtenidos indican el mayor carácter amorfo de los materiales estudiados: $4,97 \pm 1,02 \%$ y 5,41 \pm 0,32 \% para el control y los muestras reforzadas respectivamente.

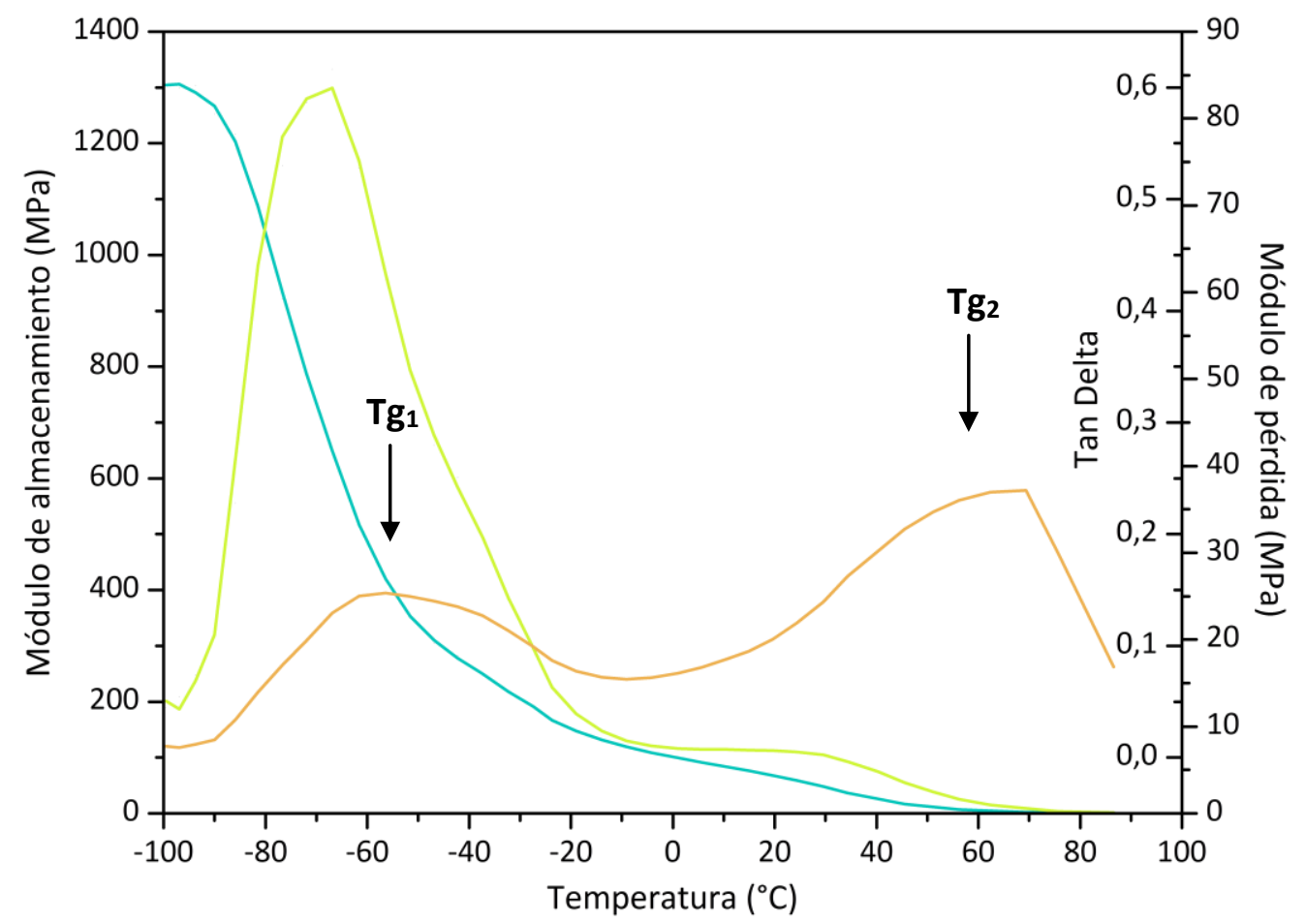

Figura V.7. Evaluación isocrónica del módulo de almacenamiento $\left(E^{\prime}\right)$, de pérdida ( $\left.E^{\prime \prime}\right)$ y factor de pérdida (tan $\delta$ ) en función de la temperatura de películas de almidón de mandioca plastificada con glicerol (OFG). 
Los análisis de DMA de las películas de almidón plastificadas con glicerol exhiben, como ya se ha mencionado, dos transiciones térmicas de segundo orden (Figura V.7): una correspondiente a la fase rica en glicerol $\left(\mathrm{Tg}_{1}\right)$ y otra correspondiente a la fase rica en almidón $\left(\mathrm{Tg}_{2}\right)$. En general, el agregado de fibra sólo modificó la temperatura de transición vítrea de la fase rica en almidón, observándose un aumento de la misma con el contenido del relleno (Tabla V.2).

\begin{tabular}{|c|c|c|c|c|}
\hline \multirow{2}{*}{ TIEMPO } & \multirow{2}{*}{$\begin{array}{c}\mathrm{Tg} \\
\left({ }^{\circ} \mathrm{C}\right)\end{array}$} & \multicolumn{3}{|c|}{ FORMULACIÓN } \\
\hline & & OFG & $0,75 F G$ & $1,5 F G$ \\
\hline \multirow{2}{*}{0 días } & $\operatorname{Tg}_{1}$ & $-44,15 \pm 1,02^{c / c}$ & $-44,09 \pm 0,17^{c / c}$ & $-42,68 \pm 1,17^{c / c}$ \\
\hline & $\mathrm{Tg}_{2}$ & $13,30 \pm 3,16^{\mathrm{a} / \mathrm{A}}$ & $36,38 \pm 3,88^{b / B}$ & $44,43 \pm 0,55^{c / c}$ \\
\hline \multirow{2}{*}{60 días } & $\mathrm{Tg}_{1}$ & $-51,20 \pm 0,30^{\mathrm{b} / \mathrm{B}}$ & $-51,85 \pm 1,40^{\mathrm{b} / \mathrm{B}}$ & $-55,70 \pm 1,21^{\mathrm{a} / \mathrm{A}}$ \\
\hline & $\mathrm{Tg}_{2}$ & $21,61 \pm 3,56^{\mathrm{a} / \mathrm{A}}$ & $45,00 \pm 1,79^{c / c}$ & $60,79 \pm 3,51^{d / D}$ \\
\hline
\end{tabular}

Nota: Letras minúsculas diferentes dentro de una misma fila indican diferencias significativas $(p<0,05)$ entre muestras en un mismo tiempo, mientras que letras mayúsculas indican diferencias significativas $(p<0,05)$ entre muestras considerando tiempo y contenido de bagazo.

Luego del almacenamiento se observó una disminución significativa $(p<0,05)$ de $\operatorname{la} \operatorname{Tg}_{1}$ tanto del control como de $0,75 \mathrm{FG}$ y $1,5 \mathrm{FG}$, posiblemente debido a las variaciones de humedad de las películas durante el almacenamiento; y un incremento de la $\operatorname{Tg}_{2}$, el cual solo resultó significativo para los materiales reforzados.

En concordancia con los resultados discutidos en el capítulo I, por lo general las películas que incluían el bagazo $(0,75 \mathrm{FG}$ y $1,5 \mathrm{FG})$ presentaron una mayor resistencia mecánica que el control (OFG). Este comportamiento se refleja en una mayor fuerza máxima a la tracción y módulo elástico, y una menor elongación a la ruptura.

Si bien todas las muestras se vieron afectadas durante el almacenamiento observándose una rigidización de los materiales - comparativamente el comportamiento mecánico del control resultó el más afectado (Figura V.8). A este 

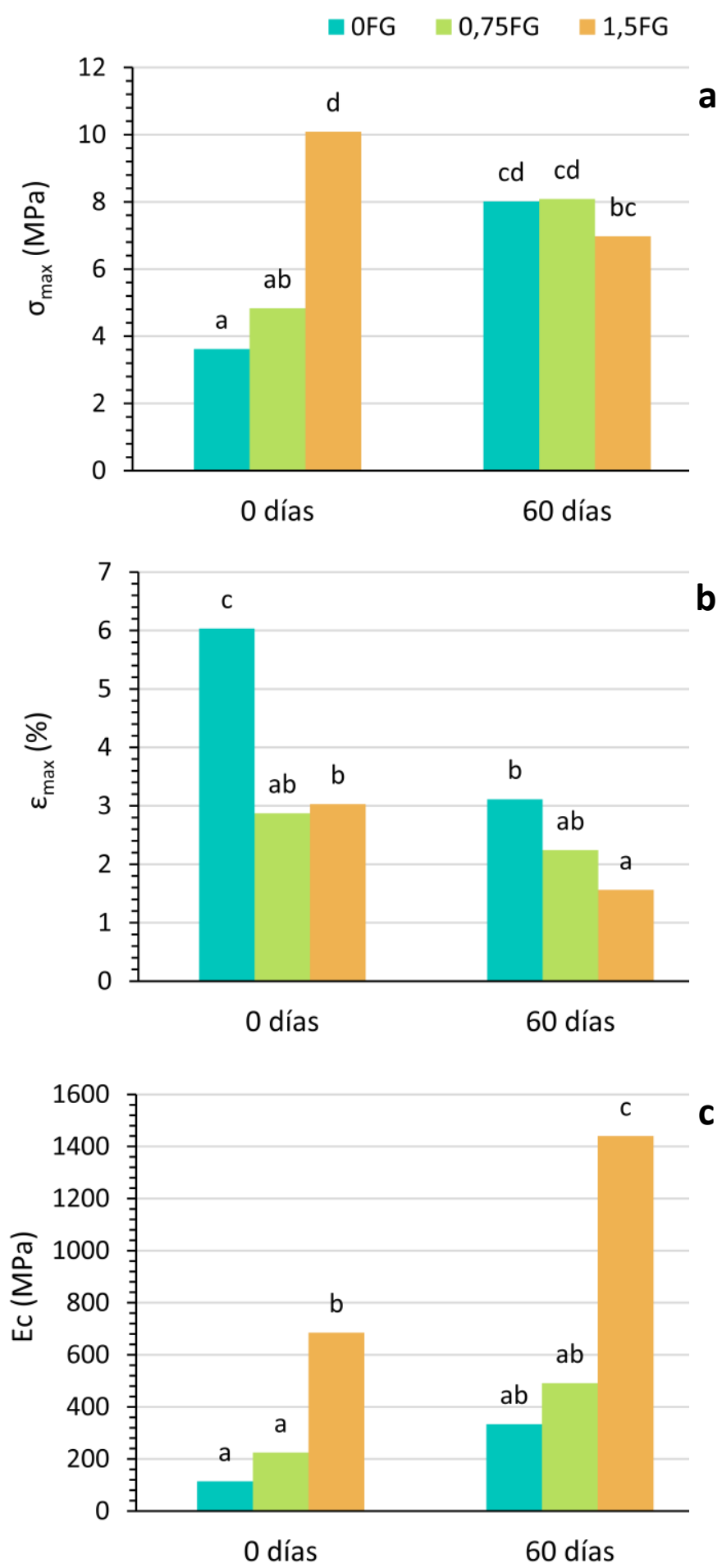

Figura V.8. Propiedades mecánicas de películas de almidón plastificadas con distintas concentraciones de bagazo: $0 \%$ (OFG); $0,75 \%(0,75 F G)$; y 1,5\% (1,5FG); a tiempo inicial (0 días) y final (60 días), evaluadas por ensayos cuasiestáticos en DMA. 
respecto, las muestras control presentaron una disminución en la elongación a la ruptura de aproximadamente un $50 \%$ y un aumento similar en la resistencia máxima a la ruptura, efecto significativamente mayor $(p<0,05)$ que para las películas reforzadas con bagazo, indicando una mayor estabilidad de las matrices reforzadas.

Asimismo, la disminución de la resistencia máxima a la tracción de las películas reforzadas 1,5FG, puede atribuirse a que una vez envejecidas las muestras, el almidón retrogradado tiene una interacción más débil con las partículas de bagazo, dando lugar a zonas de defecto estructural que disminuyen la fuerza del material. En concordancia, el aumento en la cristalinidad observado por difracción de rayos $\mathrm{X}$ explica también la mayor fragilidad del material.

El efecto sobre las películas 0,75FG resultó intermedio, no observándose diferencias significativas $(p>0,05)$ en la elongación y la fuerza máxima a la ruptura de los materiales envejecidos con distinta concentración de carga.

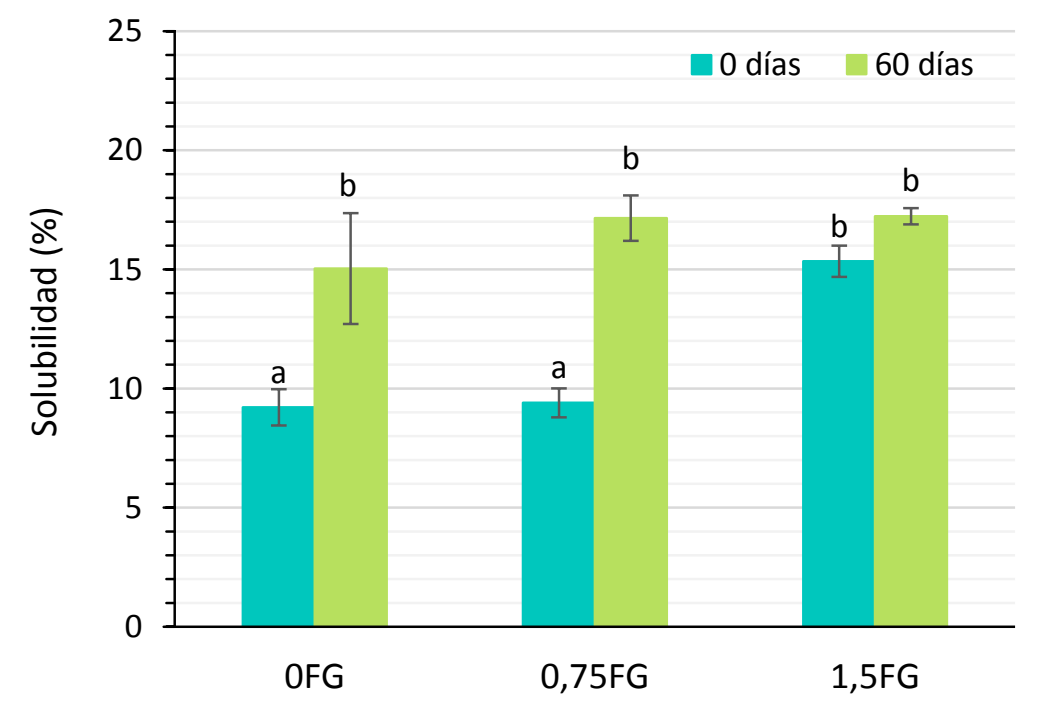

Figura V.9. Solubilidad en agua a $25^{\circ} \mathrm{C}$ de películas de almidón plastificadas con distintas concentraciones de bagazo: $0 \%$ (OFG); $0,75 \%(0,75 F G)$; y 1,5\% (1,5FG); a tiempo inicial (0 días) y final (60 días). 
La disminución en la fuerza de interacción entre las partículas de relleno y la matriz arriba mencionada se evidencia también en el aumento significativo $(p>0,05)$ de la solubilidad de las películas reforzadas con el tiempo de almacenamiento (Figura V.9). Del mismo modo se observó un aumento aún mayor $(\approx 63 \%)$ en la solubilidad de las películas sin fibra, el cual se correlaciona con una evidente fragilización de la matriz de almidón con el tiempo (Figura V.8) sumada a la mayor absorción de agua por parte de la película (la cual se mencionó anteriormente).

Como era de esperar, la solubilidad en agua a $100{ }^{\circ} \mathrm{C}$ de todas las películas estudiadas resultó del $100 \%$ independientemente del tiempo de almacenamiento.

\subsubsection{Comportamiento bajo condiciones ambientales reales}

Típicamente, los materiales de cobertura deben ser perforados para el implante del plantín siendo su función principal mantener la humedad y temperatura del suelo, y evitar el crecimiento de malezas. Por lo tanto, la resistencia del material a la punción resulta una característica de interés para esta aplicación. En la Figura V.10 se muestran los resultados obtenidos para la película de almidón de mandioca control y aquellas reforzadas con bagazo.

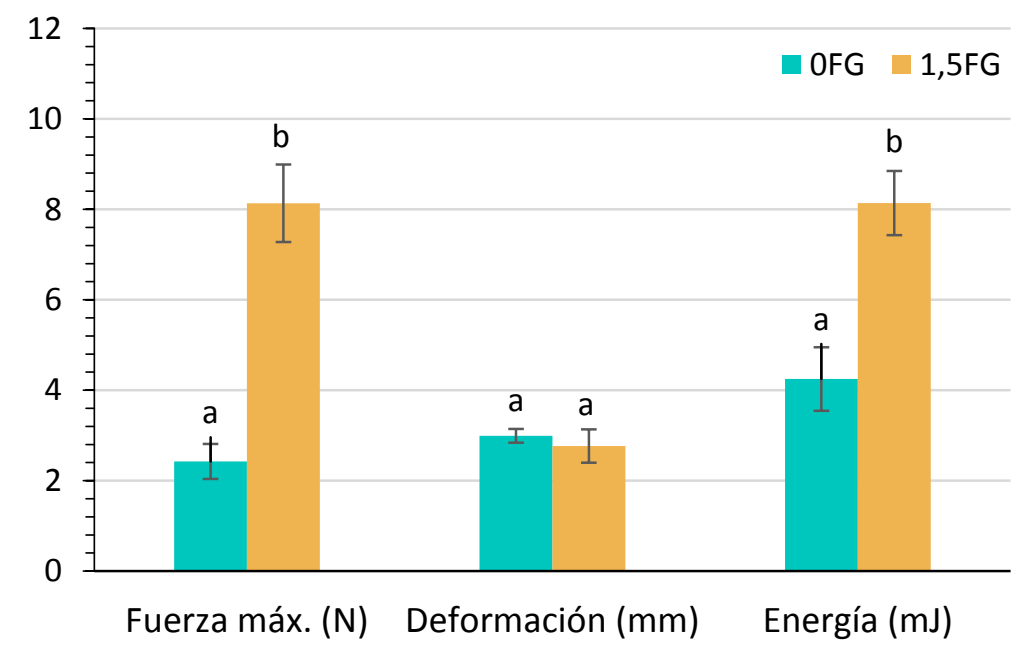

Figura V.10. Parámetros de resistencia a la punción de películas a base de almidón de mandioca control (OFG) y reforzadas con $1,5 \%$ de bagazo de mandioca $(1,5 \mathrm{FG})$. 
Como era de esperar, las películas compuestas presentaron una mayor resistencia a la punción, siendo la fuerza máxima y la energía requerida para la perforación del material significativamente mayores $(p<0,05)$.

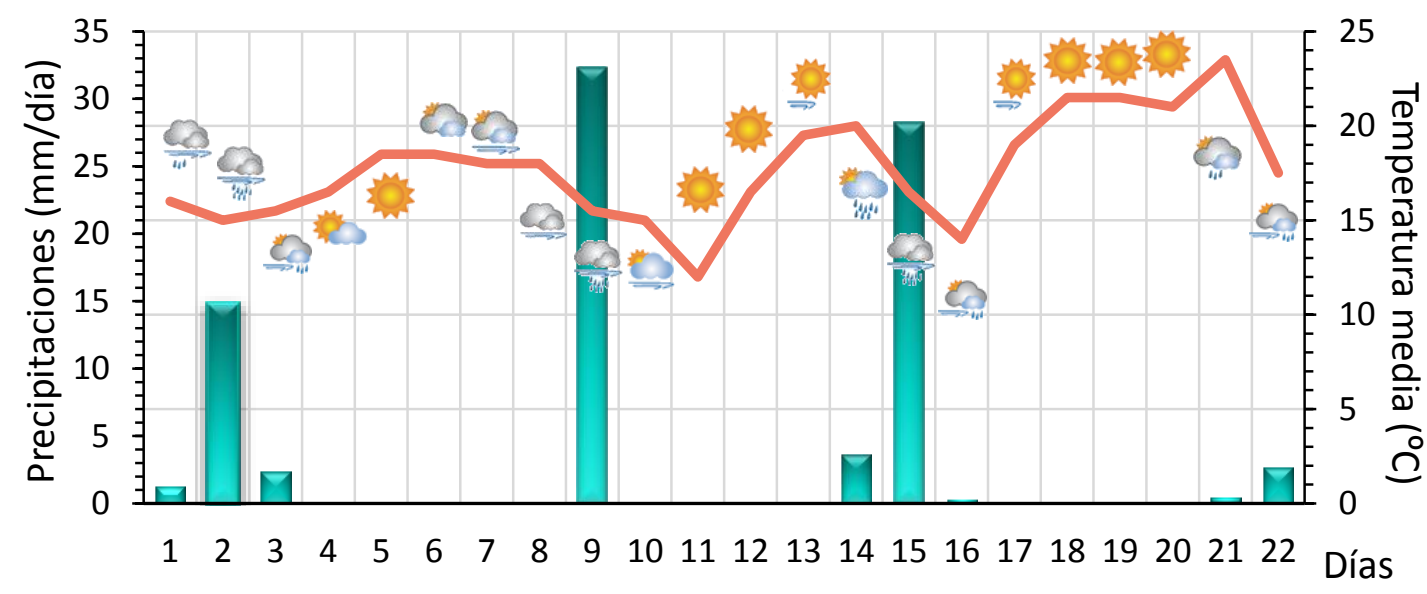

Figura V.11. Registro de las condiciones climáticas durante el período de estudio.

Durante el período de estudio se registraron días con abundantes precipitaciones y temperaturas moderadas $\left(17,7 \pm 3^{\circ} \mathrm{C}\right)$. En relación al régimen de lluvias, el acumulado fue de $86,4 \mathrm{~mm}$ con un registro máximo de 32,4 mm/día (Figura V.11), siendo estas condiciones atípicas para el mes de octubre y particularmente adversas para los materiales tratados dada su naturaleza hidrofílica.

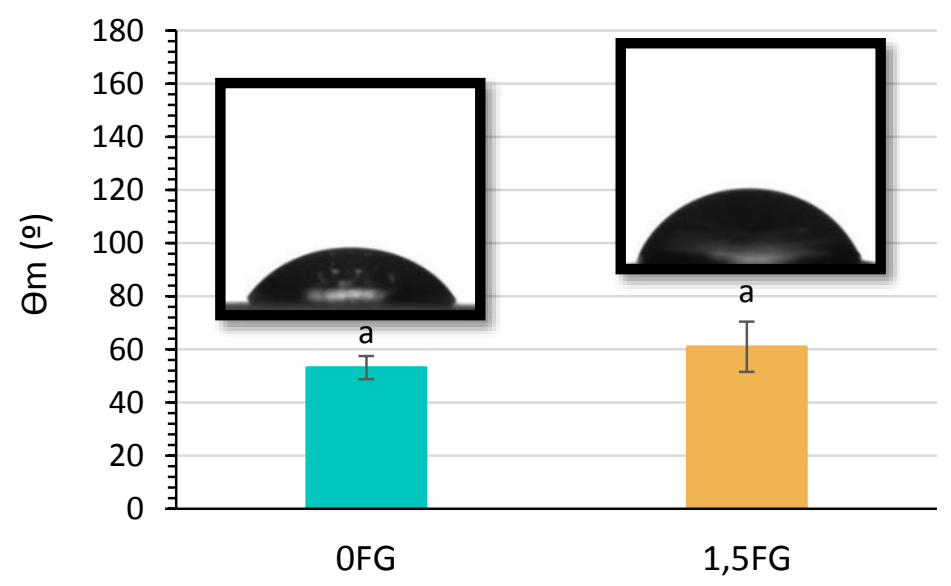

Figura V.12. Ángulo de contacto de películas de almidón de mandioca control (OFG) y reforzadas $(1,5 \mathrm{FG})$. 
Las medidas del ángulo de contacto confirmaron la naturaleza hidrofílica de los materiales, no encontrándose diferencias significativas $(p>0,05)$ entre las formulaciones ensayadas (Figura V.12).

Las películas ensayadas en condiciones de campo reales mostraron una degradación mayor a la esperada dadas las condiciones climáticas imperantes, por lo cual a los 21 días el ensayo debió ser detenido. Como se puede observar en la Figura V.13 los materiales reforzados con bagazo presentaron, contrario a lo esperado según los resultados de biodegradación en suelo descriptos previamente, una degradación mayor como material de cobertura. Cabe mencionar que en esta aplicación la degradación del material ocurre principalmente por factores abióticos como humedad, radiación solar, erosión eólica, entre otros. No obstante, ambos materiales lograron mantener la humedad del suelo, ya que a tiempo inicial se registraron valores de 24,4 $\pm 0,5 \%$ y al final del ensayo la humedad del suelo cubierto con la película control fue de $26,0 \pm 1,8 \%$ y de $24,9 \pm 2,9 \%$ para el suelo cubierto con la película reforzada.

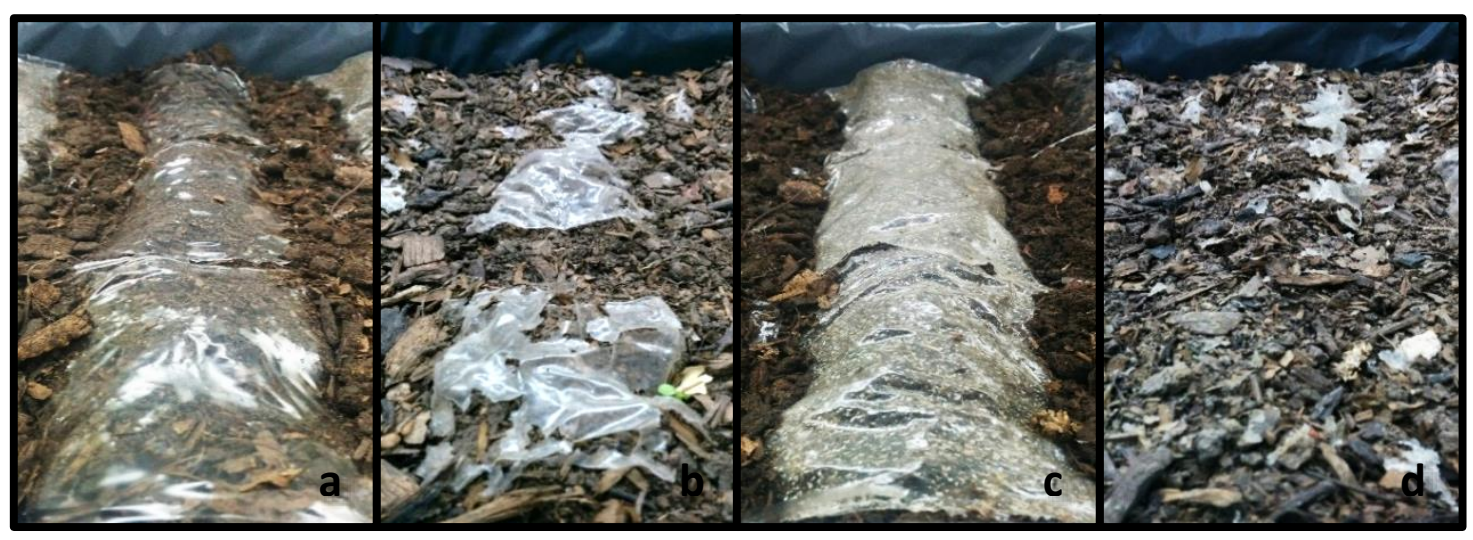

Figura V.13. Fotografía de películas sobre suelo: a) OFG incial; b) OFG luego de 21 días a la intemperie; c) 1,5FG inicial; d) 1,5FG luego de 21 días a la intemperie.

Como se mencionó en la sección anterior otro parámetro relevante en las aplicaciones agronómicas es la estimación de la radiación fotosintéticamente activa (PAR) transmitida por el material en el rango de longitudes de onda $400-700 \mathrm{~nm}$. Esta 
radiación se asocia a la necesaria para la fotosíntesis que es el proceso básico para la producción de cultivos [30] y el crecimiento de malezas. Por ende, los materiales empleados para cultivos bajo túnel o invernadero requieren transmisividades PAR altas, mientras que por el contrario aquellos empleados en mulching deben minimizar dicha transmitancia con el fin de controlar el crecimiento de las malezas. En la Figura V.14 presentan los valores de transmisividad PAR obtenidos para los materiales ensayados. Como se había observado en la sección anterior el material compuesto es significativamente $(p<0,05)$ más opaco a la radiación visible del espectro que la película control. Asimismo, en forma análoga a los resultados obtenidos bajo condiciones controladas, las propiedades ópticas de los materiales compuestos no se modificaron significativamente $(p>0,05)$ luego de ser expuestos a condiciones de trabajo reales. Por el contrario, las películas control si se vieron afectadas por el tratamiento observándose, como se explicó en la sección anterior, un emblanquecimiento de las mismas que se refleja en una disminución de la transmisividad del material.

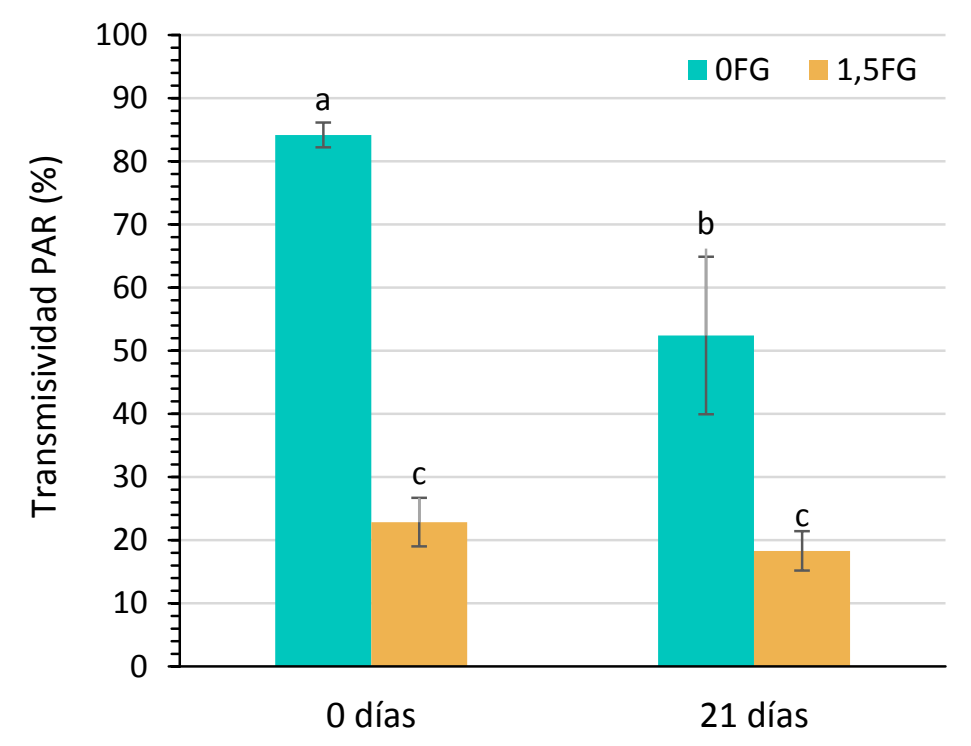

Figura V.14. Transmisividad PAR de películas de almidón de mandioca control (OFG) y reforzadas $(1,5 \mathrm{FG})$ a tiempo inicial y luego de 21 días bajo condiciones ambientales reales. 
Si bien el material reforzado presentó mejores propiedades mecánicas y ópticas como material de cobertura de suelo, los resultados indican que su desempeño es pobre debido a su elevada velocidad de degradación en comparación al de las películas control.
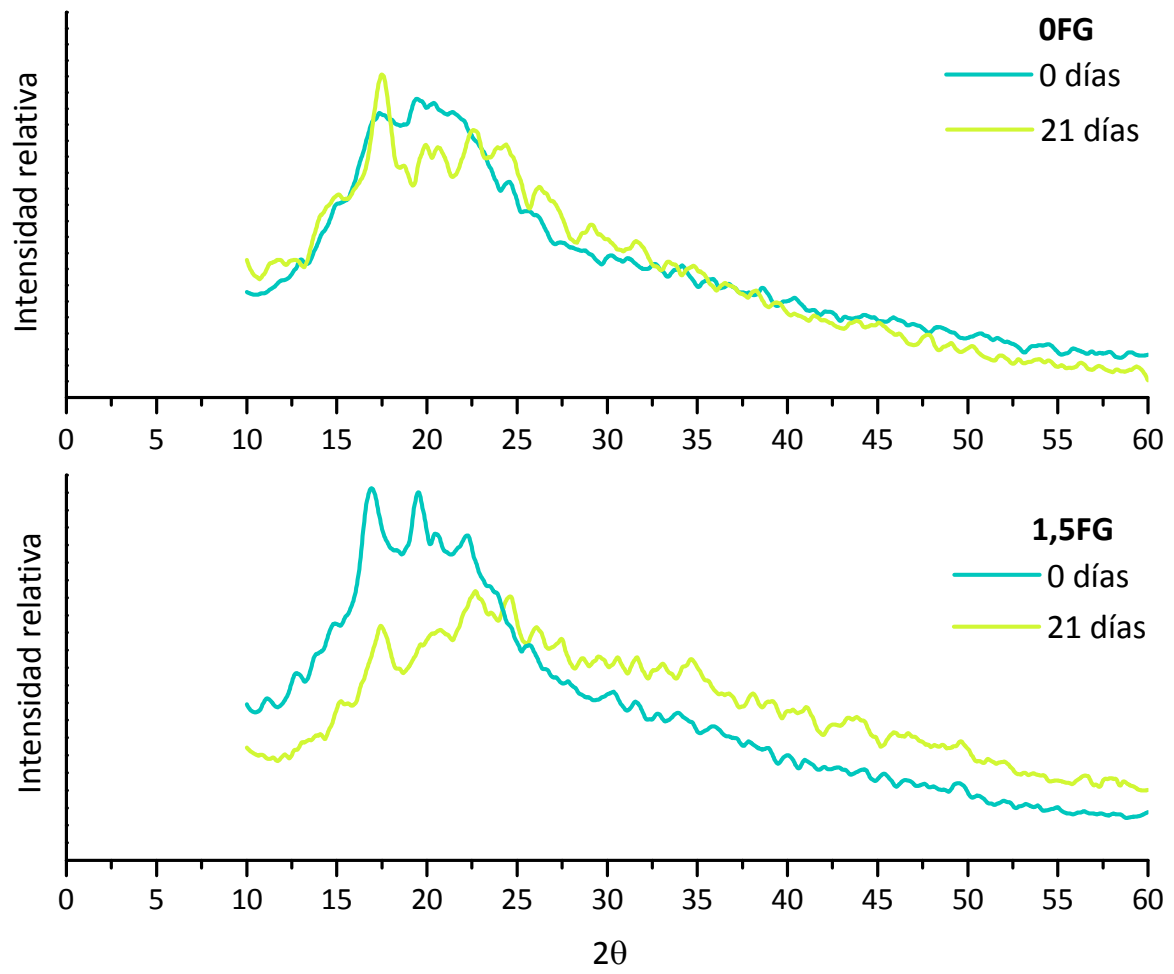

Figura V.15. Difractogramas de películas de almidón para cobertura de suelo: OFG y 1,5FG inicial y luego de 21 días a la intemperie.

En la Figura V.15 se muestran los difractogramas obtenidos inicialmente y luego de 21 días de exposición, para ambos materiales. Como se explicó en la sección anterior, el grado de cristalinidad de la matriz de almidón incrementa en el tiempo debido a la retrogradación del mismo y puede ser acelerado por las condiciones del medio. Correspondientemente con los resultados obtenidos en el almacenamiento bajo condiciones ambientales controladas, se observó un aumento significativo del grado de cristalinidad de las dos formulaciones ensayadas expuestas a condiciones ambientales reales. Sin embargo, en comparación al ensayo anterior en este caso el 
incremento de la cristalinidad fue significativamente mayor $(p<0,05)$ para los materiales compuestos que para el control ( $41,5 \%$ y $22,9 \%$, respectivamente), lo cual podría explicar la degradación más acelerada del primero (Figura V.13).

Los resultados obtenidos por difracción de rayos $\mathrm{X}$ se corresponden con aquellos obtenidos por espectroscopía de infrarrojo ATR-FTIR (Figura V.16). Como ya se ha mencionado, algunos autores han indicado que existe una relación entre las intensidades de absorbancia relativas de los picos a 995 y $1047 \mathrm{~cm}^{-1}$ respecto al pico a $1022 \mathrm{~cm}^{-1}$ y el grado de cristalinidad en muestras de almidón [31-33].

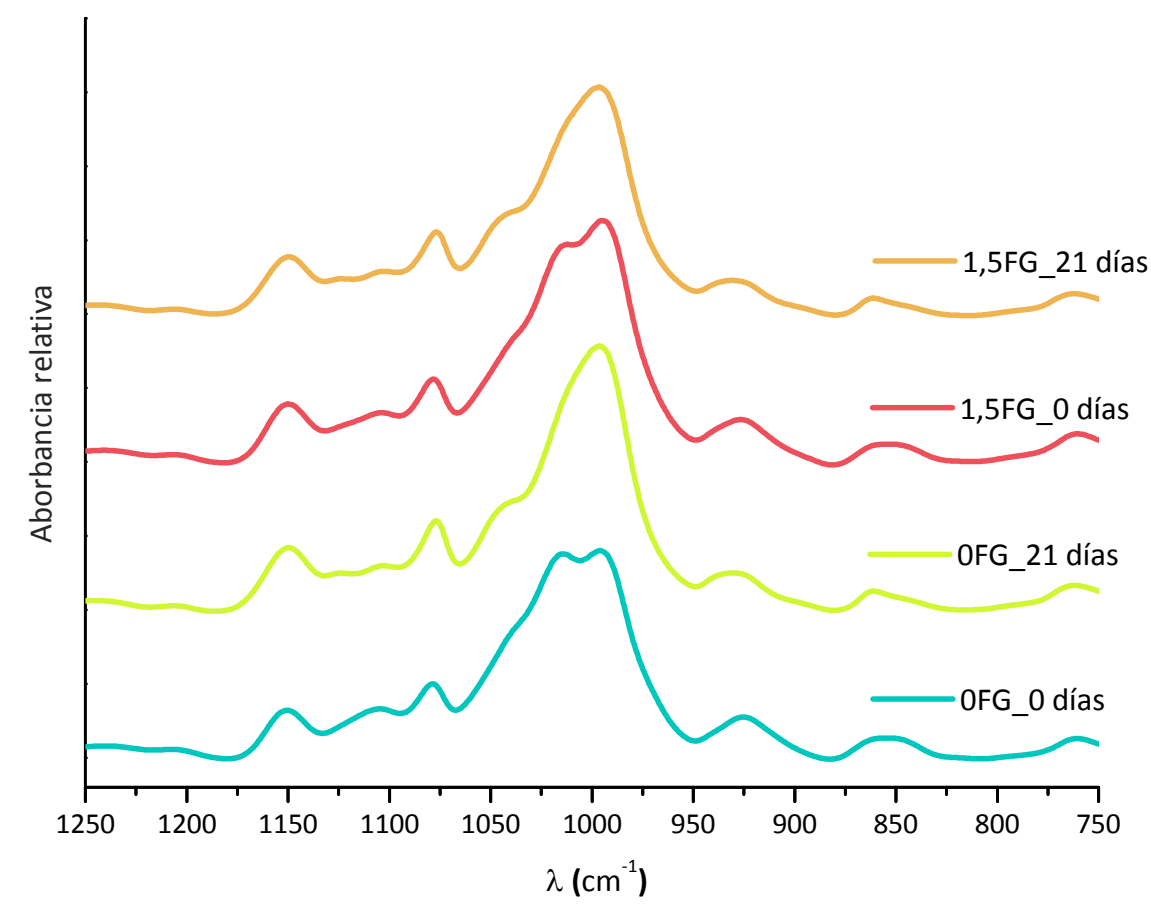

Figura V.16. Espectros FTIR-ATR de películas de almidón para cobertura de suelo: $0 \mathrm{FG}$ y 1,5FG inicial (0 días) y luego de 21 días a la intemperie (21 días).

Las bandas a 1047 y $1022 \mathrm{~cm}^{-1}$ han sido asignadas a los modos de plegado del enlace $\mathrm{COH}$ del almidón en la región ordenada y amorfa respectivamente [31], consecuentemente la reducción del pico a $1022 \mathrm{~cm}^{-1}$ observado en las muestras a los 21 días de exposición respecto a las muestras iniciales (Tabla V.3) devela el aumento 
del grado de cristalinidad de las formulaciones ensayadas con el tratamiento ya reportado por DRX.

Tabla V.3- Relación de picos 995, 1047 y $1022 \mathrm{~cm}^{-1}$ obtenidas por espectrofotometría ATRFTIR de las películas de almidón mandioca control (OFG) y reforzadas (1,5FG) a tiempo inicial y luego de $\mathbf{2 1}$ días de almacenamiento

\begin{tabular}{cccc} 
TIEMPO & MUESTRA & $\mathbf{R}_{\mathbf{9 9 5} / \mathbf{1 0 2 2}}$ & $\mathbf{R}_{\mathbf{1 0 4 7 / 1 0 2 2}}$ \\
\hline \multirow{2}{*}{0 días } & OFG & $1,29 \pm 0,09^{\mathrm{a}}$ & $0,35 \pm 0,03^{\mathrm{a}}$ \\
& $1,5 \mathrm{FG}$ & $1,45 \pm 0,12^{\mathrm{a}}$ & $0,41 \pm 0,03^{\mathrm{ab}}$ \\
\hline \multirow{2}{*}{21 días } & OFG & $1,37 \pm 0,06^{\mathrm{a}}$ & $0,39 \pm 0,01^{\mathrm{ab}}$ \\
& $1,5 F G$ & $1,44 \pm 0,07^{\mathrm{a}}$ & $0,50 \pm 0,09^{\mathrm{b}}$ \\
\hline
\end{tabular}

Nota: Letras diferentes indican diferencias significativas $(p<0,05)$.

En general, no se observaron mayores diferencias en los espectros de FTIR-ATR de las muestras inicial y luego de 21 días a la intemperie. Las asignaciones de bandas se corresponden con las descriptas en la Tabla II.1 del capítulo II. En este capítulo se ha puntualizado en los cambios observados en la región de 900 a $1200 \mathrm{~cm}^{-1}$ que se corresponde con la denominada zona de la huella digital del material.

\subsection{Material para la liberación controlada de fertilizante}

\subsubsection{Almacenamiento en condiciones controladas}

Como se detalló en el capítulo anterior, el efecto del contenido de urea afectó fuertemente el comportamiento mecánico de las películas a base de almidón funcionalizadas. El objetivo de esta sección es por tanto, estudiar la estabilidad de dichas propiedades con el almacenamiento en condiciones ambientales controladas de los materiales obtenidos. Con este fin se evaluó el efecto del almacenamiento durante 30 días a $20^{\circ} \mathrm{C}$ y $60 \% \mathrm{HR}$ principalmente sobre sus propiedades mecánicas.

En la Figura V.17 se presentan los resultados obtenidos para las películas reforzadas con bagazo con distintos contenidos de urea y glicerol, antes y después del almacenamiento. Como se observó previamente, la urea es un plastificante más efectivo para la matriz de almidón que el glicerol o que la mezcla de ambos. 


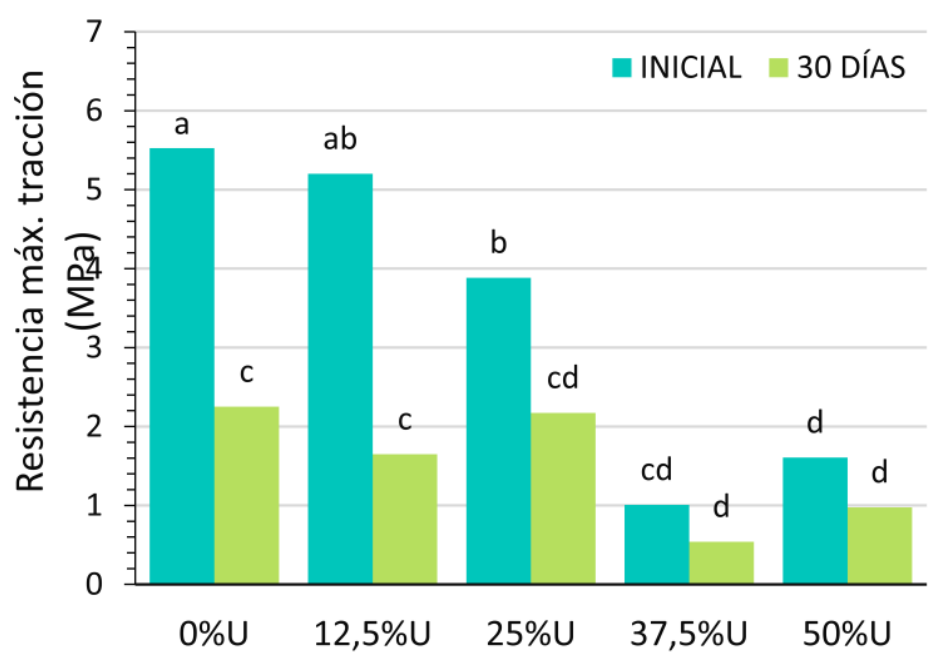

a

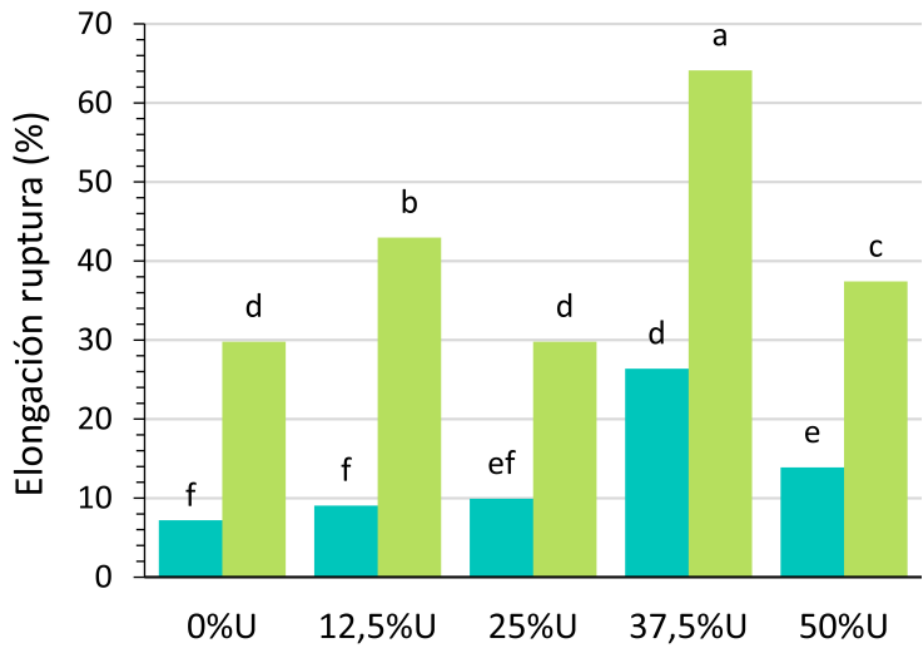

b

Figura V.17. Comportamiento mecánico de películas a base de almidón de mandioca

funcionalizadas con fibra y urea a tiempo inicial y luego de 30 días de almacenamiento:

a) resistencia máxima a la tracción ( $\mathrm{MPa}$ ) y b) elongación máxima antes de la ruptura (\%).

Luego de 30 días de almacenamiento el comportamiento mecánico de todos los materiales estudiados se modificó drásticamente, exhibiendo perfiles de esfuerzodeformación correspondiente a materiales más flexibles lo cual se traduce en una disminución marcada de la resistencia máxima a la ruptura y un incremento de la elongación. 


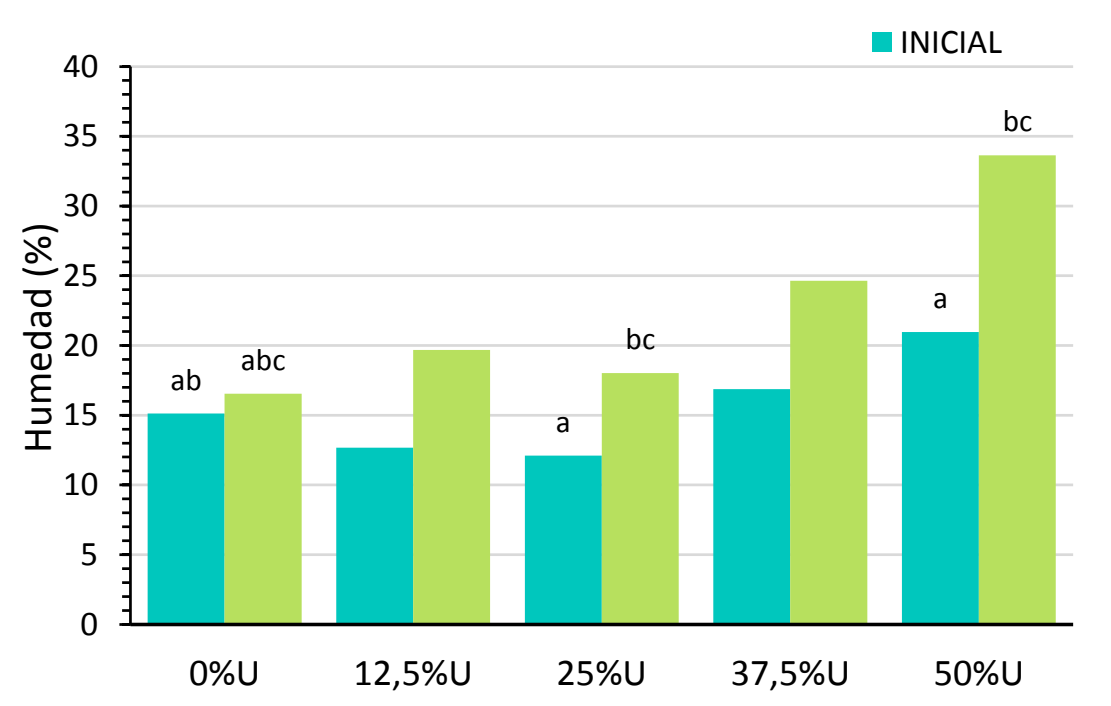

Figura V.18. Contenido de humedad de películas a base de almidón de mandioca funcionalizadas con fibra y urea a tiempo inicial y luego de 30 días de almacenamiento.

A pesar de que las variaciones en el contenido de humedad fueron menos significativas para las películas que incluían glicerol en su formulación ( $0 \%$ y y $12,5 \% U$ ), el efecto del almacenamiento sobre la resistencia mecánica fue más importantes (Figura V.18). A mayor contenido de urea, la absorción de agua por parte de la matriz polimérica resultó mayor, fenómeno que podría explicar la mayor ductilidad de estos materiales luego del almacenamiento.

Dichos resultados se vincularon con la modificación de los patrones de difracción de rayos X del material (Figura V.19). En general las muestras estudiadas presentan una estructura esencialmente amorfa, con un grado de cristalinidad bajo (aproximadamente un 10\%). Con el almacenamiento las películas de almidón presentaron un leve incremento de la cristalinidad, siendo éste más significativo $(p<0,05)$ para las muestras que contienen glicerol ( $0 \%$ y $12,5 \%)$; lo cual se correlaciona con las variaciones observadas en el comportamiento mecánico de las mismas y las observaciones por microscopía SEM detallados en la sección 4.2 del capítulo IV. 

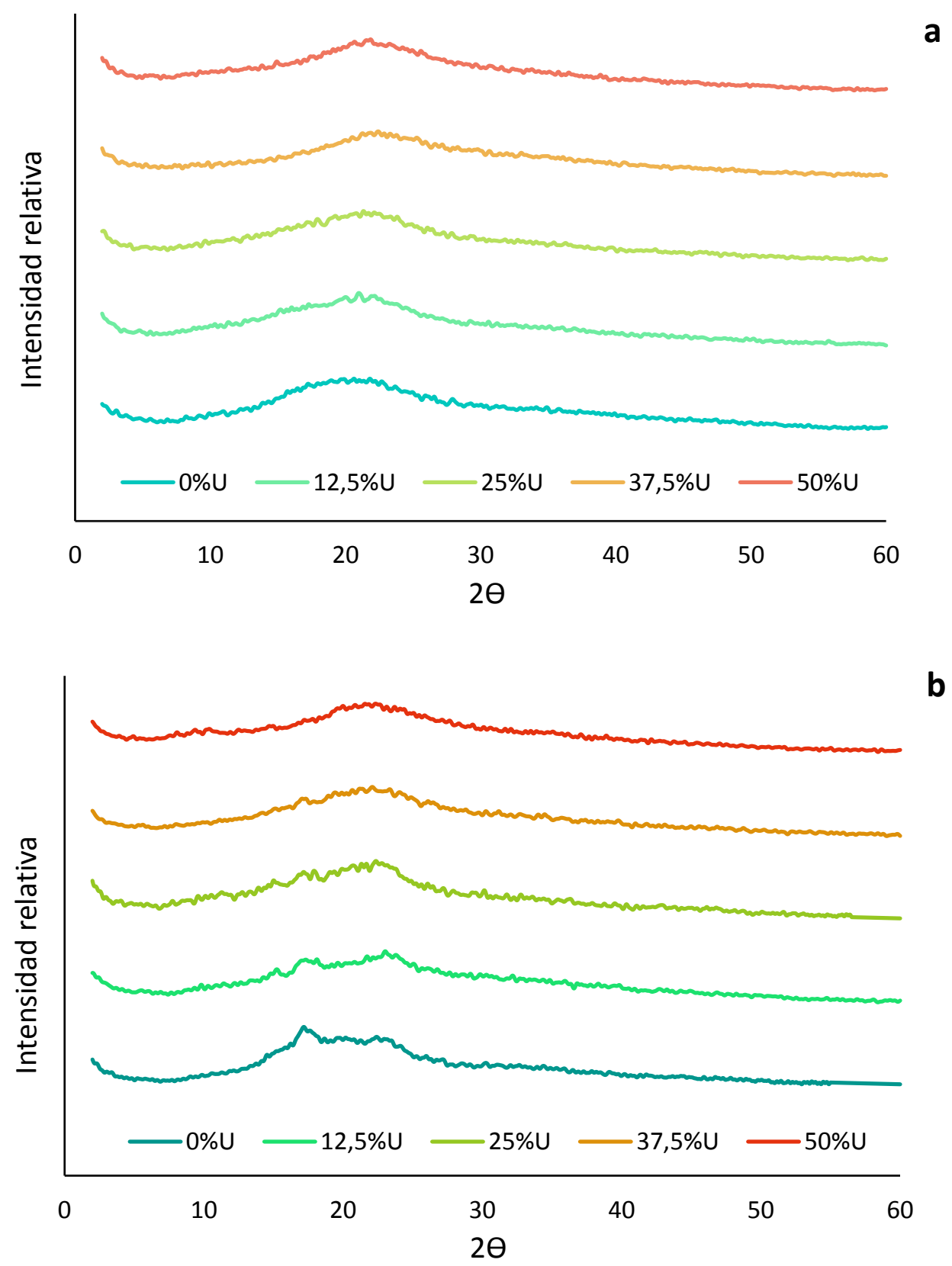

Figura V.19. Difractogramas de películas a base de almidón de mandioca funcionalizadas con fibra y urea a tiempo inicial (a) y luego de 30 días de almacenamiento (b).

Considerando los resultados aquí expuestos, para los ensayos sucesivos se decidió emplear las películas funcionalizadas solo con 25 y $37,5 \% \mathrm{p} / \mathrm{p}$ de urea respecto al contenido de almidón. 
4.2.2. Efecto del material sobre el crecimiento de plantines de tomate

Las semillas ensayadas, fueron elegidas considerando que estas hortalizas son ampliamente comercializadas en el cinturón hortícola del Gran La Plata, y que para su cultivo en invernáculos, típicamente se parte de plantines producidos en almácigo.

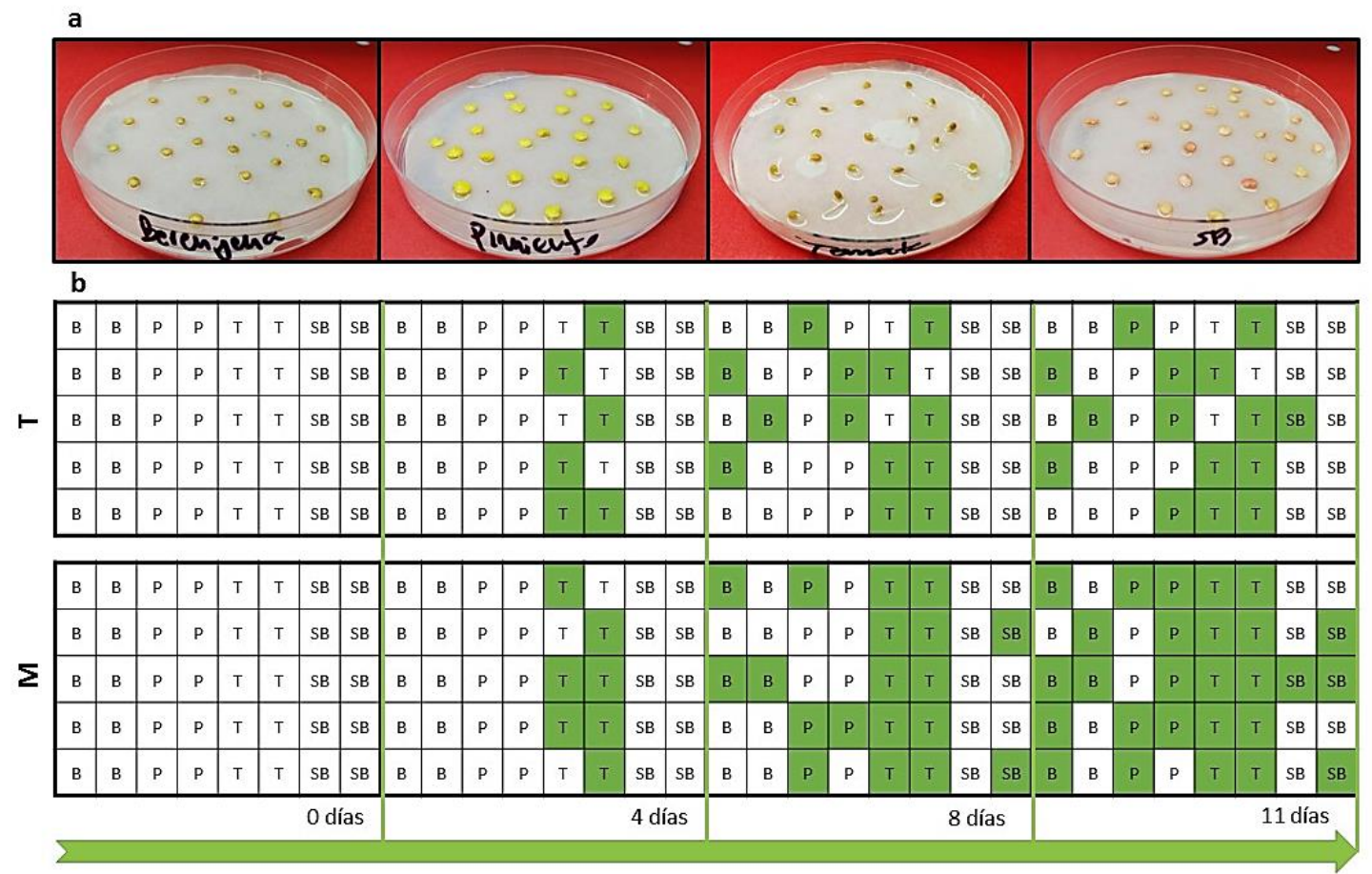

Figura V.20. a) Fotografía de germinación de semillas de berenjena (B), pimiento red-bell (P), tomate perita (T) y pimiento sweet-banana (SB) luego de 3 días de incubación;

b) esquema de germinación de semillas en suelo: tierra fértil (T) y mezcla profesional (M) luego de 0, 4, 8 y 11 días. Las celdas que presentaron brotes se indican con color verde.

En forma comparativa, las semillas de tomate perita presentaron un mayor poder germinativo a corto plazo y una velocidad de crecimiento mayor al cabo de 11 días de cultivo (Figura V.20). Por ello se seleccionaron estas semillas para los ensayos subsiguientes, puesto que permitiría abordar los mismos en un menor tiempo.

Los resultados observados en los ensayos de germinación se explican a partir de los valores de humedad y capacidad de campo de los sustratos (Figura V.21). Las semillas 
requieren temperaturas moderadas $\left(22-29^{\circ} \mathrm{C}\right)$ y altas humedades que permitan el hinchamiento y ablandamiento de la episperma (capa exterior de la semilla conformada por la testa y el tegmen), y la rehidratación del embrión para impulsar el desarrollo de la nueva plántula [23].
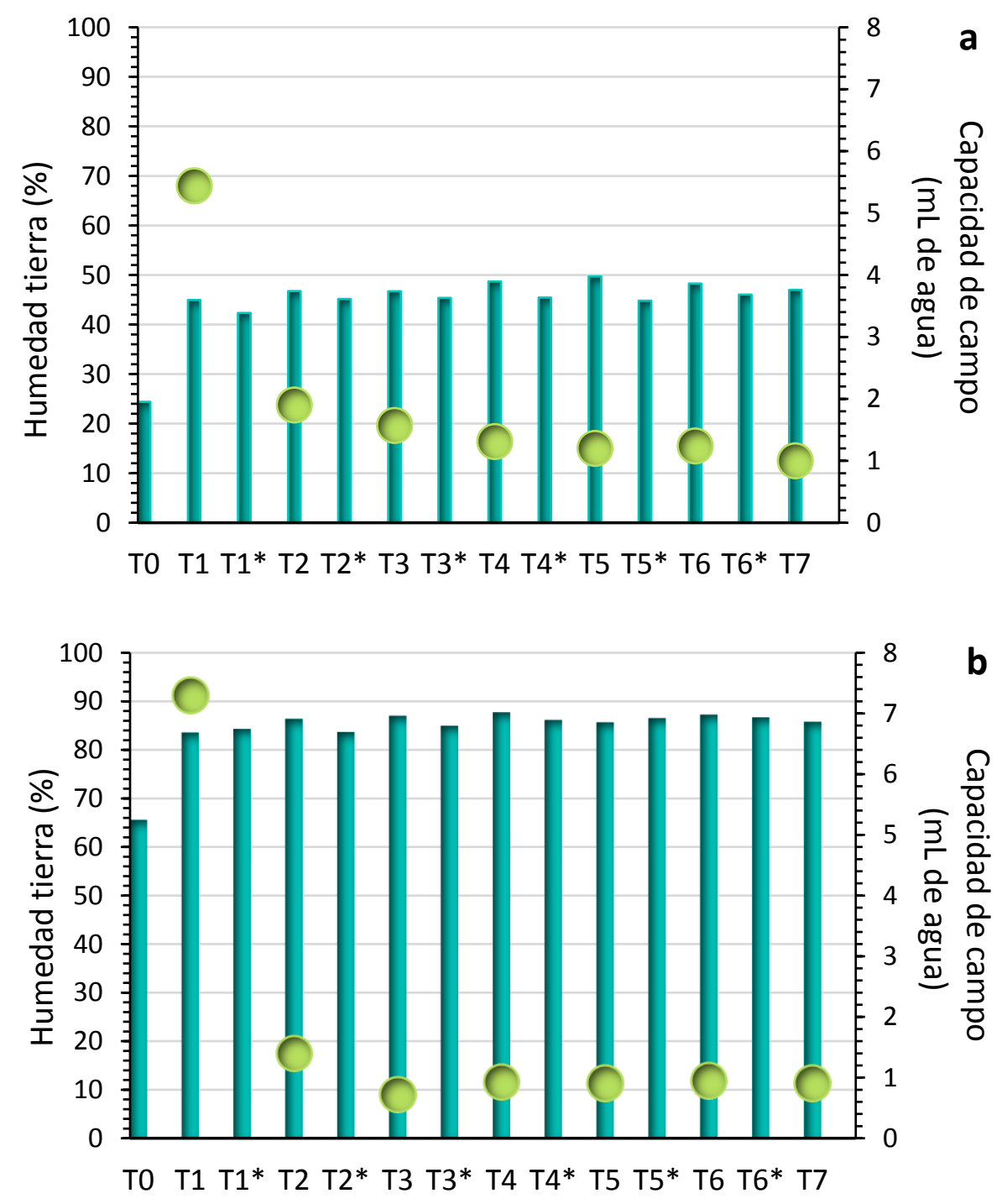

Figura V.21. Capacidad de campo y humedad del sustrato registradas durante 7 días de ensayo en condiciones de humedad y temperatura controlada de celdas de reproducción de plantines para: a) tierra fértil y b) mezcla profesional. Para cada tiempo analizado $(T)$ se indica la humedad del sustrato antes y luego $\left({ }^{*}\right)$ del riego. 
Como se observa en la Figura V.20 la humedad media del sustrato profesional es mayor que la de la tierra negra, debido a su mayor porosidad y menor densidad, lo cual explica el mayor rendimiento de las semillas en el primer sustrato que en el segundo.

Como alternativa a las bandejas de speedling de polietilieno, se consideró el uso de las películas de almidón desarrolladas reforzadas con 1,5\% de bagazo y funicionalizadas con urea. Consecuentemente como primera arpoximación se prepararon macetas en forma de cono del mismo volumen que las celdas de las bandejas de speedling utilizadas en los ensayos preliminares (Figura V.22). Se realizó un diseño experimental con al menos 40 replicados por tratamiento, puesto que se preveían extracciones a los 4, 7, 11 y 14 días desde la siembra. Se estudió el efecto de películas control (U0), con $25 \%$ de urea (U25) y $37,5 \%$ de urea (U375) y las mismas formulaciones aplicadas como recubrimiento sobre papel (P0, P25 y P375), comparándolo con controles sin película. En la Figura V.22 se muestran ejemplos de las macetas con y sin papel de soporte.

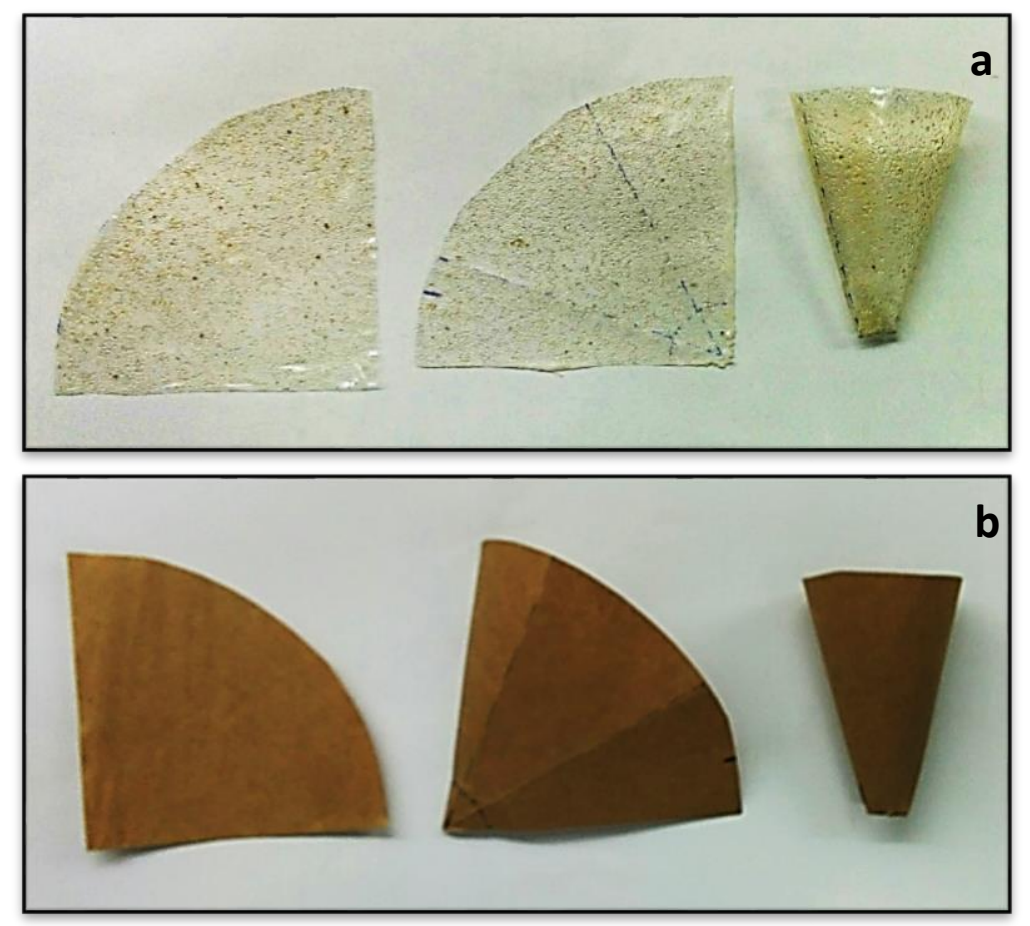

Figura V.22. Fotografías de macetas de speedling a partir de películas de almidón reforzadas con $1,5 \%$ de bagazo (a) y la misma formulación aplicada como recubrimiento sobre papel (b). 
Cabe aclarar que dado que el material exhibe capacidad de termosellado, las mismas podrían obtenerse por esta técnica.

El ensayo sin embargo debió ser interrumpido puesto que se identificó un intenso olor amoniacal en el invernadero lo cual indicaba la hidrólisis de la urea presente en las películas y la consecuente liberación de amonio al suelo seguido de su conversión a amoníaco y su volatilización a la atmósfera. Esto inhibió la germinación de las semillas de tomate en las macetas que contenían urea, y parcialmente de las otras macetas por contaminación de la atmósfera circundante.

Revisando la bibliografía se encontraron referencias que indican que dos efectos importantes deben considerarse en la aplicación de fertilizantes: el índice salino y el efecto sobre el pH del suelo [34-36]. El índice salino se refiere al aumento de la presión osmótica en la disolución del suelo producida por la aplicación de un fertilizante, respecto a la producida por la misma cantidad de nitrato de sodio [36]. Si la zona de aplicación del fertilizante se encuentra muy cerca de las raíces o semillas, este aumento de la presión osmótica del suelo promueve daños por deshidratación y toxicidad, lo cual se conoce como quemado por fertilizante $[34,35]$. Por ello, a pesar de que el índice salino de la urea no es muy alto $(1,68)$, la proximidad de la misma en las macetas de speedling indujo la deshidratación osmótica de la semilla y por ende condujeron a su muerte. Además, las condiciones de humedad tan elevadas como las presentes en el sustrato profesional (cercanas al $80 \%$ ), promovieron la hidrólisis de la urea con la consecuente liberación de amoníaco al ambiente y aumento del $\mathrm{pH}$ del suelo (Figura V.23).

En base a los resultados anteriores se procedió a evaluar el efecto del fertilizante de las películas en plantines de mayor edad, puesto que podría ubicarse el film más lejos de la raíz, en un sustrato más denso y por tanto con menor humedad que evitarían los efectos adversos observados previamente. 


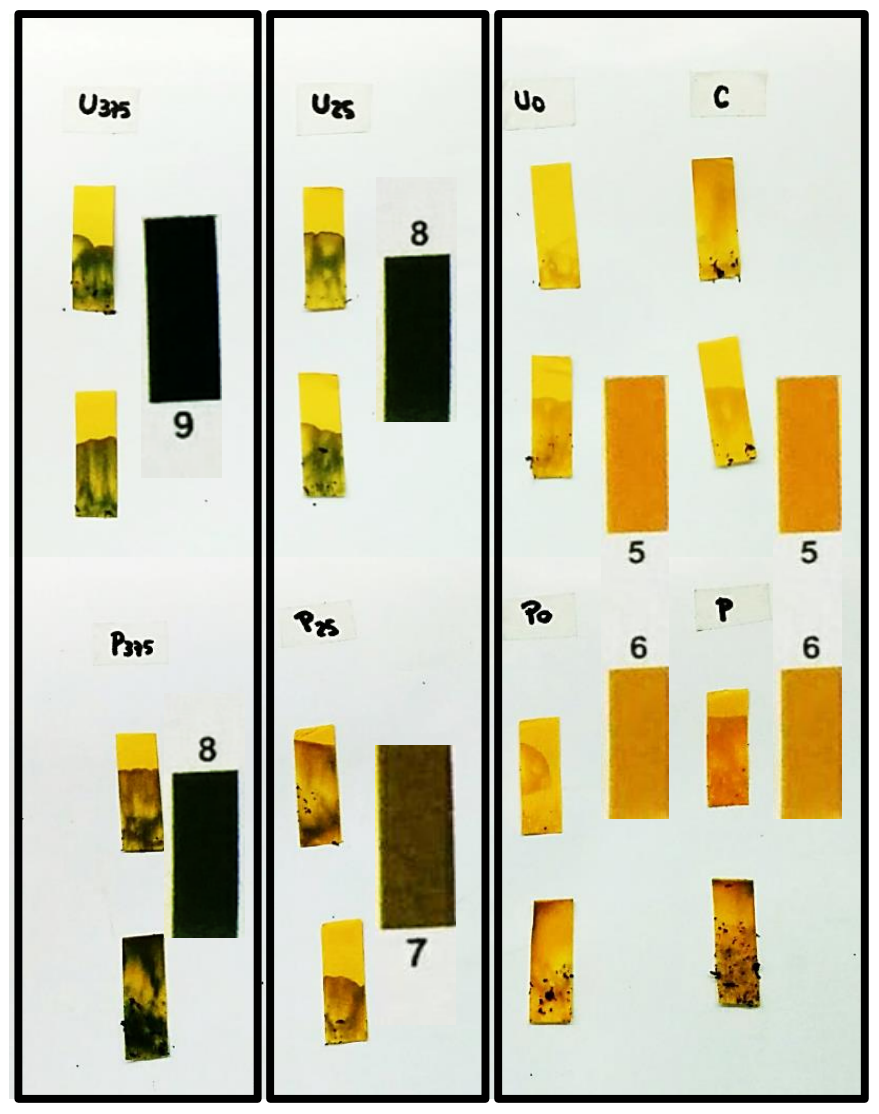

Figura V.23. Fotografías de las medidas de $\mathrm{pH}$ del suelo en macetas para plantines de tomate con problemas de toxicidad por amoníaco y deshidratación osmótica.

Para el segundo ensayo se utilizaron semillas de tomate perita de las cuales se evaluó el poder germinativo para poder determinar el número de semillas que era necesario sembrar para tener un número final de plantines adecuado. Las semillas presentaron un poder germinativo de aproximadamente $72 \%$, por lo cual se sembraron 256 celdas para asegurar la obtención de al menos 144 plantines de tomate para el trabajo experimental diseñado (Figura V.24). Al cabo de 18 días se obtuvieron plantines de tomate con 2 hojas verdaderas bien desarrolladas (debido a que el tomate presenta hojas denominadas "compuestas" cada hoja verdadera está formada por 3 o 4 hojas más pequeñas), sin embargo la altura del tallo era desproporcionada en relación al desarrollo foliar observado. Este resultado se atribuyó a que la densidad de plantas 
resultó ser muy alta y a que la distancia mínima a la que se podía disponer las plantas respecto a los tubos de luz del invernadero no fuese óptima. En este respecto Vagnoni y col. [21] estudiando el efecto del tamaño de celda sobre la calidad de plantín obtenido concluyeron que con celdas de $40 \mathrm{~cm}^{3}$ o mayores se obtienen plantines de mayor calidad. Por lo tanto para evitar un desarrollo desproporcionado de los plantines se procedió al trasplante de los mismos en este estadio.
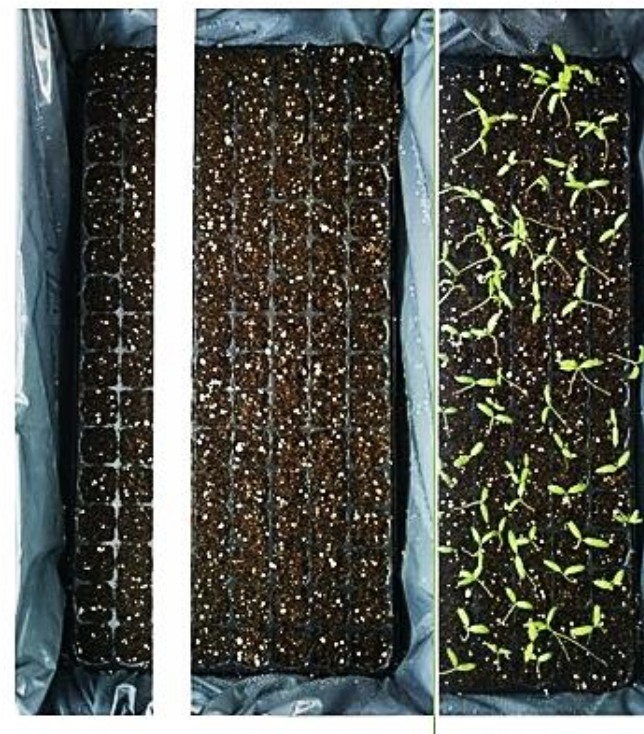

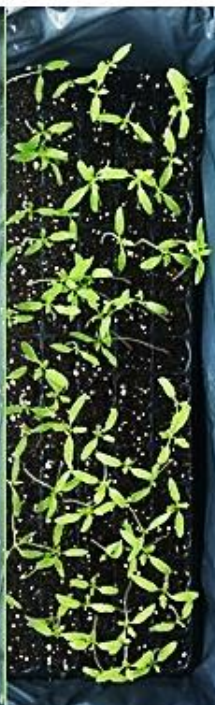

8 días

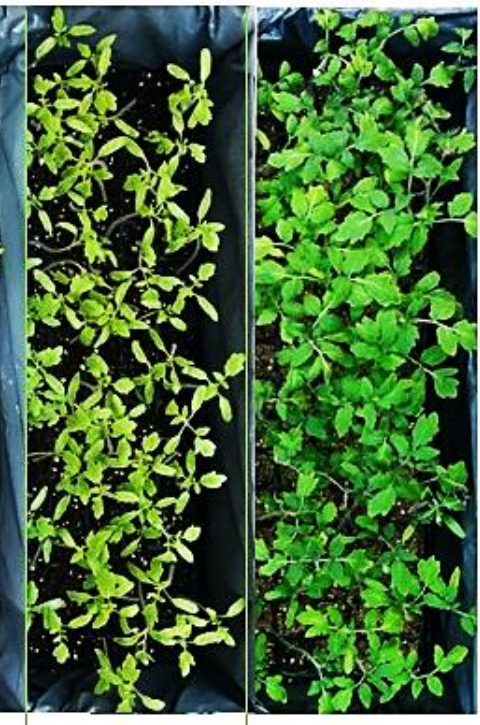

11 días

18 días

Figura V.24. Fotografías del crecimiento de plantines de tomate para ensayo en maceta.

Como se explicó en la sección 3.3.2.4 de este capítulo, los plantines de tomate fueron trasplantados a macetas \#10 con sus distintos tratamientos como se muestra a la izquierda de la Figura V.25. En la misma Figura V.25 se puede observar el crecimiento de los plantines en los primeros 28 días de tratamiento. A pesar de que las diferencias en el tamaño de las plantas son difíciles de apreciar a simple vista, se hallaron diferencias significativas $(p<0,05)$ tanto en el desarrollo foliar como en el crecimiento relativo de raíces, tallo y hojas como se resume en las Tabla V.4 y V.5, y puede observarse en la Figura V.26. 


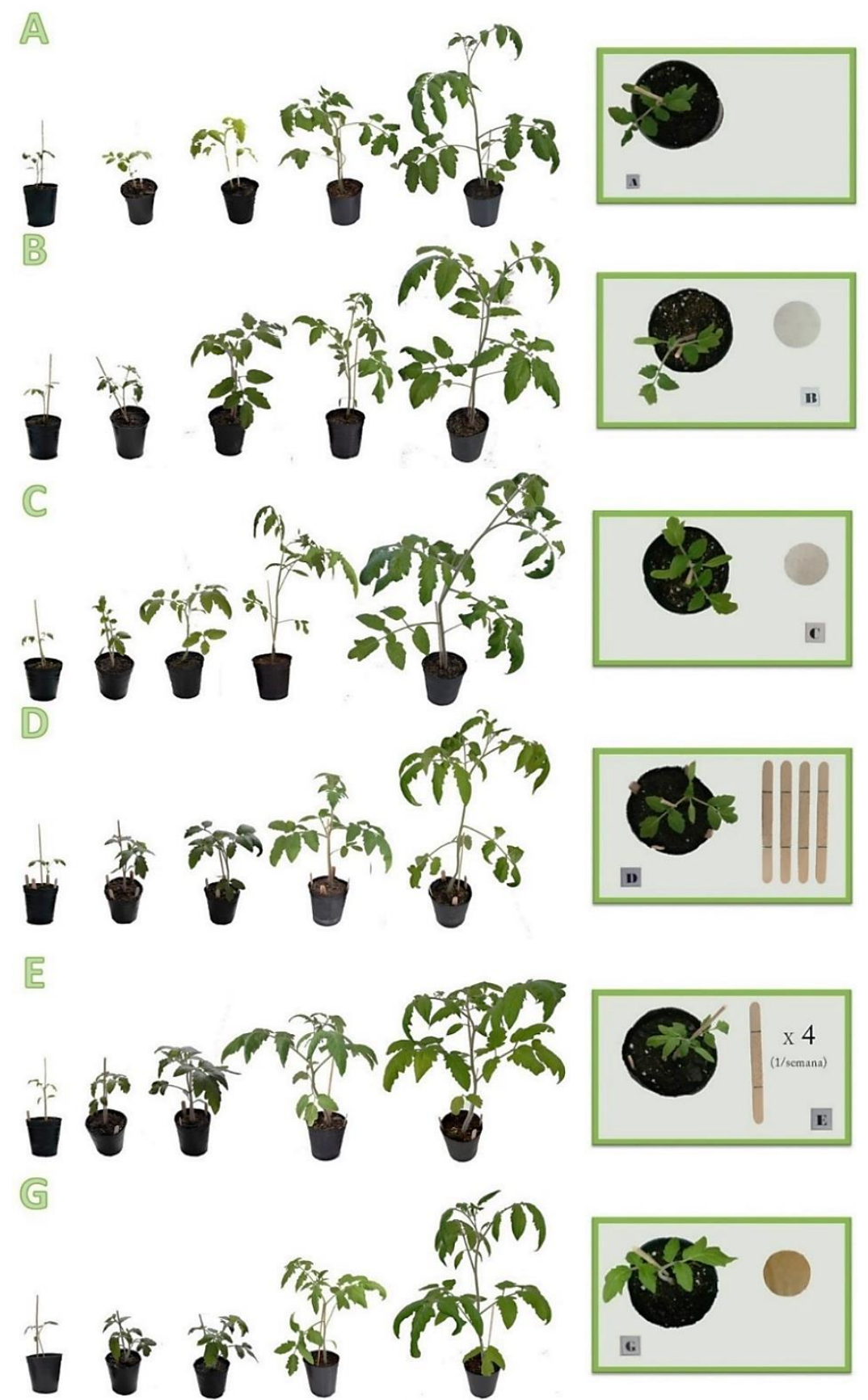

Figura V.25. Fotografías de seguimiento semanal del crecimiento de plantines de tomate en 28 días de ensayo, y ejemplo de preparación de los distintos tratamientos: A) control; B) disco de $5 \mathrm{~cm}$ de película $25 \mathrm{U}$; C) disco de $4,7 \mathrm{~cm}$ de película $37,5 \mathrm{U}$; D) bastones con película $25 \mathrm{U}$ x4 en simultáneo; E) bastones con película $25 \mathrm{U}$ colocados de a uno por semana (en total 4); y G) disco de papel de $5 \mathrm{~cm}$ con película $25 \mathrm{U}$. 


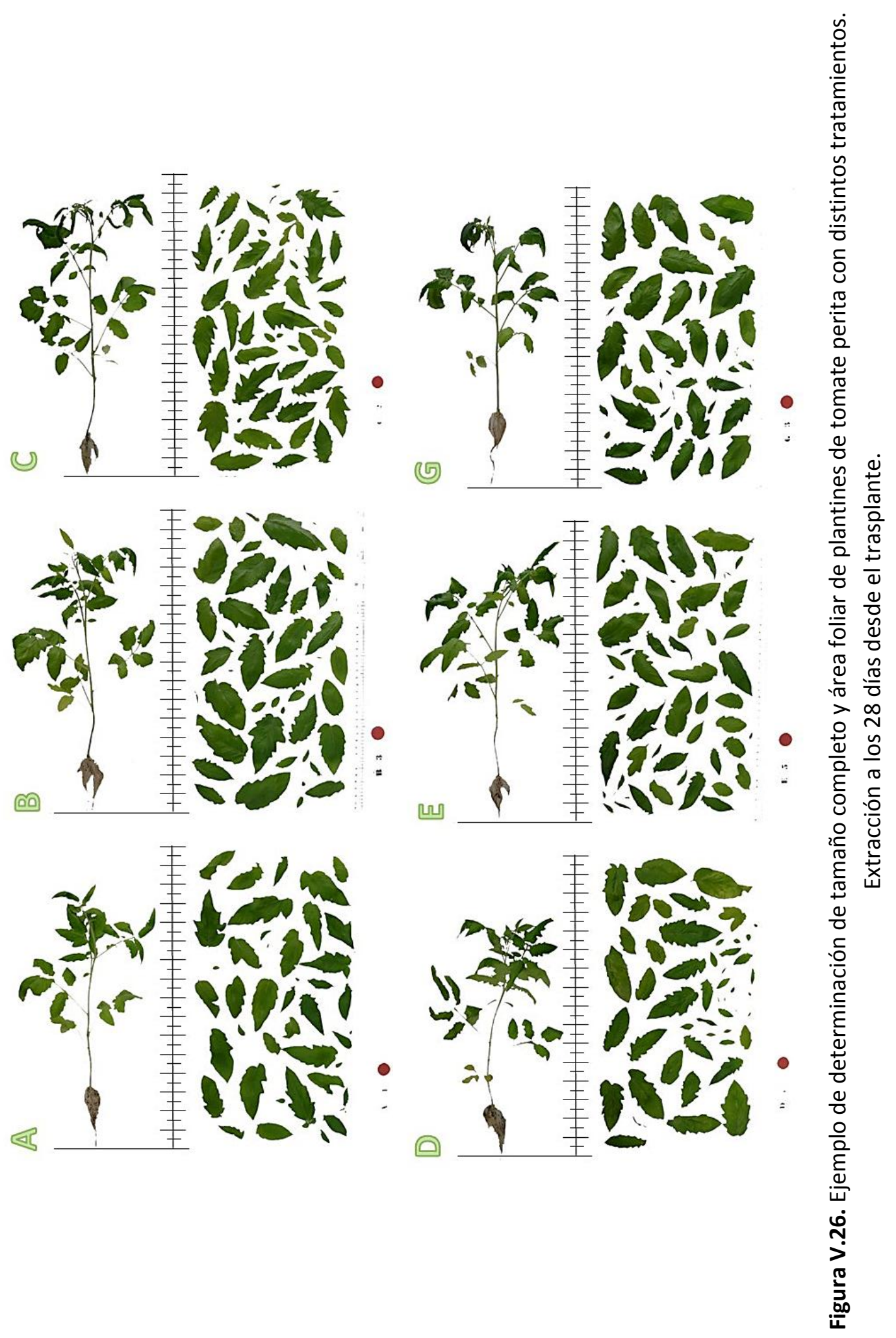




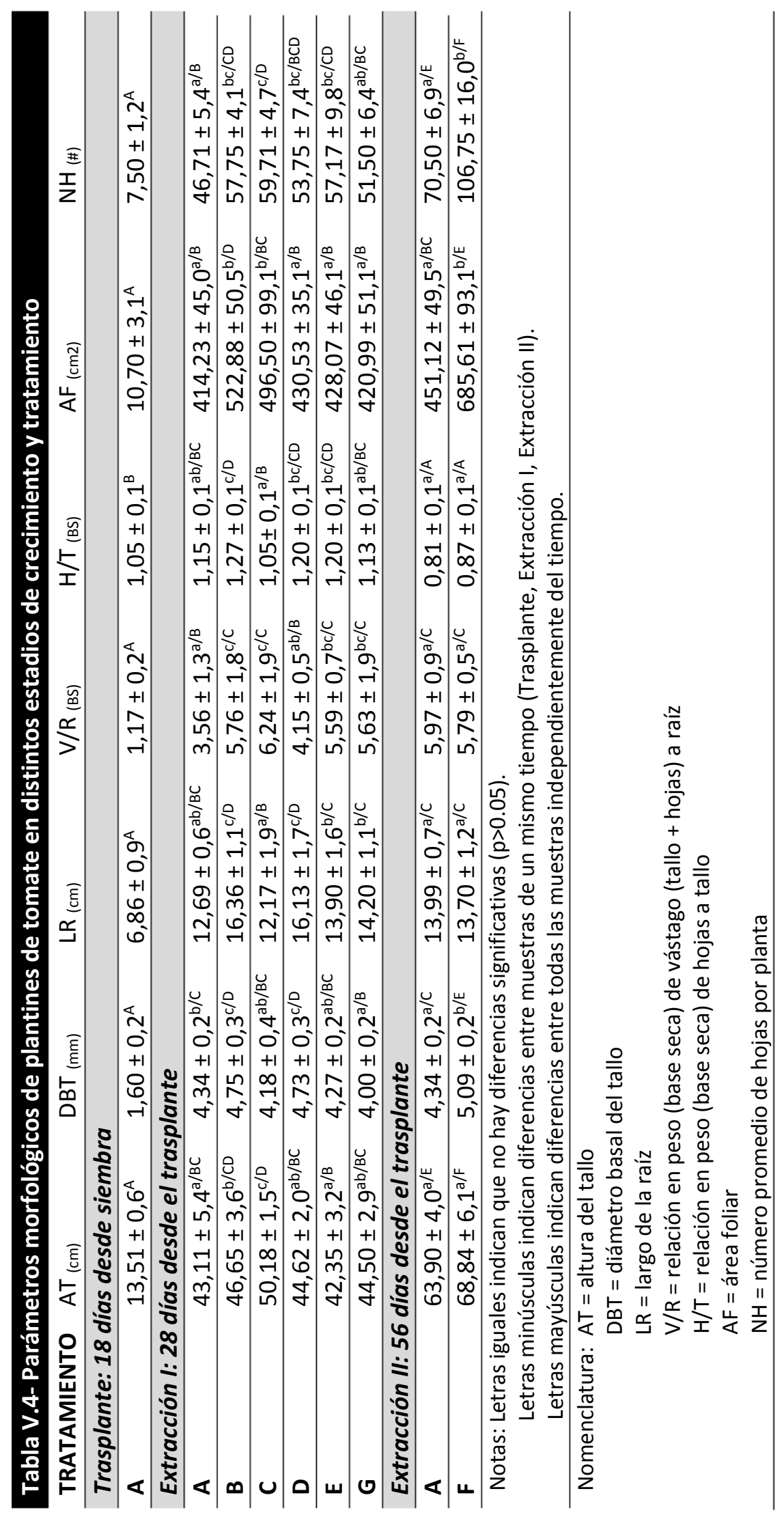




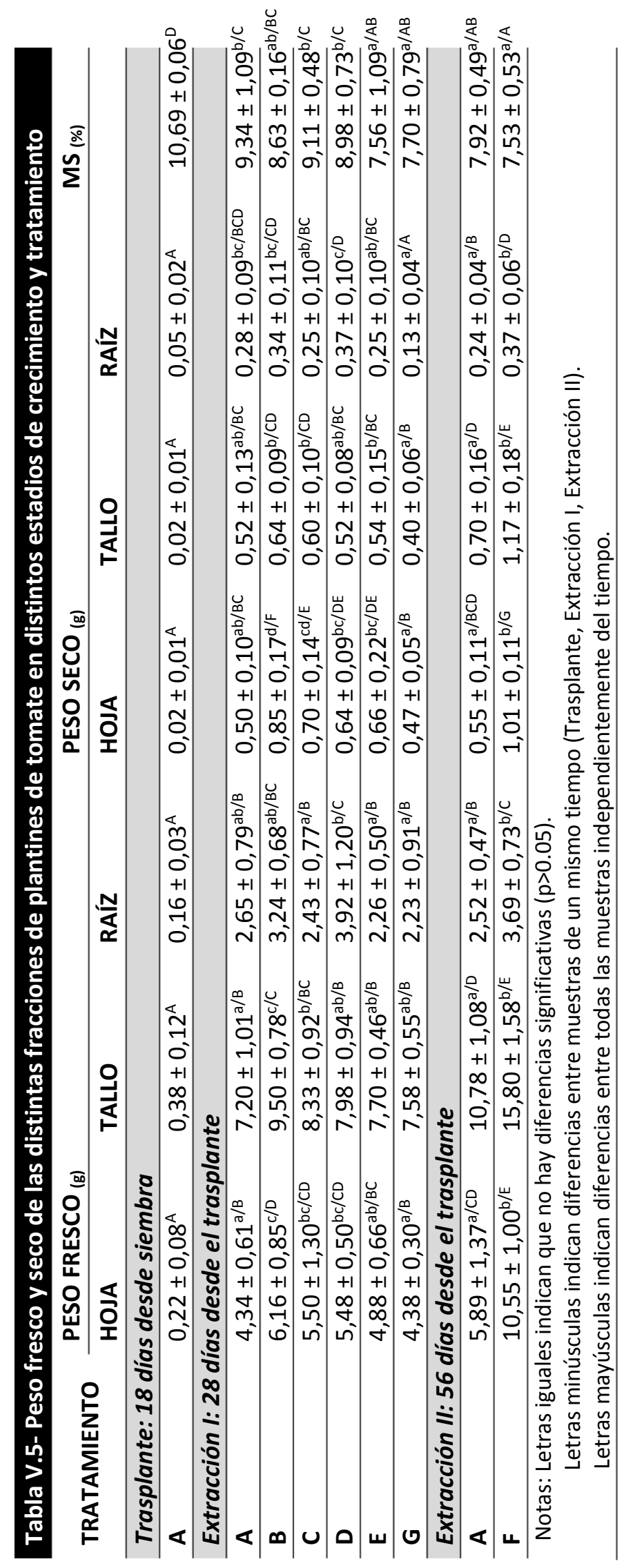




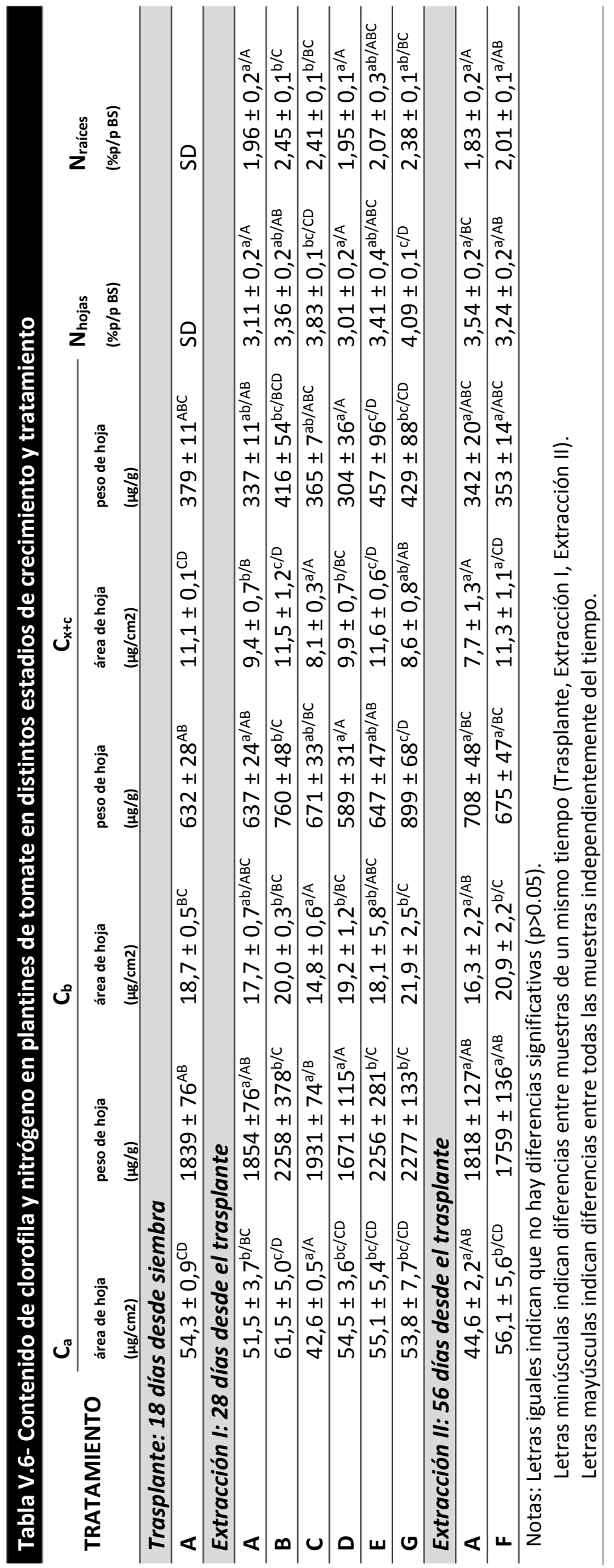


En general, en la primera extracción las diferencias entre las muestras que incluían las películas funcionalizadas con fertilizante y el control difieren según la forma de dosificación empleada y en algunos casos (por ejemplo, D y G) no son muy marcadas, puesto que la carga orgánica del sustrato empleado resultó importante y posiblemente suficiente para un buen desarrollo inicial de la planta. Sin embargo, se observa una tendencia hacia una mayor superficie foliar, tamaño y peso de la planta.

El análisis por componentes principales para el experimento realizado da cuenta de que existe una relación entre el material empleado para la liberación de la urea como fertilizante y los distintos parámetros de crecimiento analizados, pudiéndose deber a la capacidad del fertilizante de difundir desde la superficie del material hasta la raíz.

La componente principal CP1 que explica el $39,3 \%$ de la varianza total se asocia a la velocidad de liberación de la urea desde el material, diferenciándose los tratamiento B y D, con efecto positivo, de C, E y G (Figura V.27). Comparando el efecto de las películas B y $C$, en el capítulo IV se había observado una mayor velocidad de biodegradación en suelo de las películas $37,5 \mathrm{U}$ que de las $25 \mathrm{U}$, lo que podría haber inducido a una liberación más rápida de la urea al suelo. Así, la alta disponibilidad de urea en los primeros días de crecimiento promovió un crecimiento excesivo del tallo a tiempos cortos (ver Figura V.24), que condujo a plantas con una altura de tallo significativamente $(p<0,05)$ mayor, así como una relación $V / R$ relativamente mayor hacia el final de la experiencia.

Un efecto contrario se puede ver en comparación de los tratamientos B y G, si bien ambos materiales fueron obtenidos a partir de la misma formulación, el hinchamiento del papel puede retardar la liberación de urea al suelo debido a que podría existir difusión de este componente tanto al medio como a la matriz del soporte. Asimismo, comparando el tratamiento B y D, la utilización de bastones (D) podría dar lugar a una disponibilidad de fertilizante más uniforme hacia la raíz y paulatina. Sin embargo, comparativamente la dosificación del fertilizante (tratamiento E), no tuvo un impacto 
significativo $(p>0,05)$ sobre el desarrollo vegetativo de los plantines probablemente debido a la calidad del sustrato empleado.

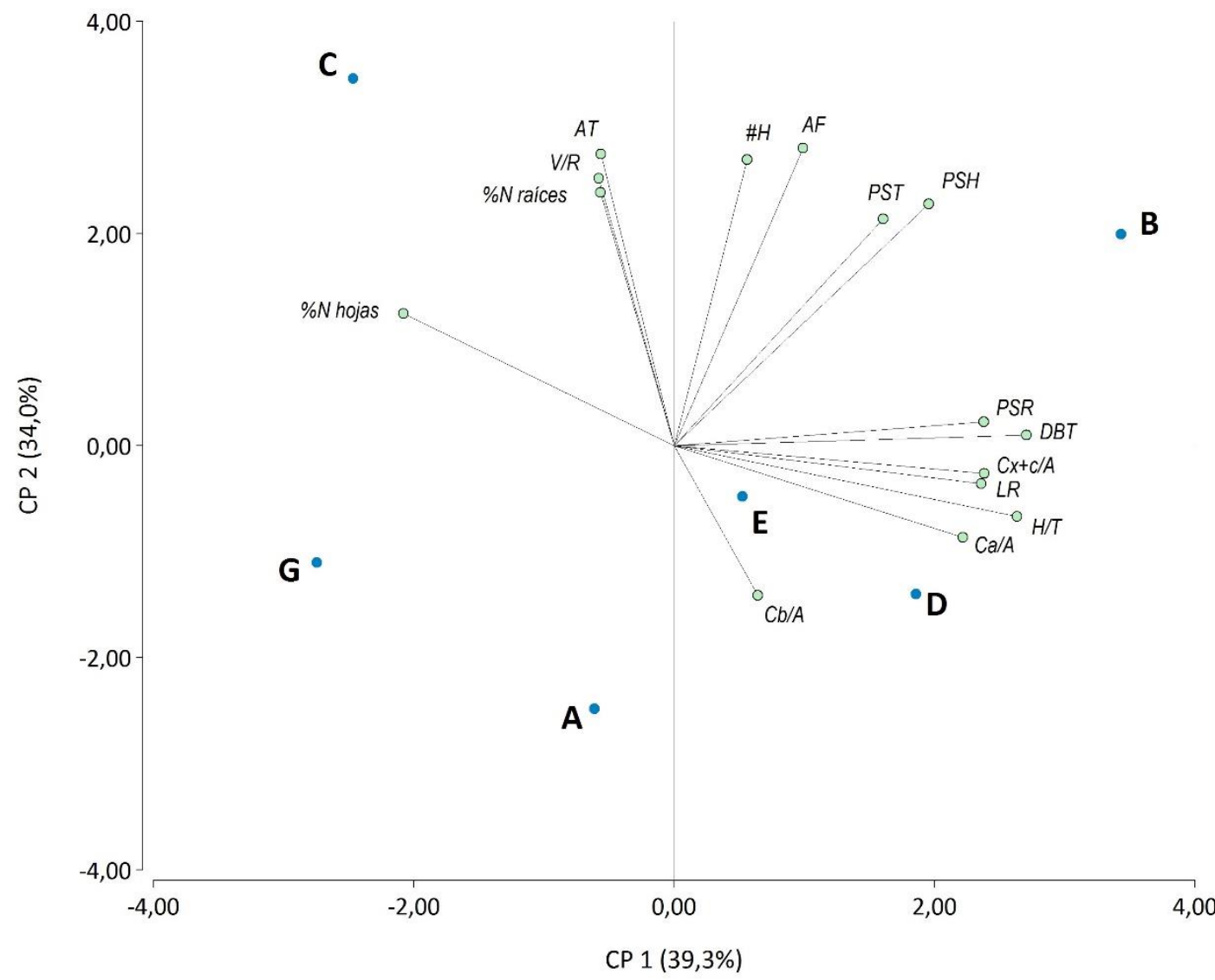

Figura V.27. Gráfico Biplot resultante del análisis por componentes principales (ACP) de los resultados de crecimiento de plantines a 28 días desde el trasplante.

La segunda componente principal (CP2) que explica el $34,0 \%$ de la varianza total (Figura V.27) se asocia al tipo de material (con o sin soporte). En este caso, el efecto resultó más positivo para los tratamiento $\mathrm{B}$ y $\mathrm{C}$ que solo contaban con la película funcionalizada de almidón con bagazo. Esto puede deberse a que la difusión del fertilizante desde la película ( $\mathrm{B}$ y $\mathrm{C}$ ) al medio se produce en ambas caras, mientras que cuando se utiliza un soporte (G, D y E) la difusión es unidireccional. Este efecto fue más notorio en los parámetros de crecimiento del tallo y las hojas. 
El parámetro de correlación cofenética $(0,964)$ encontrado indica que el agrupamiento de datos analizado describe adecuadamente las variables experimentales estudiadas.

Por otra parte, si se comparan los resultados obtenidos en la segunda extracción, se observa que la aplicación del fertilizante dosificado semanalmente (F) tuvo un efecto significativo sobre el crecimiento vegetativo de los plantines de tomate, el cual es importante para el futuro desarrollo de la planta en suelo (Figura V.28). Si bien el tamaño de las planta (AT y LR) resultó dependiente del tiempo de crecimiento de la planta y no del tratamiento empleado (Tabla V.4); las plantas en presencia de las películas con fertilizante mostraron un desarrollo más vigoroso con un aumento significativo $(p<0,05)$ en todos los demás parámetros de crecimiento (Tabla V.4 y 5 ).
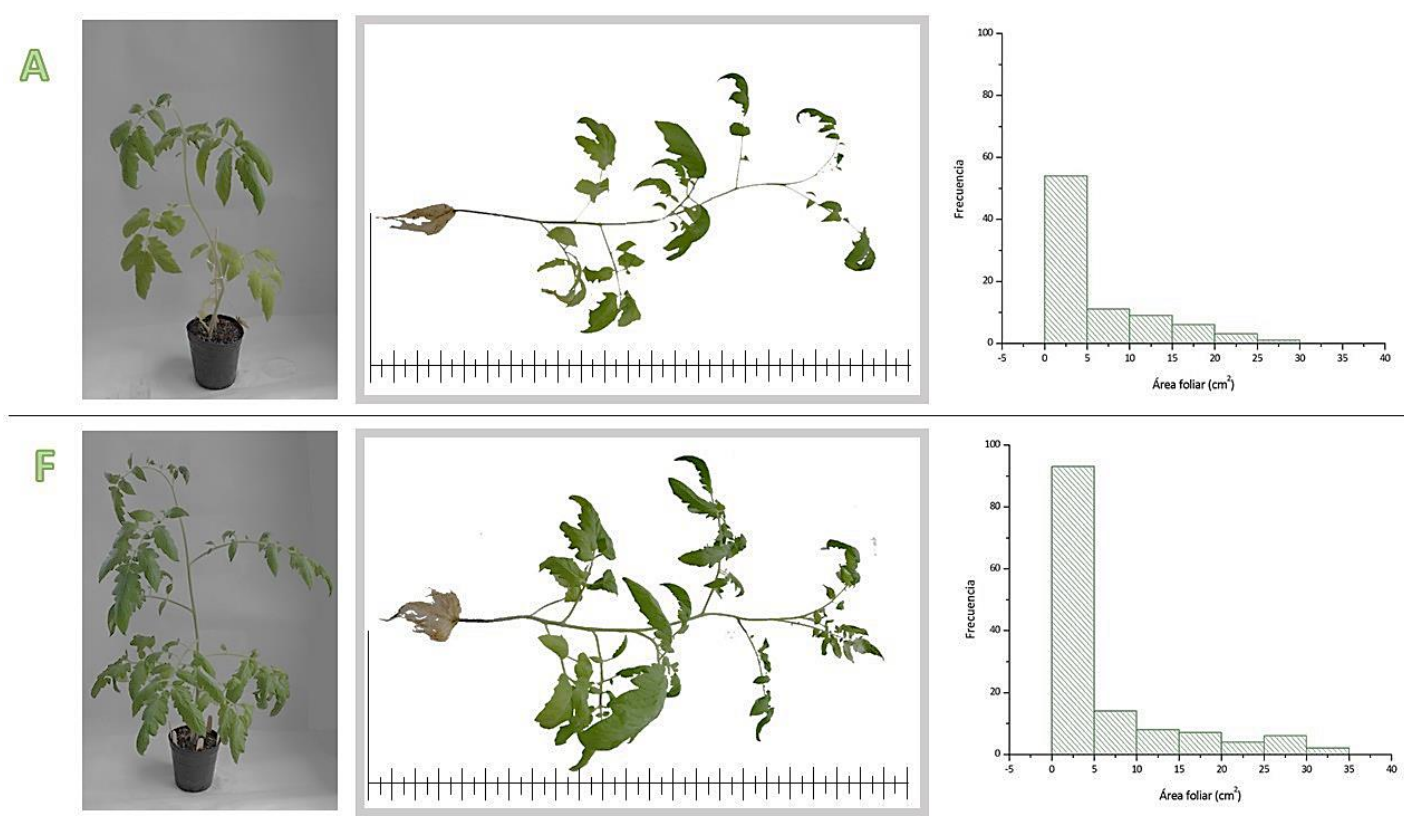

Figura V.28. Fotografías de la planta en maceta y descalzada, e histograma de tamaño de hojas para plantines de tomate perita control (A) y tratadas con películas de $25 \%$ de urea dosificadas semanalmente en bastones (F).

Es importante resaltar que las plantas tratadas (F) presentaron un mayor desarrollo de radicular si bien no en el largo de la raíz (el cual también se ve limitado por el tamaño 
del recipiente), más bien en su densidad y ancho (Tabla V.5 y Figura V.28), evidenciando un crecimiento fuerte y equilibrado de la planta. Asimismo, como puede apreciarse en los histogramas de la Figura V.28, las plantas de tomate tratadas (F) presentaron como se mencionó anteriormente un desarrollo foliar mayor que las plantas control (A), observándose una gran proporción de hojas pequeñas en las muestras $\mathrm{F}$ que indican el crecimiento constante de las plantas.

Como se mencionó previamente, la clorofila es un pigmento importante para la fotosíntesis de las plantas, y su contenido y composición afectan directamente la capacidad fotosintética, nivel de nutrientes, crecimiento y desarrollo de las mismas [37]. Los contenidos de Clorofila-a y Clorofila-b, así como su proporción afectan directamente a la absorción selectiva de luz y su utilización por la planta. El tipo y contenido de pigmentos foliares varía dependiendo de la especie, y las variaciones en su concentración total y relativa puede deberse a factores internos de crecimiento y las condiciones ambientales [22, 37].

En todos los casos se observa una alta relación de Clorofila-a a Clorofila-b, lo cual indica que las plantas se encontraban bien iluminadas [22]. De la Tabla V.6 puede observarse que en los controles $(A)$ el contenido de estos pigmentos disminuyó significativamente $(p<0,05)$ durante el desarrollo de los plantines (entre primera y segunda extracción), mientras que por el contrario dichos valores se mantuvieron o aumentaron en los plantines tratados (F) independientemente del crecimiento global del plantín (Figura V.29).

En la Figura V.29 y la Tabla V.6 también puede apreciarse que el contenido de pigmentos totales por unidad de superficie resulta significativamente mayor $(p<0,05)$ únicamente para el tratamiento $B$ y significativamente menor al control $(p<0,05)$ para el tratamiento C. Este comportamiento se atribuye a que los discos de $25 \mathrm{U}$ permitieron una dosificación más controlada del fertilizante en el tiempo (por las 


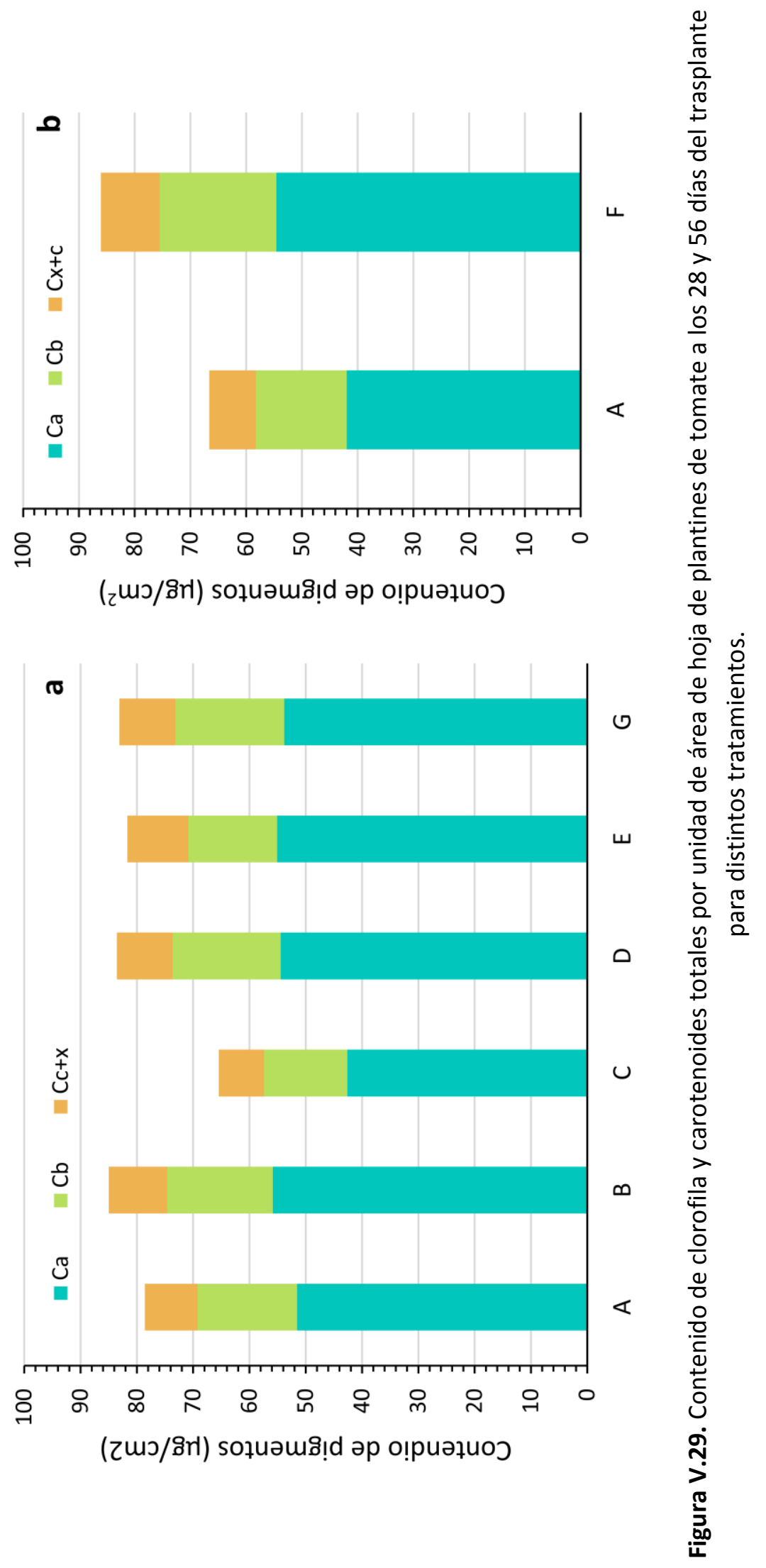


características previamente analizadas), dando lugar a un crecimiento mayor y más equilibrado del plantín de tomate; mientras que los discos de película $37,5 \mathrm{U}$ promovieron un crecimiento desproporcionado de la planta, favoreciendo el crecimiento del tallo respecto del desarrollo foliar y por ello su menor contenido de pigmentos fotosintéticos.

Por otro lado en la Tabla V.6 se ve que los contenidos de clorofilas y carotenoides no presentan el mismo comportamiento si se evalúa en función del área o peso (fresco) de hoja. Estas variaciones se deben a las distintas concentraciones de humedad de la planta que se refleja en el contenido de masa seca (MS) de las mismas (ver Tabla V.5). Las muestras $\mathrm{G}$ y $\mathrm{E}$ presentaron menor proporción de agua que la muestra $\mathrm{B}$ y es por ello que el contenido de pigmentos por peso entre estas muestras no resulta significativamente $(p>0,05)$ diferente entre sí.

El contenido de $\mathrm{N}$, por otro lado, es indicativo de la producción de proteínas por parte de la planta y está íntimamente ligado a la absorción de este macronutriente [23]. El contenido de este nutriente resultó mayor en las hojas que en la raíz y el tallo, por lo que para la comparación del efecto del tratamiento sobre la absorción de $\mathrm{N}$ se decidió evaluar su contenido en hojas y raíz ${ }^{1}$.

Los resultados porcentuales indican que la absorción de $\mathrm{N}$ fue mayor para las muestras $C$ y $G$, que $B, D$ y $E$, y que estas últimas no tuvieron diferencias significativas $(p>0,05)$ con el control (Tabla V.6). El primer efecto se atribuye a la alta disponibilidad de urea en el corto plazo que proporcionan las películas en forma de disco con $37,5 \%$ de urea (C). El segundo efecto se atribuye al mayor contenido de humedad que presentaron las plantas tratadas con $G$, ya que dado que los ensayos se realizaron sobre las muestras

\footnotetext{
${ }^{1}$ Esta determinación preliminar se realizó por Kjeldhal solo para el control por estimarse que sus contenidos de $\mathrm{N}$ serían menores y así poder determinar la cantidad de muestra necesaria para los ensayos por Micro Kjeldahl de todos los tratamientos analizados. A partir de estos resultados se descartó el análisis del contenido de $\mathrm{N}$ en el tallo.
} 


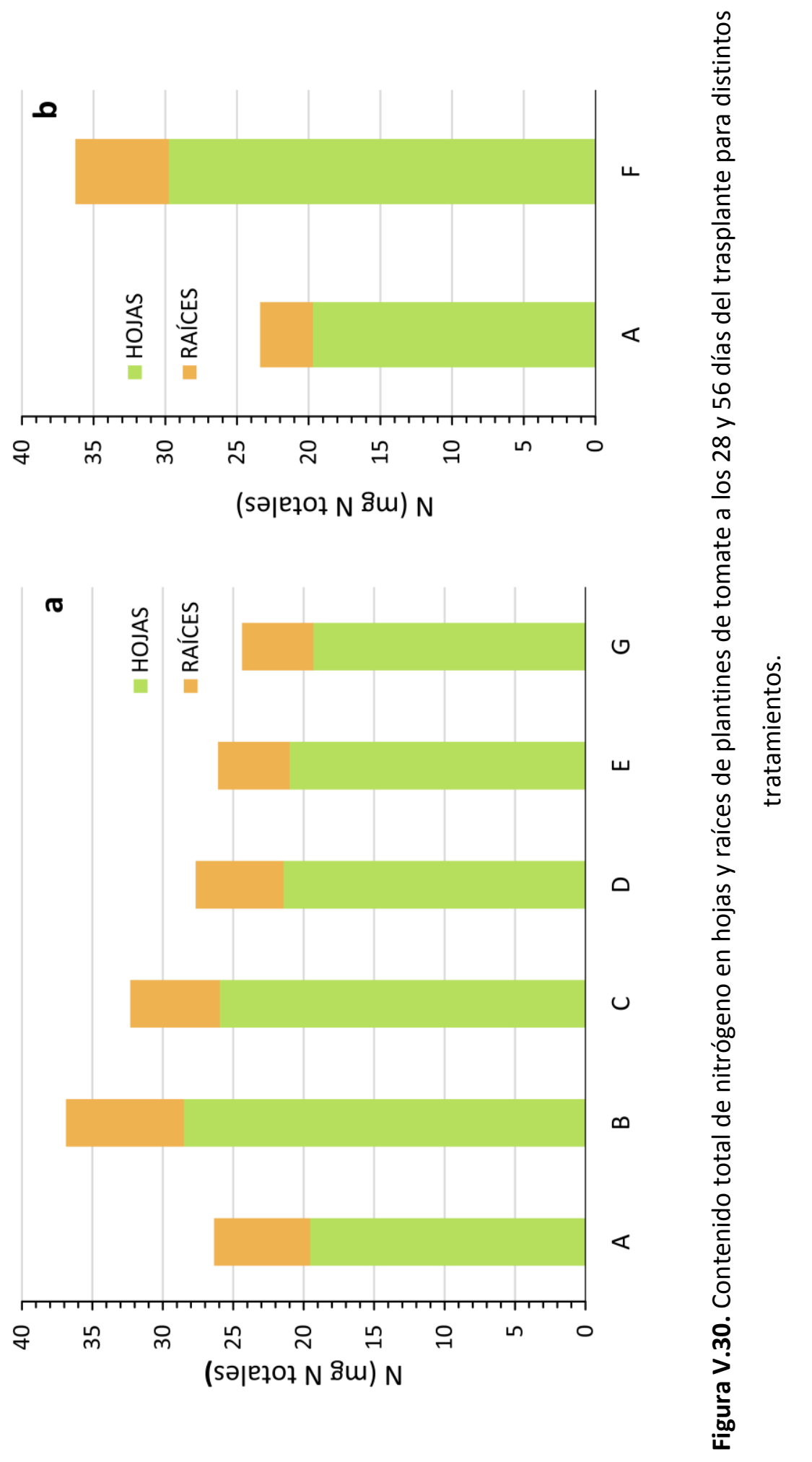


secas un mismo peso de muestra sería representativo de una fracción mayor de la planta viva, entonces si bien los contenidos de $\mathrm{N}$ en base seca resultan mayores si se analizaran los resultados en base húmeda estos valores resultarían sustancialmente menores.

Por último, aunque el contenido porcentual de $\mathrm{N}$ los tratamiento con las películas $25 \mathrm{U}$ en sus distintas presentaciones $(B, D$ y $E$ ) no resultaron significativamente mayores que la absorción de $\mathrm{N}$ por parte del control (A), si se analiza la absorción de $\mathrm{N}$ total por peso de planta (Figura V.30) se ve un incremento significativo $(p<0,05)$ para los tratamientos B, C y D.

Como puede apreciarse en la Tabla V.6 y la Figura V.30, el efecto a largo plazo resultó similar en relación al contenido porcentual de $\mathrm{N}$ en base seca, pero el efecto sobre el contenido total de $\mathrm{N}$ fue aún más significativo $(p<0,05)$, posiblemente debido a que el sustrato se había empobrecido en nutrientes.

\section{CONCLUSIONES}

\subsection{Material de cobertura}

En los capítulos anteriores se observó que las películas biodegradables a base de almidón de mandioca reforzadas con el bagazo de la raíz daban lugar a materiales más opacos, con mayor resistencia mecánica, y menor velocidad de biodegradación en suelo, bajo condiciones ambientales controladas, en relación a las películas a base de almidón sin relleno. Luego de 60 días de almacenamiento bajo fotoperíodos regulares de luz UV-visible, se observó que ambos materiales presentaron signos de envejecimiento, siendo este efecto menor para los reforzados con fibras. Considerando que estos materiales podrían ser adecuados para cobertura de suelo de cultivos de ciclo corto, en este trabajo se estudió la estabilidad de las películas bajo condiciones ambientales reales. Consecuentemente, se expusieron los materiales a la intemperie 
durante un período de 21 días; se registraron las condiciones meteorológicas y se evaluaron los cambios estructurales de los materiales estudiados mediante difracción de rayos $\mathrm{X}$ y espectroscopía FTIR-ATR. Al finalizar el ensayo, las películas empleadas lograron mantener la humedad del suelo durante el período estudiado, aunque las reforzadas con fibra habían sufrido una degradación mayor que aquellas sin relleno probablemente debido a que presentan una mayor solubilidad y un mayor grado de retrogradación del almidón de la matriz polimérica. Asimismo la transmisividad PAR de las películas reforzadas no se modificó en condiciones reales de uso, lo que resulta de particular interés para aplicaciones agronómicas.

5.2. Material para la liberación controlada de un fertilizante

Fue posible obtener macetas biodegradables a partir de las películas reforzadas desarrolladas. La inclusión de urea en la formulación permitió funcionalizar las matrices. Debido a que el contenido de urea afecta el comportamiento mecánico del material se seleccionaron las formulaciones con 25 y 37,5\% de urea. Se propusieron diferentes estrategias de uso de las películas funcionalizadas como sistemas de liberación controlada de fertilizante. Se observó un efecto de las películas sobre el crecimiento de las plantas de tomate, el cual fue más marcado en la segunda etapa de crecimiento. En relación a la utilización de sistemas soportados, el uso de barras o bastones fue más eficiente que el de papel. Por tanto los materiales desarrollados resultan una alternativa eficiente y de fácil implementación que podrían utilizarse como sistemas de dosificación de urea para la producción de plantines de almácigo, entre otros.

\section{BIBLIOGRAFÍA}

[1] H. Horinouchi, N. Katsuyama, Y. Taguchi, M. Hyakumachi, Control of Fusarium crown and root rot of tomato in a soil system by combination of a plant growth-promoting fungus, Fusarium equiseti, and biodegradable pots, Crop Protection 27 (2008) 859-864. 
[2] A.P. Bilck, M.V.E. Grossmann, F. Yamashita, Biodegradable mulch films for strawberry production, Polymer Testing 29 (2010) 471-476.

[3] M.M. Moreno, A. Moreno, Effect of different biodegradable and polyethylene mulches on soil properties and production in a tomato crop, Scientia Horticulturae 116 (2008) 256263.

[4] D. Briassoulis, Mechanical behaviour of biodegradable agricultural films under real field conditions, Polymer Degradation and Stability 91 (2006) 1256-1272.

[5] Z.N. Azwa, B.F. Yousif, A.C. Manalo, W. Karunasena, A review on the degradability of polymeric composites based on natural fibres, Materials \& Design 47 (2013) 424-442.

[6] O.V. López, L.A. Castillo, M.A. García, M.A. Villar, S.E. Barbosa, Food packaging bags based on thermoplastic corn starch reinforced with talc nanoparticles, Food Hydrocolloids 43 (2015) 18-24.

[7] S. Rimdusit, S. Jingjid, S. Damrongsakkul, S. Tiptipakorn, T. Takeichi, Biodegradability and property characterizations of Methyl Cellulose: Effect of nanocompositing and chemical crosslinking, Carbohydrate Polymers 72 (2008) 444-455.

[8] A. Shalwan, B.F. Yousif, In State of Art: Mechanical and tribological behaviour of polymeric comopistes based on natural fibres, Materials \& Design 48 (2013) 14-24.

[9] L. Chen, Z. Xie, X. Zhuang, X. Chen, X. Jing, Controlled release of urea encapsulated by starch-g-poly(I-lactide), Carbohydrate Polymers 72 (2008) 342-348.

[10] P. Rychter, M. Kot, K. Bajer, D. Rogacz, A. Siskova, J. Kapusniak, Utilization of starch films plasticized with urea as fertilizer for improvement of plant growth, Carbohydrate Polymers 137 (2016) 127-138.

[11] S.A. Riyajan, Y. Sasithornsonti, P. Phinyocheep, Green natural rubber-g-modified starch for controlling urea release, Carbohydrate Polymers 89 (2012) 251-258.

[12] K. Baccaro, M. Degorgue, M. Lucca, L. Picone, E. Zamuner, Y. Andreoli, Calidad del agua para consumo humano y riego en muestras del cinturón hortícola de Mar del Plata., Revista de Investigaciones Agropecuarias, INTA, Argentina. 35 (2006) 95-110.

[13] A. Lopez-Rubio, B.M. Flanagan, E.P. Gilbert, M.J. Gidley, A novel approach for calculating starch crystallinity and its correlation with double helix content: a combined XRD and NMR study, Biopolymers 89 (2008) 761-768.

[14] G. Scarascia-Mugnozza, E. Schettini, G. Vox, Effects of Solar Radiation on the Radiometric Properties of Biodegradable Films for Agricultural Applications, Biosystems Engineering 87 (2004) 479-487.

[15] C.I.G.L. Sarantópoulos, L.M. de Oliveira, M. Padula, L. Coltro, R.M. Vercelino Alves, E.E. Corrêa Garcia, Poropiedades Mecânicas, en: P.R. Citrângulo (Ed.) Embalagens Plásticas Flexíveis: Principais Polímeros e Avaliação de Propiedades, Centro de Tecnologia de Embalagem, Campinas, SP, Brasil, 2002, pp. 137-175.

[16] J.L. Chambouleyron, en: Enciclopedia argentina de agricultura y jardinería, Editorial ACME S.A.C.I., Buenos Aires, 1980, pp. 43-62. 
[17] R.d.L. Holzmann, en, INTA Ediciones, Allen, RN, Argentina, 2015.

[18] H.T. Holwerda, en, SQM S.A., 2006.

[19] D. Pérez, M. Lovisolo, A. Chiesa, Estudio morfoanatómico de plantines de Tomate (Solanum lycopersicum L.) con agua de riego salinas, Revista de Divulgación Técnica Agropecuaria, Agroindustrial y Ambiental Facultad de Ciencias Agrarias, UNLZ 3 (2016) 38.

[20] J. de Grazia, P.A. Tittonell, Á. Chiesa, Fertilización nitrogenada en plantines de pimiento (Capsicum annuum L.) cultivados en sustratos con diferentes proporciones de materiales compostados: efecto sobre los parámetros de calidad del plantín, Revista de la Facultad de Ciencias Agrarias 43 (2011) 175-186.

[21] R. Vagnoni, M. Buyatti, J.C. Favaro, Efecto del tamaño de celda de bandejas de siembra sobre la morfología y fisiología de plantines de tomate (Lycopersicon esculentum Mill.), Horticultura Argentina 33 (2014) 15-19.

[22] N. Sumanta, C. Imranul Haque, J. Nishika, R. Suprakash, Spectrophotometric Analysis of Chlorophylls and Carotenoids from Commonly Grown Fern Species by Using Various Extracting Solvents, Research Journal of Chemical Sciences 4 (2014) 63-69.

[23] L. Taiz, E. Zeiger, Cell Walls: Structure, Biogenesis, and Expansion, en: Plant Physiology, Sinauer Associates, Sunderland, Massachusetts, United States, 2002, pp. 313-338.

[24] R. Moran, D. Porath, Chlorophyll Determination in Intact Tissues Using N,NDimethylformamide, Plant Physiology 65 (1980) 478-479.

[25] A.R. Wellburn, H. Lichtenihaler, Formulae and program to determine total carotenoids and gilorophylls $a$ and $b$ of leaf extraci's in different solvents, en: C. Sybesma (Ed.) Advances in Photosynthesis Research, II, Martinus Nijhoff/Dr W. Junk Publishers, The Hague/Boston/Lancaster, 1984, pp. 9-11.

[26] R.J. Porra, The chequered history of the development and use of simultaneous equations for the accurate determination of chlorophylls $a$ and $b$, Photosynthesis Research 73 (2002) 149-156,.

[27] D. Scheiner, Determination of Ammonia and Kjeldahl Nitrogen by Indophenol Method, Water Research 10 (1976) 31-36.

[28] A. Tabacco, F. Meiattini, E. Moda, P. Tarli, Simplified Enzymic/Colorimetrlc Serum Urea Nitrogen Determination, Clinical Chemistry 25 (1979) 336-337.

[29] J.A. Di Rienzo, F. Casanoves, M.G. Balzarini, L. Gonzalez, M. Tablada, C.W. Robledo, InfoStat, (2011).

[30] J.L. Monteith, M.H. Unsworth, Principles of Environmental Physics: Plants, Animals, and the Atmosphere, 4 ed., Elsevier Ltd., Oxford, UK, 2013.

[31] I. Capron, P. Robert, P. Colonna, M. Brogly, V. Planchot, Starch in rubbery and glassy states by FTIR spectroscopy, Carbohydrate Polymers 68 (2007) 249-259. 
[32] P. Rubens, J. Snauwaert, K. Heremans, R. Stute, In situ observation of pressure-induced gelation of starches studied with FTIR in the diamond anvil cell, Carbohydrate Polymers 39 (1999) 231-235.

[33] J.J.G. van Soest, H. Tournois, D. de Wit, J.F.G. Vliegenthart, Short-range structure in (partially) crystalline potato starch determined with attenuated total reflectance Fouriertransform IR spectroscopy, Carbohydrate research 279 (1995) 201-214.

[34] F. Gavi Reyes, en, Secretaria de Agricultura, Ganaderia, Desarrollo Rural Pesca Y Alimentacion (SAGARPA) de México, Montecillo, México, 2012, pp. 1-11.

[35] C.M. L., D.E. Kissel, B.R. Bock, Urea hydrolysis in soil: Effects of urea concentration and soil $p H$, Soil Biology and Biochemistry 23 (1991) 1121-1124.

[36] G. Navarro Garcia, S. Navarro García, Fertilizantes: química y acción, Ediciones Paraninfo S.A., Madrid, España, 2014.

[37] W. Jianfeng, H. Dongxian, S. Jinxiu, D. Haijie, D. Weifen, Non-destructive measurement of chlorophyll in tomato leaves using spectral transmittance, International Journal Agricultural \& Biological Engineering 8 (2015) 73-78. 


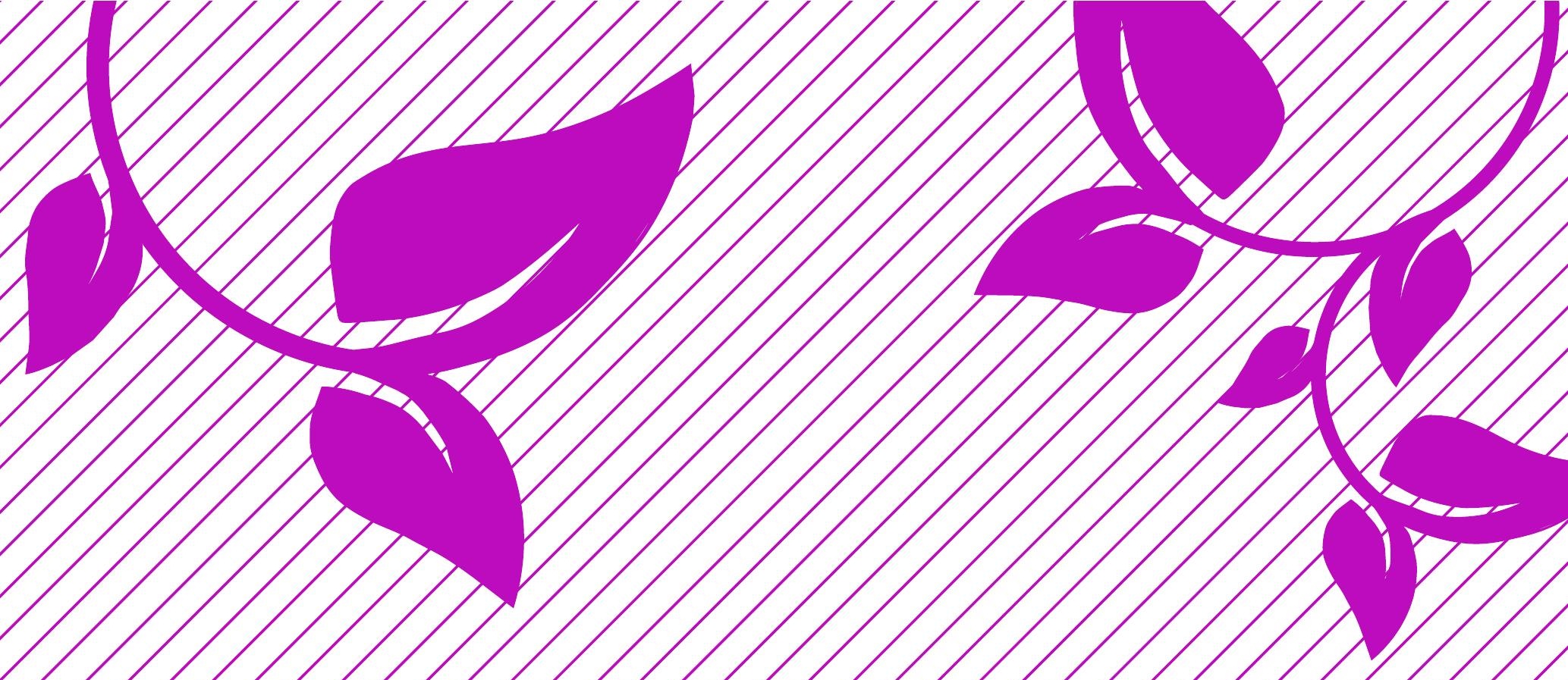

\section{CONCLUSIONES}
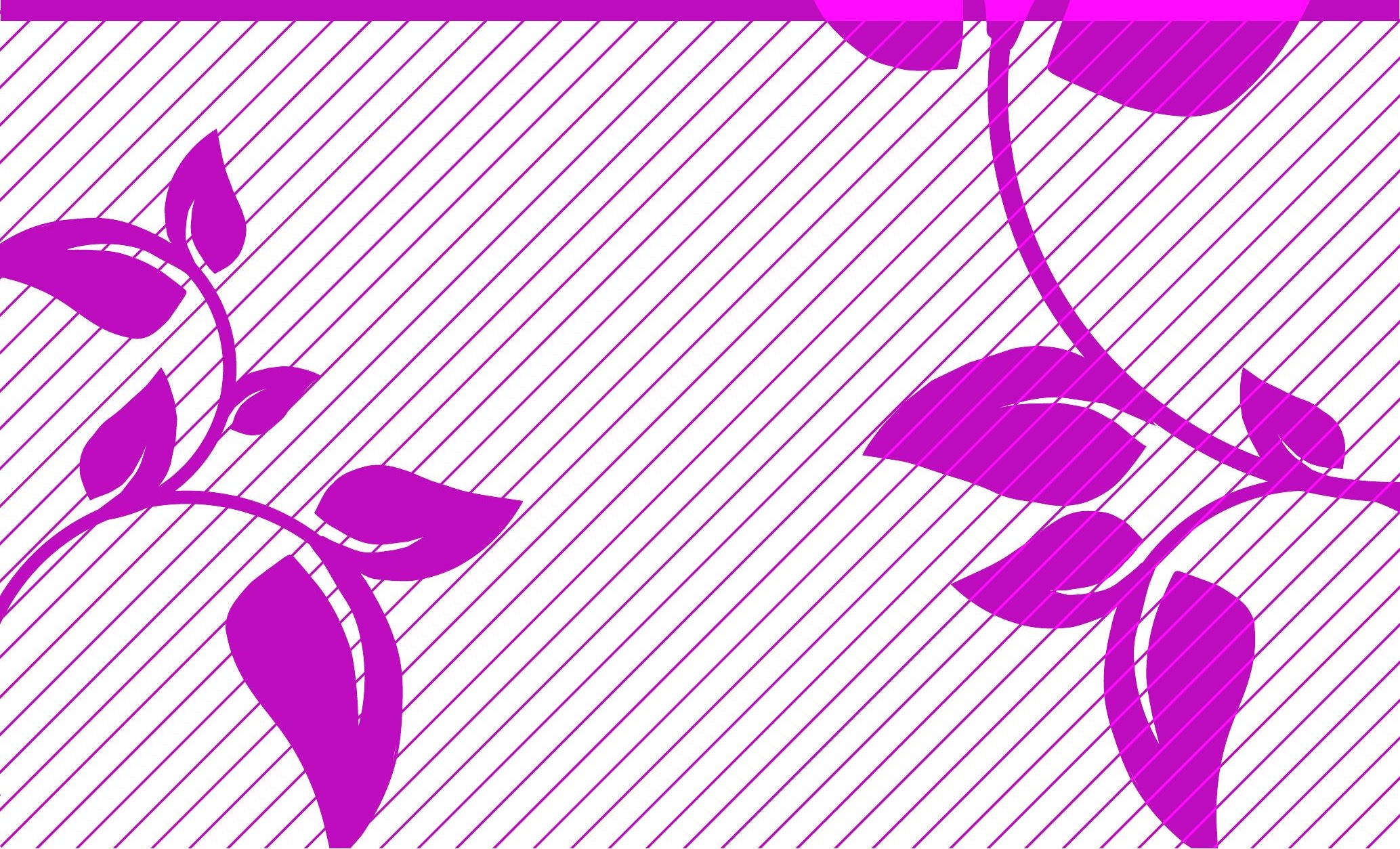
Como conclusión de este trabajo de Tesis puede decirse que: a partir del procesamiento de raíces tuberosas de mandioca para la extracción de almidón se obtiene como subproducto, además de la piel o cáscara, un residuo fibroso remanente (bagazo) que se diferencia de la primera en su composición química y distribución del tamaño de partícula. El bagazo presentó una distribución heterogénea del tamaño de partículas, con una fracción importante (56 \%) de partículas pequeñas $(<53 \mu \mathrm{m})$, constituidas principalmente por el almidón residual.

Mediante la técnica de casting es posible obtener películas a base de almidón de mandioca reforzadas con distintas concentraciones de relleno y plastificante (glicerol). Las micrografías SEM evidenciaron que la carga estaba estructuralmente incorporada en la matriz polimérica, indicando la compatibilidad química de los componentes.

Considerando el compromiso entre las propiedades mecánicas y de barrera al vapor de agua y a la luz UV-visible, se seleccionaron las formulaciones con $25 \mathrm{~g}$ de glicerol/ $100 \mathrm{~g}$ de almidón y 1,5\% de bagazo. El agregado de bagazo no sólo mejoró la resistencia mecánica de las películas sino que contribuyó a la capacidad de barrera UV-visible de las mismas, características de particular interés en el desarrollo de materiales para mulching.

El tamaño de partícula de relleno afectó las propiedades de los materiales compuestos. Las partículas de mayor tamaño (G) aumentan la capacidad de barrera UV-visible de la matriz, las de tamaño medio (M) mejoran el comportamiento mecánico propiedades mecánicas, y las partículas pequeñas (P) reducen la WVP. La incorporación del bagazo conteniendo todas las fracciones (F) presentó un comportamiento intermedio debido a la combinación de los efectos individuales de G, M y P en la matriz.

Los materiales desarrollados presentan capacidad de termosellado, el modo de falla (cerca del cierre) se atribuyó en todos los casos a la resistencia del sello. Además, se confirmó que en un plazo menor a 50 días las películas de almidón presentan un alto 
grado de degradación en suelo, siendo la cinética de biodegradación más lenta para las matrices reforzadas. La naturaleza biodegradable de las películas desarrolladas y su capacidad de termosellado, podrían conducir al desarrollo de envases para aplicaciones específicas, como por ejemplo la conservación de productos orgánicos donde el consumidor valora especialmente la utilización de envases sustentables.

Considerando la mayor opacidad, resistencia mecánica y menor velocidad de biodegradación en suelo de las películas biodegradables a base de almidón de mandioca reforzadas con el bagazo de la raíz se evaluó su estabilidad bajo condiciones ambientales controladas simulando fotoperíodos regulares de luz UV-visible. Luego de 60 días de almacenamiento se observaron signos de envejecimiento atenuados por la inclusión del refuerzo.

Además, dado que estos materiales podrían ser adecuados para cobertura de suelo de cultivos de ciclo corto, se estudió la estabilidad de las películas bajo condiciones ambientales reales, registrando las condiciones meteorológicas y evaluando los cambios estructurales de los materiales. Las películas empleadas lograron mantener la humedad del suelo durante el período estudiado, aunque las reforzadas con fibra habían sufrido una degradación mayor que aquellas sin relleno. Asimismo, la transmisividad PAR de las películas reforzadas no se vio alterada, lo cual resulta de particular interés para aplicaciones agronómicas.

Por otra parte, fue posible obtener materiales compuestos a base de TPS por moldeo y termo-compresión reforzados con subproductos del procesamiento de mandioca: bagazo y cáscara, la cual contenía mayores cantidades de fibra y proteína que el bagazo.

Bajo las condiciones de procesamiento ensayadas las interacciones entre almidón y relleno se vieron favorecidas, disminuyendo la energía necesaria para la termo- 
plastificación. Se demostró la compatibilidad entre matriz y relleno por análisis de FTIR y TGA.

Ambos subproductos refuerzan las matrices de TPS, a pesar de la baja concentración utilizada, siendo el bagazo un relleno más eficiente debido a su alto contenido en almidón residual y menor proporción de partículas de mayor tamaño. Además, la adición de las cargas mejoró las propiedades de barrera UV-visible del material, especialmente aquellos que contienen cáscara.

El agregado de urea a la formulación permite no sólo la funcionalización de la matriz polimérica sino también su plastificación. Comparativamente, tanto la urea como el glicerol y la mezcla de ambos son plastificantes compatibles con la matriz. Las interacciones plastificante-polímero, que tiene lugar principalmente a través de puentes de $\mathrm{H}$, se estudiaron por la técnica ATR-FTIR; los desplazamientos observados (particularmente en la banda a $3300 \mathrm{~cm}^{-1}$ ) sugirieren una interacción más fuerte entre los grupos $\mathrm{O}-\mathrm{H}$ del almidón y N-H de la urea. Además la mayor eficiencia de la urea como plastificante se demostró por la disminución de la $\mathrm{Tg}$ y la mejora del comportamiento mecánico.

La estructura y propiedades de las películas de almidón de mandioca reforzadas dependen fuertemente del contenido de urea incorporado, siendo 37,5 g de urea/ $100 \mathrm{~g}$ de almidón la máxima concentración admitida por la matriz, sin evidencia de migración superficial del aditivo.

Los resultados obtenidos de liberación controlada de urea en suelo se correlacionan con los de biodegradación y de capacidad de absorción de agua ya que estos procesos ocurren en forma simultánea. Así las películas reforzadas con agregado de urea permiten dosificar el aporte de nutrientes al suelo según las demandas del cultivo y su estado fenológico; minimizando el impacto ambiental del uso de altas concentraciones de fertilizantes. 
En este sentido, fue posible obtener macetas biodegradables a partir de las películas reforzadas desarrolladas. Debido a que el contenido de urea afecta el comportamiento mecánico del material se seleccionaron las formulaciones con 25 y 37,5\% de urea. Sin embargo, el uso de estos materiales para el desarrollo de macetas de speedling no resultó viable, evidenciándose problemas de toxicidad por liberación de amoníaco al suelo y deshidratación osmótica de las semillas.

Por otra parte, se propusieron diferentes estrategias de uso de las películas funcionalizadas como sistemas de liberación controlada de fertilizante, los que favorecieron el desarrollo vegetativo de platines de tomate. En relación al empleo de sistemas soportados, la utilización de barras o bastones fue la opción más eficiente. Por tanto los materiales desarrollados resultan una alternativa eficiente y de fácil implementación que podrían utilizarse como sistemas de dosificación de urea para la producción de plantines de almácigo.

Finalmente, en el presente trabajo de Tesis se propuso un uso integral de la raíz tuberosa de mandioca, ya que se desarrollaron películas a base del almidón que se reforzaron con el bagazo y/o la cáscara de la raíz, valorizando estos subproductos agroindustriales. Teniendo en cuenta sus propiedades, se propusieron distintas aplicaciones agronómicas específicas para estos materiales. La funcionalización con urea de la matriz permitió el desarrollo de sistemas de liberación controlada del fertilizante los que demostraron su eficiencia en cultivos de ciclo corto. 